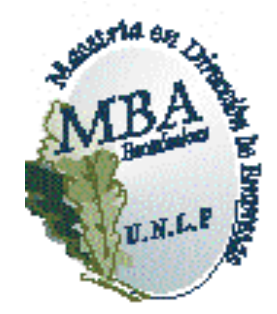

Universidad Nacional de La Plata

Facultad de Ciencias Económicas

MBA - Maestría en Dirección de Empresas

\title{
"Asimetrías Informativas entre los Bancos Comerciales y las Empresas PyMEs en La Plata y localidades vecinas"
}

\section{Trabajo final para optar al título de Magister}

Autor: Lic. Maximiliano Sebastián Ramírez

Director: Dr. Gastón Milanesi

\section{La Plata}

Mayo de 2011 


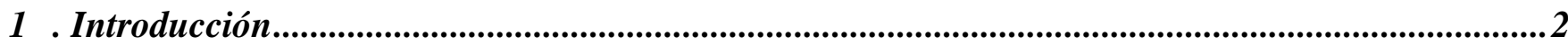

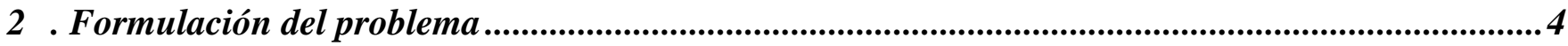

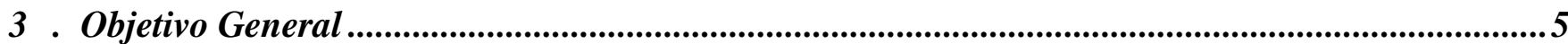

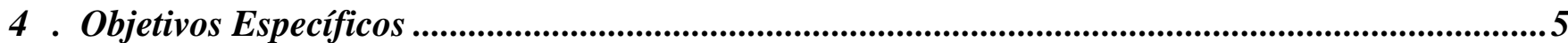

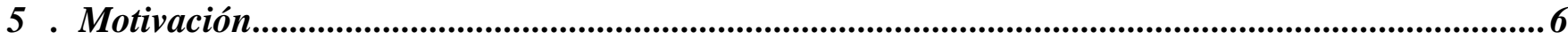

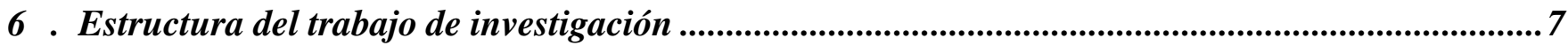

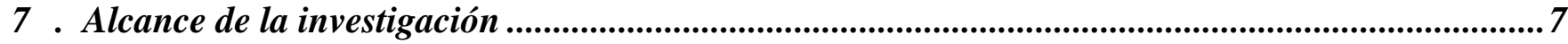

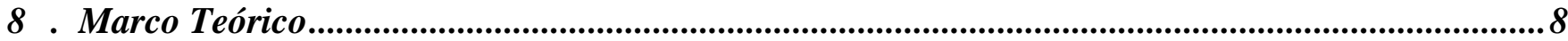

8.1 . Definición de PyMEs e importancia en el sistema económico .................................................14

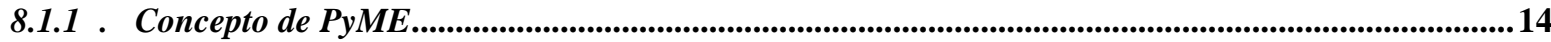

8.1.2 . Su importancia económica: ..................................................................................................................................

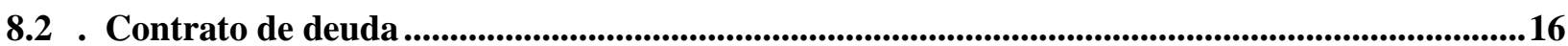

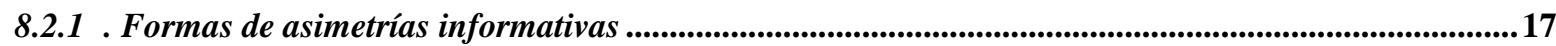

8.3 . Obstáculos identificados por las PyMEs para desarrollarse .......................................................18

8.3.1 . El problema de financiamiento ..................................................................................................... 18

8.4 . Vías tradicionales de financiamiento de las PyMEs ...............................................................19

8.4.1 . Orden de jerarquía en el financiamiento PyME ........................................................................19

8.4.2 . Bancos vs. Empresas..............................................................................................................................20

8.5 . El mercado de capitales: ¿una alternativa para el financiamiento de la empresa PyME?.......22

8.5.1 . Beneficios para la empresa de acceder al mercado de capitales ...............................................................22

8.5.2 . Disponibilidad de instrumentos en el mercado de capitales .......................................................................23

8.5.3 . El Mercado de capitales para PyMEs en Argentina .........................................................................................25

8.6 . Deuda Empresaria: Obligaciones Negociables PyME ......................................................................27

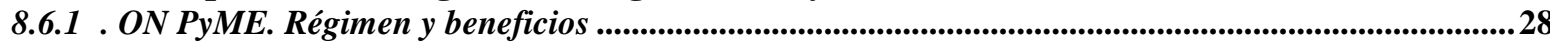

8.6.2 . Evolución local de ON PyME y VCP ..............................................................................................30

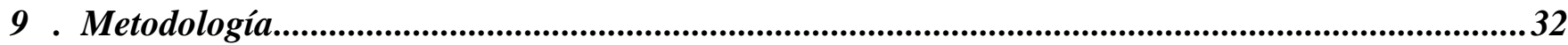

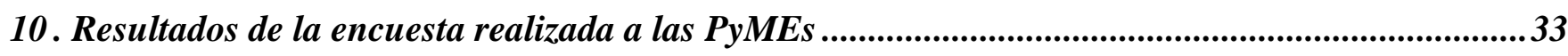

10.1 . Características generales de los encuestados .............................................................................33

10.1.1. Tamaño de la empresa .......................................................................................................................................33

10.1.2. Antigüedad de las firmas .......................................................................................................................34

10.1.3. Firmas Exportadoras .............................................................................................................................................35

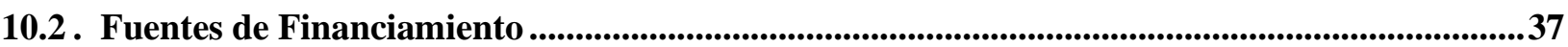

10.3 . Disposición a tomar crédito por parte de los empresarios...........................................................44

10.4 . Tiempo que hace que tomó el último crédito ......................................................................................44

10.5 . Tipo de Créditos tomados .....................................................................................................................46

10.6 . Destino del último crédito obtenido y banco en el cual accedió al mismo ....................................50

10.7 . Colaterales of recidos como respaldo de los créditos obtenidos ................................................51

10.8 . Evaluación general de la oferta crediticia por parte de los tomadores de crédito........................52

10.8.1. Resumen de los resultados obtenidos en la evaluación del último crédito obtenido por los tomadores de los mismos........................................................................................................................................................57

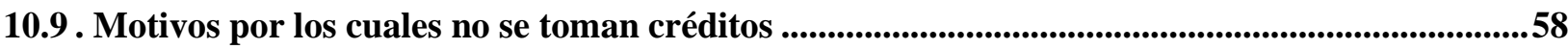


10.10 . Condiciones consideradas accesibles para acceder a un crédito ...................................................60

10.11 . Fuentes de financiamiento habituales por tipo de instrumento .............................................62

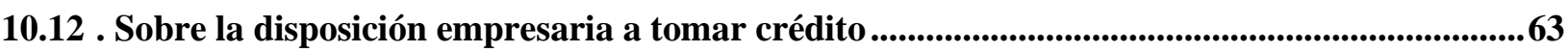

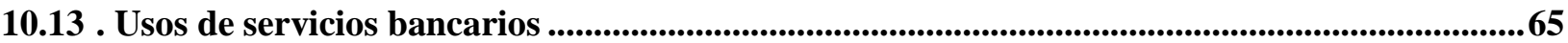

10.13.1 . Cuenta corriente ......................................................................................................................................65

10.13.2 . Caja de ahorro ................................................................................................................................................66

10.13.3 . Plazo fijo ............................................................................................................................................................................67 67

10.13.4 . Pago de salarios ........................................................................................................................................................68

10.13.5 . Pago de Impuestos ..............................................................................................................................................68

10.13.6 . Inversiones financieras .....................................................................................................................................69

10.13.7 . Cobro de facturas .................................................................................................................................................70

10.14 . Preferencias Generales respecto a los bancos que operan en la región bajo estudio...............71

10.15 . Calificaciones obtenidas por los bancos ..............................................................................................72

10.16 . Relación entre tasas de interés de un crédito y agilidad en su otorgamiento ..............................74

10.17 . Nivel de conocimiento de líneas crediticias especiales disponibles en la Provincia..................75

10.18 . Evaluación de las líneas de fomentos disponibles...................................................................76

10.19 . Evaluación de los resultados sobre situación actual de las empresas y expectativas de

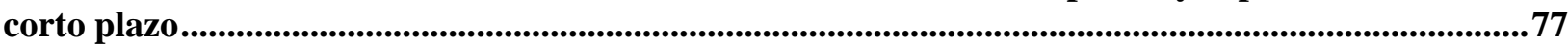

10.19.1 . Demanda ......................................................................................................................................................77

10.19.2 . Estimaciones de las inversiones para el segundo semestre de 2010 con relación al

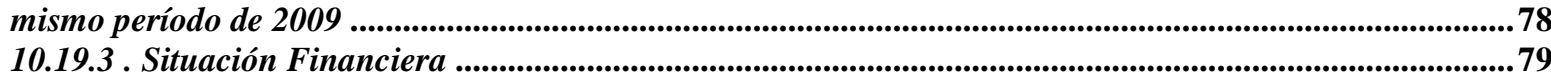

10.19.4 . Evaluación de las exportaciones en los primeros cinco meses de 2010 ..............................................80

10.20 . Análisis Econométrico ................................................................................................................................81

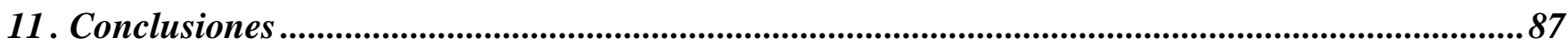

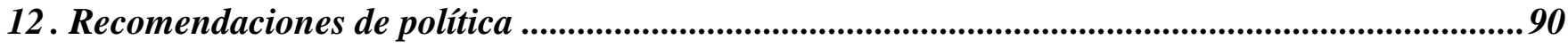

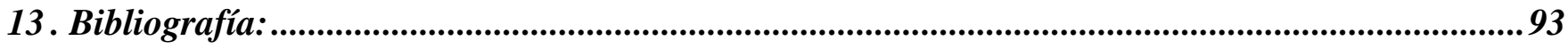

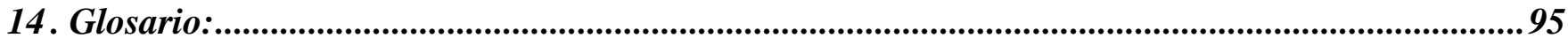

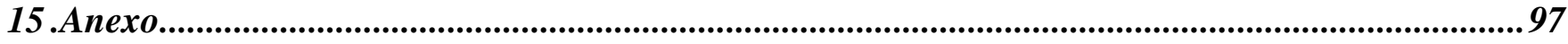

15.1 .Cuadros estadísticos ....................................................................................................................................97

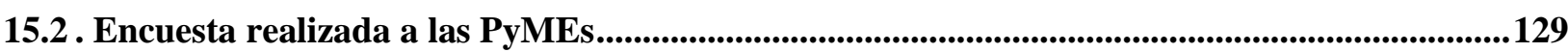





\title{
Resumen
}

El objetivo del presente documento es mostrar el análisis llevado a cabo en relación al grado de acceso al crédito por parte de las pequeñas y medianas empresas en el partido de La Plata y otras localidades vecinas ${ }^{1}$.

A tal efecto, el estudio revisó diversos preconceptos de amplia difusión entre los encargados de política e incluso entre personas con un importante conocimiento en el tema.

En particular, este trabajo puso énfasis en el real alcance de la demanda de préstamos bancarios (tanto laborales como de inversión), los requisitos necesarios para acceder a un crédito, así como también el conocimiento y transparencia de los programas públicos que fomenta el estado provincial para el desarrollo PyME de la región.

A partir de este análisis, fundamentado particularmente en argumentos teóricos y trabajos de campo realizado por medio de encuestas enviadas a las empresas y también con ayuda de modelos econométricos, se estableció cual es la situación que atraviesa la Ciudad de La Plata y demás ciudades vecinas con respecto al tema referido en primer término.

\begin{abstract}
The aim of this thesis is to show the analysis carried out with respect to the degree of access to credit by small and medium enterprises in the La Plata city and surroundings areas.

To this end, the study reviews various preconceptions of widely spread among policy makers and even among people with significant experience in this area.

In particular, this work emphasizes the extent of real demand for bank loans (both labor and investment), the requirements for accessing credit, as well as the knowledge and transparency of public programs which are encouraged by provincial government for the SME's development in the region.

From this analysis, which is based on theoretical arguments, field work conducted from surveys sent to businesses and also econometric models, it was established the situation in which the SME's are at moment in La Plata and surroundings cities on the issue referred to in the first place.
\end{abstract}

\footnotetext{
${ }^{1}$ Avellaneda, Berisso, Ensenada, Berazategui, Florencio Varela, Magdalena y Quilmes.
} 


\section{Introducción}

Las PyMEs constituyen un eslabón esencial en el encadenamiento de la actividad económica y generación de empleo de nuestro país. Sin embargo, su realidad económica y financiera lejos está de ser la ideal.

Dada su naturaleza, son empresas sujetas a los vaivenes del mercado. Numerosos son los obstáculos que enfrentan para crecer y consolidarse en un mercado altamente volátil como el argentino. Entre ellos el proceso de financiamiento ocupa un lugar sumamente relevante.

La falta de capital de trabajo, la concentración de vencimientos de deuda en el corto plazo y la no disponibilidad de fondos para financiar proyectos altamente rentables ponen un freno a su crecimiento e incluso, en casos extremos, conducen a la PyMEs a su desaparición.

En un país como Argentina, donde el mercado de capitales no ha logrado desarrollarse plenamente, el sistema bancario se erige como la alternativa de fondeo por excelencia. Sin embargo, lejos de constituirse como la herramienta de asistencia esperada por las empresas, el crédito bancario ha estado signado en la mayoría de los casos por condiciones casi prohibitivas, ya sea en términos de tasa de interés, plazo de los créditos, garantías exigidas entre otras. Esto ha generado numerosas limitaciones para las empresas en acceder al financiamiento que les permitan desarrollarse, condicionando su crecimiento futuro.

El presente trabajo intenta identificar las deficiencias en el acceso al crédito de las pequeñas y medianas empresas (en adelante PyMEs) en el partido de La Plata y otras localidades cercanas (Avellaneda, Quilmes, Berazategui, etc.) así como también establecer características y formas de comportamiento, por parte de los bancos, que la empresas consideran de relevancia a la hora de solicitar un crédito o realizar cualquier otro tipo de trámite bancario. Asimismo, se indagará acerca de cuáles son los bancos que más compatibilizan su accionar con las necesidades de las PyMEs y por último establecer mecanismos alternativos de financiamiento para las PyMEs como ser el Mercado de Capitales, en particular, las obligaciones negociables.

Con el objetivo en mente, el trabajo se organiza de la siguiente manera:

En la sección 8 se desarrolla el marco teórico, el cual está conformado por:

La sección 8.1 analiza la relevancia de las pequeñas y medianas empresas en el sistema económico nacional, principalmente en términos de empleo y producto.

La sección 8.2 se ocupa de los contratos de deuda y de las asimetrías informativas que se presentan en los mismos.

La sección 8.3 se ocupa de los obstáculos que este tipo de empresa enfrenta durante su ciclo de negocios, destacándose entre estos las dificultades para acceder a fuentes de financiamiento.

Ante esta realidad, la sección $\mathbf{8 . 4}$ describe los mecanismos usualmente utilizados por los empresarios para financiar sus necesidades, como son la reinversión de utilidades, el crédito de proveedores y el crédito bancario. Se pone particular atención a las dificultades que tienen las pequeñas y medianas empresas en acceder al crédito bancario y el efecto que esto último genera sobre el crecimiento y supervivencia de este tipo de empresas. 
A continuación la sección 8.5 destaca la relevancia de mecanismos alternativos de las empresas, el Mercado de Capitales. En este ítem se detallan los beneficios de las empresas por acceder a este mercado así como los distintos instrumentos que el mercado les ofrece en función de sus características particulares y necesidades de financiamiento. Por último, se realiza una descripción de la evolución del Mercado de Capitales para Argentina.

La sección 8.6 se ocupa en particular de la Obligaciones Negociables PyME, su régimen simplificado y los beneficios que generan sobre las empresas. Asimismo, se realiza una descripción de la evolución de este instrumento en el período posterior a la salida de la convertibilidad.

En las secciones 9 se presenta la metodología utilizada.

En las secciones 10 se presentan los principales resultados que surgen de la encuesta realizada a las PyMEs de La Plata y localidades vecinas.

Las conclusiones y recomendaciones de política se esbozan en la sección 11 y 12.

Finalmente, las referencias bibliográficas, el glosario de términos y el anexo: los apéndices I (cuadros estadísticos) y II (encuesta realizada a las empresas PyMEs), se encuentran en la sección 13,14 y 15 , respectivamente. 


\section{Formulación del problema}

Los recursos financieros son vitales para iniciar y llevar adelante una empresa. Ello se debe a que se necesitan fondos para adquirir activos para fabricar un producto o brindar un servicio. La falta de fondos entorpece el crecimiento de las empresas sobre todo si se trata de pequeñas y medianas (PyMEs) debido a que son, en su gran mayoría, mano de obra intensiva. Por ende, dicho problema repercute en el desarrollo de una región. En cuanto al origen de los fondos, se reconocen dos fuentes: internas y externas. La primera se corresponde con los fondos aportados por los propios dueños o los generados por las propias empresas (reinversión de utilidades). El origen externo se materializa en forma de deuda o la apertura del capital.

Entre las fuentes mencionadas, los fondos provenientes de origen interno junto a la toma de deuda fundamentalmente bancaria constituye la forma en que las PyMEs financian su actividad. Según Mason (1998): "La apertura de capital no representa una opción atractiva para este tipo de empresas debido a la perdida de propiedad o control que la misma implica".

No obstante, acceder al financiamiento bancario no resulta una tarea fácil. En general, se observa que el mercado bancario no funciona eficientemente debido a la existencia de información asimétrica. Esto es, los demandantes de créditos poseen mayor información sobre el éxito de sus proyectos que los oferentes. Como consecuencia se genera una brecha entre la demanda de fondos (empresas) y la oferta (entidades bancarias).

Asimismo, el problema de asimetría informativa se agudiza cuando son las PyMEs las demandantes de estos fondos.

En función de los presentes argumentos surge la importancia de estudiar dichas asimetrías informativas y sus causas, lo cual constituirá el tema de la presente investigación.

En materia de financiamiento, el actual contexto se caracteriza por restricciones en el acceso al crédito, aun habiendo fondos disponibles en tal sentido. La hipótesis principal del presente trabajo se fundamenta en que, si bien las Pequeñas y Medianas empresas necesitan del crédito para poder sostener inversiones en activos fijos y de trabajo y generar empleo, el acceso al mismo se les dificulta por potenciales problemas de asimetría de información, los cuales pueden ser resueltos a través de determinadas decisiones de política económica.

“CUÁL ES EL IMPACTO DE LA DISTRIBUCIÓN DE LA INFORMACIÓN EN EL SISTEMA FINANCIERO ARGENTINO, EN LA RELACIÓN ENTRE LOS BANCOS COMERCIALES Y LAS PYMES, DURANTE LOS AÑNOS 2009 / 2010?” 


\section{Objetivo General}

El objetivo de la tesis es estudiar las asimetrías informativas entre las Empresas PyMEs y los Bancos comerciales, así como también sus causas.

Determinar cuál es el impacto de la distribución de la información que fluye a través de la relación entre las PyMEs y los bancos comerciales en la Ciudad de La Plata y localidades vecinas en el período 2009-2010.

\section{Objetivos Específicos}

1. Determinar las características del sistema financiero en las localidades bajo estudio (características y requisitos para el otorgamiento de los créditos).

2. Realizar una descripción de la situación actual de las PyMEs en cuanto a los créditos tomados, la situación económica -financiera actual y perspectivas futuras, tipo de mercado en que se encuentra y a cual apunta, participación de las PyMEs Exportadoras.

3. Establecer los principales problemas de asimetría de información que surgen de la relación entre los bancos y las PyMEs.

4. Establecer un ranking de bancos considerado por las empresas PyMEs (es decir, lo que mayor facilidad brindan) a la hora de generar crédito, a los requisitos, período de gracias, tasa de interés, etc. 


\section{Motivación}

La elección de este tema en particular para realizar la presente tesis ha sido motivado por el hecho de que como resultado de décadas de volatilidad macroeconómica y deficiente protección de los derechos de los ahorristas, el crédito bancario en Argentina se ha contraído hasta un valor del 13\% del PBI, un valor que llega al tercio del promedio para América Latina y un décimo del nivel en países de la OCDE.

Esta baja profundidad crediticia no se explica exclusivamente bajo la forma de ahorro intermediado o la forma de depósitos bancarios sino también por la estructura de activos a los cuales se aplica la capacidad prestable del sistema bancario. A septiembre del 2009, del total de recursos (pasivos más patrimonio neto) del sistema bancario, solo el $35.8 \%$ se canalizaba a créditos privados. Dejando de lado los activos fijos, el resto se vuelca al mantenimiento de altos niveles de disponibilidad (17.5\%), títulos públicos $(22.5 \%)$ y préstamos interbancarios (11.2\%). Estos usos implican que los bancos en Argentina, no encuentran suficientemente atractiva la actividad del préstamo al sector privado (en general, no solo a las PyMEs) y/o que la demanda de crédito es exigua en relación a la captación de recursos del sistema (que como se mencionó antes es extremadamente baja para los cánones internacionales).

Resulta paradójico, sin dudas, que la transformación del ahorro en crédito privado, la principal función social que justifica la existencia de los bancos, absorbe apenas la tercera parte de los recursos. Otra medida que refuerza el juicio anterior es la proporción de gasto privado (consumo más inversión) que se financia con nuevos créditos bancarios: para 2007, este valor alcanza un $2.2 \%$, implicando que un $97.8 \%$ restante se financia mayormente con recursos propios ${ }^{2}$.

En suma, la falta de crédito comercial y bancario, la estructura de activos destinados a crédito y la necesidad de generar instrumentos en forma rápida, dentro de un escenario de tanta confusión, incertidumbre y falta de confianza, es lo que torna sumamente interesante abordar y estudiar este tema.

\footnotetext{
${ }^{2}$ Las emisiones primarias de bonos y acciones, otra posible fuente de financiamiento para el sector empresario (aunque vedado a las familias) representan en Argentina un porcentaje despreciable del total. En el caso de las PyMEs, la emisión de obligaciones negociables (bonos) en 2007 fue de apenas \$19.5 millones (ver BCBA (2009)). Debe tenerse presente que las condiciones del sistema bancario y del mercado de capitales se endurecieron con posterioridad a la crisis internacional que tuvo su pico en 2008- 2009, debido a lo cual la situación descripta en 2007 debe haber sido incluso más favorable que en el trienio 2008-2010.
} 


\section{Estructura del trabajo de investigación}

La investigación de este trabajo de tesis comprende la recopilación de información obtenida a partir de una encuesta de elaboración propia realizada a 165 empresas PyMEs de la zona de La Plata, Berisso, Ensenada, Avellaneda, Berazategui, Florencio Varela, Magdalena y Quilmes y también de información obtenida de libros, documentos, y otros medios de información.

La parte estadística se realizó en función de la encuesta efectuada y también se utilizó el programa econométrico STATA edición 11 versión 11.0. Para realizar el análisis econométrico de los datos se utilizó el modelo Mínimo Cuadrados Ordinarios.

También se utilizó información del Instituto Argentino de Mercado de Capitales (IAMC), y del Banco Central de La República Argentina (BCRA). Si bien es cierto que la bibliografía es amplia, el uso de internet como medio de investigación es de suma importancia, debido a que el conocimiento de los problemas de asimetría informativa no son relativamente recientes, por lo que gran parte de la información se encuentra en formato digital, facilitando en gran medida los procesos de búsqueda y obtención de la misma.

El trabajo presenta una breve introducción con el detalle de los objetivos planteados, la motivación y la estructura general de la tesis. Luego se presenta el Marco teórico donde se realiza un repaso de los aportes literarios más relevantes hasta el momento sobre el tema.

Primeramente se expondrán los conceptos básicos como la definición de PyMEs, situación actual de las PyMEs, fuentes de financiamiento y alternativas a las fuentes de financiamiento tradicionales, como el Mercado de Capitales. También se indagarán las causas de las principales asimetrías informativas como así también el tipo de asimetrías informativas al que se enfrentan en este tipo de mercado, entre otras cuestiones relevantes. Seguidamente se expone un análisis detallado de los datos obtenidos por medio de las respuestas suministradas por las PyMEs que contestaron el cuestionario, el cual constaba de 30 preguntas. Finalmente y como complemento se realizó un análisis econométrico de los mismos por medio de la utilización del programa econométrico STATA edición 11 versión 11.0.

El presente trabajo finaliza con la exposición de las conclusiones, anexos y bibliografía correspondiente dando respuesta a los objetivos planteados inicialmente y se proponen temas de interés para futuros trabajos.

\section{Alcance de la investigación}

Se trata de un estudio explicativo, debido básicamente "a la falta de antecedentes de investigaciones en la Ciudad de La Plata y Localidades vecinas (Berisso, Ensenada, Avellaneda, Berazategui, Florencio Varela, Magdalena y Quilmes) que encaren el problema planteado, con sus particulares variables e indicadores (manifestaciones medibles de una variable)".

El trabajo de investigación analiza a las Empresas PyMEs y Bancos Comerciales de la Ciudad de La Plata, Berisso, Ensenada, Avellaneda, Berazategui, Florencio Varela, Magdalena y Quilmes entre el período 2009 y 2010. 


\section{Marco Teórico}

El problema general planteado se inserta en la tradición "clásica" de la economía política, es decir, el estudio de las leyes que regulan la producción y distribución de riqueza. Se trata de problemas esencialmente dinámicos relacionados con la reproducción del capital y la distribución del producto social.

La temática del financiamiento bancario de empresas representa un aspecto particular de esta cuestión, y puede aproximarse a través de herramientas de la teoría microeconómica, de carácter esencialmente estático. Estas técnicas de análisis microeconómicas son plausibles de interés, especialmente cuando no se pierde de vista que se ocupan de una cuestión parcial de un problema más amplio del que no puede ni pretende rendir cuentas en su totalidad.

Así, este estudio toma elementos que se desprenden de la teoría de la empresa, de los mercados, y de cuestiones asociadas a la información y a la racionalidad de los agentes que intervienen: empresas e instituciones financieras. Sin embargo, se deja de lado aspectos de racionalidad estratégica (no económica) o de poder que deberían ser tomados en cuenta para entender la evolución de una estructura productiva liderada por grupos económicos industrial y financiero, nacional y trasnacionales.

\section{Empresas}

Las justificaciones de la existencia de las empresas como unidad de análisis teórico son variadas, se destacan dos: la primera se desprende de R. Coase, (1937), que funda el origen de la empresa en un problema de eficiencia, y la segunda de M. Aoki, (1986), donde la empresa representa una oportunidad para obtener rentas específicas que serán repartidas entre los integrantes de las empresas: trabajadores, accionistas y administradores. Ambos enfoques hacen residir la noción de empresa en un punto distante a la de "mercado".

Para Coase (1937), la empresa representa una posibilidad de administrar recursos de manera directa, más conveniente que el sistema de precios propios que el mercado, minimizando costos de transacción. Para Aoki (1988), la empresa permite la generación de rentas y su distribución a través de un sistema de acuerdos entre los integrantes de la empresa que no siguen un sistema único y anónimo de recompensas (como sería esperable del mercado) sino que abre el paso a modalidades de negociación entre los grupos de participantes.

Apartándose de la cuestión esencial de la existencia de las empresas, una vasta literatura desarrolló modelos explicativos de las propiedades de esta, su lógica de expansión y funcionamiento; la tarea era entenderla a través de sus principios organizadores.

Una clasificación útil de estos dos enfoques distingue dos grupos: aquel que hace hincapié en la empresa como unidad de optimización (maximización de una función de beneficios sujeta a restricciones que implica una noción fuerte de racionalidad) y otra basada en nociones débiles de racionalidad (racionalidad limitada y también limitaciones computacionales) y en problemas de información. Las empresas optimizadoras son aquellas incluidas en la teoría neoclásica pura, donde no se plantea el problema de la existencia de ellas, sino que permite la existencia de "cajas negras" apartadas del mercado.

La visión de la empresa basada en el concepto de "costo de transacción" y "racionalidad limitada", "información incompleta" o "costos y asimetría de información" puede apartarse más o menos del 
paradigma neoclásico- según el autor que se trata- pero permite una aproximación realista del mundo capitalista donde no solo existen empresas, sino que estás exhiben una notable diversidad configurando una estructura peculiar al entorno en el que se mueven.

\section{Mercancía y mercado de créditos}

El uso tradicional retiene una acepción específica y limitada del concepto de mercancía: mercancía es todo aquello para lo cual pueda identificarse una oferta y una demanda. Esto alcanza al crédito y al "mercado de crédito", y como caso particular de la teoría de mercados, la existencia del mercado implica el reconocimiento de la mercancía "crédito" o dinero diferido.

Los demandantes de crédito pueden pertenecer al ámbito público (empresas públicas y los distintos niveles de la administración) y privados (personas jurídicas y personas físicas). Los oferentes de crédito son el conjunto de agentes capaz de generar depósitos en el sistema financiero, es decir son todos aquellos agentes dispuestos a entregar dinero a cambio de instrumentos financieros. Este formato deja entrever, por otra parte, la estrecha relación entre demanda de activos financieros (demanda de agregados monetarios como por ejemplo el M3) por parte de los agentes de la economía y la provisión de la masa de fondos que componen el crédito.

Como caso particular de la teoría de mercados, la demanda de crédito debe partir de la preferencia de los demandantes, dado el vector de precios de la economía. El resultado es un esquema de demanda de créditos en la economía del cual debería esperarse una relación inversa entre la cantidad de dinero que se demanda en empréstitos y su precio (medido por una tasa de interés), y probablemente una relación directa entre el monto total concedido a préstamos en el mercado y el tamaño de la economía.

Por otra parte, la oferta de crédito debería producir un esquema similar al de la oferta de cualquier otra mercancía: relación positiva entre la cantidad total de empréstito ofertada y su precio -o tasa de interés-, y relación también positiva entre aquella cantidad y el tamaño de la economía.

Bajo los supuestos apropiados podría concebirse la existencia y unicidad de un equilibrio en este "mercado de crédito", en el que existe un precio en el que la oferta y la demanda de crédito son iguales. Bajo condiciones todavía más estrictas, puede discutirse la propiedad de estabilidad de este equilibrio. Esta última característica no es trivial, pues indica la capacidad del mercado de alcanzar y mantenerse en equilibrio.

\section{Asignación del crédito en un contexto de información asimétrica}

En contexto de información imperfecta la asignación del crédito se dificulta de manera extrema. Según Tenjo-Galarza (1995), cuando este concepto se aplica a los mercados de créditos, la noción de información asimétrica se refiere básicamente en la situación en la cual quien presta y quien toma el crédito tienen diferentes visiones o conocimiento sobre la rentabilidad esperada y los riesgos de un proyecto en particular, especialmente en términos de rentabilidad y de concreción de dicho proyecto: "mientras el que solicita el préstamo tiene una estimación suficientemente ajustadas de estas variables, el prestamista solo se puede aproximar a las mismas a partir de referencias al proyecto promedio de la economía".

Esta imperfección del mercado se deriva, según el artículo de Jaffee y Stiglitz (1990), del hecho de que no existe una relación monotónica entre la tasa de interés aplicada y la rentabilidad esperada por la institución financiera, como surgen de las entrevistas que les realizaron a las entidades. 
Asimismo, el trabajo de Stiglitz y Weiss (1981) muestra que ante incrementos en la tasa de interés que se carga a los préstamos por parte de los bancos que presentan aversión al riesgo, se produce un proceso denominado "selección adversa", en el cual solo proyectos de alto riesgo son los elegidos, o peor aún, se privilegia aquellos en los cuales el tomador de crédito no tiene intenciones de honrar su deuda (riesgo moral o moral hazzard). Los tomadores potenciales a tasas que podrían ser consideradas compatibles con la rentabilidad media de los proyectos de la economía, se retiran del mercado de crédito ante la dificultad de generar las utilidades demandadas por las entidades prestamistas.

También puede darse un fenómeno de incentivos adversos, ya que aquellos que estaban dispuestos a solicitar financiamiento para un proyecto de rentabilidad media, ante el aumento de la tasa de interés deciden encarar negocios más riesgosos, a solo efecto de poder cubrir el premium de tasa que se solicita. La incertidumbre fundamental que planteaba Keynes (1964), en sus escritos originales, es potenciada por una situación que se retroalimenta agravando las condiciones de financiamiento de las empresas.

\section{Red-liners y empresas que enfrentan racionamiento}

Por variados motivos, las empresas suelen no suscribir todos los contratos de créditos que pretenden. Esta imposibilidad de acceder al crédito reviste distintas formas, aunque pueden considerarse dos casos polares: Red-liners y racionamiento (Stiglitz y Weiss 1992).

En el primer grupo se encuentran aquellas empresas que por sus características específicas o estructurales son excluidas del crédito bancario y que no pueden conseguir préstamos ni siquiera en condiciones más onerosas (mayores tasas de interés y requisitos más exigentes de garantías).

El segundo grupo de excluidos del crédito está compuesto por empresas que no tienen características muy diferentes de otras que si acceden a préstamos bancarios, y a las que se aplican un criterio restrictivo básicamente formal; estas empresas sufren lo que se denomina racionamiento de crédito en el sentido estricto.

Ambos fenómenos pueden deberse tanto a consecuencias de la reglamentación del crédito bancario, como a imperfecciones de los mercados emergentes en contexto de información asimétrica.

Este racionamiento puede ocurrir en diferentes niveles (en mercados de créditos segmentados) y para diversos tipos de contratos.

El resultado del racionamiento y discriminación se observa independientemente de las condiciones que den origen a la oferta de crédito y de la mayor o menor rigidez de la política monetaria ${ }^{3}$.

Finalmente, es necesario destacar que en países en vía de desarrollo, de mercados de capitales e instrumentos financieros limitados, con dominio de formas tradicionales de financiamiento de la producción, estas trabas de acceso al crédito son más importantes, las asimetrías de información más acuciantes, y consecuencias en la economía real más profundas.

\footnotetext{
${ }^{3}$ La generación de situaciones de racionamiento de crédito no necesita explicarse recurriendo a configuraciones institucionales específicas (Stiglitz y Weiss, 1992), por lo que este tipo de argumentaciones fueron omitidas. Sin embargo, los cambios de las tasas de interés activas y pasivas, junto a todo aquello que determine la parte de la renta nacional que es percibida por el sector financiero, sí deberían incluir aspectos institucionales en su explicación.
} 
Es decir, que no solo las empresas están condicionadas en su acceso al crédito por sus características específicas, sino también por las características propias del mercado en el que participan.

\section{a) Problemas en el mercado de crédito: el racionamiento}

Los supuestos que garantizan el "buen comportamiento" de las funciones de demanda neta del mercado, i.e. aquellos que permiten existencia, unicidad y estabilidad del equilibrio son abstracciones sin correlato en la realidad ${ }^{4}$. Entre ellos especial atención se ha puesto a problemas asociados a la información: la ausencia de información comprehensiva para todos los agentes, así como la existencia de procesamientos constituyen un impedimento al funcionamiento del mercado que pueden inclusive llevar a la desaparición de algunas mercancías.

Aplicado al mercado de crédito estos problemas de información pueden dar lugar a equilibrios múltiples y a situaciones de equilibrio insatisfactorias. La información no es un bien libre, sino que tiene costos de apropiación y de procesamiento; visto en una dimensión estática, la información resulta desigualmente distribuida, muy particularmente cuando lo que juega son conocimientos muy difícilmente apropiables de manera sistemática ${ }^{5}$.

Una consecuencia notoria, de estos problemas de información en el funcionamiento del mercado, es la incapacidad del precio vigente de cumplir con las condiciones de equilibrio señalada anteriormente, es decir, la de igualar el monto global de crédito demandado al monto global que el sistema está dispuesto a otorgar dadas las condiciones vigentes en la economía. Una consecuencia de este error en el funcionamiento del sistema es el llamado racionamiento de crédito (Jaffee y Stiglitz, 1990).

Se habla de tres estados hipotéticos en relación con la obtención del crédito bancario que se supone, por conveniencia, limitado a las empresas.

La situación más cómoda toca a aquellas empresas que obtienen todo el financiamiento requerido al precio del mercado (independientemente de cómo este se forme).

La más incómoda afecta a otro grupo de empresas excluidas del crédito pues sus planes de producción y su situación de balances las excluye de cualquier monto de crédito al precio vigente (que nuevamente se supone existente y fijado por algunas instancias que exceden la presente investigación).

En medio de ambas categorías se encuentran las empresas racionadas del crédito en el sentido estricto del término. Se trata de empresas cuyas características objetivas son indistinguibles de otras que han conseguido el crédito que a ellas les ha sido denegado.

Obviamente, esta clasificación de estados con relación al crédito solo sirve como una aproximación a una realidad que es mucho más compleja. Las características institucionales de los países en desarrollo agregan importantes condicionamientos a la teoría de racionamiento. Debería postularse que en estos países todos los agentes están racionados de una u otra manera, siendo los senderos de desarrollo de las empresas una variable que tendría mucho más de contextual que de decisión por parte de los empresarios. Paradójicamente, esto también opera en momentos en los cuales se

\footnotetext{
${ }^{4}$ Vale la pena aclarar que este enfoque en términos de mercado sólo cuenta una parte de la historia, siendo necesario ahondar en el concepto de dinero y de capital para entender el contexto que da vida al mencionado "mercado de crédito".

${ }^{5}$ En este sentido se puede mencionar a los animal spirits keynesianos que definen parte del comportamiento empresario y sobre el cual las empresas solicitan el crédito.
} 
dispone de cantidades ilimitadas de fondos, básicamente inducidos por la liberación de la cuenta capital y la liberación de los flujos financieros antes de la crisis.

Vale la pena resaltar alguna de las dificultades que encuentra la teoría de mercados en hacerse cargo del crédito como caso en particular:

i) No debe obviarse que son no pocos los autores que se resisten a aceptar el carácter de mercancía del crédito, o que pueda hablarse de oferta y demanda independientemente del crédito;

ii) No es tan fácil interpretar (y no hay consenso en la literatura) el significado de lo que se utiliza como "precio" en este mercado- tasa de interés-, ni tampoco son evidentes las leyes que guían su evolución en una economía concreta;

iii) La interpretación correcta del mercado de crédito y de los racionamientos que experimentan las empresas no deja de ser una cuestión confusa: el "precio que ha sido fijado por el mercado" puede no coincidir con el hipotético e inobservable precio de equilibrio del mercado (por ejemplo por problemas de información). Por ejemplo:

a) Si la tasa de interés que fija el mercado es más baja que aquella que resultaría de las condiciones de equilibrio, la teoría de mercado diagnosticaría un exceso de demanda de crédito.

b) Si se utilizara a una referencia a un precio vigente en el pasado (en lugar del inobservable precio de equilibrio), la interpretación del exceso de demanda podría cambiar e incluso invertirse.

c) Si se asumiera (como debería hacerse al aceptarse la existencia de un mercado de crédito) que su demanda es independiente de su oferta y se observara evidencia de que esta oferta no cambio drásticamente; nuevas tasas de interés más elevadas (por causa de los mismos problemas de información) deberían desalentar demandantes de crédito generándose un exceso de oferta y no de demanda de crédito.

\section{b) El racionamiento de crédito y su contexto: instituciones y trayectorias nacionales}

La correspondencia entre la teoría en la que se basa la idea de diferenciación de empresas y el racionamiento del crédito y el estudio concreto de las unidades de producción y su financiamiento se enriquece a partir de la incorporación de las características locales ( a nivel nacional). Sin pretender un desarrollo completo de estos elementos que dan complejidad adicional a la teoría (pues se trata en definitiva referencias contextuales a este estudio), deben mencionarse algunas características importantes.

En primer lugar, debe reconocerse que ya en la aproximación al problema general del financiamiento de la expansión de capital dominado por las empresas, intervienen elementos relacionados con la trayectoria nacional.

Esta idea un tanto vaga responde a la configuración específica de la economía, que fue gestada durante años de evolución y que surge de la interacción entre varios tipos de agentes. Ello determinó, a nivel del problema general, una cierta estrategia particular de financiamiento del sistema productivo.

A partir de 1940, esta estrategia estuvo basada, en cuanto compete al financiamiento interno altamente protegido, signado por la estrategia de Industrialización Sustitutiva de Importaciones.

El financiamiento externo a las empresas se constituía a partir de redes de crédito comercial y de un sistema de crédito dirigido por la banca oficial. Al margen de éste, coexistía un segmento 
"competitivo" e informal de crédito, que sin tener gran importancia en término del volumen de los recursos movilizados afectaban la dinámica de los ajustes económicos y alimentaba las heterogeneidades de las empresas.

A nivel macroeconómico, la particular situación de las instituciones que configura la trayectoria nacional restringe el rango de opciones de los agentes. Específicamente, la configuración del "mercado de crédito" y sus entidades y sus instrumentos disponibles, que son endógenas al desarrollo de la economía en su conjunto de manera que las empresas están posibilitadas de endeudarse solo dentro del conjunto de instrumentos existentes en el país.

El relativo subdesarrollo del mercado de crédito se convierte entonces en una limitación al endeudamiento bancario de todas las empresas y en un elemento más que contribuye a mantener o aumentar la heterogeneidad entre empresas.

En resumen, desde el punto de vista de la asignación del crédito, el sendero de endeudamiento bancario de las empresas expresa tanto características específicas a la empresa como cuestiones específicas al mercado de crédito. 


\subsection{Definición de PyMEs e importancia en el sistema económico}

Las PyMEs constituyen una parte significativa del sistema productivo argentino, sobre todo por su participación en el producto, en el empleo y por su diversidad de naturaleza. En particular, en Argentina este tipo de empresas poseen una participación en término de empleo que se encuentra entre las más elevadas de América Latina.

En esta sección se definirá el concepto y se analizará su relevancia en el sistema económico.

\subsection{1 . Concepto de PyME}

Si bien existe bastante consenso en considerar a las pequeñas y medianas empresas en función de su número de empleados, la realidad es que existe otro tipo de características que definen a este tipo de empresas y que ésta, así como la cantidad de empleados considerada, difieren según el país que se analice. Es decir, no existe una definición categórica de PyME, sino más bien depende del ente que la defina y del lugar en que este radicada la firma.

En Argentina la caracterización de PyME está reglamentada por la resolución 21/2010 de la Subsecretaria de pequeña y mediana empresa (Sepyme). En este sentido, se considera como criterio al nivel de facturación o valor de ventas totales anuales, excluidos los impuestos internos y el valor agregado, según el sector económico ${ }^{6}$.

En el siguiente cuadro se detallan los niveles máximos que rigen en la actualidad:

SEPYME - Disposición 21/2010

\begin{tabular}{|c|c|c|c|c|c|}
\hline $\begin{array}{c}\text { Tamaño/ } \\
\text { Sector }\end{array}$ & Agropecuario & $\begin{array}{c}\text { Industria y } \\
\text { Minería }\end{array}$ & Comercio & Servicios & Construcción \\
\hline Pequeña & $\$ 4.100 .000$ & $\$ 10.300 .000$ & $\$ 14.000 .000$ & $\$ 4.300 .000$ & $\$ 4.800 .000$ \\
\hline Mediana & $\$ 24.100 .000$ & $\$ 82.200 .000$ & $\$ 111.900 .000$ & $\$ 28.300 .000$ & $\$ 37.700 .000$ \\
\hline
\end{tabular}

No obstante ello, la categoría de PyME se amplía para aquellas empresas que aun superando los topes máximos de la Sepyme, están comprendidas por los límites que propone la Resolución General 506/2007 que dispone la Comisión Nacional de Valores (CNV).

\footnotetext{
${ }^{6}$ Entre los antecedentes se encuentra la resolución 24 del año 2001 donde la SEPyME definió límites a los niveles de facturación según el rubro económico de la compañía diferenciándola entre sector agropecuario, industria y comercio, minería, servicios y construcción. Posteriormente la resolución 675 del año 2002 readecuo los niveles máximos de facturación debido a los efectos de la devaluación de la moneda nacional del mismo año.
} 
Cabe destacar que si las empresas exceden el parámetro de la Sepyme, aún a pesar de seguir comprendida en los límites de la CNV, sus emisiones no gozaran de los beneficios que otorga esta Subsecretaría, ni podrán ser avaladas por una Sociedad de Garantía Recíproca (SGR). ${ }^{7}$

\section{CNV - Resolución General 506/2007}

\begin{tabular}{|c|c|c|c|c|c|}
\hline $\begin{array}{c}\text { Tamaño/ } \\
\text { Sector }\end{array}$ & Agropecuario & $\begin{array}{c}\text { Industria y } \\
\text { Minería }\end{array}$ & Comercio & Servicios & Construcción \\
\hline Pequeña & $\$ 6.080 .000$ & $\$ 15.000 .000$ & $\$ 22.100 .000$ & $\$ 6.732 .000$ & $\$ 6.000 .000$ \\
\hline Mediana & $\$ 36.480 .000$ & $\$ 120.000 .000$ & $\$ 177.600 .000$ & $\$ 44.880 .000$ & $\$ 48.000 .000$ \\
\hline
\end{tabular}

Fuente: Comisión Nacional de Valores

\subsubsection{Su importancia económica:}

La evidencia internacional muestra que en casi la totalidad de las economías de mercado las empresas pequeñas y medianas constituyen una parte sustancial del sistema económico.

En particular, se destaca su relevancia fundamental en las primeras fases del crecimiento económico, donde las PyMEs, ya sea produciendo o demandando bienes y servicios o añadiendo valor agregado, constituyen un eslabón determinante en el encadenamiento de la actividad económica y la generación de empleo.

Argentina no es la excepción, en particular debido a la elevada contribución al empleo y el alcance a los más diversos sectores económicos que tienen este tipo de empresas.

Especialmente, las PyMEs nacionales reúnen empresas muy diversas en producción, tecnología, empleo y eficiencia, y, según el Censo Nacional Económico de 1994, casi la totalidad de los establecimientos poseían menos de 50 empleados y eran fuente de empleo de más del $70 \%$ del total de los trabajadores de la actividad privada. ${ }^{8}$

Entre otros aspectos su importancia radica en que:

a) Poseen una elevada participación en el mercado laboral, abarcando una amplia cantidad de sectores económicos y grado de calificación en las tareas.

b) Son ámbitos de desarrollo para emprendedores con proyectos rentables e innovadores.

c) Poseen mayor adaptabilidad tecnológica y menor costo de infraestructura, lo que les otorga mayor flexibilidad para adaptarse a entornos cambiantes.

d) Generan importantes efectos socioeconómicos, ya que permiten la desconcentración de la renta y la capacidad productiva desde un número reducido de grandes empresas hacia uno mayor.

e) Establecen un vínculo más estrecho entre empleado y empleador por tratarse de unidades laborales pequeñas $y$, en general, de origen familiar.

\footnotetext{
${ }^{7}$ Las Sociedad de Garantía Reciproca (SGR), son sociedades comerciales que tienen por objeto facilitar el acceso al crédito de las pequeñas y medianas empresas a través del otorgamiento de garantías para el cumplimiento de sus obligaciones. Consiste en una estrategia asociativa entre grandes empresas y PyMEs, que permite garantizar cualquier tipo de compromisos u obligaciones susceptibles de apreciación dineraria.

${ }^{8}$ Cristini, M y Bermudez,G, FIEL, (2004).
} 
A pesar de su alta relevancia, la realidad de este tipo de empresas está lejos de ser la ideal. En general, se destacan por (i) contar con una administración no profesional, usualmente dirigida y operada por el propio dueño; (ii) escasa especialización en el trabajo, tanto en el aspecto productivo como en el administrativo, siendo en este último el mismo empresario quien atiende todos los sectores: ventas, compras, producción, personal, etc.; (iii) actividad no intensiva en capital; es decir, con predominio de mano de obra; (iv) tecnología inadecuada; y la más relevante para nuestro caso; (v) limitados recursos financieros, con el capital de la empresa suministrado principalmente por sus propios dueños.

Estas características y su importancia como unidad de producción de bienes y servicios y como fuente generadora de empleo, conducen a establecer políticas públicas que fomenten su desarrollo. Erradicar los obstáculos que enfrentan este tipo de empresas para crecer se vuelve un deber de las autoridades públicas y privadas con el objeto de apuntalar el desarrollo económico y financiero de la nación.

\subsection{Contrato de deuda}

El contrato de deuda establece los derechos y las obligaciones legales que le caben a quienes demandan financiamiento (el deudor) y a quienes lo proveen (el acreedor). Básicamente, el deudor se compromete a devolver el capital, más el rendimiento exigido por el acreedor, en un plazo estipulado. Sin embargo, más allá de todas las provisiones legales, el contrato es endeble una vez que entran en escena los aspectos económicos.

En primer lugar, la incertidumbre intrínseca que envuelve a cualquier proyecto de inversión condiciona la capacidad de repago de todo deudor. Trascendente como es, este obstáculo puede salvarse estimando la probabilidad de repago y ajustando consecuentemente la tasa de interés. El segundo obstáculo es menos sencillo de superar y radica en la frágil promesa del deudor de obedecer fielmente la letra del contrato. No escapa al observador avezado que el deudor puede enmascarar la verdadera naturaleza de su proyecto, o una vez en posesión de los fondos desviarlos hacia otros fines u ocultar los resultados. Estos son los llamados problemas de Información Asimétrica. Si estas conductas afectan la estabilidad del acreedor se desatará un conflicto de intereses.

Para comprender las implicancias de la información asimétrica sobre los mercados financieros se necesita en primera instancia discutir los fundamentos de la relación entre deudor y acreedor. Se entablará un contrato financiero únicamente si tanto el deudor como el acreedor obtienen un beneficio esperado igual o superior al que podrían obtener en un proyecto alternativo. Esta es la llamada restricción de participación o restricción de racionalidad individual: ningún individuo racional participará en una inversión a pérdida, ni tampoco lo hará si el beneficio no alcanza el umbral determinado por la oportunidad de inversión a la cual se está renunciando por embarcarse en este proyecto particular; este piso de rentabilidad se conoce como costo de oportunidad o rendimiento requerido.

En un mundo con información perfecta, este contrato es relativamente simple de establecer y analizar debido a que el acreedor conoce a ciencia cierta las características del proyecto, tanto sus flujos de caja como las probabilidades asociadas. El riesgo de quiebra está presente, pero el acreedor toma las precauciones necesarias en la forma de una tasa de interés más alta en el estado favorable. En virtud de que el deudor y el acreedor tienen acceso a la misma información, se dice que este contrato se celebra bajo información simétrica. En cambio, existe información asimétrica en un contrato financiero cuando el deudor cuenta con información que el acreedor ignora. Esta asimetría 
concierne al acreedor siempre que el deudor pueda utilizar su mayor información para extraer un beneficio a sus expensas, y para que ello ocurra es preciso que concurran los siguientes tres factores:

1) El deudor viola el contrato ocultando información sobre las características o los ingresos efectivos del proyecto.

2) El acreedor no cuenta con la información ni el control suficiente sobre el deudor como para evitar la defraudación.

3) Existe riesgo de repago de la deuda y responsabilidad limitada del deudor.

\subsection{1 . Formas de asimetrías informativas}

Las asimetrías informativas en los mercados financieros pueden adoptar cualquiera de las siguientes modalidades: selección adversa, riesgo ético y costo de monitoreo. Se dice que el acreedor padece selección adversa cuando no es capaz de distinguir entre proyectos con diferentes niveles de riesgo al momento de asignar el crédito. Bajo un contrato de deuda y a igualdad de valor esperado, el acreedor prefiere los proyectos más seguros y el deudor los más arriesgados. En este contexto los emprendedores de proyectos con riesgo encuentran conveniente ocultar la verdadera naturaleza del proyecto, explotando así la desinformación relativa del acreedor.

Por riesgo ético se entiende la habilidad del deudor para aplicar los fondos a un uso distinto al acordado con el acreedor, amparado en la información y control parciales con que cuenta este último.

Al igual que el riesgo ético, los costos de monitoreo se vinculan a una acción oculta por parte del deudor, en este caso aprovechando su superioridad informativa para declarar ganancias inferiores a las reales.

En resumen, la selección adversa aparece antes de que el acreedor desembolse el crédito, en contraste con el riesgo ético y los costos de monitoreo, en los cuales el problema tiene lugar después de concedida la financiación. En la selección adversa y en los costos de monitoreo se supone que los deudores han escogido de antemano el proyecto, mientras que en el caso del riesgo ético tiene el poder de optar por el proyecto que considere más beneficioso una vez en posesión del crédito. El siguiente cuadro sintetiza estas propiedades:

\begin{tabular}{|l|l|l|}
\hline & Antes del desembolso & Después del desembolso \\
\hline Proyecto preestablecido & Selección Adversa & Costo de Monitoreo \\
\hline Elección entre proyectos & & Riesgo Ético \\
\hline
\end{tabular}




\section{3 . Obstáculos identificados por las PyMEs para desarrollarse}

A pesar de ser un sector con elevada flexibilidad para adaptarse al entorno cambiante del mercado, ha sucesivamente enfrentado numerosos obstáculos que han limitado su crecimiento y, en el peor de los casos, han condenado a este tipo de empresas a su desaparición.

Según la encuesta empresaria FIEL, 2003-2004, los principales obstáculos que enfrentan las PyMEs en Argentina son, entre otros:

1. El clima desfavorable de las reglas impositivas;

2. La insuficiente protección policial;

3. El deficiente estado de la red de logística, en particular, carreteras;

4. La insuficiente disponibilidad de crédito;

5. El clima político enrarecido;

6. La discrecionalidad en las políticas del gobierno; y

7. La arbitrariedad y demoras en las sentencias judiciales y los altos costos de litigar.

Por resultar uno de los más relevantes para este tipo de empresas y estar en el centro de nuestro estudio, a continuación se analizará con mayor grado de detalle el problema de acceso al crédito o financiamiento.

\subsection{1 . El problema de financiamiento}

Identificando como uno de los principales obstáculos que enfrentan las empresas pequeñas y medianas en la Argentina, el acceso al financiamiento y los mecanismos para agilizarlos han sido desde siempre tema de debate público.

La naturaleza de este tipo de empresas requiere de constantes inversiones en períodos cortos de tiempo, marcando un crecimiento acelerado y un mejoramiento continuo de procesos de modo de permanecer en un mercado cambiante y exigente.

Numerosos estudios han demostrado que una gran parte de los problemas de las pequeñas y medianas empresas radica en su administración, dado que en la mayoría de los casos se trata de empresas familiares que carecen de formalidad tanto en la organización como en el planeamiento y no poseen manuales de procedimiento ni políticas preestablecidas para la toma de decisiones. Es por ello que el manejo financiero de la compañía muchas veces se vuelve determinante en la vida de las PyMEs.

Las principales necesidades financieras que enfrentan las empresas durante su ciclo de negocios se focaliza en:

(i) El financiamiento de proyectos de inversión, de elevada rentabilidad y con dificultades para ser financiados por la vía bancaria tradicional.

(ii) El financiamiento de capital de trabajo, de manera de evitar el descalce entre ingresos y egresos en el normal funcionamiento del negocio.

(iii) La reestructuración de pasivos, cambiando el perfil de la deuda, con vencimientos concentrados en el corto plazo por compromisos a largo plazo que doten a la empresa de mayor flexibilidad. 
Tal como se puede apreciar, tanto en términos de crecimiento (i y ii) como de solvencia financiera (iii), el financiamiento se vuelve un aspecto de elemental importancia para la gerencia administrativa de la empresa, que lidia constantemente con la forma de contar con liquidez para abastecer el funcionamiento normal del negocio, impulsar la consolidación, y el crecimiento en el mercado y lograr que la compañía se vuelva más rentable.

En otras palabras, aprovechar los recursos económicos disponibles y administrarlos de manera eficiente resulta vital para impulsar el éxito y estabilidad del negocio.

\section{4 . Vías tradicionales de financiamiento de las PyMEs}

El mecanismo tradicional de financiamiento de las PyMEs ha sido el uso de fondos propios vía la reinversión de utilidades y el crédito de proveedores. El sistema bancario también se constituyó durante largo tiempo en una importante fuente de asistencia financiera para las empresas.

En esta sección se repasa el orden de jerarquía en los mecanismos de financiamiento que utilizan las PyMEs en Argentina, poniéndose el acento en la dificultad que representa para las empresas depender del crédito bancario para financiar su desarrollo.

\subsection{1 . Orden de jerarquía en el financiamiento PyME}

El orden de jerarquía en los mecanismos de financiamiento indica que los fondos propios, bajo la forma de reinversión de utilidades, son el principal instrumento de financiamiento de las empresas. Esto se basa en ventajas como flexibilidad y facilidad en la disponibilidad de los fondos, ausencia de costos administrativos o de emisión que poseen fuentes de financiamiento externos, y privacidad de información relevante que en caso de acceder a fondos públicos la empresa debe dar a conocer. ${ }^{9}$

En el caso de las pequeñas y medianas empresas, los administradores (que por lo general son los dueños) evitan recurrir a fondos externos debido a que no quieren ceder el control de la compañía. Existe una resistencia a la apertura de capital y a la participación de socios no pertenecientes al entorno cercano en las decisiones de la firma.

Un repaso en la bibliografía local confirma lo anterior. En este sentido Briozzo y Vigier (2006) ${ }^{10}$ indican que, en general, los trabajos descriptivos realizados sobre las PyMEs en Argentina reportan elevada participación de los recursos propios en la estructura de capital y poca incidencia de financiamiento bancario.

Cristini et al (2003) ${ }^{11}$ señala que la reinversión de utilidades, el crédito de proveedores y el crédito bancario se constituyen en la principales fuentes de financiamiento en Argentina, tomando mayor relevancia las dos primeras en el caso particular de las PyMEs.

Panigo et al (2006) $)^{12}$ muestra que, entre los distintos tipos de instrumentos de financiamiento, se destaca una mayor importancia del capital propio (incluyendo ganancias retenidas y reservas) y del

\footnotetext{
${ }^{9}$ La teoría del Pecking Order fue desarrollada inicialmente por Stewart Myers y Nicolás Maijluf en 1984 y establece que las empresas priorizan su fuente de financiamiento de acuerdo con el siguiente orden: en primer lugar el uso de fondos internos, luego la emisión de deuda, y por último la emisión de acciones.

${ }^{10}$ Brioso, A y Vigier, H (2006).

${ }^{11}$ Cristini, M., Acosta, P., Susmel, N. (2003).
} 
endeudamiento a través de obligaciones negociables y del financiamiento bancario, en términos comparativos al financiamiento con deuda comercial o con retrasos de compromisos con el fisco y el sistema de seguridad social.

Si bien a la luz de la evidencia empírica queda claro que el mecanismo de financiamiento interno resulta el más elegido por las empresas, el ciclo de negocios propio de cada compañía las lleva a requerir financiamiento externo en algún momento de su existencia. Las posibilidades entonces se reducen a dos: bancos o mercados de capitales.

En un país como Argentina, donde el mercado de capitales no ha logrado desarrollarse plenamente, el sistema bancario se erigió durante mucho tiempo como la única alternativa. ${ }^{13}$ Sin embargo, el acceso al crédito bancario ha estado signado en la mayoría de los casos por condiciones casi prohibitivas para las empresas, ya sea en términos de tasa de interés, plazo de los créditos, garantías exigidas, entre otras. Esto ha generado numerosas limitaciones para las empresas en acceder al financiamiento que les permita desarrollarse, condicionando su crecimiento futuro.

\subsection{2 . Bancos vs. Empresas}

El sistema bancario ha sido históricamente una de las principales fuentes de financiamiento de las empresas.

Sin embargo, amplias son las diferencias entre lo que una entidad bancaria está dispuesta a ofrecer a las empresas y lo que estas últimas realmente necesitan. Su estructura muchas veces no le permite acceder a los términos y condiciones que los bancos imponen, limitando el acceso al financiamiento, y condicionando de este modo su desarrollo futuro.

\footnotetext{
12 Panigo, D.; Pasquíni, R.; Streb, M. (2007).

${ }^{13} \mathrm{La}$ falta de conocimiento del mercado de capitales por parte de las empresas ha sido una de las principales causas de su escaso desarrollo.
} 
Entre las diferencias se destacan:

\begin{tabular}{|l|l|l|}
\hline Características & La PyME demanda : & El Banco ofrece: \\
\hline Fondeo & De Largo Plazo & Mayormente de Corto Plazo \\
\hline Moneda & Pesos o Dólares & Preferentemente Pesos \\
\hline Tasa & Variable en Pesos - Fija en Dólar & Variable base BADLAR Privada \\
\hline Operatividad & Agilidad & Limitada \\
\hline Productos & $\begin{array}{l}\text { Adecuados a necesidad. } \\
\text { Contempla estacionalidad del } \\
\text { negocio }\end{array}$ & $\begin{array}{l}\text { Estructuración rígida: } \\
\text { "Enlatados" }\end{array}$ \\
\hline Comercialización & $\begin{array}{l}\text { Sólo lo necesario / } \\
\text { Transparencia }\end{array}$ & $\begin{array}{l}\text { Paquete Integral / Cross-Sell y } \\
\text { Comisiones sorpresas }\end{array}$ \\
\hline
\end{tabular}

Fuente: elaboración propia en base a información del mercado.

La evidencia empírica muestra que las PyMEs presentan mayores dificultades que empresas grandes para acceder al crédito bancario. Con relación al costo de financiamiento, la realidad indica un importante diferencial de tasas según el tamaño de la empresa. Numerosas son las razones que conducen a este hecho, entre las que se destacan la dificultad en la evaluación adecuada del riesgo del proyecto, tanto por falta de información objetiva y poco conocimiento del negocio de las PyMEs por parte de los bancos, así como dificultades de gestión administrativa de las mismas. Por otro lado, es de esperar que las PyMEs operen con menos bancos debido a la escasez de activos reales disponibles para utilizar como garantías con cada institución. Asimismo, se vuelve difícil para una PyME aumentar la cantidad de bancos con que realiza transacciones debido a que la historia crediticia no se puede trasladar entre estas entidades.

Es decir, en la mayoría de los casos, la asimetría informativa a que está expuesta la PyME condiciona su acceso al préstamo bancario. 


\section{5 . El mercado de capitales: ¿Una alternativa para el financiamiento de la empresa PyME?}

Las dificultades que presenta el sistema bancario para financiar las necesidades de las empresas han impulsado al mercado de capitales como un mecanismo alternativo de financiamiento.

A pesar de su escaso desarrollo, cabe destacar que aunque en medio de la fuerte crisis económica y financiera que atravesó Argentina tras la salida de la convertibilidad, devaluación de la moneda y ruptura de la cadena de pagos, y con la desaparición de las fuentes tradicionales de financiamiento, el mercado de capitales se mantuvo relativamente activo.

En los siguientes incisos se estudian, por un lado, los beneficios que obtienen las empresas para acceder al mercado de capitales, y por el otro, los distintos instrumentos que existen en este mercado para que cada empresa logre que sus negocios sean sustentables desde el punto de vista del financiamiento, poniendo énfasis en las obligaciones negociables, que es el instrumento guía en este estudio.

\subsection{1 . Beneficios para la empresa de acceder al mercado de capitales}

Los principales beneficios que obtienen las empresas al financiarse en el mercado de capitales son:

a) Acceso a una fuente de financiamiento permanente, incluso en momentos difíciles de la economía, vía el contacto con una amplia cartera de inversores de diverso perfil.

b) Menor costo financiero total frente a otras alternativas disponibles.

c) Flexibilidad, debido a la posibilidad de estructurar el instrumento de acuerdo al flujo de fondos y a las necesidades específicas de la empresa.

d) Transparencia del sistema y de sus componentes esenciales ante los ojos del empresario PyME y del público inversor.

e) Ordenamiento de la información contable de la empresa para cumplir con los requisitos exigidos por los organismos de control.

f) Prestigio de cotizar en la bolsa, que le abre nuevas puertas a las PyME, con nuevos clientes, proveedores y con otras fuentes de financiación complementaria, como bancos.

g) Mejorar la imagen institucional debido a la cotización pública.

Por su parte, los costos que enfrentan las empresas al hacerse públicas son:

a. Selección adversa: en general los inversores están menos informados que los emisores del verdadero valor de las compañías. Esta asimetría informativa afecta la calidad promedio de las emisoras y así el precio al cual sus valores son vendidos. Este costo es más importantes en empresas jóvenes y pequeñas, que tienen escaso track record y visibilidad comparadas con empresas grandes y antiguas ${ }^{14}$.

b. Honorarios y costos administrativos: Cotizar en la bolsa implica considerables costos directos y honorarios para las diversas partes involucradas. Además existen costos anuales de auditoria y certificaciones y difusión de información requerida para los organismos de control. Dados que muchos de estos gastos son fijos y no proporcionales al tamaño de la emisión, pesan relativamente más en empresas pequeñas.

\footnotetext{
${ }^{14}$ Chemmanur y Fulghieri (1995).
} 
c. Perdida de confidencialidad: Los requisitos de difusión de información fuerzan a las compañías a revelar datos relevantes de su negocio. Además están sujetas a un importante control de autoridades fiscales. Asimismo, están sujetas a un importante control de autoridades fiscales, reduciendo la posibilidad de elusión y evasión relativas a compañías privadas ${ }^{15}$.

\subsection{2 . Disponibilidad de instrumentos en el mercado de capitales}

El mercado de capitales ofrece múltiples instrumentos de financiación que las empresas pueden utilizar en función de las necesidades específicas.

A través de la cotización de acciones, las compañías pueden financiarse incorporando nuevos socios que compartan el riesgo de negocio con los accionistas originales. Las acciones lanzadas a la oferta pública son negociables en el mercado de capitales una vez realizada la colocación en el mercado primario. Luego, el precio de la acción estará determinado por la interacción de oferta y demanda entre los inversores en el mercado secundario, quienes podrán desprenderse de su participación cuando así lo deseen sin afectar el capital social de la empresa. En la Bolsa, las PyMEs cuentan con un régimen certificado de oferta pública y cotización.

Los instrumentos de renta fija, como las obligaciones negociables (ON) y los cheques de pago diferido (CPD), permiten a la empresa financiarse en diversos plazos acorde al flujo de fondos de su negocio, con el objeto de lograr una financiación eficiente sin descalce de plazo ni tasa.

Las obligaciones negociables son bonos privados que presentan valores de deuda de la sociedad anónima y/o cooperativa que la emite y pueden ser colocadas entre el público inversor calificado mediante su cotización y negociación en la bolsa. Las compañías se comprometen a devolver a los inversores acreedores el dinero adeudado en el plazo pactado y con el interés correspondiente. Por otro lado, las sociedades anónimas pueden invertir obligaciones que brinden al inversor la posibilidad de convertirlas en acciones de las firmas según las condiciones determinadas en la inversión.

Estas obligaciones combinan las necesidades de financiamiento a mediano y a largo plazo con la intensión de apertura futura de capital. En Argentina, las pequeñas y medianas empresas pueden emitir obligaciones negociables bajo un régimen simplificado de oferta pública y cotización instituido por un Decreto del Poder Ejecutivo, normas complementarias de la Comisión Nacional de Valores (CNV) y resoluciones de la Bolsa de Comercio de Buenos Aires (BCBA).

Los cheques de pago diferido permiten a quienes tienen cheques a cobrar en un futuro (por un plazo máximo de 360 días) adelantar su cobro vendiéndolos en la Bolsa; y a quienes poseen fondos líquidos, comprar estos cheques a cambio de tasa de interés. En sentido estricto, es una orden de pago librada a una fecha determinada, posterior a la de su libramiento, contra una entidad autorizada, en la cual el librador a la fecha de vencimiento debe tener fondos suficientes depositados a su orden en cuenta corriente, o autorización para girar en descubierto. Los cheques de pagos diferidos cuentan con dos sistemas de negociación:

\footnotetext{
${ }^{15}$ Campbell (1979) fue el primero en estudiar la confidencialidad como un obstáculo a que la empresa obtenga fondeo en mercados públicos.
} 
(i) Patrocinados: en este sistema una empresa grande o PyME es autorizada por el BCBA para emitir cheques de pago diferido para el pago a proveedores, que pueden ser negociados en el mercado de capitales.

(ii) Avalados: en el sistema avalado, las pequeñas y medianas empresas o personas físicas pueden negociar cheques propios o de terceros (clientes), a través de una Sociedad de Garantía Recíproca (SGR). La SGR autorizada por la Bolsa pueden cotizar cheques que tengan como beneficiarios a sus socios PyMEs y garantizar el pago mediante un aval.

La experiencia local muestra que la mayor parte de las PyMEs que han entrado al mercado de capitales lo realizaron mediante este instrumento.

Los valores de corto plazo (VCP) son un instrumento que tienen como objetivo facilitar el acceso al financiamiento a empresas que deseen endeudarse a plazos inferiores a los 365 días. Las firmas deben estar constituidas bajo la forma de sociedad por acciones, de responsabilidad limitada, cooperativa, o ser sucursal de sociedades por acciones constituidas en el extranjero. Estos VCP pueden emitirse como pagares seriados, valores representativos de deuda a corto plazo $u$ obligaciones de corto plazo, de acuerdo a la naturaleza societaria del emisor ${ }^{16}$, y deben ser ofrecidos con exclusividad a inversores calificados.

El fideicomiso financiero consiste en la securitización de flujos de fondos futuros aislando el riesgo de la empresa para obtener costos financieros más convenientes que con otras alternativas. Se trata de una herramienta mediante la cual las PyMEs, en forma individual o conjunta, pueden obtener fondos separando determinados activos (reales o financieros) de su patrimonio cediéndolo a un administrador en propiedad fiduciaria.

El administrador interviene para que los activos cedidos sean transformados en activos financieros líquidos y se puedan negociar en el mercado bursátil ${ }^{17}$.

De esta forma, el mercado de capitales ofrece una variedad de instrumentos, para que en función de las necesidades, flujos de ingresos, disposición de garantías y demás condiciones específicas, cada empresa logre que su negocio sea sustentable desde el punto de vista del financiamiento.

A continuación se ilustra la situación actual del mercado de capitales argentino para PyMEs y su evolución total y por instrumento desde la salida de la convertibilidad. Asimismo, se indagan las razones acerca de porqué un instrumento particular fue el más elegido por las empresas para buscar financiamiento.

\footnotetext{
${ }^{16}$ Las Sociedades de responsabilidad limitada solo pueden emitir Valores Representativos de Deuda de Corto Plazo o Pagarés seriados.

${ }^{17}$ El hecho de que los bienes fideicomitidos queden separados del riesgo comercial de la empresa hace que ésta pueda acceder a mejores calificaciones de riesgo y emitir títulos valores garantizando su pago con el flujo de fondo generado por esos activos específicos. La mejor calificación de riesgo y las mejores garantías implican un menor costo de financiamiento para la emisora.
} 


\subsection{3 . El Mercado de capitales para PyMEs en Argentina}

En Argentina el mercado de capitales dirigido a pequeñas y medianas empresas tiene un desarrollo incipiente.

Si bien desde su creación fue un mecanismo de captación de fondos para grandes empresas, recién luego de la salida de la Convertibilidad en el año 2002 es que comenzó a tomar impulso el financiamiento de pequeñas y medianas empresas, momento que coincidió con la creación del Departamento PyME de la Bolsa de Comercio de Buenos Aires, un ente creado en septiembre del 2002 con el objetivo de facilitar el acceso de este tipo de empresas a fuentes de financiamiento alternativo.

Mientras que en el 2002 el financiamiento captado por las PyMEs fue de US\$ 5,4 millones, para el año 2008 dicho monto ascendió a casi US\$ 361 millones. Esta cifra representó el $8.6 \%$ del financiamiento total en el mercado de capitales (US\$ 4186 millones) ${ }^{18}$, la proporción más alta de la serie histórica, lo que denota un gran avance en el objetivo de acercar el mercado de capitales en este tipo de empresas.

\section{Participación del Financiamiento a PyMEs por año}

(en porcentaje del financiamiento total)

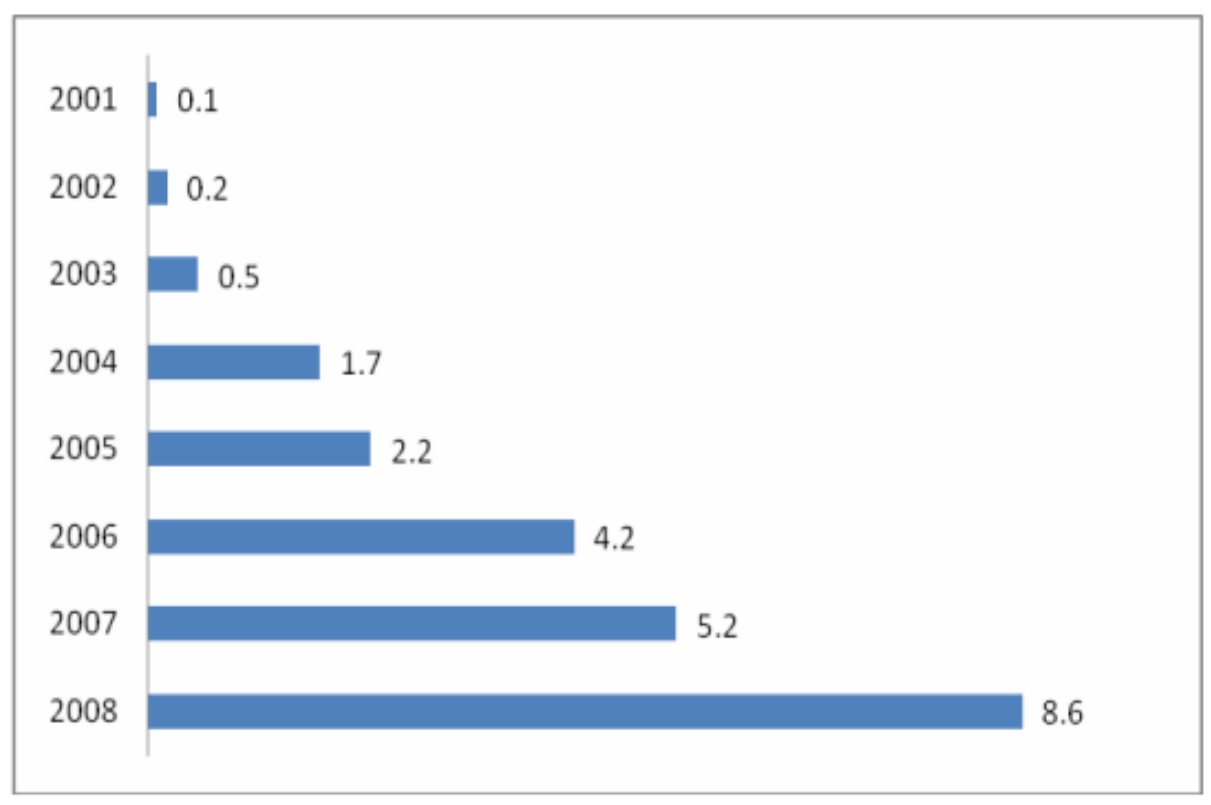

Fuente: Elaboración propia en base a datos del IAMC

En el año 2008, los cheques de pago diferido y los fideicomisos financieros resultaron los principales instrumentos escogidos por las PyMEs para obtener financiamiento del mercado. Los CPD abarcaron el 53,9\% de las emisiones PyME, mientras que los fideicomisos financieros significaron el $45 \%$ del total. En tanto, las obligaciones negociables representaron el $1 \%$ restante. Cuando se compara las emisiones por instrumento contra el año anterior se aprecia que el monto de las

\footnotetext{
18 Dicha suma resulto un $41 \%$ inferior al registrado en el 2007 , hecho que se explica por la coyuntura local e internacional desfavorable.
} 
colocaciones de ON creció casi un $90 \%$ mientras que los CPD se mantuvieron relativamente estables $^{19}$.

Analizando la evolución de los instrumentos desde el tercer trimestre del 2002 al año 2008, se aprecia que los CPD fueron el instrumento de mayor uso, a pesar de haber sido implementados recién a fines del 2003. En orden de importancia le siguió la figura de FF y luego las ON. En particular, el mayor uso de instrumentos de corto plazo (CPD y FF) se explica por el escenario poscrisis, donde prevalecen decisiones de corto plazo, complejidad y desconfianza a los análisis de largo plazo y marcos jurídicos inestables, entre otras razones.

\section{Financiamiento PyME por instrumento.}

Acumulado 2002-2008

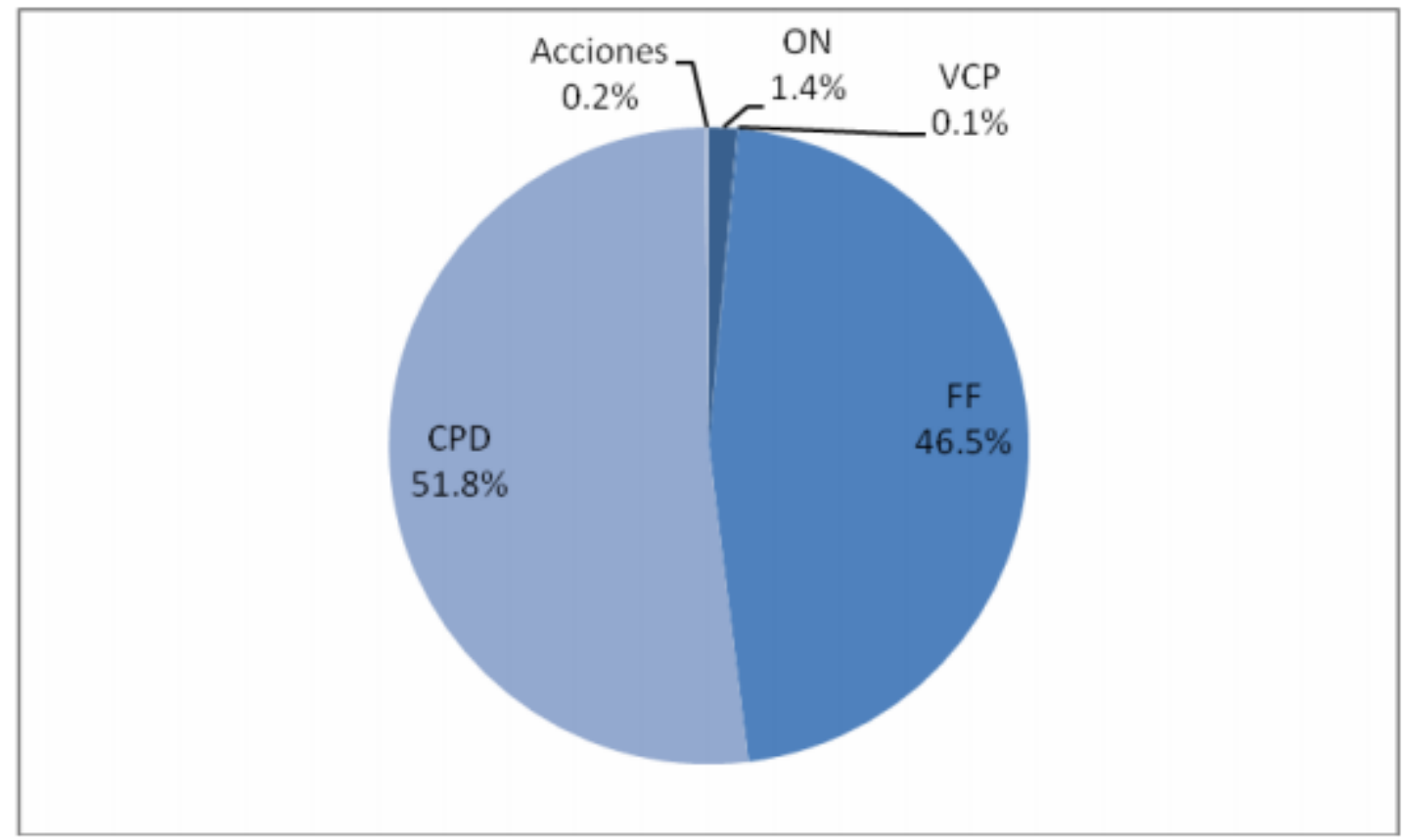

Fuente: Elaboración propia en base a datos del IAMC.

En cuanto a la evolución de cada instrumento en particular, mientras que en el año 2002 casi el $75 \%$ del financiamiento PyME se realizó mediante ON o VCP - en su mayor parte en el primer semestre-, comenzaron a instrumentarse los primeros fideicomisos financieros, absorbiendo estos últimos el $25 \%$ del fondeo total.

En el año 2003 los fideicomisos generaron el $82 \%$ del financiamiento a PyMEs, mientras que el restante $17 \%$ consistió en ON o VCP. Los CPD hicieron este año su aparición en escena, proveyendo apenas el 1\% restante. A partir del 2004 los CPD comenzaron a ganar participación como el instrumento de mayor uso entre las PyMEs, con participaciones cercanas al 45-50\% del total, similar a la de los fideicomisos financieros. Los VCP, que tras la crisis se volvieron un mecanismo relevante por el cortoplacismo de las operaciones, pasaron de representar el 5,6\% del financiamiento PyME en 2002 al 0,2\% en el año 2005 para luego dejar de utilizarse. En tanto, las ON que ocuparon un lugar significativo en los años 2002 y 2003, redujeron significativamente su

\footnotetext{
${ }^{19}$ En el caso de las ON adquieren relevancia si se observa que la emisión total de ON cayó bruscamente con respecto al año anterior (86\%).
} 
participación en el total, representando en promedio para los años sucesivos el $1 \%$ del financiamiento total a las PyMEs. Por último, el mecanismo de menor aceptación entre las pequeñas y medianas empresas fue la emisión de acciones, con sólo dos empresas que abrieron su capital desde el año $2002^{20}$.

\section{Financiamiento PyME por instrumento.}

Participación porcentual anual del total

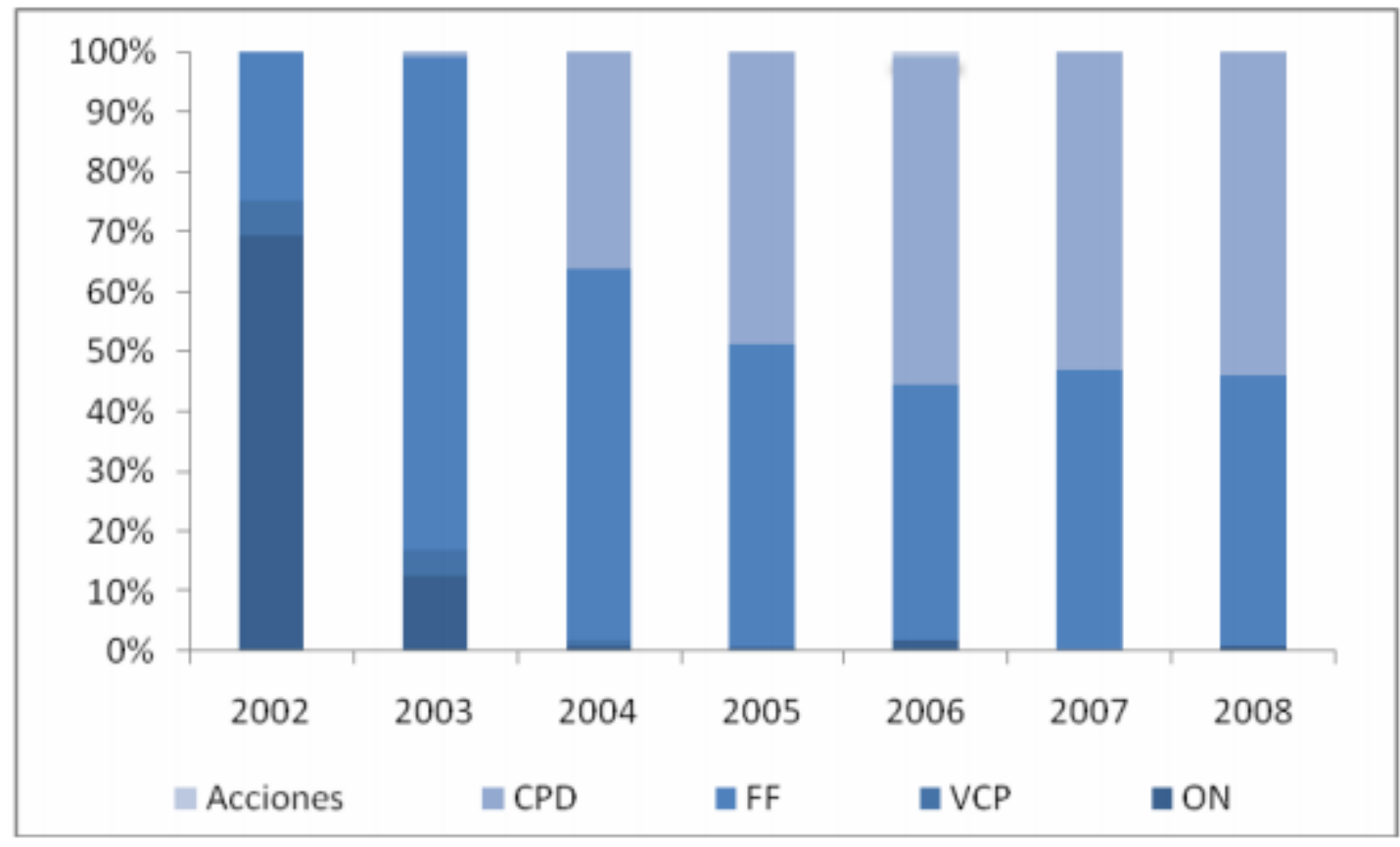

Fuente: Elaboración propia en base a datos del IAMC.

Actualmente, son más de 4.000 las PyMEs que se financian a través de los instrumentos disponibles en el mercado de capitales, por un total de US\$ 1.000 millones de dólares.

\section{6 . Deuda Empresaria: Obligaciones Negociables PyME}

Cuando una empresa necesita financiar sus proyectos puede recurrir al mercado de capitales y obtener fondos de corto, mediano o largo plazo, mediante la emisión de obligaciones negociables.

Quienes compran estos papeles son los obligacionistas o inversores, que prestan dinero en efectivo a cambio de una tasa de interés y se convierten en acreedores de la empresa. Por su parte, la compañía se compromete a devolverles el dinero adeudado en el plazo pactado y con el interés correspondiente.

A diferencia de las acciones, las obligaciones negociables son instrumentos de renta fija, ya que tienen un cronograma de pagos predefinido. Llegado el vencimiento de la obligación, la empresa cumple sus compromisos y el obligacionista deja de ser su acreedor. El capital de la ON se devuelve generalmente en cuotas periódicas llamadas amortizaciones, que pueden realizarse en forma anual, semestral o en otro plazo acorde con las necesidades del emisor. Por su parte, el pago de intereses se denomina pago de renta y también puede realizarse periódicamente, con tasa de interés que puede

\footnotetext{
${ }^{20}$ Ambas emisiones de acciones PyMEs se realizaron en el cuarto trimestre de 2006.
} 
ser fija, variable o mixta. No obstante, la empresa puede preferir devolver un monto fijo al vencimiento por lo que emitirá una obligación negociable con descuento denominada cero cupón. Por otra parte, las ON tipo bullet son aquellas que realizan pagos de capital íntegramente al vencimiento pero pagan intereses en forma periódica.

La ON se pueden emitir en el marco de un programa global, que es el procedimiento por el cual las empresas autorizadas a la oferta pública pueden solicitar el permiso para financiar un monto global total que podrá obtenerse en varias etapas mediante la emisión de distintas series de obligaciones negociables. Al solicitar el programa global la empresa elaborará un prospecto completo y las emisiones podrán efectuarse dentro de los 5 años contando a partir de la autorización original del programa. El programa es útil para aquellas compañías que prevén una necesidad de fondos en forma regular por un período o monto determinado, con el consecuente ahorro de tiempo y costo. Si bien cada serie de obligación negociable requiere el permiso de oferta pública de la CNV y el permiso de cotización de la Bolsa, cuando la emisión se realiza en el marco de un programa global, son menores los pasos para autorizar cada serie y se presenta un prospecto reducido en cada emisión, con la posibilidad de realizar la colocación de las series en el momento más adecuado del mercado.

Para dar conocimiento de la emisión se publica el prospecto de emisión. Se trata de un documento a disposición de los potenciales inversores, que ofrece información de la empresa, tal como sus orígenes y proyecciones, y un detalle sobre la emisión en particular. En las condiciones, el prospecto debe informar todas las características del título como la forma de pago de amortización y renta, moneda de emisión, régimen impositivo y calificaciones de riesgo.

Existen diversas modalidades de emisión de obligaciones negociables, que se adaptan a las circunstancias y necesidades particulares de cada empresa, así como también a las exigencias del mercado. Por ello, cuando se emiten obligaciones negociables la empresa debe tener en cuenta no sólo sus necesidades de fondo sino también los requerimientos de los inversores, según la proporción de riesgo e interés que se demanda en cada momento.

\subsection{1 . ON PyME. Régimen y beneficios}

En Argentina, las pequeñas y medianas empresas pueden emitir obligaciones negociables bajo un régimen simplificado de oferta pública y cotización instituido por un decreto del Poder Ejecutivo, normas complementarias de la Comisión Nacional de Valores (CNV) y resoluciones de la Bolsa de Comercio de Buenos Aires (BCBA), creado a efectos de que la citada empresa acceda al financiamiento necesario para el desarrollo de las actividades y proyectos, ya sea para la realización de inversiones o el refinanciamiento de deudas. Muchas empresas recurren a estos bonos para ampliar capital, mejorar tecnología o implementar proyectos de investigación. 
Las principales diferencias entre las ON de Régimen General y las ON PyME son las siguientes:

\begin{tabular}{|l|l|l|}
\hline Régimen & General & ON PyME \\
\hline Plazo & Sin Restricciones & 5 Años \\
\hline Monto & Sin Restricciones & $\$ 15.000 .000$ \\
\hline \multirow{2}{*}{ Información } & - Balance anual & - Balance anual \\
\cline { 2 - 3 } & - Balance trimestral & - Informes semestrales \\
\hline Inversores & Todos & Calificados \\
\hline Síndicos & Sindicatura colegiada & Un síndico \\
\hline Trámites & CNV/BCBA & BCBA \\
\hline
\end{tabular}

Fuente: Elaboración propia en base a datos del BCBA.

Para que una PyME pueda ingresar en este régimen, además de estar encuadrada en los límites establecidos previamente (Disposición 147/2006 de la Sepyme), la normativa exige que la empresa:

(i) Esté registrada como Sociedad Anónima.

(ii) El veinte por ciento (20\%) o más del capital y/o de los derechos políticos de las entidades no deberán pertenecer a otras entidades que no encuadren en la definición legales de PyMEs.

(iii) No podrán utilizar simultáneamente programas de subsidios específicos u otras ventajas destinadas a PyMEs.

A los beneficios que genera el mercado de capitales enumerados anteriormente se suman los siguientes, propios de las ON PyME:

a) Instrumentos "Taylor-made", es decir, a medida de lo que cada empresa requiere.

b) Transparencia en la tasa que percibe el inversor, los costos de la estructuración, y por lo tanto de la tasa final de financiamiento.

c) Menores requisitos de información. La empresa debe presentar documentación básica una vez autorizada la cotización.

d) Extensión de obligatoriedad de calificación de riesgo de la emisión, que repercute favorablemente en los costos.

e) Financiación por hasta 15.000 .000 (Pesos) a tasa de interés atractivas y plazos superiores respecto de otras alternativas de financiación.

Estas características por el lado de la oferta del producto y un perfil de inversor de clara preferencia por la renta fija por el lado de la demanda, lo vuelven un instrumento relevante para el mercado de capitales local. 
Luego de la más severa crisis económica financiera que atravesara nuestro país en el primer semestre del 2002, las pequeñas y medianas empresas volvieron a buscar financiamiento en el mercado local. Las condiciones imperantes en los primeros meses post crisis solo permitían endeudamiento de muy corto plazo y siempre garantizado por un ente solvente y calificado. En este sentido, el instrumento elegido para tomar fondos, vía endeudamiento empresario resultó el Valor de Corto Plazo (VCP) y como garantía el mercado aceptaba únicamente Sociedad de Garantía Recíproca (SGR). ${ }^{21}$

Así fue que en el tercer trimestre del 2002 y el segundo trimestre del 2005 casi la totalidad de las emisiones de deuda PyME fueron instrumentadas a través de VCP con SGR de respaldo. En total, durante los 36 meses del período citado, las pequeñas y medianas empresas recolectaron del mercado US\$ 3,05 Millones de dólares. Las emisiones de ON resultaron escasas en ese período: tan solo dos empresas emitieron este tipo de deuda hasta mediados de 2005.

Recién a partir de mediados de julio de 2005, y dadas las mejoras percibidas en el ambiente económico y social empresario, la deuda pudo exceder sus plazos, tomando impulso la emisión de obligaciones negociables con amortización superior al año. Por su parte, alentada por la posibilidad de conseguir financiamiento de mediano plazo, las pequeñas y medianas empresas dejaron de emitir VCP.

\section{Emisiones PyME de ON y VCP - en dólares}

Segundo semestre de 2002 a 2008

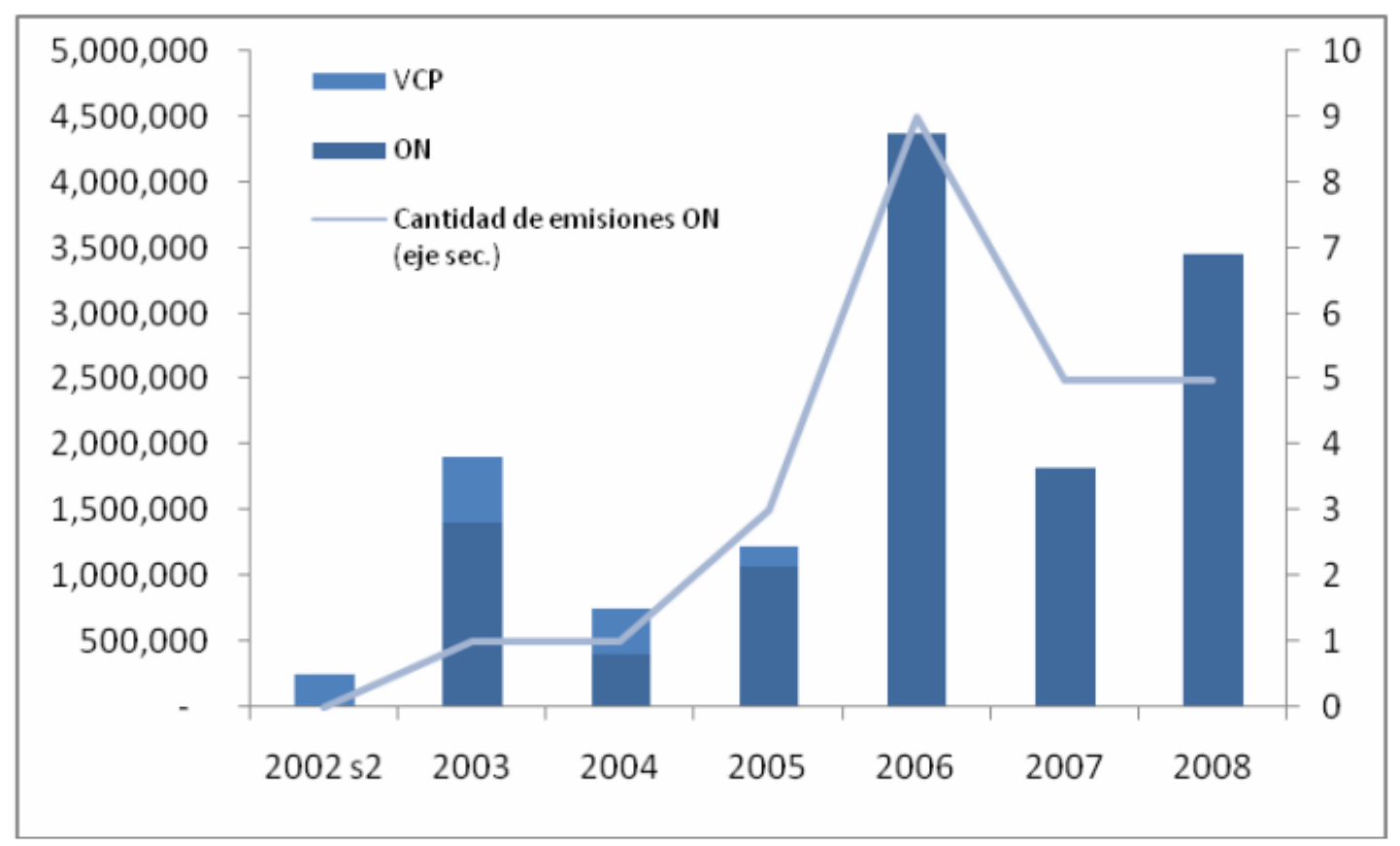

Fuente: Elaboración propia en base a datos del IAMC.

\footnotetext{
${ }^{21}$ Cabe destacar que en el período mencionado tomaron impulso otros mecanismos de financiamiento PyME, como los Fideicomisos Financieros y los Cheques de Pago Diferido.
} 
Si bien con relación a los instrumentos "estrellas" del mercado (Fideicomisos Financieros y Cheques de Pago Diferido) los fondos recogidos por las PyMEs con estos instrumentos son sustancialmente menores, con el objetivo de mejorar la imagen institucional volviéndose públicas muchas empresas continuaron utilizando la deuda como mecanismo de financiamiento. En total, unas 19 PyMEs financiaron sus proyectos mediante 41 emisiones de $\mathrm{ON}$ y VCP en el período comprendido entre el segundo semestre del 2002 y fines de 2008. 


\section{Metodología}

Población: PyMES y Bancos comerciales de la Ciudad de La Plata, Berisso, Ensenada, Avellaneda, Berazategui, Florencio Varela, Magdalena y Quilmes.

Unidad de análisis: Se tomó 165 empresas PyMES del total de la población.

\section{Variables:}

- Independiente: Carencia de información de las empresas PyMES.

- Dependiente: Relación crediticia entre los bancos comerciales y las PyMES durante los años 2009/20010.

\section{Tipo de Investigación:}

Esta investigación es del tipo Explicativa, debido a que trata de probar la incidencia entre determinadas variables.

\section{Técnicas y herramientas de recolección de datos:}

En este caso se utilizó:

- La realización de encuestas a 165 Empresas PyMES.

- Datos históricos de lugares como :

- BCRA

- SePyME

- INDEC

- IAMC

- BCBA

- Registros de Observación.

\section{Técnicas de análisis de datos:}

Se realizó un análisis univariado como bivariado de las distintas variables arriba mencionadas, Para la realización del análisis econométrico se utilizó el programa STATA edición 11 versión 11.0. 


\section{Resultados de la encuesta realizada a las PyMEs}

En esta sección se estudiará a partir de unos muestreos aleatorios de 165 empresas PyMEs manufactureras (clasificadas según el código CIIU a dos dígitos) ubicadas en partidos pertenecientes a la Provincia de Buenos Aires: La Plata, Berisso, Ensenada, Avellaneda, Berazategui, Florencio Varela, Magdalena, Quilmes.

La idea surge a partir de las respuestas obtenidas por parte de las mismas y de poder observar las relaciones que existen entre las Empresas PyMEs y los Bancos comerciales no sólo en cuanto a la obtención de créditos por parte de las PyMEs, sino también otras series de características que fueron consultadas en la encuesta que se consideraron relevantes para saber el grado de relación que existe, como también cuáles son aquellas particularidades que faltan pulir para que las diferencias que existen entre los mismo se puedan reducirse de modo de tener una relación más armoniosa que lleve a que las empresas PyMEs no sufran de restricciones que las lleven a no acercarse a los bancos y de este modo puedan ampliar su capacidad productiva para, de este modo, poder seguir aportando al crecimiento económico.

\subsection{Características generales de los encuestados}

\subsubsection{Tamaño de la empresa}

El tamaño de las firmas, medido por la cantidad de empleados, presentó una media de 31.8 empleados con una mediana de 15 empleados (con el p25 = 9 y el p75=35), lo que indica un grado importante de asimetrías en los tamaños de las firmas según este parámetro. No obstante ello, se aprecia que existe una alta concentración de empresas con hasta 30 empleados (70\% de la muestra).

Otros datos relevantes a tener en cuenta a la hora de realizar el análisis es el desvío estándar de la muestra que para este caso es de 39.70, lo cual está indicando que los datos están bastantes dispersos con relación a su media muestral. Otras medidas de dispersión a tener en cuenta es el coeficiente de variación 1.25 lo que señala una homogeneidad entre el tamaño de las empresas y el coeficiente skewness $^{22}$ da un valor de 2.40 indicado un sesgo positivo lo cual indica que la cola de la distribución en el lado derecho es más larga que el lado izquierdo y la mayor parte de los valores se encuentran a la izquierda de la media como fue explicado anteriormente.

\footnotetext{
${ }^{22}$ Es una medida de la asimetría de la distribución de probabilidad de una variable real con valores aleatorios. El valor de la asimetría puede ser positivo o negativo, o incluso indefinido. Cualitativamente, un sesgo negativo indica que la cola en el lado izquierdo de la función de densidad de probabilidad es más largo que el lado derecho y la mayor parte de los valores (incluyendo la media) se encuentran a la derecha de la media. Un sesgo positivo indica que la cola en el lado derecho es más largo que el lado izquierdo y la mayor parte de los valores se encuentran a la izquierda de la media. Un valor cero indica que los valores son relativamente uniformemente distribuidas a ambos lados de la media, por lo general pero no necesariamente implica una distribución simétrica.
} 
Gráfico1:

Distribución de frecuencia PyMES por empleado

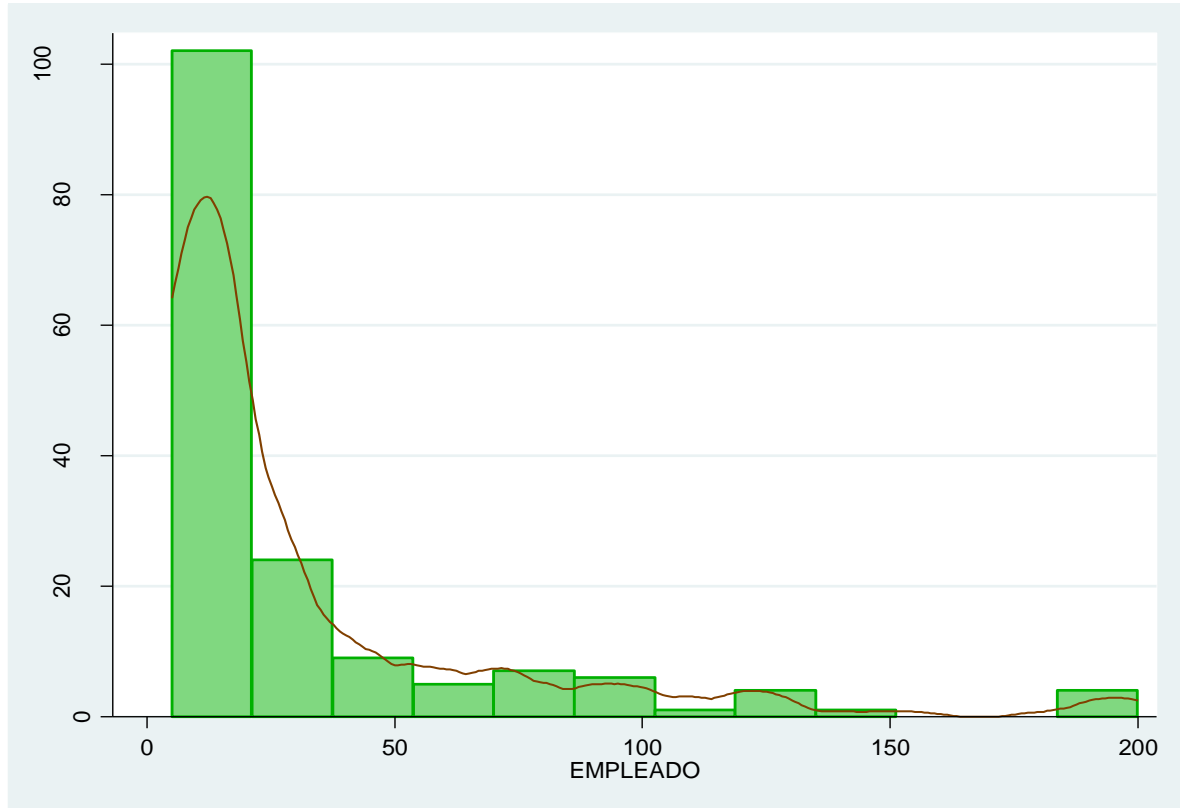

Fuente: Elaboración propia en base a la información obtenida de las encuestas realizadas a las empresas

\begin{tabular}{|l|c|}
\hline Estadisticos & Valores \\
\hline Media & 31,81 \\
Mediana & 15,00 \\
P25 & 9,00 \\
P75 & 35,00 \\
Valor Max & 200,00 \\
Valor Min & 5,00 \\
SD & 39,70 \\
CV & 1,24 \\
Skew ness & 2,40 \\
\hline
\end{tabular}

\subsection{2 . Antigüedad de las firmas}

La investigación permitió identificar industrias manufactureras cuya antigüedad media resulta ser levemente superior a los 30 años con una mediana de 30 años (con el p25 = 18 y el p75=40), la cual indicaría una simetría en la antigüedad de las empresas encuestadas. El desvío estándar que presenta la muestra es de 16.88, indicando una menor dispersión de la media muestral que en el caso de los empleados. El coeficiente de variación y el coeficiente de skewness estarían aseverando lo mostrado con el desvío estándar, ya que los valores de los mismos son 0.56 y 0.53 , respectivamente. 


\section{Gráfico 2:}

Distribución de frecuencia PyMES por años de antigüedad

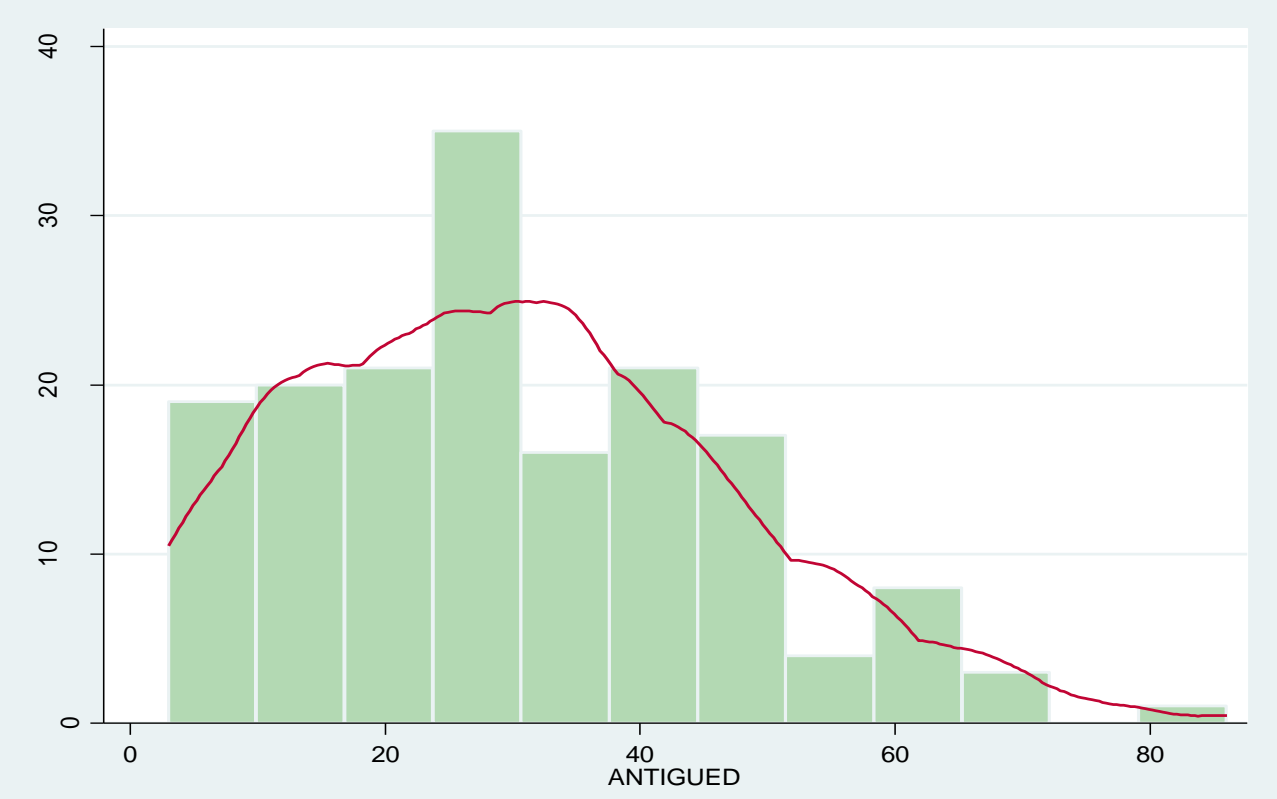

Fuente: Elaboración propia en base a la información obtenida de las encuestas realizadas a las empresas.

\begin{tabular}{|l|c|}
\hline \multicolumn{1}{|c|}{ Estadisticos } & Valores \\
\hline Media & 30,17 \\
Mediana & 30,00 \\
P25 & 18,00 \\
P75 & 40,00 \\
Valor Max & 86,00 \\
Valor Min & 3,00 \\
SD & 16,88 \\
CV & 0,56 \\
Skew ness & 0,53 \\
\hline
\end{tabular}

\subsection{3 . Firmas Exportadoras}

En la muestra un $34.4 \%$ declaró que exporta, lo cual representa un valor relativamente alto, en términos de investigación comparable a nivel de todo el país para el sector industrial $\mathrm{PyME}^{23}$.

El grupo de empresas pequeñas (de 5 a 25 empleados) resultó menos exportador que el resto. Tres cuarta parte de este tramo $(76.2 \%)$ manifestó no ser exportador. Los no exportadores del tramo de entre 26 a 50 empleados alcanzaron al $47.5 \%$ de estos. Y un tercio del tramo superior (con más de 51 empleados) se declaró no exportador (ver anexo 1).

No obstante lo anterior, el grupo de empresas exportadoras se halla fuertemente concentrada en aquellas que destinan una parte relativamente poco importante de su producción al mercado interno. Así, el $20 \%$ de las empresas exportan entre 1 y un $10 \%$ de su producción y el $6.2 \%$ exporta entre un 11 y un $20 \%$.

La mitad de quienes exportan entre 1 al $10 \%$ de su producción está compuesta por empresas de menos de 25 empleados. En términos generales, no se presenta una marcada correlación entre mayor tamaño relativo de las empresas y mayor proporción de la producción que exportan.

\footnotetext{
${ }^{23}$ Francisco Gatto, en seminario CEI- CEPAL, Estructura y desafío del Comercio Exterior Argentino, 29 de Agosto de 2007.
} 
Gráfico 3:

Distribución de frecuencia PyMES exportadoras en la muestra

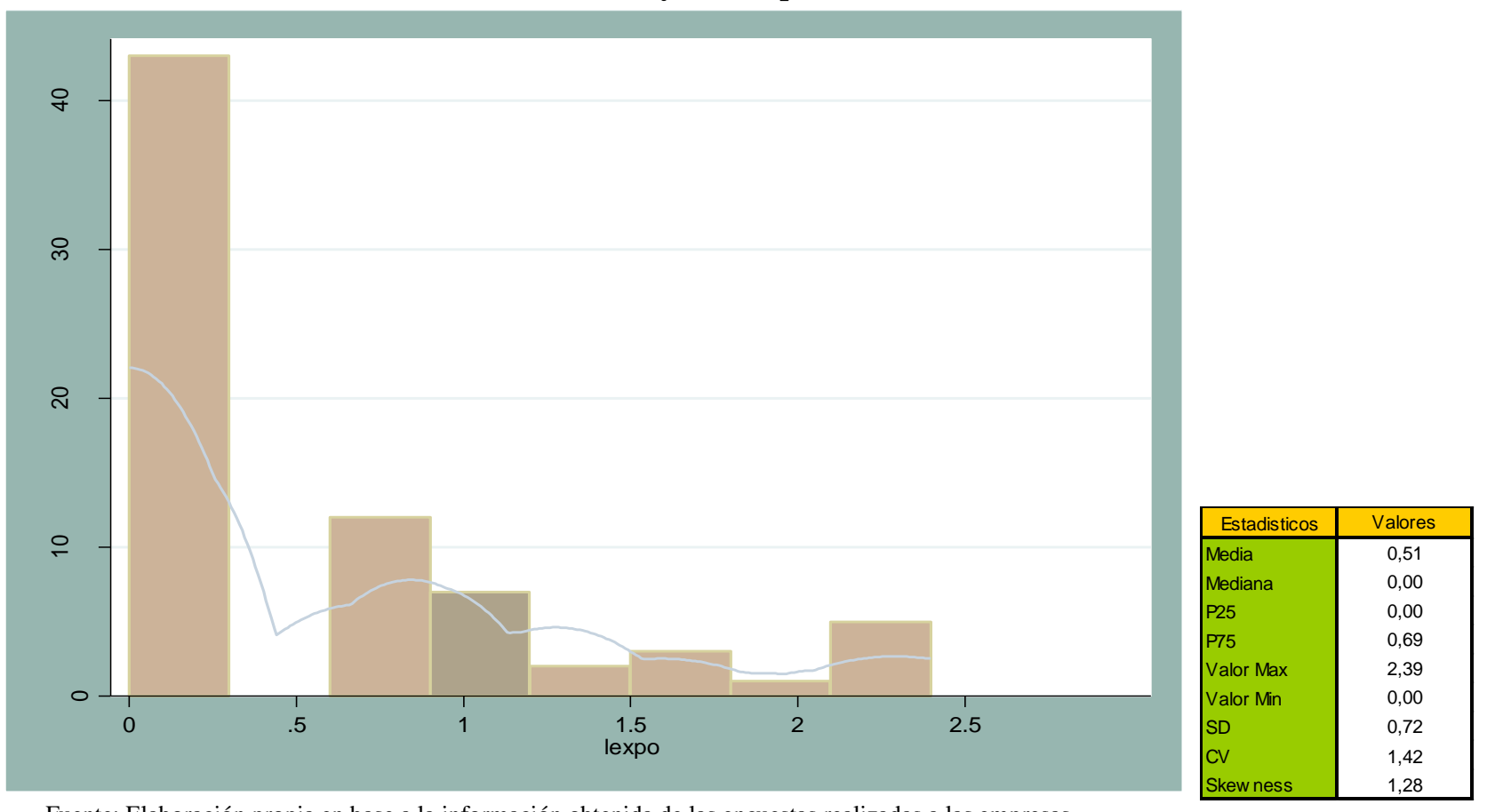

Fuente: Elaboración propia en base a la información obtenida de las encuestas realizadas a las empresas. 


\subsection{Fuentes de Financiamiento}

A continuación, se presentan los resultados correspondientes a las fuentes de financiamiento a las que las empresas han recurrido en el período bajo estudio.

Establecidas las frecuencias de utilización de las cuatro alternativas establecidas en el cuestionario ("a través de proveedores", "a través del sistema financiero", " en sistemas no formales de crédito" y "mediante autofinanciamiento") se obtuvieron los resultados que a continuación se expone, haciendo la salvedad de que los resultados tienen un margen de error no medible por carga de subjetividad.

De las cuatro formas de financiamiento planteadas, la más utilizada es la de autofinanciamiento con un $83,4 \%$. La segunda más utilizada es el financiamiento por proveedores utilizada por un $45,6 \%$ de la muestra, le sigue el "financiamiento en el sistema financiero" usado por un 31,4\% y cierran los "sistemas no formales de crédito" con un escaso $6,7 \%$.

Gráfico 4:

\section{Uso Comparativo de los métodos de financiamiento}

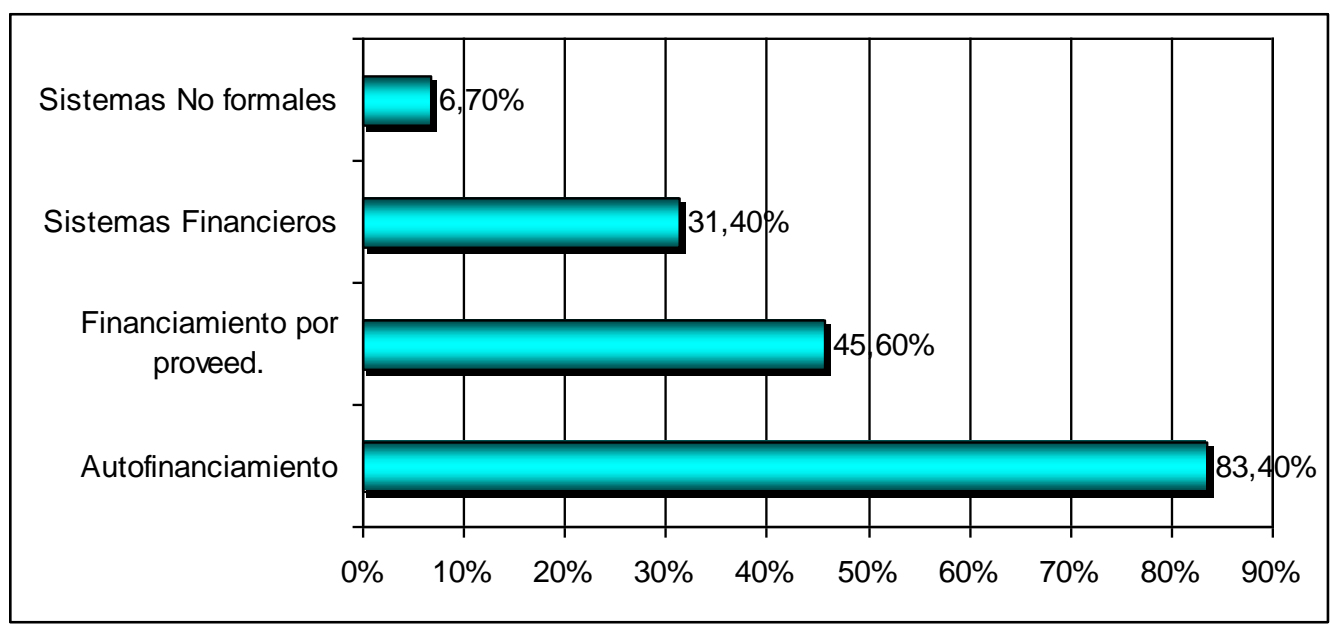

Fuente: Elaboración propia en base a la información obtenida de las encuestas realizadas a las empresas.

$\mathrm{Si}$ consideramos las respuestas agrupadas en porcentajes de usos para las categorías: "no se financia", "financia de 1 a 30\%", "financia del 31 al 60\%" y " financia del 61 al 100\%", se observa que el método de autofinanciación es el preferido para los tramos de mayor financiamiento (62\%) mientras que los sistemas no formales solo se utilizan para financiamientos pequeños. El método de financiamiento por proveedores se colocaría en una situación intermedia dado que los encuestados reconocen utilizarlo en los tramos del 1 al 30\%(17,2\%), 31 al $60 \%(15,8 \%)$ y 61 al $100 \%(12,6 \%)$.

El método de financiamiento recurriendo al sistema financiero tiene una presencia en el tramo de 1 a $30 \%(22 \%)$ y una pequeña importancia en el tramo de 31 al 60\% (6,2\%). Los sistemas no formales de crédito tienen escasa utilización, el 93,4\% dice no utilizarlos, un 5,5\% los utiliza en el tramo de financiación del 1 al 30\% y el resto, insignificante, $(1,1 \%)$ se distribuye en los otros tramos. Es importante aclarar que cuando se hace referencia al financiamiento por medio del sistema financiero no hay que confundir este concepto con el concepto de niveles de bancarización, dado que esto se refiere solamente al financiamiento mediante crédito y en este punto aparece, además, sesgado en la comparación con otras formas de financiamiento. Los 
niveles de bancarización hay que concluirlos del uso de cuentas corrientes. Los otros instrumentos bancarios y financieros serán analizados más adelante. Para ilustrar lo previamente mencionado se adjunta el siguiente cuadro.

Cuadro 1: Fuentes de financiamiento

\begin{tabular}{|l|c|c|c|c|}
\hline Categoría & no se financia & del 1 al 30\% & del 31 al $60 \%$ & del 61 al $100 \%$ \\
\hline por prov & $54,4 \%$ & $17,2 \%$ & $15,8 \%$ & $12,6 \%$ \\
Sist. Financ. & $68,6 \%$ & $22,0 \%$ & $6,2 \%$ & $3,2 \%$ \\
no formales & $93,4 \%$ & $5,5 \%$ & $0,6 \%$ & $0,5 \%$ \\
Autofinanc. & $12,0 \%$ & $7,0 \%$ & $19,0 \%$ & $62,0 \%$ \\
\hline
\end{tabular}

Fuente: Elaboración propia en base a la información obtenida de las encuestas realizadas a las empresas.

El gráfico de líneas resultante muestra con claridad el comportamiento de las variables bajo análisis. El caso de autofinanciamiento muestra una curva que crece a medida que se incrementa el porcentaje de financiamiento (es bajo en el punto de no uso y muy alto para la categoría en la que se financia entre el 61 y el 100\%); en el caso del financiamiento por proveedores, por sistemas financieros y por canales no formales las curvas muestran un comportamiento inverso. Este resultado confirma que la fuente de financiamiento más utilizada es el autofinanciamiento. Si se observa la caída abrupta de la curva correspondiente a sistemas no formales de crédito se concluye que es utilizada en muy bajo porcentaje para una parte importante del financiamiento total y en porcentaje alto para el caso de pequeños financiamientos. Un itinerario similar siguen las curvas correspondientes a "sistema financiero" y "financiamiento por proveedores", aunque con menos diferencias entre extremos.

Gráfico 5:

Comparación de fuentes de financiamiento

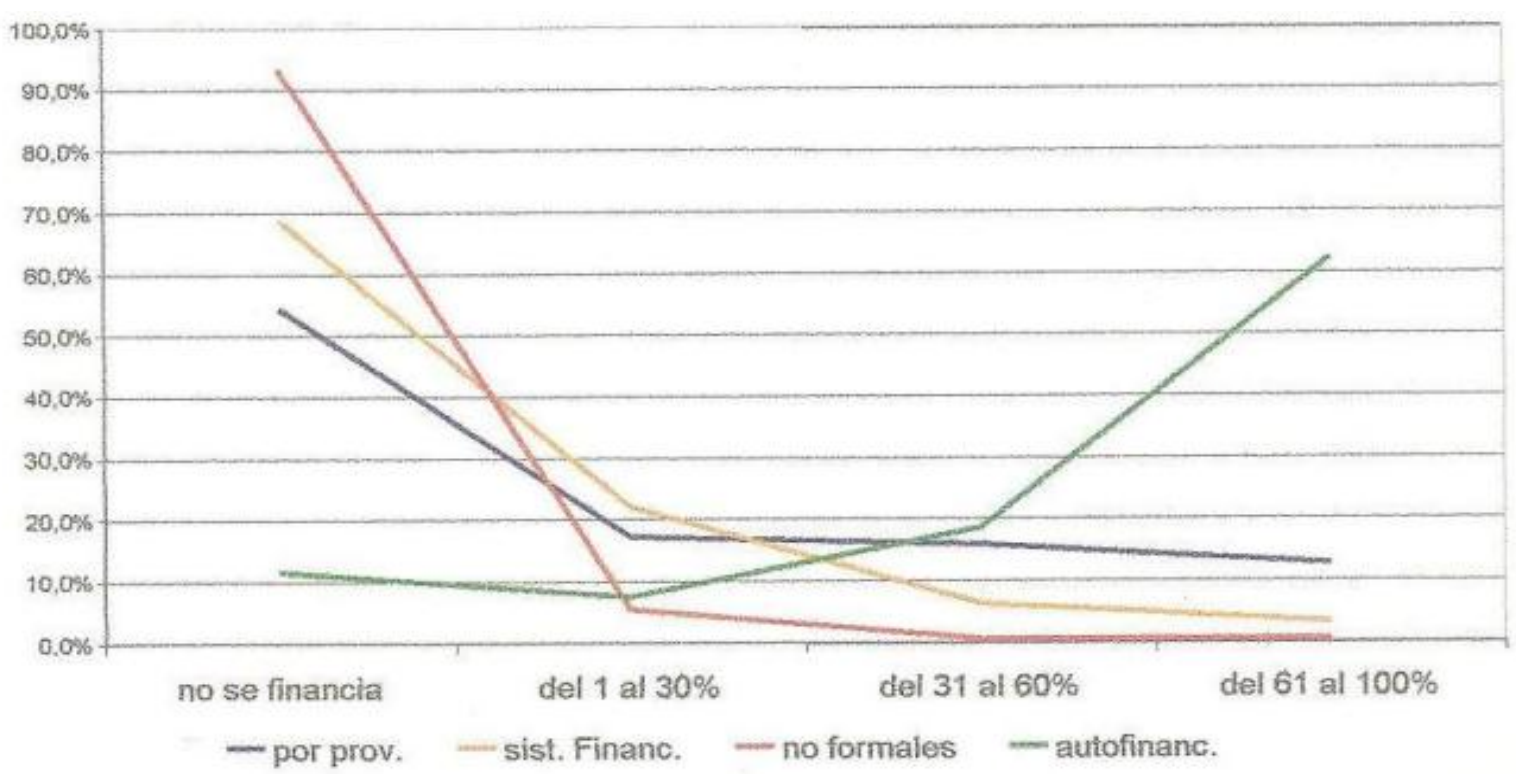

Fuente: Elaboración propia en función a la información obtenida de encuestas, BCRA y IAMC. 


\section{Autofinanciamiento}

La tabla de frecuencia resultante para esta categoría es la siguiente:

Cuadro 2: Autofinanciamiento, Análisis por decil

\begin{tabular}{|c|c|c|}
\hline Decil & Porcentaje & $\%$ acumulado \\
\hline 0\% & $11,6 \%$ & $11,6 \%$ \\
1 a $10 \%$ & $1,7 \%$ & $13,3 \%$ \\
11 a $20 \%$ & $2,4 \%$ & $15,7 \%$ \\
21 a $30 \%$ & $3,3 \%$ & $19,0 \%$ \\
31 a $40 \%$ & $3,1 \%$ & $22,1 \%$ \\
41 a $50 \%$ & $13,4 \%$ & $35,5 \%$ \\
51 a $60 \%$ & $2,1 \%$ & $37,6 \%$ \\
61 a $70 \%$ & $5,6 \%$ & $43,2 \%$ \\
71 a $80 \%$ & $10,8 \%$ & $54,0 \%$ \\
81 a $90 \%$ & $4,6 \%$ & $58,6 \%$ \\
91 a $100 \%$ & $41,6 \%$ & $100 \%$ \\
\hline Total & $100 \%$ & \\
\hline
\end{tabular}

Esta forma de financiamiento aparece en la encuesta como la más utilizada, solo el 11,6\% manifestó no usarla y el decil más representativo es el de más alto rango, es decir que el decil 91 a $100 \%$ de financiación alcanza con el 41,3\% el valor más alto de uso. También se puede observar en la siguiente tabla en la que se han agrupado los deciles:

Cuadro 3: Autofinanciamiento, Análisis por grupo de decil

\begin{tabular}{|l|c|}
\hline Categoría & $\%$ \\
\hline no se financia & $12,0 \%$ \\
del 1 al 30\% & $7,0 \%$ \\
del 31 al $60 \%$ & $19,0 \%$ \\
del 61 al $100 \%$ & $62,0 \%$ \\
\hline Total & $100,0 \%$ \\
\hline
\end{tabular}

Fuente: Elaboración propia en base a la información obtenida de las encuestas realizadas a las empresas.

En este cuadro se verifica que el sistema de autofinanciamiento es el más utilizado. Solo el $12 \%$ no recurre a el autofinanciamiento, el 7\% se autofinancia entre el 1 y el 30\% de sus necesidades, el $19 \%$ recurre a estas formas de financiar entre el 31 y el $60 \%$ y el $60 \%$ de los encuestados se autofinancia entre el 61 y 100\%, siendo el decil de 91 a $100 \%$ el más representativo con el $42 \%$. En el gráfico se visualiza dicho comportamiento: 
Gráfico 6:

Empresas que recurren al autofinanciamiento

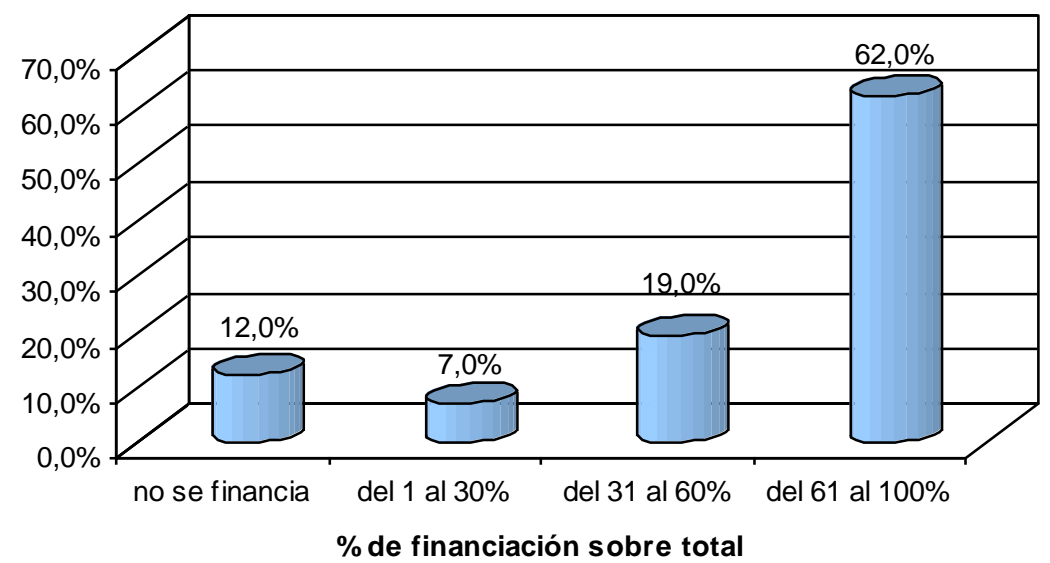

Fuente: Elaboración propia en base a la información obtenida de las encuestas realizadas a las empresas.

\section{A través de empresas proveedoras}

Al analizar esta forma de financiamiento se pudo observar que el $54.4 \%$ del universo no se financia a través de los proveedores, el 17,2\% obtienen una financiación entre de entre 1 y el 30\%; el $15,8 \%$ logra financiar entre el 31 y el $60 \%$ y solo el $12,6 \%$ logra que financiar entre el 61 y el $100 \%$.

Para llegar a los resultados que se exponen a continuación se ha partido de la tabla obtenida de la respuesta de la pregunta 7 de la encuesta. Dicha tabla está dividida en deciles con limitada representación por grupo por lo que lo se ha agrupado en cuatro grupos: "no se financian con proveedores", "financian entre el 1 y el 30\%", "financia entre el 31 y 60\%" y "financia entre el 61 y el 100\%".

Cuadro 4: Empresas proveedoras análisis por decil

\begin{tabular}{|c|c|c|}
\hline Decil & Porcentaje & $\%$ acumulado \\
\hline $0 \%$ & $54,4 \%$ & $54,4 \%$ \\
1 a $10 \%$ & $3,5 \%$ & $57,9 \%$ \\
11 a $20 \%$ & $6,8 \%$ & $64,7 \%$ \\
21 a $30 \%$ & $6,9 \%$ & $71,6 \%$ \\
31 a $40 \%$ & $3,2 \%$ & $74,8 \%$ \\
41 a $50 \%$ & $10,8 \%$ & $85,6 \%$ \\
51 a $60 \%$ & $1,8 \%$ & $87,4 \%$ \\
61 a $70 \%$ & $2,9 \%$ & $90,3 \%$ \\
71 a $80 \%$ & $1,8 \%$ & $92,1 \%$ \\
81 a $90 \%$ & $0,9 \%$ & $93,0 \%$ \\
91 a $100 \%$ & $7,0 \%$ & $100 \%$ \\
\hline Total & $100 \%$ & \\
\hline
\end{tabular}

Fuente: Elaboración propia en base a la información obtenida de las encuestas realizadas a las empresas. 
Cuadro 5: Empresas proveedoras, Análisis por grupo de decil

\begin{tabular}{|l|c|}
\hline Categoría & $\%$ \\
\hline no se financia & $54,4 \%$ \\
del 1 al 30\% & $17,2 \%$ \\
del 31 al $60 \%$ & $15,8 \%$ \\
del 61 al $100 \%$ & $12,6 \%$ \\
\hline Total & $100,0 \%$ \\
\hline
\end{tabular}

Fuente: Elaboración propia en base a la información obtenida de las encuestas realizadas a las empresas.

\section{Gráfico 7:}

Empresas que obtienen financiación de proveedores

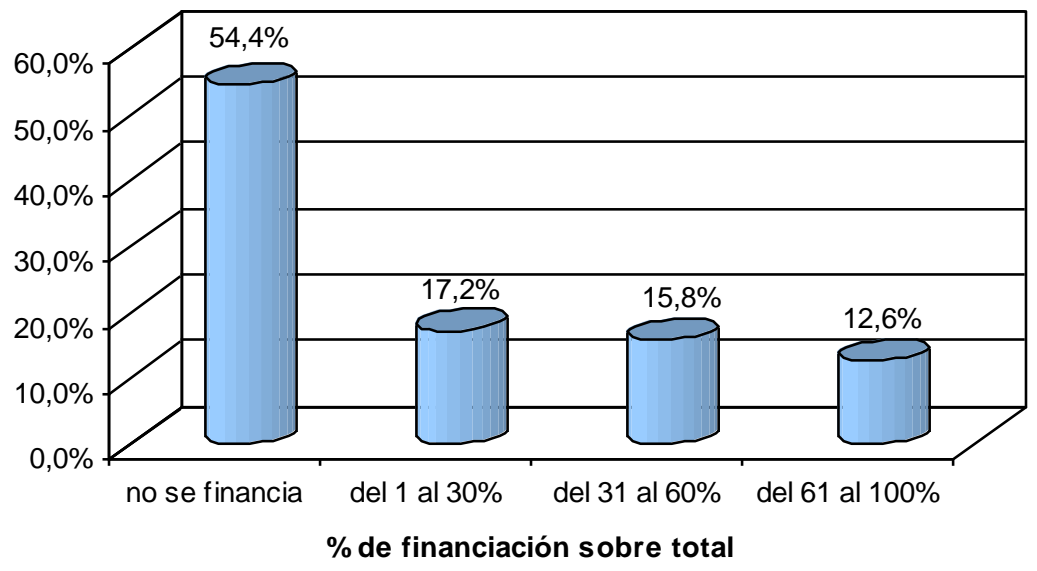

Fuente: Elaboración propia en base a la información obtenida de las encuestas realizadas a las empresas.

\section{A través del sistema financiero}

El $68,6 \%$ de los encuestados manifestó no recurrir al sistema financiero, el $22 \%$ se financia mediante el mismo hasta un $30 \%$ de las operaciones, el 6,2\% entre el 31 y el $60 \%$ y solo el 3,2\% obtiene financiamiento del $61 \mathrm{y}$ el $100 \%$. En estos resultados es notable el bajo porcentaje de los empresarios que manifiestan financiarse en el sistema financiero formal. Aplicando la metodología utilizada en el acápite anterior se obtuvo la siguiente tabla fue utilizada para el análisis precedente:

Cuadro 6: Sistema financiero, Análisis por grupo de decil

\begin{tabular}{|l|c|}
\hline Categoría & $\%$ \\
\hline no se financia & $68,6 \%$ \\
del 1 al $30 \%$ & $22,0 \%$ \\
del 31 al $60 \%$ & $6,2 \%$ \\
del 61 al $100 \%$ & $3,2 \%$ \\
\hline Total & $100,0 \%$ \\
\hline
\end{tabular}

Fuente: Elaboración propia en base a la información obtenida de las encuestas realizadas a las empresas. 
Estos resultados se pueden visualizar en el siguiente gráfico:

Gráfico 8:

Financiación a través del sistema financiero

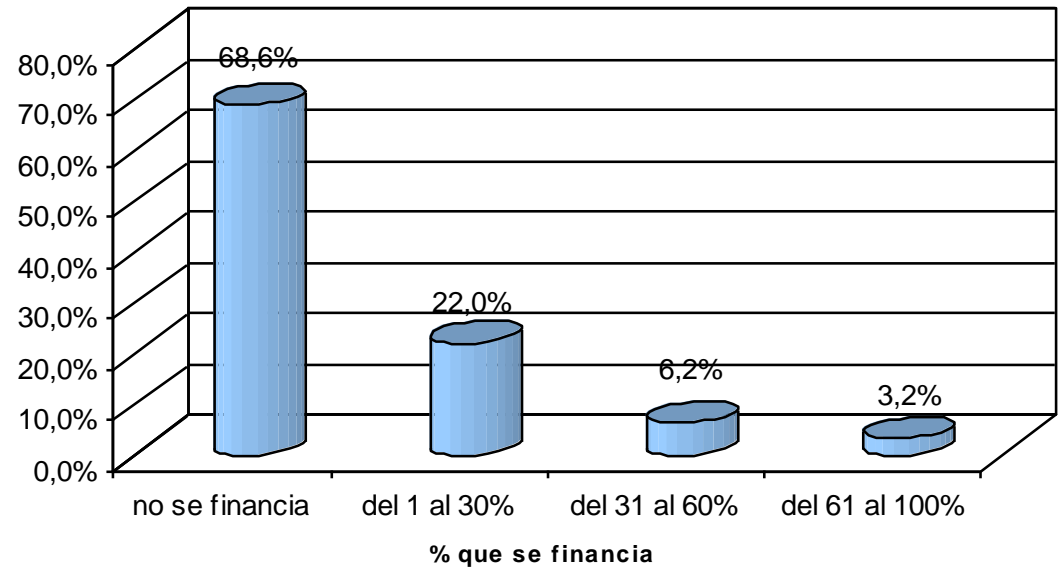

Fuente: Elaboración propia en base a la información obtenida de las encuestas realizadas a las empresa

La tabla de frecuencia de las respuestas que agrupan por deciles a las empresas que se financian a través del sistema financiero permite un mayor detalle de lo expresado:

\section{Cuadro7: Sistema financiero análisis por decil}

\begin{tabular}{|c|c|c|}
\hline Decil & Porcentaje & $\%$ acumulado \\
\hline 0\% & $68,6 \%$ & $68,6 \%$ \\
1 a $10 \%$ & $8,7 \%$ & $77,3 \%$ \\
11 a $20 \%$ & $9,0 \%$ & $86,3 \%$ \\
21 a $30 \%$ & $4,3 \%$ & $90,6 \%$ \\
31 a $40 \%$ & $2,1 \%$ & $92,7 \%$ \\
41 a $50 \%$ & $3,8 \%$ & $96,5 \%$ \\
51 a $60 \%$ & $0,3 \%$ & $96,8 \%$ \\
61 a $70 \%$ & $0,5 \%$ & $97,3 \%$ \\
71 a $80 \%$ & $0,7 \%$ & $98,0 \%$ \\
81 a $90 \%$ & $0,2 \%$ & $98,2 \%$ \\
91 a 100\% & $1,8 \%$ & $100 \%$ \\
\hline Total & $100 \%$ & \\
\hline
\end{tabular}

Fuente: Elaboración propia en base a la información obtenida de las encuestas realizadas a las empresa

\section{A través de sistemas no formales de créditos}

$\mathrm{Al}$ analizar la tabla de resultados de los casos que reconocieron financiarse a través de sistemas no formales de crédito, se observada que la financiación mediante sistemas no formales de crédito es poco utilizada, dado que el 93,3\% manifiesta no utilizarla, por lo que sólo el 6,7\% la utiliza en algún grado. No obstante, y a efectos meramente comparativos se presenta la tabla resultante de agrupar los deciles y el gráfico correspondiente: 
Cuadro 8: Sistema no formales de crédito análisis por grupo de decil

\begin{tabular}{|l|c|}
\hline Categoría & $\%$ \\
\hline no se financia & $93,4 \%$ \\
del 1 al $30 \%$ & $5,5 \%$ \\
del 31 al $60 \%$ & $0,6 \%$ \\
del 61 al $100 \%$ & $0,5 \%$ \\
\hline Total & $100,0 \%$ \\
\hline
\end{tabular}

Fuente: Elaboración propia en base a la información obtenida de las encuestas realizadas a las empresa

\section{Gráfico 9:}

\section{Financiación a través del sistema no formales}

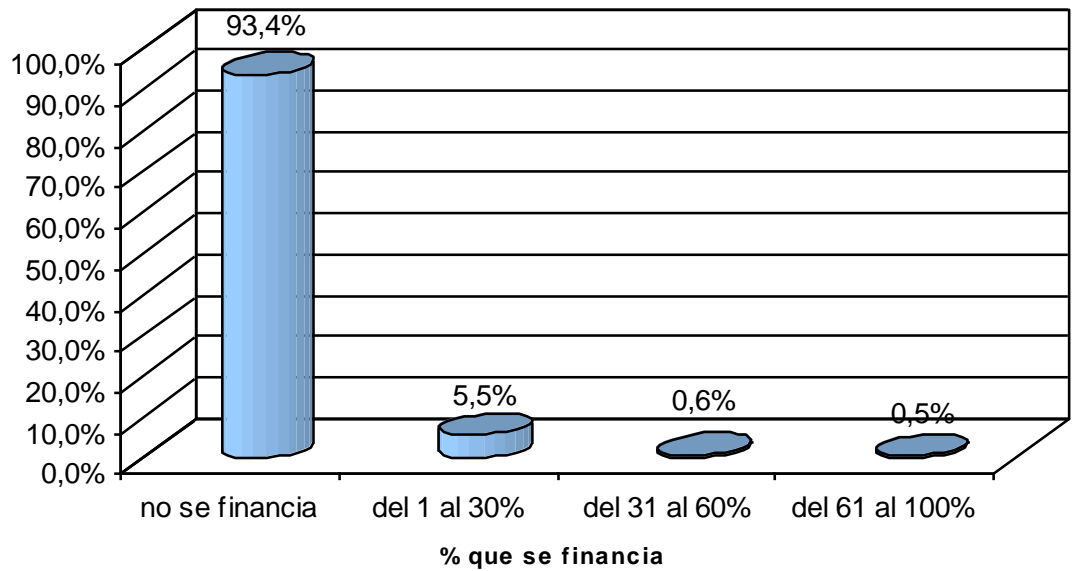

Fuente: Elaboración propia en base a la información obtenida de las encuestas realizadas a las empresa.

La tabla de frecuencias por deciles obtenida para esta categoría de financiación es la siguiente:

Cuadro 9: Sistema no formales de crédito análisis por decil

\begin{tabular}{|c|c|c|}
\hline Decil & Porcentaje & $\%$ acumulado \\
\hline $0 \%$ & $93,3 \%$ & $93,3 \%$ \\
1 a $10 \%$ & $2,9 \%$ & $96,2 \%$ \\
11 a $20 \%$ & $1,8 \%$ & $98,0 \%$ \\
21 a $30 \%$ & $0,8 \%$ & $98,8 \%$ \\
31 a $40 \%$ & $0,2 \%$ & $99,0 \%$ \\
41 a $50 \%$ & $0,4 \%$ & $99,4 \%$ \\
51 a $60 \%$ & $0,0 \%$ & $99,4 \%$ \\
61 a $70 \%$ & $0,1 \%$ & $99,5 \%$ \\
71 a $80 \%$ & $0,3 \%$ & $99,8 \%$ \\
81 a $90 \%$ & $0,0 \%$ & $99,8 \%$ \\
91 a $100 \%$ & $0,2 \%$ & $100 \%$ \\
\hline Total & $100 \%$ & \\
\hline
\end{tabular}

Fuente: Elaboración propia en base a la información obtenida de las encuestas realizadas a las empresa 


\subsection{Disposición a tomar crédito por parte de los empresarios}

La actitud de los empresarios ante la posibilidad de tomar crédito está medida directamente en la pregunta 8 del cuestionario. Considerando que el 34\% manifiesta no haber tomado crédito nunca, el $49 \%$ ve el hecho de tomar crédito como una situación "no habitual" y sólo el $17 \%$ lo asume como una operación "habitual", se puede inferir una reducida toma de créditos en el sistema financiero, algunas de cuyas causas analizaremos al referirnos a los puntos 14, 15, 16a y $16 \mathrm{~b}$ y a la imagen del sistema bancario. A continuación se presentarán cuadros y gráficos que expresan lo argumentado:

\section{Cuadro10: Disposición a tomar crédito}

\begin{tabular}{|l|c|}
\hline Actitud & $\%$ \\
\hline Habitual & $17,0 \%$ \\
No habitual & $49,0 \%$ \\
Nunca tomar credito & $34,0 \%$ \\
\hline Total & $100,0 \%$ \\
\hline
\end{tabular}

Fuente: Elaboración propia en base a la información obtenida de las encuestas realizadas a las empresa

\section{Gráfico 10:}

Actitud ante la toma de créditos

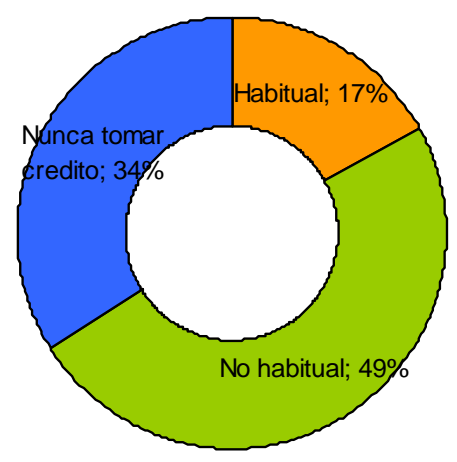

Fuente: Elaboración propia en base a la información obtenida de las encuestas realizadas a las empresa

\subsection{Tiempo que hace que tomó el último crédito}

En la pregunta $\mathrm{N}^{\circ} 9$ de la encuesta se consulta sobre la antigüedad del último crédito tomado en el sistema financiero. Las opciones de respuesta van de "menos de un año" a "más de cinco años o nunca".

Sólo el 2,8 \% de los encuestados no contestó la pregunta, lo que genera una aproximación fehaciente a la situación de antigüedad de los créditos. Lo que más se destaca de las respuestas obtenidas es que un $60 \%$ de los encuestados nunca tomó créditos o hace más de 5 años que los obtuvo y que la misma se concentró en los últimos dos años, dado que la categoría "entre 1 y 2 años" representando el 12,7\% y la categoría "hace menos de un año" el 17,9\%. Entre las dos suman el 30,6\%. La suma de los conceptos que abarcan entre 2 y 5 años totaliza un 9\%. Estos datos son fácilmente observables en el siguiente cuadro: 


\section{Cuadro11: Solicitud del último crédito solicitado}

\begin{tabular}{|c|c|}
\hline \multicolumn{2}{|c|}{ Tiempo que hace que tomó el último crédito } \\
\hline Tiempo & Porcentaje \\
\hline Menos de un año & $17,9 \%$ \\
entre 1 y 2 años & $12,7 \%$ \\
entre 2 y 3 años & $5,3 \%$ \\
entre 3 y 4 años & $2,1 \%$ \\
entre 4 y 5 años & $1,6 \%$ \\
más de 5 años & $60,4 \%$ \\
nunca & $0,0 \%$ \\
\hline Total & $100 \%$ \\
\hline
\end{tabular}

Fuente: Elaboración propia en base a la información obtenida de las encuestas realizadas a las empresa

Respecto a los bancos en que las empresas declaran haber tomado el último crédito, el Credicoop aparece como el preferido con el $26,4 \%$ de los créditos, segundo se ubica el Provincia con el $18,1 \%$, tercero el Nación $(12,3 \%)$ y cuarto el Galicia $(10,1 \%)$.

Cuadro12: Bancos en los cuales tomaron el crédito

\begin{tabular}{|c|c|}
\hline \multicolumn{2}{|c|}{ Banco en que tomaron el último crédito en \% } \\
\hline Banco & Porcentaje \\
\hline Nación & $12,3 \%$ \\
Provincia & $18,1 \%$ \\
Credicoop & $26,4 \%$ \\
Galicia & $10,1 \%$ \\
BBVA & $3,7 \%$ \\
Santander & $8,8 \%$ \\
HSBC & $3,2 \%$ \\
Otros & $14,9 \%$ \\
Sin Datos & $2,4 \%$ \\
\hline Total & $100 \%$ \\
\hline
\end{tabular}

Fuente: Elaboración propia en base a la información obtenida de las encuestas realizadas a las empresa

A continuación se observa cómo se distribuyen dichos créditos por banco, según la antigüedad de los créditos.

Cuadro13: Análisis de antigüedad de los bancos en lo que se solicitó el último crédito

\begin{tabular}{|c|c|c|c|c|c|c|}
\hline \multicolumn{7}{|c|}{ Banco en que tomaron el último crédito, por antigüedad, en \% } \\
\hline Banco & $\begin{array}{c}\text { Menos de un } \\
\text { año }\end{array}$ & de 1 a 2 años & de 2 a 3 años & de 3 a 4 años & de 4 a 5 años & $\begin{array}{c}\text { más de } 5 \text { años o } \\
\text { nunca }\end{array}$ \\
\hline Nación & $16,5 \%$ & $10,0 \%$ & $10,0 \%$ & $0,0 \%$ & $6,7 \%$ & $0,0 \%$ \\
Provincia & $15,3 \%$ & $22,5 \%$ & $18,0 \%$ & $20,0 \%$ & $13,3 \%$ & $0,0 \%$ \\
Credicoop & $27,1 \%$ & $29,2 \%$ & $24,0 \%$ & $25,0 \%$ & $6,7 \%$ & $0,0 \%$ \\
Galicia & $11,2 \%$ & $10,8 \%$ & $4,0 \%$ & $15,0 \%$ & $6,7 \%$ & $0,0 \%$ \\
BBVA & $3,5 \%$ & $5,0 \%$ & $4,0 \%$ & $0,0 \%$ & $0,0 \%$ & $0,0 \%$ \\
Santander & $6,5 \%$ & $8,3 \%$ & $10,0 \%$ & $25,0 \%$ & $6,7 \%$ & $0,2 \%$ \\
HSBC & $2,4 \%$ & $2,5 \%$ & $6,0 \%$ & $5,0 \%$ & $6,7 \%$ & $0,0 \%$ \\
Otros & $2,4 \%$ & $1,7 \%$ & $4,0 \%$ & $0,0 \%$ & $13,3 \%$ & $0,0 \%$ \\
Sin Datos & $15,3 \%$ & $10,0 \%$ & $20,0 \%$ & $10,0 \%$ & $40,0 \%$ & $99,8 \%$ \\
\hline Total & $100 \%$ & $100 \%$ & $100 \%$ & $100 \%$ & $100 \%$ & $100 \%$ \\
\hline
\end{tabular}

Fuente: Elaboración propia en base a la información obtenida de las encuestas realizadas a las empresa 
Según se puede observar en el cuadro precedente, el período de 4 a 5 años, el Banco Provincia ocupaba el primer lugar en el otorgamiento de créditos, con un 13,3\% del total. El Credicoop, el Nación, el Galicia, el Santander y el HSBC se adjudicaban un 6,7\% cada uno. Se podría decir que existe un reparto parejo del mercado crediticio en el que sólo se destaca el Provincia que duplicaba a cualquiera de los otros bancos. De todas maneras hay que relativizar la importancia de este resultado dado que los créditos de este período representan sólo el $4 \%$ de los reconocidos por los encuestados.

En los créditos tomados entre 3 y 4 años atrás la composición del mercado cambia. El Credicoop y el Santander ocupan el primer lugar de los créditos con un $25 \%$ cada uno, es decir entre los dos ocuparían la mitad de los créditos reconocidos por los encuestados. El Provincia, con el 20\% se colocaría en el segundo lugar y el Galicia en el tercero con un 15\%. También en este caso el resultado es relativo dado que los créditos de ese año (de 3 a 4 años) representan el 5,3\% de los tomados en el lapso total de tiempo considerado (menos de un año a cinco años).

En período de 2 a 3 años de antigüedad, el comportamiento también es distinto. El Credicoop conserva el primer lugar con $24 \%$ de los créditos, pero el Santander cae al tercer lugar, que ocupa junto al Nación con el 10\%. El Provincia sigue en segundo lugar, en este caso con un $18 \%$ de los casos. Si bien los créditos de ese año representan un 13,3\% de todo el espacio de tiempo analizado no parece tener una representación relativa suficiente para indicar una tendencia definitoria.

Los dos períodos que le siguen, por el contrario con los anteriores, parecen ser más útiles para indicar una propensión que merezca una mayor consideración. Al menos, por dos razones: la primera por su proximidad en el tiempo (estamos examinando las categorías de créditos tomados en los últimos dos años, "de 1 a 2 años" y "menos de un año") y por su significativa representación porcentual sobre el total del período, dado que sumados ambos representan el 77,3\% del total del crédito reconocido por los encuestados (32\% "de 1 a 2 años" y $45,3 \%$ "menos de un año").

Al analizar la categoría "de 1 a 2 años" se observa que el Credicoop mantiene la preeminencia en el mercado de créditos empresarios $(29,2 \%)$, iniciada en los dos períodos anteriores, el Provincia confirma, con el 22,5\%, el segundo lugar que ocupaba en el lapso anterior, el Galicia ocupa el tercer lugar con el 10,8\%, el Nación se ubica muy cerca con el $10 \%$ y el Santander cae al quinto lugar con el $8,3 \%$.

En la etapa más reciente, "menos de un año", el Credicoop continua en el primer lugar con $(27,1 \%)$, segundo aparece el Nación 16,5\%, el Provincia retrocede al tercer lugar 15,3\%, el Galicia en el cuarto puesto con el 11,2\% de los créditos empresarios y el Santander sigue en el quinto lugar con el $6,5 \%$, aunque con una representación menor en los porcentajes.

\subsection{Tipo de Créditos tomados}

La consulta por el tipo de crédito (pregunta 10) presenta las siguientes alternativas de respuesta: "personal pero destinado a la empresa", "empresarial con garantía empresarial", "empresarial con garantía personal" y "empresarial sin garantía". El 62,6\% de los encuestados respondió no haber tomado créditos o no contestó. El 37,4\% reconoció haber tomado algún crédito. Este 37,4\% se compone de la siguiente manera: $5,1 \%$ tomo crédito personal pero destinado a la empresa, el $24,4 \%$ crédito empresario con garantía empresarial, el 3,9\% empresarial con garantía personal y un $4 \%$ accedió a un crédito empresarial sin garantía. 


\section{Gráfico 11}

Tipo de crédito según garantía

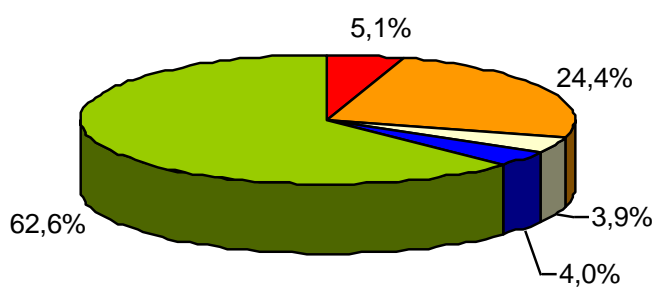

口 Personal, pero con destinado a empresas $\square$ Empresarial con garantia empresarial $\square$ Empresarial con garantía personal $\quad$ Empresarial sin garantía

$\square$ No tomaron

Fuente: Elaboración propia en base a la información obtenida de las encuestas realizadas a las empresa.

Considerando el total de créditos tomados y su distribución según tipo de crédito, el 13,7\% corresponde a créditos personales destinados a la empresa, el 65,2\% son créditos empresariales con garantía empresaria, 10,4\% empresariales con garantía personal y el 10,7 \% empresariales sin garantía. Se hace evidente la preferencia por créditos empresariales con garantía empresaria que, con un total de 40 casos sobre los 62 totales, representan el $65 \%$ del total de créditos tomados y, asimismo, preocupa la elocuencia del nivel agregado del crédito personal con destino a la empresa y del empresarial con garantía personal.

\section{Gráfico 12}

$\%$ de incidencia de cada tipo de crédito sobre el total

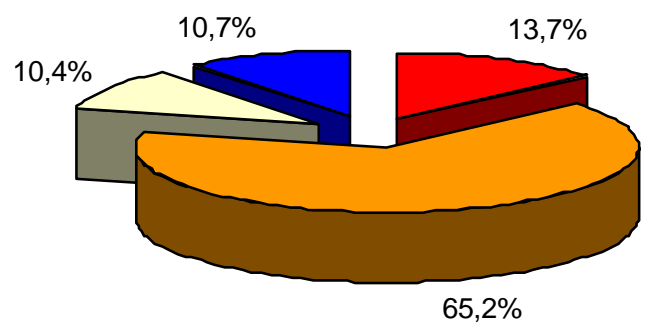

口 Personal, pero con destinado a empresas $\square$ Empresarial con garantia empresarial

$\square$ Empresarial con garantía personal $\square$ Empresarial sin garantía

Fuente: Elaboración propia en base a la información obtenida de las encuestas realizadas a las empresa. 
Cuadro14: Tipo de crédito solicitado con relación al tipo de garantía

\begin{tabular}{|l|c|c|c|c|}
\hline \multicolumn{5}{|c|}{ Tipo de Crédito con relación al tipo de garantía } \\
\hline & Frecuencia & Porcentaje & $\begin{array}{c}\text { Porcentaje } \\
\text { válido }\end{array}$ & $\begin{array}{c}\text { Porcentaje } \\
\text { acumulado }\end{array}$ \\
\hline Validos: & & & & \\
Personal, pero con destinado a empresas & 8 & $5,1 \%$ & $13,7 \%$ & $13,7 \%$ \\
Empresarial con garantia empresarial & 40 & $24,5 \%$ & $65,2 \%$ & $78,9 \%$ \\
Empresarial con garantía personal & 6 & $3,9 \%$ & $10,4 \%$ & $89,3 \%$ \\
Empresarial sin garantía & 7 & $4,0 \%$ & $10,7 \%$ & $100,0 \%$ \\
Validos Total & 62 & $37,6 \%$ & $100,0 \%$ & \\
Perdidos & 103 & $62,4 \%$ & & \\
\hline Total & 165 & $100 \%$ & $100 \%$ & $100 \%$ \\
\hline
\end{tabular}

Fuente: Elaboración propia en base a la información obtenida de las encuestas realizadas a las empresa.

\section{Personal con destino a la empresa}

Sobre las razones por las cuales el empresario tomo crédito personal con destino a la empresa (pregunta 10.b), el 35,9\% manifestó que no podía cumplir los requisitos, el 10,3\% no le alcanzaron los montos de los créditos empresarios, el 30,8\% lo fundamentó en que "era más rápido y lo necesitaba con urgencia", el $7,7 \%$ en que no había créditos para empresas disponibles y el restante $15,4 \%$ en el rubro "otros".

\section{Cuadro15: Razón por la cual tomo un crédito personal destinado a la empresa}

\begin{tabular}{|l|c|c|c|c|}
\hline \multicolumn{5}{|c|}{ Razón por la cual tomó un crédito personal destinado a la empresa } \\
\hline & Frecuencia & Porcentaje & $\begin{array}{c}\text { Porcentaje } \\
\text { válido }\end{array}$ & $\begin{array}{c}\text { Porcentaje } \\
\text { acumulado }\end{array}$ \\
\hline Validos: & & & & \\
No podía cumplir con los requisitos & 14 & $8,5 \%$ & $35,9 \%$ & $35,9 \%$ \\
No le alcanzaban los montos de los créditos e & 4 & $2,4 \%$ & $10,3 \%$ & $46,2 \%$ \\
Era más rapido y lo necesitaba con urgencia & 12 & $7,3 \%$ & $30,8 \%$ & $77,0 \%$ \\
No había créditos para empresas disponibles & 3 & $1,8 \%$ & $7,7 \%$ & $84,7 \%$ \\
Otros & 6 & $3,6 \%$ & $15,4 \%$ & $100 \%$ \\
Validos Total & 39 & $23,6 \%$ & $100 \%$ & \\
& & & & \\
Perdidos & 126 & $76,4 \%$ & $100 \%$ \\
\hline Total & 165 & $100 \%$ & $100 \%$ & 100 \\
\hline
\end{tabular}

Fuente: Elaboración propia en base a la información obtenida de las encuestas realizadas a las empresa.

A continuación se muestra como se distribuyen estos créditos entre bancos:

Si consideramos el total de los créditos, el porcentaje mayor lo tiene el Credicoop con un $27 \%$ del total, seguido por el Provincia con el 18,7\%, el Nación 12,3\%, Galicia 10,6\% y Santander 8,9\%.

En el caso de los créditos personales destinados a la empresa, el Santander Río tiene la mayor proporción de los créditos con el 18\%, seguido por el Credicoop 16\%, Provincia y Galicia 12\% y Nación y Citibank con $12 \%$ cada uno; en este rubro es donde se observa mayor paridad en el mercado. 
En el rubro más importante en cantidad de créditos obtenidos (65\% de los créditos), el Banco Credicoop aparece con mayor proporción con el 27,7\% seguido por el Provincia 21,3\%, luego el Nación $11,9 \%$, el Galicia $11,1 \%$ y el Santander 6,8\%.

\section{Cuadro16: Distribución en \% de crédito por banco en que tomaron}

\begin{tabular}{|c|c|c|c|c|c|}
\hline \multicolumn{6}{|c|}{ Distribución en \% de crédito por banco en que lo tomaron } \\
\hline \multirow[b]{2}{*}{ Banco } & \multicolumn{4}{|c|}{ Tipo de crédito con relación al tipo de garantia } & \multirow[b]{2}{*}{$\begin{array}{l}\text { Distribución tota } \\
\text { de créditos }\end{array}$} \\
\hline & $\begin{array}{c}\text { Personal, pero } \\
\text { con destinado a } \\
\text { empresas }\end{array}$ & $\begin{array}{c}\text { Empresarial con } \\
\text { garantia } \\
\text { empresarial }\end{array}$ & $\begin{array}{c}\text { Empresarial con } \\
\text { garantía } \\
\text { personal }\end{array}$ & $\begin{array}{c}\text { Empresarial sin } \\
\text { garantía }\end{array}$ & \\
\hline Nación & $10,0 \%$ & $11,9 \%$ & $20,0 \%$ & $10,5 \%$ & $12,3 \%$ \\
\hline Provincia & $12,0 \%$ & $21,3 \%$ & $14,3 \%$ & $15,8 \%$ & $18,7 \%$ \\
\hline Credicoop & $16,0 \%$ & $27,7 \%$ & $45,7 \%$ & $21,1 \%$ & $27,0 \%$ \\
\hline Galicia & $12,0 \%$ & $11,1 \%$ & $2,9 \%$ & $13,2 \%$ & $10,6 \%$ \\
\hline BBVA & $2,0 \%$ & $3,8 \%$ & $2,9 \%$ & $5,3 \%$ & $3,6 \%$ \\
\hline Santander & $18,0 \%$ & $6,8 \%$ & $8,6 \%$ & $10,5 \%$ & $8,9 \%$ \\
\hline Ciudad & $4,0 \%$ & $2,1 \%$ & $2,9 \%$ & $10,5 \%$ & $3,3 \%$ \\
\hline HSBC & $6,0 \%$ & $2,6 \%$ & $0,0 \%$ & $7,9 \%$ & $3,3 \%$ \\
\hline Citibank & $10,0 \%$ & $0,4 \%$ & $0,0 \%$ & $0,0 \%$ & $1,7 \%$ \\
\hline Otros & $10,0 \%$ & $12,3 \%$ & $2,9 \%$ & $5,3 \%$ & $10,6 \%$ \\
\hline Total & $100 \%$ & $100 \%$ & $100 \%$ & $100 \%$ & $100 \%$ \\
\hline
\end{tabular}

Fuente: Elaboración propia en base a la información obtenida de las encuestas realizadas a las empresa.

En los créditos empresarios con garantía personal el Credicoop también se ubica en primer lugar con el 45,7\%, seguido por el Nación con el 20\%, el Provincia 14,3\% y Santander 8,6\%.

Finalmente en los créditos empresarios sin garantía se coloca primero el Credicoop con el 21,1\% y segundo el Provincia 15,8\%, seguido del Galicia 13,2\% y Nación, Santander y Ciudad con el $10,5 \%$ cada uno.

\section{Gráfico 13}

Distribución del tipo de crédito por banco en \%

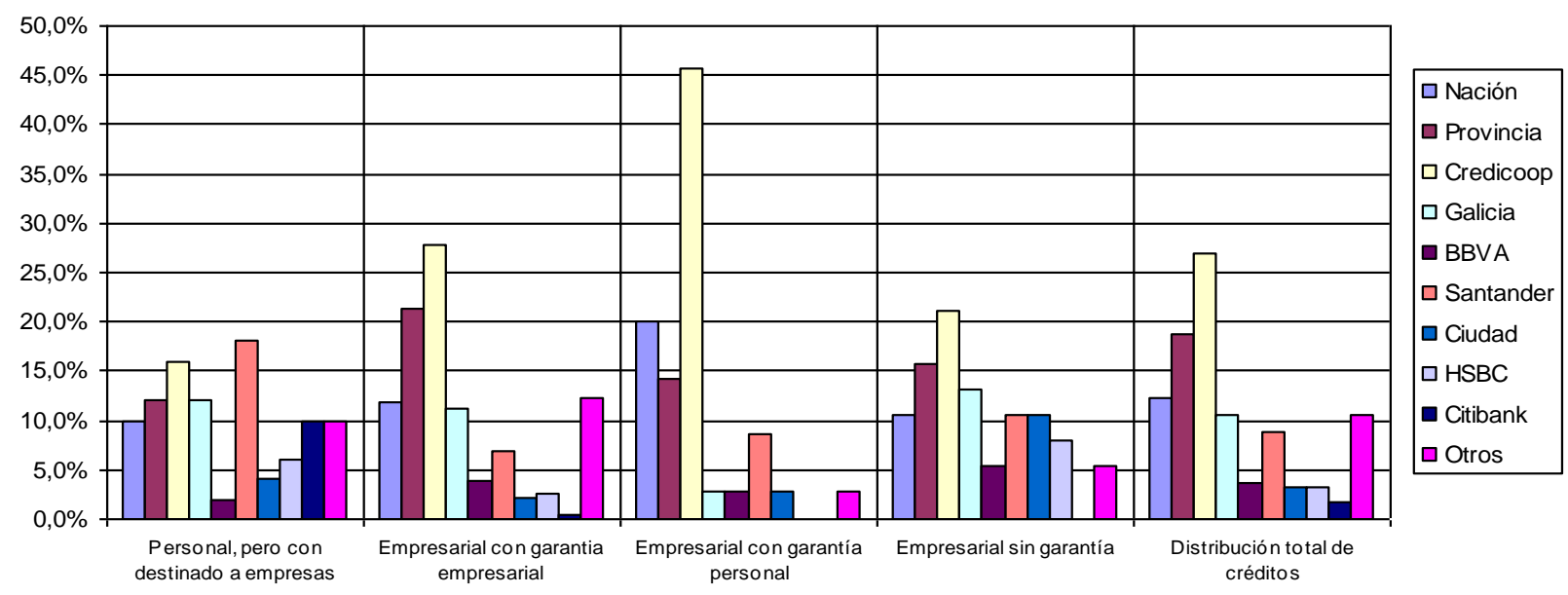

Fuente: Elaboración propia en base a la información obtenida de las encuestas realizadas a las empresa. 


\subsection{Destino del último crédito obtenido y banco en el cual accedió al mismo}

Un conjunto de 62 empresas (el 37,5\% de la muestra) declaró finalidades específicas para el último crédito obtenido (pregunta 11.a). Se trata del 98,4\% de quienes obtuvieron créditos en los últimos cinco años.

Considerando el total de créditos por banco (cruce pregunta 11.a y 11.b), sumando todos los destinos, el banco que más créditos otorgó es el Banco Credicoop, con el 27,5\%. Segundo, se ubica el Banco Provincia con el 18,6\%. En tercer lugar se ubica el Banco Nación con el 12,5\% y en el cuarto lugar el Banco Galicia con el 10,8\%.

Por otra parte, se presenta una alta concentración en los últimos créditos obtenidos según la finalidad a la cual fueron aplicados. Más del $61 \%$ de los últimos créditos obtenidos se destinaron a inversión (la categoría de inversión incluyó: Nuevos proyectos productivos, inversión en I+D, ampliación de planta, compras de maquinarias y mejora de estructura de ventas y distribución).

En esa perspectiva, los dos primeros bancos que los otorgaron fueron el Banco Provincia y el Credicoop, ambos con el 13,6\% de los créditos concedidos a los respondientes y aplicados a esos fines. En segundo lugar se ubica el Nación con el 8,6\% y en tercer lugar se ubicó el Santander Río con el $6,11 \%$.

Efectuando un análisis más detallado del total de las finalidades dadas al último crédito obtenido, se observa que la compra de maquinaria ocupa el 37,2\% del total de esos créditos. El banco más citado al declarar esta finalidad resultó el Banco Provincia, el cual participó con el 23,1\% del total de esos créditos. El banco Credicoop participó con el 20,1\% y el Banco Nación concedió el 15,7\% de esos créditos.

Los créditos destinados para la compra de materias primas resultaron, en este nivel de análisis, el segundo destino más declarado. El Banco Credicoop concentró el 30,4\% del total de los créditos con este destino, el Banco Galicia concentró el 17,7\%, en el tercer lugar el banco Provincia con el $13,9 \%$ y el cuarto lugar el Banco Nación con el 11,4\%.

La tercera finalidad más citada resultó ser la ampliación de planta. En este caso el banco más citado resulto el Banco Provincia con el 31,4\% de estos créditos, seguido por el Banco Nación con el $25,7 \%$ y el tercero el Credicoop con el $11,4 \%$.

Los bancos que ocupan los tres primeros lugares en cuanto a cantidad de créditos otorgados (Banco Credicoop, Provincia y Nación), muestran la mayor amplitud en las finalidades de los créditos que los empresarios manifiestan haber tomado. El Banco Nación concentra en los tres destinos más comunes (ampliación de planta, compra de maquinaria y compra de materias primas) el 86,7 de sus créditos y el Banco Provincia un 74,11\% en los mismos. Por su parte, el Banco Credicoop concentra con estos destinos el 55,5\% de los créditos, denotando que otras líneas crediticias que tiene activas poseen buen nivel relativo de actividad. 
Cuadro17: Tipo de crédito por banco en porcentaje

\begin{tabular}{|c|c|c|c|}
\hline \multicolumn{4}{|c|}{ Tipo de crédito por banco en \% } \\
\hline & $\begin{array}{c}\text { Compra de } \\
\text { maquinaria }\end{array}$ & $\begin{array}{c}\text { Compra de } \\
\text { materias primas }\end{array}$ & $\begin{array}{c}\text { Ampliación de } \\
\text { planta }\end{array}$ \\
\hline Nación & $15,7 \%$ & $11,4 \%$ & $25,7 \%$ \\
Provincia & $23,1 \%$ & $13,9 \%$ & $31,4 \%$ \\
Credicoop & $20,6 \%$ & $30,4 \%$ & $11,4 \%$ \\
Galicia & $7,4 \%$ & $17,7 \%$ & $0,0 \%$ \\
BBVA & $3,7 \%$ & $6,3 \%$ & $0,0 \%$ \\
Santander & $12,6 \%$ & $7,5 \%$ & $5,7 \%$ \\
HSBC & $3,7 \%$ & $1,2 \%$ & $0,0 \%$ \\
Otros & $13,2 \%$ & $11,6 \%$ & $25,8 \%$ \\
\hline Total & $100 \%$ & $100 \%$ & $100 \%$ \\
\hline
\end{tabular}

Fuente: Elaboración propia en base a la información obtenida de las encuestas realizadas a las empresa.

Gráfico 14

Participación de los bancos según tipo de crédito, en \%

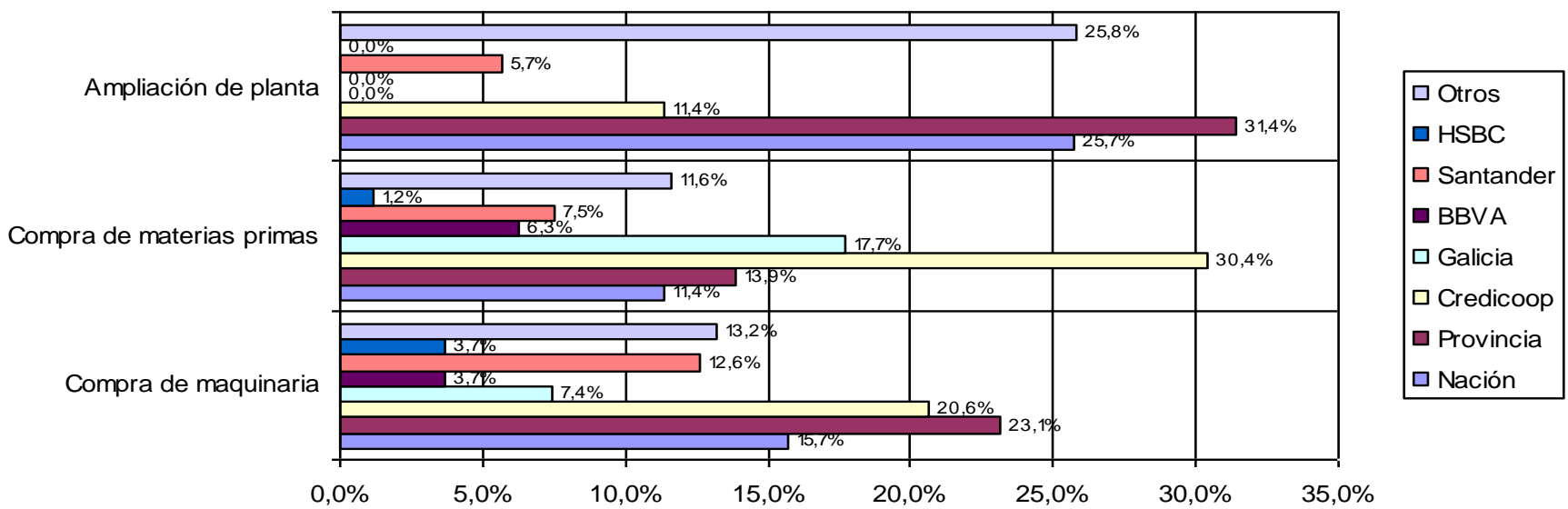

Fuente: Elaboración propia en base a la información obtenida de las encuestas realizadas a las empresa.

\subsection{Colaterales ofrecidos como respaldo de los créditos obtenidos}

La pregunta 12 permite apreciar el tipo de crédito al que la empresa manifiesta haber accedido en la última oportunidad, en perspectiva de los colaterales de respaldo. Por otra parte, permite inducir el nivel de acceso al crédito de la muestra el cual, por esta pregunta se infiere cercano al $38,1 \%$.

Del total de informes sobre colaterales, la mayoría $(60,9 \%$ de estos o $23 \%$ sobre la muestra total) indicó que obtuvo el crédito a sola firma. Es un valor alto, de modo que se infiere varias alternativas no necesariamente excluyentes. De más a menos probables estas alternativas pudieran ser: 1) no se trataron de montos importantes, 2) fueron ampliaciones, refinanciaciones o renovaciones y soslayaron la mención del colateral subyacente pues su compromiso previo seguía instrumentadamente válido y/o 3) respondieron en perspectivas de incluir adelantos en cuenta corriente con esa condición. No obstante, tal vez la alta proporción de créditos a sola firma 
señalados como provenientes del Credicoop y la agresividad mostrada por éste se encuentran detrás de ese tan buen resultado.

El 22,9\% presentó una prenda, tanto al exponer sobre créditos en general como por tratarse de operaciones de leasing y la garantía hipotecaria sólo se ofreció en el 7,3\% de los casos. En este último caso, cabe interesarse en esta baja aplicación en futuras investigaciones; sin embargo, no parece constituir una vía atractiva para atraer clientes de crédito empresarial.

La utilización de Sociedades de Garantía Recíproca alcanzó un escaso 3,8\% de los tipos de colaterales presentados, salvo en los colaterales presentados en créditos obtenidos en el Banco Provincia el cual se destaca en este punto. Cabe señalar que no resulta sorprendente que el nivel de penetración de este tipo de colateral, en general, resulte limitado en términos de su utilización por parte del universo encuestado $(1,4 \%)$.

Cuadro18: Tipo de crédito que obtuvieron las PyMEs

\begin{tabular}{|l|c|c|c|}
\hline \multicolumn{4}{|c|}{ Tipo de crédito que obtuvo } \\
\hline & Frecuencia & Porcentaje & $\begin{array}{r}\text { Porcentaje } \\
\text { acumulado }\end{array}$ \\
\hline Validos: & 38 & $60,9 \%$ & $60,9 \%$ \\
Crédito a sola firma & 5 & $7,3 \%$ & $68,2 \%$ \\
Crédito hipotecario & 14 & $22,9 \%$ & $91,1 \%$ \\
Crédito prendario válidos & 2 & $3,8 \%$ & $94,9 \%$ \\
Fianza por SGR & 3 & $5,1 \%$ & $100,0 \%$ \\
Otros & 63 & $100,0 \%$ & \\
Validos Total & 102 & & \\
Perdidos & & & $100 \%$ \\
\hline Total & 165 & $100 \%$ & \\
\hline
\end{tabular}

Fuente: Elaboración propia en base a la información obtenida de las encuestas realizadas a las empresa.

\section{8 . Evaluación general de la oferta crediticia por parte de los tomadores de crédito}

Observando esta evaluación (pregunta 13), se aprecia que casi la totalidad de quienes obtuvieron un crédito en los últimos 5 años (aproximadamente un 98\%) se prestaron a contestar respecto a las condiciones del último crédito obtenido.

Si bien los tomadores de crédito reflejaron sus opiniones para el conjunto de las entidades financieras, seguidamente se consideran las evaluaciones para el conjunto y la comparación entre los bancos más relevantes en este análisis, es decir cotejamos al Banco Provincia, el Credicoop y el Nación.

\section{Tasa de interés}

Un 55,8\% de quienes evaluaron la tasa de interés pagadas en los créditos obtenidos, la calificó como accesibles, mientras que un $29 \%$ las considero altas y un $9,5 \%$ muy altas. Por su parte, menos del cinco por ciento las calificó de muy accesibles. 
Una lectura llana de estos resultados motivaría a pensar en una amplia aceptación del costo de uso del dinero en el mercado financiero. Sin embargo, hay que tener presente que se trata de los tomadores de crédito y no del universo bajo estudio. En esta perspectiva, en cambio, resulta muy significativo que más del $39 \%$ de quienes tomaron créditos lo consideren alto o muy alto.

Estos últimos están claramente influenciados en el hecho de que han debido absorber el costo financiero en un contexto de incremento de los costos de producción en general sin un corrimiento proporcional de sus precios, con la mayor consecuente reducción de los márgenes de rentabilidad. Considérese que la mayor proporción de tomadores de crédito en la muestra se concentra en los últimos dos años.

Cuadro19: Evaluación del crédito en cuanto a la tasa de interés

\begin{tabular}{|l|c|c|c|}
\hline \multicolumn{4}{|c|}{ Evaluación del crédito en cuanto a la tasa de interés } \\
\hline & Frecuencia & Porcentaje & $\begin{array}{c}\text { Porcentaje } \\
\text { acumulado }\end{array}$ \\
\hline Validos: & 3 & $4,9 \%$ & $4,9 \%$ \\
Muy accesible & 35 & $55,8 \%$ & $60,7 \%$ \\
Accesible & 18 & $29,8 \%$ & $90,5 \%$ \\
Alta & 6 & $9,5 \%$ & $100,0 \%$ \\
Muy alta & 62 & $100,0 \%$ & \\
Validos Total & & & \\
& 103 & & $100 \%$ \\
\hline
\end{tabular}

\section{Período de gracia}

Del total de tomadores de créditos que respondieron sobre este aspecto, 52,4\% expresó que no tuvieron período de gracia, mientras que el 32,8\% lo consideró conveniente y 13,7\% lo calificó como corto o muy corto.

La evaluación de estos aspectos resultó muy similar entre los bancos seleccionados. Se aprecia que el Banco Nación posee las mejores evaluaciones al respecto seguidos por el Banco Provincia y el Credicoop que se sitúan prácticamente un escalón más abajo. 
Cuadro 20: Análisis del crédito en función del período de gracia

\begin{tabular}{|l|c|c|c|}
\hline \multicolumn{3}{|c|}{ Evaluación del crédito en cuanto al período de gracia } \\
\hline & Frecuencia & Porcentaje & $\begin{array}{r}\text { Porcentaje } \\
\text { acumulado }\end{array}$ \\
\hline Validos: & 1 & $1,1 \%$ & $1,1 \%$ \\
Muy conveniente & 20 & $32,8 \%$ & $33,9 \%$ \\
Conveniente & 6 & $10,6 \%$ & $44,5 \%$ \\
Corto & 2 & $3,1 \%$ & $47,6 \%$ \\
Muy corto & 31 & $52,4 \%$ & $100,0 \%$ \\
Nulo & 60 & $100,0 \%$ & \\
Validos Total & & & \\
Perdidos & 105 & & $100 \%$ \\
\hline Total & 165 & $100 \%$ & \\
\hline
\end{tabular}

Fuente: Elaboración propia en base a la información obtenida de las encuestas realizadas a las empresa.

\section{Plazo de amortización}

El 69,1\% consideró al plazo de amortización como conveniente, en tanto un $24 \%$ lo calificó como corto y un $5 \%$ muy corto. Resulta muy significativo que un $30 \%$ de los tomadores de crédito empresariales se hayan sentido incómodos con los plazos de amortización a los que se comprometieron.

En este sentido, el desempeño del Banco Nación fue superior al del Banco Provincia que resultó algo superior al del conjunto, ya que un $71,6 \%$ consideró conveniente a los plazos mientras que un $25,4 \%$ lo estimó como corto y ninguno lo calificó como muy corto.

Cuadro 21: Análisis del crédito en cuanto al plazo de amortización

\begin{tabular}{|l|c|c|c|}
\hline \multicolumn{3}{|c|}{ Evaluación del crédito en cuanto al plazo de amortización } \\
\hline & Frecuencia & Porcentaje & $\begin{array}{c}\text { Porcentaje } \\
\text { acumulado }\end{array}$ \\
\hline Validos: & 1 & $1,9 \%$ & $1,9 \%$ \\
Muy conveniente & 42 & $69,1 \%$ & $71,0 \%$ \\
Conveniente & 15 & $24,0 \%$ & $95,0 \%$ \\
Corto & 3 & $5,0 \%$ & $100,0 \%$ \\
Muy corto & 61 & $100,0 \%$ & \\
Validos Total & 104 & & \\
Perdidos & & & $100 \%$ \\
\hline
\end{tabular}

Fuente: Elaboración propia en base a la información obtenida de las encuestas realizadas a las empresa. 


\section{Evaluación de los montos otorgados}

Un 71,1\% consideró suficiente a los montos, mientras que $26,7 \%$ los calificó de insuficiente o muy insuficiente. La evaluación de desempeño del Banco Provincia es algo mejor a la de los competidores Credicoop y Nación.

Cuadro 22: Análisis del crédito en cuanto al monto otorgado

\begin{tabular}{|l|c|c|c|}
\hline \multicolumn{4}{|c|}{ Evaluación del crédito en cuanto al monto } \\
\hline & Frecuencia & Porcentaje & $\begin{array}{c}\text { Porcentaje } \\
\text { acumulado }\end{array}$ \\
\hline Validos: & 1 & $2,2 \%$ & $2,2 \%$ \\
Muy suficiente & 43 & $71,1 \%$ & $73,3 \%$ \\
Suficiente & 15 & $25,3 \%$ & $98,6 \%$ \\
Insuficiente & 1 & $1,4 \%$ & $100,0 \%$ \\
Muy insuficiente & 61 & $100,0 \%$ & \\
Validos Total & 104 & & \\
& & & \\
Perdidos & 165 & $100 \%$ & $100 \%$ \\
\hline Total & & & \\
\hline
\end{tabular}

Fuente: Elaboración propia en base a la información obtenida de las encuestas realizadas a las empresa.

\section{Evaluación de requisitos solicitados}

Para el conjunto, $72,7 \%$ considero accesible a los requisitos solicitados y un 16,0\% los evaluó como altos. De nuevo, casi $30 \%$ se encuentra disconforme y se trata de tomadores de créditos.

El Banco Credicoop obtuvo el mejor desempeño en este ítem seguido por el Banco Provincia.

Cuadro 23: Análisis del crédito en cuanto a los requisitos solicitados

\begin{tabular}{|l|c|c|c|}
\hline \multicolumn{3}{|c|}{ Evaluación del crédito en cuanto a los requisitos solicitados } \\
\hline & Frecuencia & Porcentaje & $\begin{array}{c}\text { Porcentaje } \\
\text { acumulado }\end{array}$ \\
\hline Validos: & 3 & $4,4 \%$ & $4,4 \%$ \\
Muy accesible & 44 & $72,7 \%$ & $77,1 \%$ \\
Accesible & 10 & $16,0 \%$ & $93,1 \%$ \\
Alto & 4 & $6,9 \%$ & $100,0 \%$ \\
Muy alto & 61 & $100,0 \%$ & \\
Validos Total & 104 & & \\
& & & $100 \%$ \\
\hline
\end{tabular}

Fuente: Elaboración propia en base a la información obtenida de las encuestas realizadas a las empresa. 


\section{Evaluación sobre la complejidad de los trámites y planillas}

El 65,2\% los consideró sencillos, 22,7\% complejos y 5,8\% muy complejos. Nuevamente casi el $30 \%$ se manifiesta disgustado sobre los aspectos del crédito que efectivamente tomó y ello sigue resultando significativo.

El Banco Nación la evaluación sobresale netamente como peor desempeño que el promedio del conjunto. En cambio, el mejor calificado es el Banco Credicoop.

Cuadro 24: Análisis del crédito en cuanto a la complejidad de trámites y planillas

\begin{tabular}{|l|c|c|c|}
\hline \multicolumn{3}{|l|}{$\begin{array}{c}\text { Evaluación del crédito en cuanto a la complejidad de los tramites y } \\
\text { planillas }\end{array}$} \\
\hline & Frecuencia & Porcentaje & $\begin{array}{c}\text { Porcentaje } \\
\text { acumulado }\end{array}$ \\
\hline Validos: & 4 & $6,4 \%$ & $6,4 \%$ \\
Muy sencillo & 40 & $65,2 \%$ & $71,6 \%$ \\
Sencillo & 14 & $22,7 \%$ & $94,3 \%$ \\
Complejo & 4 & $5,8 \%$ & $100 \%$ \\
Muy complejo & 61 & $100 \%$ & \\
Validos Total & 104 & & \\
\hline & & & $100 \%$ \\
\hline
\end{tabular}

Fuente: Elaboración propia en base a la información obtenida de las encuestas realizadas a las empresa.

\section{Atención recibida para la gestión}

Para el conjunto, la atención resultó cordial para el 86,2\% y muy cordial para el 12,4.

Cuadro 25: Análisis del crédito en cuanto a la atención recibida

\begin{tabular}{|l|c|c|c|}
\hline \multicolumn{3}{|c|}{ Evaluación del crédito en cuanto a la atención recibida } \\
\hline & Frecuencia & Porcentaje & $\begin{array}{c}\text { Porcentaje } \\
\text { acumulado }\end{array}$ \\
\hline Validos: & & & \\
Muy cordial & 7 & $12,4 \%$ & $12,4 \%$ \\
Cordial & 52 & $86,2 \%$ & $98,6 \%$ \\
Mala & 1 & $1,1 \%$ & $99,7 \%$ \\
Muy mala & 0 & $0,3 \%$ & $100 \%$ \\
Validos Total & 60 & $100 \%$ & \\
Perdidos & 105 & & $100 \%$ \\
\hline Total & 165 & $100 \%$ & \\
\hline
\end{tabular}

Fuente: Elaboración propia en base a la información obtenida de las encuestas realizadas a las empresa. 


\section{Tiempo de adjudicación}

Dos terceras partes de los tomadores de crédito se manifestaron satisfechos con el tiempo de adjudicación. Un $68,2 \%$ de las respuestas correspondió a la calificación de rápido, y un 18,1\% a lento.

En este campo el mejor desempeño lo obtuvo el Banco Credicoop, seguido por el Banco Provincia y, en tercer lugar el Banco Nación.

Cuadro 26: Análisis del crédito en cuanto al período de adjudicación

\begin{tabular}{|l|l|c|c|}
\hline \multicolumn{3}{|c|}{ Evaluación del crédito en cuanto al tiempo de adjudicación } \\
\hline & Frecuencia & Porcentaje & $\begin{array}{c}\text { Porcentaje } \\
\text { acumulado }\end{array}$ \\
\hline Válidos: & 6 & $9,5 \%$ & $9,5 \%$ \\
Muy rápido & 42 & $68,2 \%$ & $77,7 \%$ \\
Rápido & 11 & $18,1 \%$ & $95,8 \%$ \\
Lento & 3 & $4,2 \%$ & $100 \%$ \\
Muy lento & 61 & $100 \%$ & \\
Validos Total & & & \\
& 104 & & $100 \%$ \\
\hline
\end{tabular}

\subsection{1 . Resumen de los resultados obtenidos en la evaluación del último crédito obtenido por los tomadores de los mismos}

Para el conjunto, las mejores calificaciones se observaron en: atención para la gestión, tiempo de adjudicación, requisitos solicitados y montos, en ese orden. Las peores calificaciones fueron para los períodos de gracia y las tasas de interés.

Comparado con el promedio del conjunto, las evaluaciones para el Banco Provincia fueron mejores en tasa de interés, monto y plazo. Asimismo, el Banco Provincia resultó igual en la evaluación del período de gracia y peor en complejidad de trámites y planillas, tiempo de adjudicación, requisitos solicitados y atención para la gestión, en ese orden. 


\subsection{Motivos por los cuales no se toman créditos}

Uno de los aspectos de la relación de las empresas con los bancos, revelado en la encuesta, es el vinculado a las razones por las que las empresas han hecho un uso restringido del crédito (pregunta15).Visto que sólo el 31,4\% de los empresarios que conforman la muestra se financian a través del sistema financiero y que en los últimos cinco años menos del $40 \%$ de los mismos han tomado crédito en el sistema bancario.

Ante la consulta ¿usted averiguó por créditos que luego no tomó? El 55,7\% dio una respuesta afirmativa, el 36,3\% no averiguó y el $8 \%$ optó por la opción Ns/Nc.

\section{Cuadro 27: Decisiones fallidas en la toma de crédito}

\begin{tabular}{|l|c|c|c|c|}
\hline \multicolumn{5}{|c|}{ Empresas que averiguaron por créditos que luego no tomaron } \\
\hline & Frecuencia & Porcentaje & $\begin{array}{c}\text { Porcentaje } \\
\text { válido }\end{array}$ & $\begin{array}{c}\text { Porcentaje } \\
\text { acumulado }\end{array}$ \\
Averiguó y no tomó & 86 & $51,9 \%$ & $55,7 \%$ & $55,7 \%$ \\
No averiguó & 56 & $33,9 \%$ & $36,3 \%$ & $92,0 \%$ \\
Ns/Nc & 12 & $7,5 \%$ & $8,0 \%$ & $100,0 \%$ \\
Validos Total & 154 & $93,3 \%$ & $100 \%$ & \\
Perdidos & 11 & $6,7 \%$ & & \\
& & & & \\
\hline Total & 165 & $100 \%$ & $100 \%$ & $100 \%$ \\
\hline
\end{tabular}

En cuanto a los bancos consultados, el que mayores consultas recibió es el Banco Provincia con el 21,2\% del total, le sigue el Banco Credicoop con 19,9\% de las consultas, luego el Banco Nación $16,8 \%$, Galicia $(9,8 \%)$, Santander $(8,1 \%)$, BBVA $(6,2 \%)$ y $\operatorname{HSBC}(4 \%)$.

Cuadro 28: Cantidad de consultas por créditos a los bancos

\begin{tabular}{|c|c|c|c|}
\hline \multicolumn{4}{|c|}{ Cantidad de consultas por créditos a los bancos } \\
\hline Bancos & Consultas & Porcentual & $\begin{array}{c}\text { Porcentual } \\
\text { acumulado }\end{array}$ \\
\hline Nación & 131 & $16,8 \%$ & $16,8 \%$ \\
Provincia & 165 & $21,2 \%$ & $38,0 \%$ \\
Macro & 4 & $0,5 \%$ & $38,6 \%$ \\
Credicoop & 155 & $19,9 \%$ & $58,5 \%$ \\
Galicia & 76 & $9,8 \%$ & $68,3 \%$ \\
BBVA & 48 & $6,2 \%$ & $74,4 \%$ \\
Santander & 63 & $8,1 \%$ & $82,5 \%$ \\
Itau & 13 & $1,7 \%$ & $84,2 \%$ \\
Ciudad & 19 & $2,4 \%$ & $86,6 \%$ \\
HSBC & 31 & $4,0 \%$ & $90,6 \%$ \\
Patagonia & 18 & $2,3 \%$ & $92,9 \%$ \\
Superville & 7 & $0,9 \%$ & $93,8 \%$ \\
Standard & 11 & $1,4 \%$ & $95,2 \%$ \\
Citibank & 7 & $0,9 \%$ & $96,1 \%$ \\
Comafi & 15 & $1,9 \%$ & $98,1 \%$ \\
Otros & 15 & $1,9 \%$ & $100,0 \%$ \\
\hline Total & 778 & $100 \%$ & \\
\hline
\end{tabular}

Fuente: Elaboración propia en base a la información obtenida de las encuestas realizadas a las empresa. 
Entre quienes han consultado por crédito y no han tomado se ha relevado las razones que aducen para no haberlo hecho. Los principales motivos enunciados son las tasas de interés inaccesibles (40\%) y requisitos inaccesibles (26\%) luego aparecen "Tramites y Planillas complejos" (9\%) y montos inapropiados (8\%). En menor medida preocupa a los entrevistados los "plazos inconvenientes" (5\%), los períodos de gracia exiguos $(2,3 \%)$ y la atención para la gestión de créditos $(1 \%)$.

Esto puede observarse en la siguiente tabla:

Cuadro 29: Motivos por los cuales no tomo crédito en el banco

\begin{tabular}{|c|c|c|c|c|c|c|c|c|c|c|}
\hline \multicolumn{11}{|c|}{ Motivos por los cuales no tomó crédito en el banco } \\
\hline Banco & $\begin{array}{c}\text { Tasa de interés } \\
\text { inaccesibles }\end{array}$ & $\begin{array}{l}\text { Período de } \\
\text { gracia exiguos }\end{array}$ & $\begin{array}{c}\text { Plazos } \\
\text { inconvenientes }\end{array}$ & $\begin{array}{c}\text { Montos } \\
\text { inapropiados }\end{array}$ & $\begin{array}{l}\text { Requisitos } \\
\text { inaccesibles }\end{array}$ & $\begin{array}{l}\text { Tramites y } \\
\text { planillas } \\
\text { complejos }\end{array}$ & $\begin{array}{c}\text { Atención para la } \\
\text { gestión hostil }\end{array}$ & $\begin{array}{l}\text { Demasiado } \\
\text { tiempo de } \\
\text { adjudicación }\end{array}$ & Otros & Total \\
\hline Nación & $5,04 \%$ & $0,42 \%$ & $0,84 \%$ & $1,60 \%$ & $5,37 \%$ & $2,85 \%$ & $0,25 \%$ & $0,17 \%$ & $1,60 \%$ & $18,14 \%$ \\
\hline Provincia & $7,39 \%$ & $0,25 \%$ & $1,09 \%$ & $1,68 \%$ & $6,13 \%$ & $2,52 \%$ & $0,34 \%$ & $0,08 \%$ & $1,85 \%$ & $21,33 \%$ \\
\hline Macro & $0,25 \%$ & $0,00 \%$ & $0,17 \%$ & $0,00 \%$ & $0,08 \%$ & $0,00 \%$ & $0,00 \%$ & $0,00 \%$ & $0,00 \%$ & $0,50 \%$ \\
\hline Credicoop & $7,89 \%$ & $0,34 \%$ & $0,59 \%$ & $1,34 \%$ & $5,37 \%$ & $1,76 \%$ & $0,34 \%$ & $0,08 \%$ & $1,26 \%$ & $18,97 \%$ \\
\hline Galicia & $5,29 \%$ & $0,17 \%$ & $0,67 \%$ & $0,84 \%$ & $2,02 \%$ & $0,59 \%$ & $0,00 \%$ & $0,25 \%$ & $0,50 \%$ & $10,33 \%$ \\
\hline BBVA & $2,60 \%$ & $0,17 \%$ & $0,25 \%$ & $0,59 \%$ & $1,60 \%$ & $0,25 \%$ & $0,00 \%$ & $0,00 \%$ & $0,42 \%$ & $5,88 \%$ \\
\hline Santander & $3,53 \%$ & $0,34 \%$ & $0,25 \%$ & $0,67 \%$ & $1,60 \%$ & $0,17 \%$ & $0,00 \%$ & $0,00 \%$ & $0,76 \%$ & $7,32 \%$ \\
\hline Itau & $0,67 \%$ & $0,00 \%$ & $0,08 \%$ & $0,34 \%$ & $0,59 \%$ & $0,00 \%$ & $0,00 \%$ & $0,00 \%$ & $0,08 \%$ & $1,76 \%$ \\
\hline Ciudad & $1,09 \%$ & $0,08 \%$ & $0,17 \%$ & $0,00 \%$ & $0,59 \%$ & $0,00 \%$ & $0,00 \%$ & $0,00 \%$ & $0,17 \%$ & $2,10 \%$ \\
\hline HSBC & $1,93 \%$ & $0,25 \%$ & $0,25 \%$ & $0,50 \%$ & $0,76 \%$ & $0,25 \%$ & $0,00 \%$ & $0,00 \%$ & $0,34 \%$ & $4,28 \%$ \\
\hline Patagonia & $1,09 \%$ & $0,00 \%$ & $0,00 \%$ & $0,17 \%$ & $0,42 \%$ & $0,17 \%$ & $0,00 \%$ & $0,08 \%$ & $0,17 \%$ & $2,10 \%$ \\
\hline Superville & $0,50 \%$ & $0,08 \%$ & $0,08 \%$ & $0,00 \%$ & $0,08 \%$ & $0,08 \%$ & $0,00 \%$ & $0,00 \%$ & $0,00 \%$ & $0,82 \%$ \\
\hline Standard & $0,59 \%$ & $0,00 \%$ & $0,08 \%$ & $0,08 \%$ & $0,34 \%$ & $0,25 \%$ & $0,08 \%$ & $0,00 \%$ & $0,25 \%$ & $1,67 \%$ \\
\hline Citibank & $0,34 \%$ & $0,00 \%$ & $0,00 \%$ & $0,08 \%$ & $0,25 \%$ & $0,00 \%$ & $0,08 \%$ & $0,00 \%$ & $0,08 \%$ & $0,83 \%$ \\
\hline Comafi & $0,76 \%$ & $0,00 \%$ & $0,08 \%$ & $0,17 \%$ & $0,50 \%$ & $0,00 \%$ & $0,00 \%$ & $0,00 \%$ & $0,17 \%$ & $1,68 \%$ \\
\hline Otros & $1,01 \%$ & $0,17 \%$ & $0,34 \%$ & $0,00 \%$ & $0,50 \%$ & $0,17 \%$ & $0,00 \%$ & $0,00 \%$ & $0,08 \%$ & $2,27 \%$ \\
\hline Total & $39,97 \%$ & $2,27 \%$ & $4,94 \%$ & $8,06 \%$ & $26,20 \%$ & $9,06 \%$ & $1,09 \%$ & $0,66 \%$ & $7,73 \%$ & $100,0 \%$ \\
\hline
\end{tabular}

Fuente: Elaboración propia en base a la información obtenida de las encuestas realizadas a las empresa. 


\subsection{Condiciones consideradas accesibles para acceder a un crédito}

Ante la consulta por las condiciones que los empresarios consideran accesibles para tomar un crédito (pregunta 16.a) se preguntó por la tasa máxima de interés que estaría dispuesto a pagar, plazos mínimos de gracia y plazos mínimos de amortización. La consulta se realizó con relación a destinos de créditos, en los que se abarcaron distintos destinos relacionados a inversiones y capital de trabajo.

Las respuestas tuvieron un alto componente de "No sabe/ No contesta" con un promedio de $66 \%$ para la tasa máxima. Las opciones por el $\mathrm{Ns} / \mathrm{Nc}$ se mostraron altas en lo referente a algún destino vinculados con capital de trabajo (pago de impuestos 84,9\%, pago de salario 82,8\%, financiación de ventas internas $75 \%$, financiación de exportaciones $75 \%$, financiación de importaciones $74,6 \%$ ); la indefinición que este tipo de respuestas expresa disminuye cuando se refiere a destinos relacionados con la inversión, especialmente nuevos productos $(45 \%)$, ampliación de planta (43\%) y compra de maquinaria (31\%). En consecuencia, una de las inferencias que se puede realizar es que el "No sabe/ No contesta" está marcando desinterés en tomar créditos para capital de trabajo, que financiarían mediante otros recursos, ese desinterés disminuiría respecto a capital para inversión, entre cuyo destinos las mayores expectativas se centrarían en "compra de maquinarias" y "ampliación de planta".

En consecuencia, las respuestas que implicaron decisiones de preferencias sobre tasas, plazos de gracia y plazos de amortización se ubican para los destinos conexos con capital de trabajo. Así, en el caso de las tasas con destino de capital de trabajo y conexos los porcentajes de respuesta válida oscilan entre $15 \%$ y $47 \%$ (pago de impuestos $15 \%$, pago de salarios $17 \%$, financiación de importaciones $25 \%$, financiación de ventas internas $25 \%$, financiación de exportaciones $25,4 \%$ ) siendo la más alta "compras de materias primas" con un $47 \%$. Un comportamiento análogo se verificó en que respecta a plazo de gracia y de amortización.

Las respuestas positivas relacionadas con destinos vinculados a inversiones fueron mayores (con excepción de "mejoras en la estructura de ventas" que se ubicó en el 30\% e "inversión en investigación y desarrollo 39,3\%); así, "nuevos productos" tuvo un nivel de respuesta positiva del $55 \%$, ampliación de planta del 57\%, siendo el de mayor respuesta "compras de maquinarias" con $69 \%$.

Una situación consonante se reveló en lo que hace a plazos de gracia y plazos de amortización.

Cuadro 30: Condiciones consideradas accesibles para acceder a un crédito

Condiciones consideradas accesibles para acceder a un crédito

\begin{tabular}{|c|c|c|c|c|c|c|c|c|c|c|c|c|c|c|c|c|}
\hline \multicolumn{17}{|c|}{ Condiciones consideradas accesibles para acceder a un crédito } \\
\hline \multirow[b]{2}{*}{ Destino del crédito } & \multicolumn{5}{|c|}{ Tasa máxima } & \multicolumn{4}{|c|}{ Tasa mínima de gracia } & \multicolumn{7}{|c|}{ Plazo mínimo de amortización } \\
\hline & $\begin{array}{c}\text { Hasta } \\
9 \%\end{array}$ & $\begin{array}{l}10 a \\
15 \%\end{array}$ & $\begin{array}{l}16 a \\
20 \%\end{array}$ & $\begin{array}{c}21 \% 0 \\
\text { más }\end{array}$ & $\mathrm{Ns} / \mathrm{Nc}$ & $\begin{array}{c}\text { Hasta } 6 \\
\mathrm{~m}\end{array}$ & $\begin{array}{c}\text { Hasta } \\
12 \mathrm{~m}\end{array}$ & $\begin{array}{l}\text { Hasta } \\
24 \mathrm{~m}\end{array}$ & $\mathrm{Ns} / \mathrm{Nc}$ & 1 año & 2 años & 3 años & 4 años & 5 años & $\begin{array}{c}\text { más de } 6 \\
\text { años }\end{array}$ & $\mathrm{Ns} / \mathrm{Nc}$ \\
\hline Nuevos productos & $30,4 \%$ & $22,2 \%$ & $1,7 \%$ & $0,6 \%$ & $45,1 \%$ & $20,4 \%$ & $22,3 \%$ & $10,9 \%$ & $46,5 \%$ & $3,8 \%$ & $5,3 \%$ & $9,6 \%$ & $5,1 \%$ & $14,9 \%$ & $14,2 \%$ & $47,1 \%$ \\
\hline Inversión en $\mathrm{I}+\mathrm{D}$ & $21,1 \%$ & $14,8 \%$ & $3,0 \%$ & $0,4 \%$ & $60,7 \%$ & $15,1 \%$ & $14,9 \%$ & $8,3 \%$ & $61,7 \%$ & $3,1 \%$ & $3,9 \%$ & $6,5 \%$ & $4,4 \%$ & $7,7 \%$ & $12,2 \%$ & $62,3 \%$ \\
\hline Ampliación de planta & $32,5 \%$ & $21,3 \%$ & $2,6 \%$ & $0,5 \%$ & $43,1 \%$ & $20,8 \%$ & $20,4 \%$ & $13,8 \%$ & $44,9 \%$ & $3,5 \%$ & $3,9 \%$ & $8,1 \%$ & $5,0 \%$ & $15,1 \%$ & $19,7 \%$ & $44,7 \%$ \\
\hline Compra de maquinaria & $41,0 \%$ & $23,3 \%$ & $4,1 \%$ & $0,5 \%$ & $31,1 \%$ & $26,3 \%$ & $25,2 \%$ & $14,8 \%$ & $33,7 \%$ & $4,3 \%$ & $4,8 \%$ & $11,3 \%$ & $5,2 \%$ & $20,7 \%$ & $19,1 \%$ & $34,6 \%$ \\
\hline Compra de mat. Prima & $25,5 \%$ & $18,3 \%$ & $2,8 \%$ & $0,3 \%$ & $53,1 \%$ & $23,3 \%$ & $14,3 \%$ & $6,5 \%$ & $56,0 \%$ & $12,3 \%$ & $8,6 \%$ & $8,5 \%$ & $2,6 \%$ & $6,5 \%$ & $4,2 \%$ & $57,3 \%$ \\
\hline Mejora estruct. Venta y distrib. & $13,7 \%$ & $14,6 \%$ & $1,3 \%$ & $0,2 \%$ & $70,2 \%$ & $15,3 \%$ & $8,7 \%$ & $3,6 \%$ & $72,4 \%$ & $6,8 \%$ & $6,4 \%$ & $5,4 \%$ & $1,7 \%$ & $5,0 \%$ & $1,4 \%$ & $73,2 \%$ \\
\hline Financiación exportaciones & $13,2 \%$ & $10,8 \%$ & $1,4 \%$ & $0,0 \%$ & $74,6 \%$ & $13,9 \%$ & $6,9 \%$ & $2,6 \%$ & $76,6 \%$ & $7,8 \%$ & $5,7 \%$ & $4,3 \%$ & $1,2 \%$ & $2,6 \%$ & $1,0 \%$ & $77,3 \%$ \\
\hline Financiación vt & $12,3 \%$ & $11,1 \%$ & $1,6 \%$ & $0,0 \%$ & $75,0 \%$ & $13,2 \%$ & $7,2 \%$ & $2,8 \%$ & $76,8 \%$ & $7,5 \%$ & $5,8 \%$ & $4,7 \%$ & $1,0 \%$ & $2,6 \%$ & $0,9 \%$ & $77,4 \%$ \\
\hline Financiación importaciones & $13,1 \%$ & $10,7 \%$ & $1,2 \%$ & $0,1 \%$ & $74,9 \%$ & $13,6 \%$ & $7,2 \%$ & $2,5 \%$ & $76,7 \%$ & $7,3 \%$ & $5,6 \%$ & $4,2 \%$ & $1,4 \%$ & $2,8 \%$ & $1,1 \%$ & $77,5 \%$ \\
\hline Pago de salario & $9,2 \%$ & $6,7 \%$ & $1,2 \%$ & $0,1 \%$ & $82,8 \%$ & $9,3 \%$ & $4,4 \%$ & $1,0 \%$ & $85,2 \%$ & $8,0 \%$ & $2,7 \%$ & $1,9 \%$ & $0,7 \%$ & $0,6 \%$ & $0,4 \%$ & $85,6 \%$ \\
\hline Pago de impuestos & $8,4 \%$ & $5,4 \%$ & $1,0 \%$ & $0,2 \%$ & $84,9 \%$ & $7,7 \%$ & $4,4 \%$ & $0,9 \%$ & $87,0 \%$ & $7,0 \%$ & $2,5 \%$ & $1,8 \%$ & $0,3 \%$ & $0,6 \%$ & $0,3 \%$ & $87,5 \%$ \\
\hline Otros & $1,8 \%$ & $1,3 \%$ & $0,1 \%$ & $0,0 \%$ & $96,7 \%$ & $1,3 \%$ & $1,0 \%$ & $0,4 \%$ & $97,2 \%$ & $1,4 \%$ & $0,3 \%$ & $0,1 \%$ & $0,3 \%$ & $0,0 \%$ & $0,3 \%$ & $97,5 \%$ \\
\hline
\end{tabular}

Fuente: Elaboración propia en base a la información obtenida de las encuestas realizadas a las empresa. 
Con las salvedades hechas, se observa la preferencia de los empresarios respecto a las condiciones consideradas accesibles para acceder a un crédito, sabiendo que el análisis que se realiza sobre el tema excluyen las respuestas Ns/Nc.

Ente las respuestas, se encuentra que hay una clara preferencia a considerar tasas accesibles a las que se ubican en el rango del 9 al 15\% anual dado que en promedio suman el 94\% (54\% suman consideran accesibles tasas de hasta un $9 \%$ y un $40 \%$ aceptan tasas de hasta un $15 \%$ ).

En este sentido no se observan variaciones destacadas como se puede visualizar en el siguiente cuadro:

Cuadro 31: Condiciones consideradas accesibles para acceder a un crédito con Ns/Nc

\begin{tabular}{|c|c|c|c|c|c|c|c|c|c|c|c|c|c|}
\hline \multicolumn{14}{|c|}{ Condiciones consideradas accesibles para acceder a un crédito excluyendo Ns/Nc } \\
\hline \multirow[b]{2}{*}{ Destino del crédito } & \multicolumn{4}{|c|}{ Tasa máxima } & \multicolumn{3}{|c|}{ Tasa mínima de gracia } & \multicolumn{6}{|c|}{ Plazo mínimo de amortización } \\
\hline & $\begin{array}{c}\text { Hasta } \\
9 \%\end{array}$ & $\begin{array}{l}10 a \\
15 \%\end{array}$ & $\begin{array}{l}16 \text { a } \\
20 \%\end{array}$ & $\begin{array}{l}21 \% \text { o } \\
\text { más }\end{array}$ & $\begin{array}{c}\text { Hasta } 6 \\
\mathrm{~m}\end{array}$ & $\begin{array}{c}\text { Hasta } \\
12 \mathrm{~m}\end{array}$ & $\begin{array}{c}\text { Hasta } \\
24 \mathrm{~m}\end{array}$ & 1 año & 2 años & 3 años & 4 años & 5 años & $\begin{array}{l}\text { más de } \\
6 \text { años }\end{array}$ \\
\hline Nuevos productos & $55,3 \%$ & $40,4 \%$ & $3,2 \%$ & $1,1 \%$ & $38,1 \%$ & $41,6 \%$ & $20,3 \%$ & $7,2 \%$ & $10,1 \%$ & $18,2 \%$ & $9,7 \%$ & $28,1 \%$ & $26,7 \%$ \\
\hline Inversión en I+D & $53,8 \%$ & $37,6 \%$ & $7,6 \%$ & $1,0 \%$ & $39,4 \%$ & $38,9 \%$ & $21,7 \%$ & $8,2 \%$ & $10,3 \%$ & $17,1 \%$ & $11,7 \%$ & $20,4 \%$ & $32,3 \%$ \\
\hline Ampliación de planta & $57,1 \%$ & $37,5 \%$ & $4,5 \%$ & $0,9 \%$ & $37,8 \%$ & $37,1 \%$ & $25,1 \%$ & $6,3 \%$ & $7,1 \%$ & $14,7 \%$ & $9,1 \%$ & $27,3 \%$ & $35,6 \%$ \\
\hline Compra de maquinaria & $59,5 \%$ & $33,8 \%$ & $6,0 \%$ & $0,7 \%$ & $39,6 \%$ & $38,1 \%$ & $22,3 \%$ & $6,6 \%$ & $7,4 \%$ & $17,2 \%$ & $8,0 \%$ & $31,7 \%$ & $29,2 \%$ \\
\hline Compra de mat. Prima & $54,5 \%$ & $38,9 \%$ & $5,9 \%$ & $0,7 \%$ & $52,9 \%$ & $32,4 \%$ & $14,7 \%$ & $28,8 \%$ & $20,2 \%$ & $20,0 \%$ & $6,0 \%$ & $15,1 \%$ & $9,9 \%$ \\
\hline Mejora estruct. Venta y distrib. & $46,0 \%$ & $48,8 \%$ & $4,5 \%$ & $0,7 \%$ & $55,4 \%$ & $31,6 \%$ & $13,0 \%$ & $25,3 \%$ & $23,8 \%$ & $20,3 \%$ & $6,5 \%$ & $18,8 \%$ & $5,4 \%$ \\
\hline Financiación exportaciones & $52,0 \%$ & $42,3 \%$ & $5,7 \%$ & $0,0 \%$ & $59,6 \%$ & $29,4 \%$ & $11,0 \%$ & $34,4 \%$ & $25,3 \%$ & $19,0 \%$ & $5,4 \%$ & $11,3 \%$ & $4,5 \%$ \\
\hline Financiación vtas internas & $49,2 \%$ & $44,3 \%$ & $6,5 \%$ & $0,0 \%$ & $57,1 \%$ & $31,0 \%$ & $11,9 \%$ & $33,2 \%$ & $25,9 \%$ & $20,9 \%$ & $4,5 \%$ & $11,4 \%$ & $4,1 \%$ \\
\hline Financiación importaciones & $52,2 \%$ & $42,4 \%$ & $4,9 \%$ & $0,4 \%$ & $58,6 \%$ & $30,8 \%$ & $10,9 \%$ & $32,4 \%$ & $25,1 \%$ & $18,7 \%$ & $6,4 \%$ & $12,3 \%$ & $5,0 \%$ \\
\hline Pago de salario & $23,6 \%$ & $38,7 \%$ & $7,1 \%$ & $0,6 \%$ & $63,2 \%$ & $29,9 \%$ & $6,9 \%$ & $55,7 \%$ & $18,6 \%$ & $13,6 \%$ & $5,0 \%$ & $4,3 \%$ & $2,9 \%$ \\
\hline Pago de impuestos & $55,8 \%$ & $36,1 \%$ & $6,8 \%$ & $1,4 \%$ & $59,1 \%$ & $33,9 \%$ & $7,1 \%$ & $55,7 \%$ & $19,7 \%$ & $14,8 \%$ & $2,5 \%$ & $4,9 \%$ & $2,5 \%$ \\
\hline Otros & $56,3 \%$ & $40,6 \%$ & $3,1 \%$ & $0,0 \%$ & $48,1 \%$ & $37,0 \%$ & $14,8 \%$ & $58,3 \%$ & $12,5 \%$ & $4,2 \%$ & $0,0 \%$ & $12,5 \%$ & $12,5 \%$ \\
\hline
\end{tabular}

Fuente: Elaboración propia en base a la información obtenida de las encuestas realizadas a las empresa.

En cuanto a los plazos mínimos de gracia, la suma de hasta 6 meses y hasta 12 meses concentra, en promedio, el $85 \%$ de las preferencias. Aquí sí se puede observar mayores variaciones según el destino de los créditos. En lo vinculado a capital de trabajo hay una preferencia por períodos de gracia de hasta 6 meses, mientras que los créditos relacionados con el capital de inversión, muestra una preferencia repetida en los tres niveles de plazo propuestos.

Al observar el comportamiento de las respuestas sobre plazo mínimo de amortización se puede deducir que para capital de trabajo se prefieren plazos cortos de amortización, sobre todo en los rubros de pago de impuestos y pago de salarios que concentran un 55,7\% de la preferencia de la opción de "un año". Otras opciones del rubro concentran alrededor del $60 \%$ de la muestra en la suma de las opciones un año y dos años.

Por el contrario, para los créditos relacionados con el capital de inversión, la opción es por plazos de amortización más largos. Así, para desarrollo de nuevos productos la opción más elegida son cinco años (28\%) y más de seis años (26,7\%), para inversiones en investigación y desarrollo cinco años $(20,4 \%)$ y más de seis años $(32,3 \%)$, para ampliación de planta cinco años $(27,3 \%)$, y más de seis años $(35,6 \%)$, para compras de maquinarias cinco años $(31,7 \%)$ y más de seis años $(29,2 \%)$. 


\subsection{Fuentes de financiamiento habituales por tipo de instrumento}

La inquisitoria sobre fuentes de financiamiento habituales (pregunta $\mathrm{N}^{\circ} 13$ ), se hizo a partir de cuatro opciones: "Descuento de documento, cheques y remesas", "Descubierto en cuenta corriente", "Prestamos amortizables de intereses vencidos (PAIV)" y "ninguna".

Computada la frecuencia de respuestas por concepto, se pudo observar que el 32,3\% de los encuestados recurren al "descuento de documento, cheques y remesas", el $32 \%$ al "descubierto en cuenta corriente" y el 5,3\% a la utilización de "préstamos amortizables de interés vencido" como fuente de financiamiento.

Del total de la muestra, el $51 \%$ manifiesta no utilizar ninguna fuente de financiamiento, esto implica que alguno de lo que conforman el $49 \%$ que si utilizan algunas de estas fuentes de financiamiento, usan más de una de ellas: 52 casos manifiestan emplear descuentos de cheques y documentos, 51 utilizan descubierto en cuenta corriente y 8 préstamos amortizables de interés vencidos (PAIV). Esto nos arroja un total de 111 frecuencias de uso de algunos de estos instrumentos mencionados. Si los empresarios que utilizaron algunas de las fuentes de financiamiento mencionadas son 78 , da como resultado una frecuencia de uso de 1,42 fuentes por empresario que si utilizan.

Si consideramos el uso respecto del total de la muestra la proporción es 0,67.

Cuadros 32-33-34-35: Análisis de fuentes de financiamiento por tipo de instrumento

\begin{tabular}{|l|c|c|c|c|}
\hline \multicolumn{5}{|c|}{ Empleo de documentos cheques y remesas } \\
\hline & Frecuencia & Porcentaje & $\begin{array}{c}\text { Porcentaje } \\
\text { válido }\end{array}$ & $\begin{array}{c}\text { Porcentaje } \\
\text { acumulado }\end{array}$ \\
\hline Válidos: & 52 & $31,3 \%$ & $32,3 \%$ & $32,3 \%$ \\
$\mathrm{Si}$ & 108 & $65,6 \%$ & $67,6 \%$ & $99,9 \%$ \\
No & 0 & $0,1 \%$ & $0,1 \%$ & $100,0 \%$ \\
Ns/Nc & 160 & $97,0 \%$ & $100,0 \%$ & \\
Validos Total & & & & \\
& 5 & $3,0 \%$ & & \\
Perdidos & 165 & $100 \%$ & $100 \%$ & $100 \%$ \\
\hline
\end{tabular}

\begin{tabular}{|l|c|c|c|c|}
\hline \multicolumn{5}{|c|}{ Empleo de descubierto en cuenta corriente } \\
\hline & Frecuencia & Porcentaje & $\begin{array}{c}\text { Porcentaje } \\
\text { válido }\end{array}$ & $\begin{array}{c}\text { Porcentaje } \\
\text { acumulado }\end{array}$ \\
\hline Validos: & 51 & $30,8 \%$ & $32,0 \%$ & $32,0 \%$ \\
Si & 108 & $65,4 \%$ & $67,9 \%$ & $99,9 \%$ \\
No & 0 & $0,1 \%$ & $0,1 \%$ & $100,0 \%$ \\
Ns/Nc & 159 & $96,4 \%$ & $100,0 \%$ & \\
Válidos Total & 6 & $3,6 \%$ & & \\
Perdidos & 165 & $100 \%$ & $100 \%$ & $100 \%$ \\
\hline Total & & & & \\
\hline
\end{tabular}

Fuente: Elaboración propia en base a la información obtenida de las encuestas realizadas a las empresa.

\begin{tabular}{|l|c|c|c|c|}
\hline \multicolumn{5}{|c|}{ Empleo de prestamos amortizables de interes vencido (PAIV) } \\
\hline & Frecuencia & Porcentaje & $\begin{array}{c}\text { Porcentaje } \\
\text { válido }\end{array}$ & $\begin{array}{c}\text { Porcentaje } \\
\text { acumulado }\end{array}$ \\
\hline Validos: & & & & \\
$\mathrm{Si}$ & 8 & $5,1 \%$ & $5,3 \%$ & $5,3 \%$ \\
No & 150 & $91,2 \%$ & $94,6 \%$ & $99,9 \%$ \\
Ns/Nc & 0 & $0,1 \%$ & $0,1 \%$ & $100,0 \%$ \\
Válidos Total & 159 & $96,4 \%$ & $100,0 \%$ & \\
& & & & \\
Perdidos & 6 & $3,6 \%$ & & \\
& 165 & $100 \%$ & $100 \%$ & $100 \%$ \\
\hline
\end{tabular}

\begin{tabular}{|c|c|c|c|c|}
\hline \multicolumn{5}{|c|}{ No emplea ninguna herramienta de financiamiento } \\
\hline & Frecuencia & Porcentaje & $\begin{array}{l}\text { Porcentaje } \\
\text { válido }\end{array}$ & $\begin{array}{l}\text { Porcentaje } \\
\text { acumulado }\end{array}$ \\
\hline Validos: & & & & \\
\hline $\mathrm{Si}$ & 81 & $49,2 \%$ & $51,1 \%$ & $51,1 \%$ \\
\hline No & 78 & $47,0 \%$ & $48,8 \%$ & $99,9 \%$ \\
\hline $\mathrm{Ns} / \mathrm{Nc}$ & 0 & $0,1 \%$ & $0,1 \%$ & $100,0 \%$ \\
\hline Válidos Total & 159 & $96,4 \%$ & $100,0 \%$ & \\
\hline Perdidos & 6 & $3,6 \%$ & & \\
\hline Total & 165 & $100 \%$ & $100 \%$ & $100 \%$ \\
\hline
\end{tabular}

Fuente: Elaboración propia en base a la información obtenida de las encuestas realizadas a las empresa. 


\subsection{Sobre la disposición empresaria a tomar crédito}

Luego de preguntar sobre las condiciones crediticias que los empresarios consideran adecuadas, en las actuales circunstancias, se requirió una respuesta sobre la disposición de las empresas a tomar nuevos créditos, dadas esas condiciones. $\mathrm{El} 63,7 \%$ de la muestra respondió de manera afirmativa, el 25,9\% contestó negativamente y el 10,4\% se enmarcó en la opción Ns/Nc.

\section{Cuadro 36: Disposición genérica a tomar créditos}

\begin{tabular}{|l|c|c|}
\hline \multicolumn{3}{|c|}{ Casos que estarían dispuestos a tomar } \\
créditos \\
\hline & Porcentaje & $\begin{array}{c}\text { Porcentaje } \\
\text { acumulado }\end{array}$ \\
\hline $\mathrm{Si}$ & $63,7 \%$ & $63,7 \%$ \\
$\mathrm{No}$ & $25,9 \%$ & $89,6 \%$ \\
$\mathrm{Ns} / \mathrm{Nc}$ & $10,4 \%$ & $100,0 \%$ \\
& & \\
\hline Total & $100 \%$ & $100 \%$ \\
\hline
\end{tabular}

Fuente: Elaboración propia en base a la información obtenida de las encuestas realizadas a las empresa.

El cuadro precedente indica la disposición genérica a tomar créditos, en condiciones que los empresarios consideran adecuadas o accesibles sin afectar la marcha de sus empresas, pero el $63,7 \%$ que lo haría no nos indica cuales sería los destinos de los créditos con mayor preferencia ni la relación con las condiciones que consideran accesible. Para lograr una aproximación a estos temas se cruzaron las respuestas correspondientes a las preguntas 16.a y 16.b de la encuesta y se elaboró las correspondientes tablas de contingencia a partir de las cuales se construirán tres cuadros que nos permiten visualizar y analizar el comportamiento que subyace de las respuestas dadas.

La primera conclusión que se obtiene está vinculada a los casos en que tomarían créditos según los niveles de tasa de interés, y las preferencias de destino de los créditos. Nuevamente se verifica que hay una mayor propensión hacia los créditos vinculados a capital de inversión. Los porcentajes en lo que se hará alusión en este punto es lo referido al total de la muestra. Los destinos más elegidos fueron, "compras de maquinarias" con el $54,4 \%$ de disposición a tomarlos, especialmente cuando la tasa se ubica entre el 9 y el 15\%, le sigue "ampliación de planta con el 45,2\%" de los casos y desarrollo de nuevos productos con el 44,7\%. Por el contrario, los destinos menos elegidos son los relacionados con el capital de trabajo; los porcentajes más altos son la financiación de exportaciones, financiación de importaciones y financiación de ventas, las tres ubicadas entre el 20 y el $21 \%$ de los destinos elegidos.

En lo que respecta a las tasas que facilitarían la toma de créditos, la mayoría de los empresarios que respondieron estas cuestiones aparecen dispuestos a tomar crédito a tasas que se ubiquen entre el $9 \%$ y un $15 \%$ anual.

En el cuadro presentado a continuación se pueden observar en detalle lo expresado: 
Cuadro 37: Condiciones consideradas accesibles para acceder a un crédito según tasa de interés

\begin{tabular}{|l|c|c|c|c|c|}
\hline \multicolumn{3}{|c|}{ Tomaría crédito en condiciones que consideran accesibles -según tasa- } \\
\cline { 2 - 7 } Destino del crédito & \multicolumn{5}{c|}{ Tasa máxima } \\
\cline { 2 - 6 } & Hasta 9\% & 10 a $15 \%$ & $\begin{array}{c}16 \text { a } \\
20 \%\end{array}$ & $\begin{array}{c}21 \% \text { o } \\
\text { más }\end{array}$ & $\begin{array}{c}\text { Total de } \\
\text { tomadores }\end{array}$ \\
\hline Nuevos productos & $23,9 \%$ & $18,8 \%$ & $1,5 \%$ & $0,5 \%$ & $44,7 \%$ \\
\hline Inversión en I+D & $16,5 \%$ & $12,1 \%$ & $2,8 \%$ & $0,3 \%$ & $31,7 \%$ \\
\hline Ampliación de planta & $25,1 \%$ & $17,5 \%$ & $2,2 \%$ & $0,4 \%$ & $45,2 \%$ \\
\hline Compra de maquinaria & $31,2 \%$ & $18,9 \%$ & $3,8 \%$ & $0,4 \%$ & $54,3 \%$ \\
\hline Compra de mat. Prima & $19,2 \%$ & $15,3 \%$ & $2,7 \%$ & $0,3 \%$ & $37,5 \%$ \\
\hline Mejora estruct. Venta y distrib. & $10,5 \%$ & $12,8 \%$ & $1,3 \%$ & $0,2 \%$ & $24,8 \%$ \\
\hline Financiación exportaciones & $10,5 \%$ & $9,7 \%$ & $1,4 \%$ & $0,0 \%$ & $21,6 \%$ \\
\hline Financiación vtas internas & $9,4 \%$ & $9,9 \%$ & $1,5 \%$ & $0,0 \%$ & $20,8 \%$ \\
\hline Financiación importaciones & $10,1 \%$ & $9,6 \%$ & $1,2 \%$ & $0,1 \%$ & $21,0 \%$ \\
\hline Pago de salario & $7,1 \%$ & $6,1 \%$ & $1,3 \%$ & $0,1 \%$ & $14,6 \%$ \\
\hline Pago de impuestos & $6,7 \%$ & $5,0 \%$ & $1,1 \%$ & $0,2 \%$ & $13,0 \%$ \\
\hline Otros & $1,4 \%$ & $1,2 \%$ & $0,1 \%$ & $2,7 \%$ & $5,4 \%$ \\
\hline
\end{tabular}

Fuente: Elaboración propia en base a la información obtenida de las encuestas realizadas a las empresa.

En lo que respecta a la condición de "período de gracia", indica la misma tendencia preferencial hacia los destinos de inversión. Nuevamente, "compras de maquinarias" aparece como el destino destacado en las opciones con el 52,2\% de la disposición a tomar este tipo de crédito, le sigue "ampliación de planta" con el 44,2\% y "desarrollo de nuevos productos" con el 43,9\%. Dentro del rubro es un poco más baja la preferencia por inversión en investigación y desarrollo con un 31,1\%. En este tema se verifica la menor disposición a tomar créditos destinados a capital de trabajo; y son también los destinos "pago de salario" (12,3\%) y "pago de impuestos" (11\%) los que muestran la menor disposición empresarial para la toma de créditos.

Cuadro 38: Condiciones consideradas accesibles para acceder a un crédito según período de gracia

\begin{tabular}{|c|c|c|c|c|}
\hline \multicolumn{5}{|c|}{$\begin{array}{l}\text { Tomaría crédito en condiciones que consideran accesibles } \\
\text { según período de gracia- }\end{array}$} \\
\hline \multirow[b]{2}{*}{ Destino del crédito } & \multicolumn{4}{|c|}{ Tasa mínima de gracia } \\
\hline & $\begin{array}{c}\text { Hasta } 6 \\
\mathrm{~m}\end{array}$ & $\begin{array}{c}\text { Hasta } \\
12 \mathrm{~m}\end{array}$ & $\begin{array}{l}\text { Hasta } \\
24 \mathrm{~m}\end{array}$ & $\begin{array}{l}\text { Total de } \\
\text { tomadores }\end{array}$ \\
\hline Nuevos productos & $17,1 \%$ & $18,0 \%$ & $8,8 \%$ & $43,9 \%$ \\
\hline Inversión en I+D & $12,7 \%$ & $11,7 \%$ & $6,7 \%$ & $31,1 \%$ \\
\hline Ampliación de planta & $16,7 \%$ & $16,1 \%$ & $11,4 \%$ & $44,2 \%$ \\
\hline Compra de maquinaria & $21,1 \%$ & $20,0 \%$ & $11,7 \%$ & $52,8 \%$ \\
\hline Compra de mat. Prima & $19,4 \%$ & $10,9 \%$ & $5,2 \%$ & $35,5 \%$ \\
\hline Mejora estruct. Venta y distrib. & $13,4 \%$ & $6,9 \%$ & $2,9 \%$ & $23,2 \%$ \\
\hline Financiación exportaciones & $12,3 \%$ & $5,4 \%$ & $2,1 \%$ & $19,8 \%$ \\
\hline Financiación vtas internas & $11,6 \%$ & $5,5 \%$ & $2,3 \%$ & $19,4 \%$ \\
\hline Financiación importaciones & $12,1 \%$ & $5,4 \%$ & $2,0 \%$ & $19,5 \%$ \\
\hline Pago de salario & $8,0 \%$ & $3,5 \%$ & $0,8 \%$ & $12,3 \%$ \\
\hline Pago de impuestos & $6,7 \%$ & $3,7 \%$ & $0,6 \%$ & $11,0 \%$ \\
\hline Otros & $1,2 \%$ & $0,8 \%$ & $0,2 \%$ & $2,2 \%$ \\
\hline
\end{tabular}

Quedaría por analizar los resultados relacionados con la condición "Plazo de amortización": El comportamiento resulta casi gemelo al de los casos anteriores; la mayor preferencia se corresponde con los destinos que podemos considerar como créditos para inversión, y nuevamente el destino 
más destacado es "compra de maquinaria" (52\%), seguido de "ampliación de planta" $(44,3 \%)$ y "desarrollo de nuevos productos" (43,2\%).

Los que muestran menor predisposición a ser tomados son los que podemos considerar "capital de trabajo", al igual que para las tasas y los plazos de gracia.

En lo que respecta a los plazos, las preferencias para los créditos destinados a inversión muestran plazos largos (5 años o más) y para los créditos cuya finalidad es capital de trabajo hay una preeminencia de opción por plazos cortos.

Cuadro 39: Condiciones consideradas accesibles para acceder a un crédito según amortización

\begin{tabular}{|l|c|c|c|c|c|c|c|}
\hline \multirow{2}{*}{\multicolumn{1}{c|}{ Destino del crédito }} & \multicolumn{5}{c|}{ Plazo mínimo de amortización } \\
\cline { 2 - 9 } & 1 año & 2 años & 3 años & 4 años & 5 años & $\begin{array}{c}\text { más de } \\
6 \text { años }\end{array}$ & $\begin{array}{c}\text { Total de } \\
\text { tomadores }\end{array}$ \\
\hline Nuevos productos & $2,9 \%$ & $4,4 \%$ & $8,1 \%$ & $4,2 \%$ & $13,3 \%$ & $10,4 \%$ & $43,3 \%$ \\
\hline Inversión en I+D & $2,3 \%$ & $3,5 \%$ & $5,2 \%$ & $3,6 \%$ & $6,8 \%$ & $9,2 \%$ & $30,6 \%$ \\
\hline Ampliación de planta & $2,8 \%$ & $3,3 \%$ & $6,2 \%$ & $4,2 \%$ & $12,3 \%$ & $15,5 \%$ & $44,3 \%$ \\
\hline Compra de maquinaria & $3,4 \%$ & $4,0 \%$ & $8,9 \%$ & $4,1 \%$ & $17,2 \%$ & $14,2 \%$ & $51,8 \%$ \\
\hline Compra de mat. Prima & $10,4 \%$ & $7,2 \%$ & $6,6 \%$ & $2,0 \%$ & $5,5 \%$ & $3,1 \%$ & $34,8 \%$ \\
\hline Mejora estruct. Venta y distrib. & $6,2 \%$ & $5,5 \%$ & $4,5 \%$ & $1,4 \%$ & $4,5 \%$ & $1,1 \%$ & $23,2 \%$ \\
\hline Financiación exportaciones & $7,3 \%$ & $4,9 \%$ & $3,6 \%$ & $1,0 \%$ & $2,1 \%$ & $0,8 \%$ & $19,7 \%$ \\
\hline Financiación vtas internas & $6,4 \%$ & $5,2 \%$ & $3,8 \%$ & $0,8 \%$ & $2,3 \%$ & $0,7 \%$ & $19,2 \%$ \\
\hline Financiación importaciones & $6,3 \%$ & $5,1 \%$ & $3,6 \%$ & $1,3 \%$ & $2,2 \%$ & $0,7 \%$ & $19,2 \%$ \\
\hline Pago de salario & $7,2 \%$ & $2,2 \%$ & $1,7 \%$ & $0,5 \%$ & $0,5 \%$ & $0,4 \%$ & $12,5 \%$ \\
\hline Pago de impuestos & $6,3 \%$ & $2,1 \%$ & $1,6 \%$ & $0,3 \%$ & $0,4 \%$ & $0,3 \%$ & $11,0 \%$ \\
\hline Otros & $1,3 \%$ & $0,2 \%$ & $0,1 \%$ & $0,0 \%$ & $0,3 \%$ & $0,1 \%$ & $2,0 \%$ \\
\hline
\end{tabular}

Fuente: Elaboración propia en base a la información obtenida de las encuestas realizadas a las empresa.

\subsection{Usos de servicios bancarios}

En este punto se ha requerido a las empresas encuestadas que indiquen sus preferencias sobre bancos para diversas operaciones. Ellas son: Cuenta corriente, Caja de ahorro, Pago de salarios, Pago de impuestos, Inversiones financieras y Cobro de facturas. A continuación se realiza el análisis de resultados a fin de tener un panorama sobre como las entidades se distribuyen a los clientes según el tipo de servicio bancario de que se trate.

\subsubsection{Cuenta corriente}

El porcentaje de empresas que poseen cuenta corriente es alto, un 93,7\% de los encuestados manifiesta tenerla. Esto refleja un alto grado de bancarización del universo en estudio dado que casi un $94 \%$ de los encuestados tienen vinculación con los bancos a partir de, al menos, una cuenta corriente.

Adicionalmente, el 93,7\% que tiene al menos una cuenta, se presenta un 38,6\% de las empresas con dos cuentas corrientes, y un $17 \%$ con tres.

El total de cuentas corrientes en la muestra alcanzó a 238 (un promedio de 1,4 cuentas corrientes considerando el total de empresas que constituyen la muestra). De ese total de cuenta corrientes; al Credicoop le correspondió la mayor proporción con un 21,3\%, le siguió el Provincia con el 19,3\% y tercero queda el Nación con $14 \%$. Le sigue Santander Río $(11,2 \%)$ y el Galicia $(10,4 \%)$. Estos cinco bancos concentran el 76,2\% del total de cuentas corrientes. El resto se reparte el $23,8 \%$ 
restante. Es importante tener en cuenta que este indicador no refleja distribución de clientes sino reparto de cuentas corrientes en el sistema.

\section{Cuadro 40: Cuenta corriente empresarial por banco}

\begin{tabular}{|l|c|c|}
\hline \multicolumn{3}{|c|}{ Banco en el que tiene cuenta corriente } \\
(totales)
\end{tabular}

Fuente: Elaboración propia en base a la información obtenida de las encuestas realizadas a las empresa.

\section{Gráfico 15}

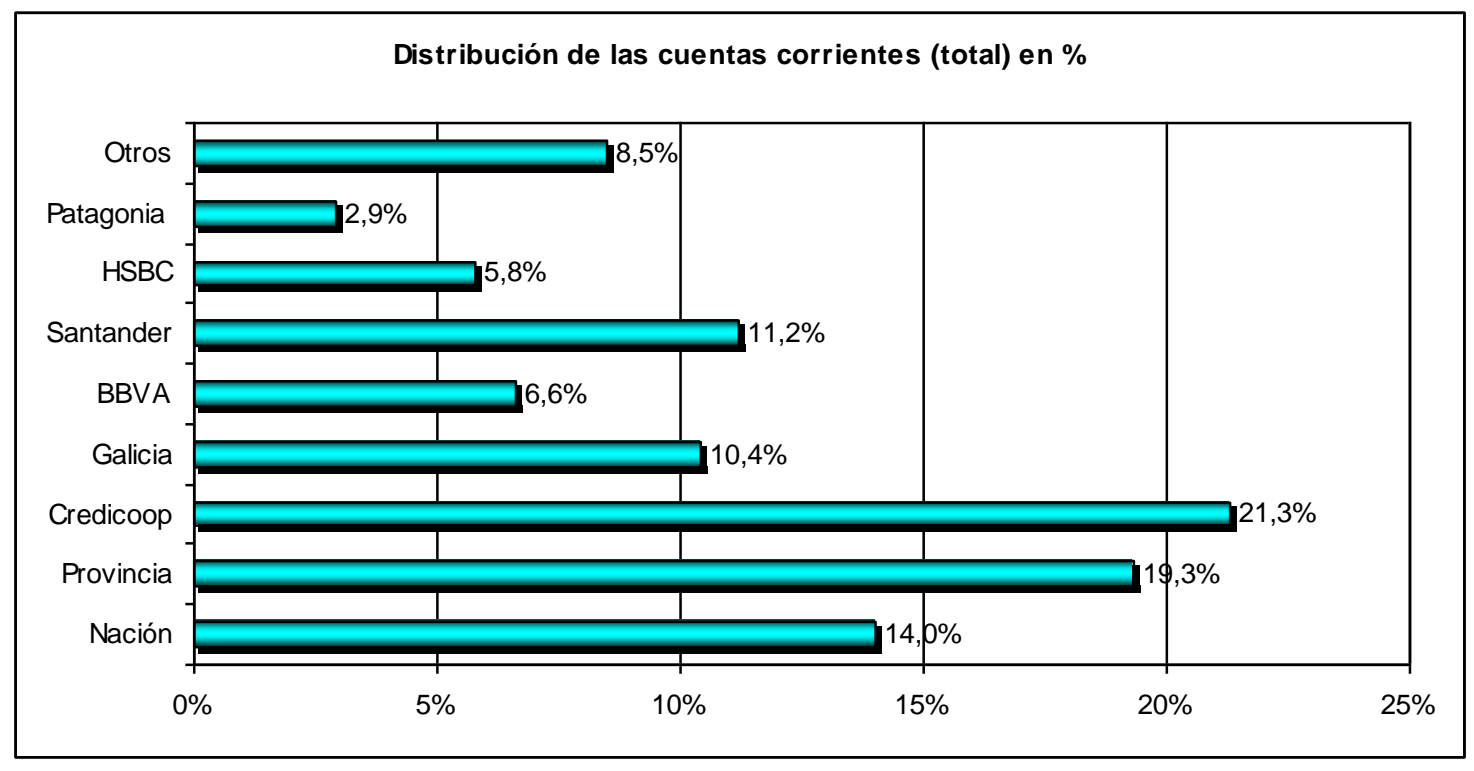

Fuente: Elaboración propia en base a la información obtenida de las encuestas realizadas a las empresa.

\subsection{2 . Caja de ahorro}

El 40,1\% de los encuestados reconoce tener una caja de ahorro. Además de los encuestados que expresaron tener una caja de ahorro, un $7,1 \%$ manifiesta tener una segunda caja de ahorro en otro banco y un $2,5 \%$ tener una tercera. 
El total de cuentas de caja de ahorro en la muestra alcanzó a 82 lo que implica que el promedio de caja de ahorro sobre la muestra total es de 0,49 por empresa. Del total, la mayor proporción le corresponde al Banco Credicoop, con el 20\% del total de las cuentas, el Banco Provincia le sigue con el 16,5\%, luego el Nación con el 13,6\%, el Galicia con 12,6\%, y el Santander Río con el $12,2 \%$. Estos cincos bancos concentran el $74,9 \%$ del total de cuentas en caja de ahorro.

\subsubsection{Plazo fijo}

Se presentó un 26,1\% de empresas con al menos un depósito a plazo fijo en el sistema bancario, entre las cuales $3,8 \%$ posee dos, y $0,8 \%$ posee tres o más.

El total de depósitos a plazo fijo en la muestra alcanzo a 69 (a un promedio de 0,42 depósitos a plazo fijo por firma, considerando el total de empresas de la muestra). De ese total, la mayor proporción correspondió al Banco Credicoop con el 22,0\% de los mismos, seguidos por el Banco Provincia y el Banco Nación, ambos con el 14,7\%. Sigue el Banco Galicia con el 12,3\% y el Banco Santander Río con el 12,0\%. Los 5 bancos concentran el 75,7\% del total de depósitos a plazo fijo.

\section{Cuadro 41: Empresas que poseen plazo fijo en los bancos}

\begin{tabular}{|l|c|}
\hline \multicolumn{1}{|c|}{ Empresas } & Porcentaje \\
\hline Tienen plazo fijo & 43 \\
No poseen plazo fijo & 122 \\
Total & 165 \\
\hline
\end{tabular}

Fuente: Elaboración propia en base a la información obtenida de las encuestas realizadas a las empresa.

Cuadro 42: Distribución de depósitos a plazo fijo por banco

\begin{tabular}{|l|c|c|c|}
\hline \multicolumn{4}{|c|}{ Distribución de los depositos a plazo fijo } \\
\hline \multicolumn{1}{|c|}{ Banco } & Frecuencia & $\begin{array}{c}\text { Porcentaje } \\
\text { por banco }\end{array}$ & $\begin{array}{c}\text { Porcentaje } \\
\text { acumulado }\end{array}$ \\
\hline Nación & 10 & $14,7 \%$ & $14,7 \%$ \\
Provincia & 10 & $14,7 \%$ & $29,4 \%$ \\
Macro & 0 & $0,3 \%$ & $29,7 \%$ \\
Credicoop & 15 & $22,0 \%$ & $51,7 \%$ \\
Galicia & 9 & $12,3 \%$ & $64,0 \%$ \\
BBVA & 4 & $6,3 \%$ & $70,3 \%$ \\
Santander & 8 & $12,0 \%$ & $82,3 \%$ \\
Itau & 1 & $1,0 \%$ & $83,3 \%$ \\
Ciudad & 0 & $0,3 \%$ & $83,6 \%$ \\
HSBC & 3 & $4,0 \%$ & $87,6 \%$ \\
Patagonia & 1 & $2,0 \%$ & $89,6 \%$ \\
Superville & 2 & $2,3 \%$ & $91,9 \%$ \\
Standard & 1 & $2,0 \%$ & $93,9 \%$ \\
Citibank & 1 & $1,0 \%$ & $94,9 \%$ \\
Comafi & 2 & $2,7 \%$ & $97,6 \%$ \\
Otros & 2 & $2,3 \%$ & $100 \%$ \\
Total & 69 & $100 \%$ & \\
Perdidos & 104 & & \\
\hline Total & 173 & $100 \%$ & \\
\hline
\end{tabular}




\subsubsection{Pago de salarios}

El 70,6\% de las firmas realiza pago de salarios por intermedio de al menos un banco, entre las cuales $11,8 \%$ en dos y $2,9 \%$ por intermedio de tres.

El total de servicios de pago de salarios en la muestra alcanza un 140 (un promedio de 0,85 por empresa, considerando al total de la muestra).

De ese total, la mayor proporción correspondió al Banco Credicoop con 24,2\% de los mismos, seguido por el Banco Provincia con 16,6\%, el Banco Galicia con el 12,2\%, el Banco Nación con 10,8\% y el Banco Santander Río con 10,7\%. Estos 5 bancos concentran el 74,5\% del total de estos servicios.

\section{Cuadro 43: Bancos que utilizan las empresas para pagar los salarios}

\begin{tabular}{|l|c|c|c|}
\hline \multicolumn{4}{|c|}{ Banco en el que realizó pago de salarios } \\
\hline \multicolumn{1}{|c|}{ Banco } & Frecuencia & $\begin{array}{c}\text { Porcentaje } \\
\text { por banco }\end{array}$ & $\begin{array}{c}\text { Porcentaje } \\
\text { acumulado }\end{array}$ \\
\hline Nación & 15 & $10,8 \%$ & $10,8 \%$ \\
Provincia & 23 & $16,6 \%$ & $27,4 \%$ \\
Macro & 1 & $0,4 \%$ & $27,8 \%$ \\
Credicoop & 34 & $24,2 \%$ & $52,0 \%$ \\
Galicia & 17 & $12,2 \%$ & $64,2 \%$ \\
BBVA & 10 & $7,0 \%$ & $71,2 \%$ \\
Santander & 15 & $10,7 \%$ & $81,9 \%$ \\
Itau & 1 & $0,6 \%$ & $82,5 \%$ \\
Ciudad & 0 & $0,2 \%$ & $82,7 \%$ \\
HSBC & 8 & $5,9 \%$ & $88,6 \%$ \\
Patagonia & 4 & $3,2 \%$ & $91,8 \%$ \\
Superville & 3 & $1,9 \%$ & $93,7 \%$ \\
Standard & 3 & $2,2 \%$ & $95,9 \%$ \\
Citibank & 1 & $0,6 \%$ & $96,5 \%$ \\
Comafi & 3 & $2,4 \%$ & $98,9 \%$ \\
Otros & 2 & $1,1 \%$ & $100 \%$ \\
Total & 140 & $100 \%$ & \\
Perdidos & 49 & & \\
\hline Total & 189 & $100 \%$ & \\
\hline
\end{tabular}

\subsection{5 . Pago de Impuestos}

El 67,3\% de la firmas declara pagar impuestos por medio de al menos un banco, entre las cuales $14,6 \%$ a través de dos y $3,3 \%$ por medio de tres.

Total de servicios de pago de impuestos en la muestra alcanzó a 140 (a un promedio de 0,85 servicios por empresas, considerando al total de las empresas de la muestra). De ese total, la mayor proporción correspondió al Banco Provincia con 24,2\% de los mismos, seguidos por el Banco Credicoop con el 21,7\%, el Banco Nación con el 13,6\%, el Banco Galicia con el 11\% y finalmente 
el Banco Santander Río con 8,6\%. Estos cinco bancos concentran el 79,1\% del total de estos servicios.

\section{Cuadro 44: Bancos que utilizan las empresas para pagar sus impuestos}

\begin{tabular}{|l|c|c|c|}
\hline \multicolumn{4}{|c|}{ Banco en el que paga impuestos } \\
\hline \multicolumn{1}{|c|}{ Banco } & Frecuencia & $\begin{array}{c}\text { Porcentaje } \\
\text { por banco }\end{array}$ & $\begin{array}{c}\text { Porcentaje } \\
\text { acumulado }\end{array}$ \\
\hline Nación & 19 & $13,6 \%$ & $13,6 \%$ \\
Provincia & 34 & $24,2 \%$ & $37,8 \%$ \\
Macro & 1 & $0,4 \%$ & $38,2 \%$ \\
Credicoop & 30 & $21,7 \%$ & $59,9 \%$ \\
Galicia & 15 & $11,0 \%$ & $70,9 \%$ \\
BBVA & 9 & $6,1 \%$ & $77,0 \%$ \\
Santander & 12 & $8,6 \%$ & $85,6 \%$ \\
Itau & 1 & $0,8 \%$ & $86,4 \%$ \\
Ciudad & 1 & $0,4 \%$ & $86,8 \%$ \\
HSBC & 7 & $4,7 \%$ & $91,5 \%$ \\
Patagonia & 3 & $2,3 \%$ & $93,8 \%$ \\
Superville & 2 & $1,2 \%$ & $95,0 \%$ \\
Standard & 2 & $1,7 \%$ & $96,7 \%$ \\
Citibank & 1 & $0,7 \%$ & $97,4 \%$ \\
Comafi & 2 & $1,7 \%$ & $99,1 \%$ \\
Otros & 1 & $1,0 \%$ & $100 \%$ \\
Total & 140 & $100 \%$ & \\
Perdidos & 54 & & \\
\hline Total & 194 & $100 \%$ & \\
\hline
\end{tabular}

Fuente: Elaboración propia en base a la información obtenida de las encuestas realizadas a las empresa.

\subsubsection{Inversiones financieras}

El 23,9\% de las firmas declaró estar realizando inversiones financieras en al manos un banco, $3,5 \%$ en dos y $0,5 \%$ en tres.

El total de inversiones en la muestra alcanzó a 46 (a un promedio de 0,28 inversiones por empresa, considerando al total de empresas de la muestra). De ese total, la mayor proporción correspondió al Banco Credicoop con 23,5\% de los mismos, seguido por el Banco Provincia con 21,0\%, el Banco Nación con 11,4\%, el Banco Galicia y finalmente el Santander Río con 9,9\%. Estos cincos bancos concentran el 77,2\% del total de inversiones financieras en la muestra. 
Cuadro 45: Bancos que utilizan las empresas para realizar inversiones financieras

\begin{tabular}{|l|c|c|c|}
\hline \multicolumn{3}{|c|}{ Banco en el que realizan inversiones financieras } \\
\hline \multicolumn{1}{|c|}{ Banco } & Frecuencia & $\begin{array}{c}\text { Porcentaje } \\
\text { por banco }\end{array}$ & $\begin{array}{c}\text { Porcentaje } \\
\text { acumulado }\end{array}$ \\
\hline Nación & 16 & $11,4 \%$ & $11,4 \%$ \\
Provincia & 30 & $21,0 \%$ & $32,4 \%$ \\
Macro & 0 & $0,0 \%$ & $32,4 \%$ \\
Credicoop & 33 & $23,5 \%$ & $55,9 \%$ \\
Galicia & 16 & $11,4 \%$ & $67,3 \%$ \\
BBVA & 10 & $7,0 \%$ & $74,3 \%$ \\
Santander & 14 & $9,9 \%$ & $84,2 \%$ \\
Itau & 2 & $1,5 \%$ & $85,7 \%$ \\
Ciudad & 1 & $0,4 \%$ & $86,1 \%$ \\
HSBC & 7 & $5,1 \%$ & $91,2 \%$ \\
Patagonia & 1 & $0,7 \%$ & $91,9 \%$ \\
Superville & 3 & $1,8 \%$ & $93,7 \%$ \\
Standard & 4 & $2,6 \%$ & $96,3 \%$ \\
Citibank & 2 & $1,1 \%$ & $97,4 \%$ \\
Comafi & 2 & $1,1 \%$ & $98,5 \%$ \\
Otros & 2 & $1,5 \%$ & $100 \%$ \\
Total & 46 & $100 \%$ & \\
Perdidos & 125 & \multicolumn{3}{|c|}{$100 \%$} & \\
\hline Total & 171 & 1009 & \\
\hline
\end{tabular}

\subsubsection{Cobro de facturas}

El 26,8\% de las firmas realiza cobros de facturas por intermedio de al menos un banco, entre las cuales $4,6 \%$ las cobra por medio de dos y $1,1 \%$ de tres.

El total de servicios de cobro de facturas en la muestra alcanzó a 59 (a un promedio de 0,36 por empresa, considerando al total de empresas de la muestra). De este total, la mayor proporción correspondió al Banco Credicoop con el 22,1\% de los mismos, seguido por el Banco Provincia con 20,2\%, el Banco Nación con el 12,6\%, el Banco Galicia con el 11,4\% y Santander Río con 11,0\%. Estos cinco bancos concentran el 77,3\% del total de estos servicios. 
Cuadro 46: Bancos que utilizan las empresas para realizar cobros de facturas

\begin{tabular}{|c|c|c|c|}
\hline \multicolumn{4}{|c|}{ Banco en el que realizan el cobro de facturas } \\
\hline Banco & Frecuencia & $\begin{array}{l}\text { Porcentaje } \\
\text { por banco }\end{array}$ & $\begin{array}{l}\text { Porcentaje } \\
\text { acumulado }\end{array}$ \\
\hline Nación & 18 & $12,6 \%$ & $12,6 \%$ \\
\hline Provincia & 28 & $20,2 \%$ & $32,8 \%$ \\
\hline Macro & 0 & $0,3 \%$ & $33,1 \%$ \\
\hline Credicoop & 31 & $22,1 \%$ & $55,2 \%$ \\
\hline Galicia & 16 & $11,4 \%$ & $66,6 \%$ \\
\hline BBVA & 8 & $5,7 \%$ & $72,3 \%$ \\
\hline Santander & 15 & $11,0 \%$ & $83,3 \%$ \\
\hline Itau & 1 & $0,6 \%$ & $83,9 \%$ \\
\hline Ciudad & 1 & $0,6 \%$ & $84,5 \%$ \\
\hline HSBC & 7 & $5,0 \%$ & $89,5 \%$ \\
\hline Patagonia & 1 & $0,9 \%$ & $90,4 \%$ \\
\hline Superville & 3 & $2,2 \%$ & $92,6 \%$ \\
\hline Standard & 3 & $2,2 \%$ & $94,8 \%$ \\
\hline Citibank & 3 & $2,2 \%$ & $97,0 \%$ \\
\hline Comafi & 1 & $0,9 \%$ & $97,9 \%$ \\
\hline Otros & 3 & $1,9 \%$ & $100 \%$ \\
\hline Total & 59 & $100 \%$ & \\
\hline Perdidos & 133 & & \\
\hline Total & 192 & $100 \%$ & \\
\hline
\end{tabular}

\subsection{Preferencias generales respecto a los bancos que operan en la región bajo estudio}

Preguntadas las empresas sobre tres bancos con los cuales preferirían trabajar en términos generales (pregunta 18), un $92,2 \%$ se avino a responder sobre su preferencia por un solo banco, $74 \%$ de la muestra eligió dos bancos y solo $51,7 \%$ indicó tres bancos.

Cabe consignar que las firmas citaron 15 bancos diferentes en esa consulta. No obstante ello, el grupo de los bancos que concitaron mayor preferencia entre las firmas encuestadas se componen de siete entidades: BBVA, Credicoop, Galicia, HSBC, Nación, Santander Río y Banco Provincia. Este grupo concentró cerca del $90 \%$ de las preferencias, tanto cuando se mencionaba al banco de mayor preferencia como al de segunda o tercera preferencia. Por lo tanto, el análisis se concentrará con lo que ocurre con estos bancos.

Como el banco de mayor preferencia, el 24,6\% eligió al Banco Credicoop, seguido por el Banco Nación con el 15,6\%, el Banco Provincia con el 14,7\%, el Banco Galicia con el 11,9\% y el Banco Santander Río con el 11,7\%.

Se observa así, una concentración significativa de las preferencias, ya que los 5 bancos concentran $78,6 \%$ del total de las respuestas.

Como segundo banco de preferencia, 21,9\% de los respondientes eligió al Banco Provincia, 14,3\% al Banco Credicoop y 13,4\% al Banco Santander Río.

Como banco en tercer lugar de preferencia, un 17,7\% señaló al Banco Provincia, 14,3\% al Banco Santander Río y un 12,9\% al Banco Nación. 
El banco mejor posicionado es el Banco Credicoop, por ser el banco elegido en el primer lugar y además por su alta representatividad como segundo y como tercer banco preferido. El Banco Nación se ubica como el segundo banco preferido $(15,6 \%)$ y el Banco Provincia cae al tercer puesto de preferencia con un 14,7\%. Puede señalarse que el Banco Provincia es elegido con amplitud en el primer puesto como segundo banco de preferencia.

Adicionalmente, si se suman los porcentajes acumulados para el primer y segundo puesto de preferencias para el Banco Nación (14,4\%), se observa que su total es inferior al acumulado por el Banco Provincia (17,8\%).

Cuadro 47: Ranking de bancos en función de preferencias generales

\begin{tabular}{|l|c|c|c|c|c|c|}
\hline \multicolumn{7}{|c|}{ Banco de preferencia $\mathbf{1}^{\circ}, \mathbf{2}^{\circ} \mathbf{y} \mathbf{3}^{\circ}$} \\
\hline Banco & $\begin{array}{c}\text { Porcentaje } \\
\text { Banco I }\end{array}$ & Orden & $\begin{array}{c}\text { Porcentaje } \\
\text { Banco II }\end{array}$ & Orden & $\begin{array}{c}\text { Porcentaje } \\
\text { Banco III }\end{array}$ & Orden \\
\hline Nación & $15,57 \%$ & 2 & $13,09 \%$ & 3 & $12,90 \%$ & 3 \\
Provincia & $14,71 \%$ & 3 & $21,90 \%$ & 1 & $17,66 \%$ & 1 \\
Credicoop & $24,63 \%$ & 1 & $14,33 \%$ & 2 & $11,71 \%$ & 4 \\
Galicia & $11,94 \%$ & 4 & $11,16 \%$ & 5 & $11,31 \%$ & 5 \\
Santander & $11,73 \%$ & 5 & $13,36 \%$ & 4 & $14,29 \%$ & 2 \\
\hline Total & $96,21 \%$ & & $74,46 \%$ & & $51,69 \%$ & \\
Perdidos & $3,79 \%$ & & $25,54 \%$ & & $48,31 \%$ & \\
\hline
\end{tabular}

Fuente: Elaboración propia en base a la información obtenida de las encuestas realizadas a las empresa.

\subsection{Calificaciones obtenidas por los bancos}

Se observa que el banco mejor posicionado en la mente de los encuestados (Preguntas 19 y 20) se lleva, en términos generales, las mejores calificaciones en todos los aspectos evaluados.

Como las evaluaciones no procedieron a realizarse mediante provisión de información concerniente, las calificaciones tienden a señalar evaluaciones teñidas de mucha subjetividad. Al incluirse en la muestra aspectos muy concretos (niveles de tasa de interés, plazo de los créditos, etc.) esta subjetividad queda expuesta con mayor fuerza.

Las calificaciones se realizaron en una escala de uno a cinco puntos, siendo cinco el valor más positivo.

Para estudiar las calificaciones en forma comparativa se procedió a efectuar el siguiente procedimiento. Primero se obtuvo para cada banco su calificación promedio ponderada: para ello se ponderó cada nota obtenida ( 1 a 5) por el porcentaje de empresas que le había colocado esa nota a ese banco. Luego, el resultado obtenido fue ponderado por el porcentaje de empresas que calificó a ese banco sobre el total de empresas calificadoras del aspecto evaluado).

Este procedimiento fue efectuado para cada uno de los aspectos evaluados en las preguntas $19 \mathrm{y}$ 20. De este modo se construyó una nota ponderada como indicador comparable entre bancos cuyo rango está entre 0 y 1 , siendo el valor más cercano a 1 el más alto. 


\begin{tabular}{|c|c|c|c|c|c|c|c|}
\hline \multicolumn{8}{|c|}{ Ejemplo: Tasa de interes } \\
\hline & \multicolumn{6}{|l|}{ Notas (a) } & \\
\hline Banco Provincia & 1 & 2 & 3 & 4 & 5 & Total & Empresas \\
\hline $\begin{array}{l}\text { Porcentual de } \\
\text { calificaiones (b) }\end{array}$ & $17,10 \%$ & $12,20 \%$ & $35,40 \%$ & $17,10 \%$ & $18,30 \%$ & $100 \%$ & 14 \\
\hline \multicolumn{6}{|c|}{ Nota promedio ponderada $\mathrm{I}: \Sigma\left(\mathrm{a}{ }^{*} \mathrm{~b}\right)$ de 1 a 5} & \multicolumn{2}{|c|}{$3,07 \%(c)$} \\
\hline $\begin{array}{l}\text { Porcentaje de } \\
\text { empresas } \\
\text { calificadoras (d) }\end{array}$ & $2,40 \%$ & $1,70 \%$ & $5,00 \%$ & $2,40 \%$ & $2,60 \%$ & $14,1 \%$ & 98 \\
\hline \multicolumn{6}{|c|}{ Nota promedio ponderada I : $\Sigma\left(c^{*} d\right)$} & \multicolumn{2}{|c|}{$0,43 \%$} \\
\hline
\end{tabular}

Fuente: Elaboración propia en base a la información obtenida de las encuestas realizadas a las empresa.

Cuando los bancos son citados como primera preferencia, el banco cómodamente mejor calificado en cuanto a los plazos de los créditos ofrecidos es el Banco Credicoop. En ese caso, su nota promedio ponderada por el total de los observadores es de 0,93. Le sigue el Banco Galicia y el Banco Nación ambos con 0,45 y, el tercer lugar, el Banco Provincia con 0,40.

Cuando se mira los puntajes otorgados a los bancos de segunda preferencia, en esta evaluación de los plazos para créditos ofrecidos, el panorama se mantiene. En primer término queda el Banco Credicoop, le sigue el Galicia y el Nación en segundo puesto compartido y en tercer lugar el Banco Provincia.

En la evaluación de la adecuación de la operatoria del banco a las necesidades de la PyME, cuando se trató del banco de primera preferencia, nuevamente el Credicoop se lleva el primer puesto y con gran margen, su nota promedio ponderada es 1,0. Le sigue el banco Galicia con 0,48. En tercera posición se encuentra el Banco Nación con 0,44 y le sigue muy de cerca el Banco Provincia, cuarto lugar, 0,43.

En esta calificación de los bancos y para la segunda preferencia de los mismos, el Banco Credicoop continúa liderando, le sigue el Banco Nación y a éste, el Banco Provincia.

Los puntajes por disponibilidad de gerentes con actitud activa para los bancos de primera opción colocan nuevamente al Banco Credicoop en el primer puesto lejos del resto. Este obtuvo una nota promedio ponderada de 1,08. Le sigue el Banco Galicia con 0,51 y el Banco Nación con 0,45 .

Cuando se calificaron bancos electos en segunda opción, en cuanto aquel aspecto, el panorama cambia un poco. Continua liderando el grupo el Banco Credicoop, le sigue el Banco Nación y el Provincia sube al tercer lugar.

La capacidad de decisión de los oficiales de cuenta finaliza la evaluación de aspectos que marcan diferencias entre bancos según los puntajes obtenidos y en el criterio de quienes evaluaron a los bancos. La puntuación de la capacidad de decisión de los oficiales de cuenta para el banco de primera opción, otorgó nuevamente al Credicoop la nota más alta. En este caso, su nota promedio ponderado resulto $1,02 \%$. Le sigue el Galicia con 0,47 y el Provincia con 0,44.

En los bancos de segunda opción las calificaciones volvieron a provocar cambios en el orden de los resultados, pero no varió el mejor calificado. Continúa el Credicoop en el primer puesto, el Nación en el segundo lugar y el Provincia en el tercero.

Finalmente en cuanto a la evaluación de la tasa de interés que concede cada banco, cuando este es elegido como primera preferencia, nuevamente resulta el Banco Credicoop el de mejor desempeño. En efecto, el Credicoop resultó con una nota promedio ponderada de 0,85. Le sigue el Banco 
Nación con 0,50. En tercer lugar se presenta el Banco Provincia, el cual obtuvo una puntuación ponderada de 0,44 .

Asimismo, en la evaluación de aquel aspecto y como banco de segunda preferencia, el Credicoop y el Nación mantienen el primer y segundo lugar, pero en esta comparación es seguido por el Galicia en tercer lugar. En este caso, el Banco Provincia ocupa el cuarto lugar.

\subsection{Relación entre tasas de interés de un crédito y agilidad en su otorgamiento}

Se preguntó a las empresas sobre "¿Cuántos puntos adicionales en las tasas de interés valdría para usted la obtención de un crédito que le asegure sencillez de tramitación y rapidez en el otorgamiento?" (Pregunta 21).

La distribución de las respuestas indicó baja predisposición a aceptar tasas de interés mayores, ya que el 51,8\% de las firmas respondió "cero" a la pregunta en cuanto a los créditos para capital de trabajo. La misma respuesta abarcó a 53,9\% de las empresas en el caso de créditos para inversión.

Respondió su disposición a pagar un punto porcentual más de tasa de interés el 12,9\% de las firmas respecto de créditos para capital de trabajo y el 12,3\% para créditos para inversión. Así mismo pagarían dos puntos adicionales el $19,4 \%$ y el $17,4 \%$ respectivamente.

Un escaso porcentual de los encuestados se mostró dispuesto a pagar más de dos puntos porcentuales adicionales.

Cuadro 48 y 49: Relación de tasa de interés de un crédito y velocidad de su otorgamiento

\begin{tabular}{|c|c|c|c|c|c|c|c|}
\hline \multicolumn{4}{|c|}{$\begin{array}{l}\text { Puntos de tasa de interés por un crédito agil para capital de } \\
\text { trabajo }\end{array}$} & \multicolumn{4}{|c|}{$\begin{array}{l}\text { Puntos de tasa de interés por un crédito agil para capital de } \\
\text { inversión }\end{array}$} \\
\hline & Frecuencia & Porcentaje & $\begin{array}{l}\text { Porcentaje } \\
\text { acumulado }\end{array}$ & & Frecuencia & Porcentaje & $\begin{array}{l}\text { Porcentaje } \\
\text { acumulado }\end{array}$ \\
\hline Validos: & & & & Validos: & & & \\
\hline 0 & 84 & $52,8 \%$ & $52,8 \%$ & 0 & 86 & $53,9 \%$ & $53,9 \%$ \\
\hline 1 & 21 & $12,9 \%$ & $65,7 \%$ & 1 & 20 & $12,3 \%$ & $66,2 \%$ \\
\hline 2 & 31 & $19,4 \%$ & $85,1 \%$ & 2 & 28 & $17,4 \%$ & $83,6 \%$ \\
\hline 3 & 10 & $6,5 \%$ & $91,6 \%$ & 3 & 13 & $8,0 \%$ & $91,6 \%$ \\
\hline 4 & 5 & $3,1 \%$ & $94,7 \%$ & 4 & 5 & $3,2 \%$ & $94,8 \%$ \\
\hline Más de 4 & 7 & $4,3 \%$ & $99,0 \%$ & Más de 4 & 6 & $3,9 \%$ & $98,7 \%$ \\
\hline $\mathrm{Ns} / \mathrm{Nc}$ & 2 & $1,0 \%$ & $100,0 \%$ & $\mathrm{Ns} / \mathrm{Nc}$ & 2 & $1,2 \%$ & $100 \%$ \\
\hline Total & 160 & $100,0 \%$ & & Total & 159 & $100 \%$ & \\
\hline Perdidos & 5 & & & Perdidos & 6 & & \\
\hline Total & 165 & $100 \%$ & $100 \%$ & Total & 165 & $100 \%$ & $100 \%$ \\
\hline
\end{tabular}




\subsection{Nivel de conocimiento de líneas crediticias especiales disponibles en la Provincia}

Un 34,3\% de los encuestados manifestaron conocer la línea de crédito de fomento disponible en la provincia (pregunta 22).

La más conocida es préstamos a PyMEs con fondos del ANSES. La cual es conocida por el 19,6\% de la muestra. Fuerza PyME es conocida por el 18,7\%, Fuerza productiva por el $16,1 \%$ y un $7,0 \%$ manifestó conocer otras líneas especiales.

\section{Gráfico 16}

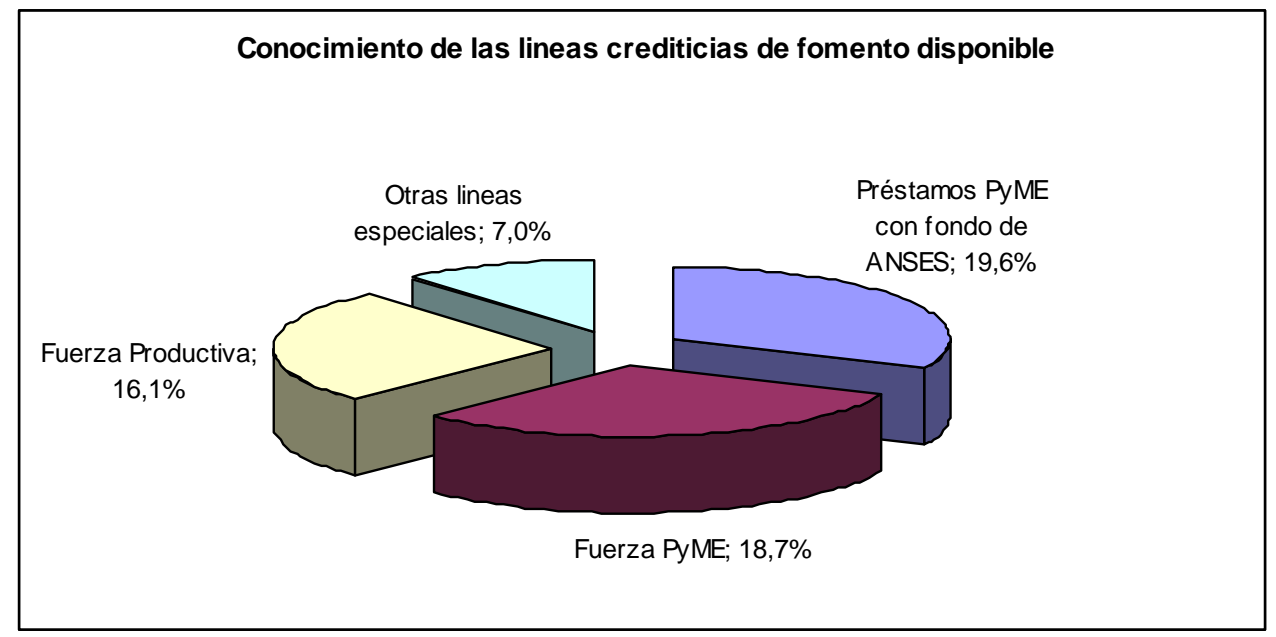

Fuente: Elaboración propia en base a la información obtenida de las encuestas realizadas a las empresa.

La forma más señalada del acceso a la información fueron los medios masivos de comunicación ya que un $29,8 \%$ de quienes respondieron dijo haberse notificado por ese medio. Le sigue la notificación por promotores del banco con $16,3 \%$. En tercer lugar se ubica la notificación por el sitio Web con el $13,9 \%$.

Quienes se informaron haber preguntado en el banco alcanzaron a presentar el $12,7 \%$ de los que contestaron y quienes dicen haberse informado por correo del banco a la empresa fueron el $12,4 \%$. Estas formas de comunicación suman $85,1 \%$ de los medios indicados. 
Gráfico 17

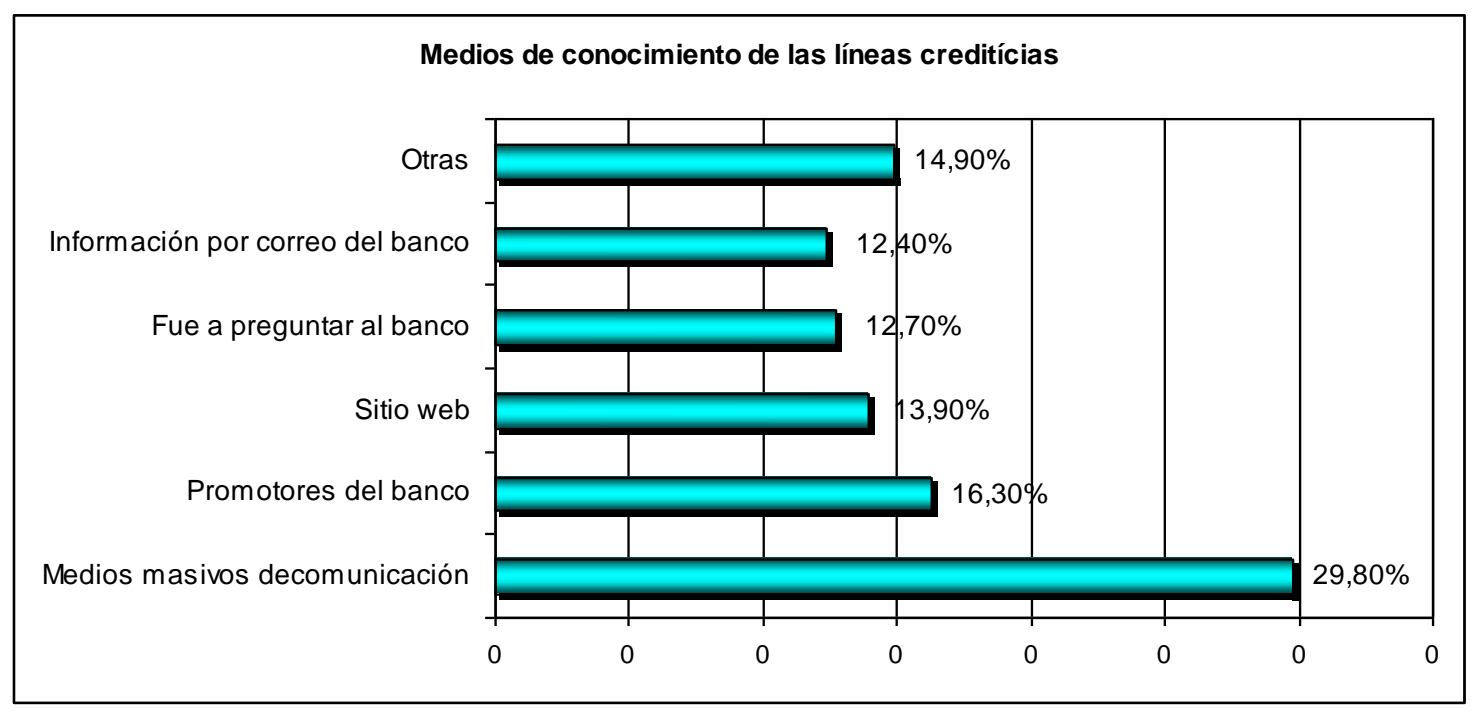

Fuente: Elaboración propia en base a la información obtenida de las encuestas realizadas a las empresa.

\subsection{Evaluación de las líneas de fomentos disponibles}

El $86 \%$ de las firmas que tomaron las líneas de fomento indicadas se avinieron a calificarlas en puntos de uno a diez (pregunta 22.d), pero su frecuencia (7 firmas, o sea 4,2\% de la muestra) no permite realizar valoraciones estadísticamente confiables de las calificaciones que propusieron.

No obstante la consideración anterior y a título informativo, se confeccionó un cuadro de resultados a esa pregunta mediante la metodología de ponderación cada nota por el porcentaje de empresas que asigno notas a cada concepto, de una línea en particular, y luego se obtuvo una nota promedio para cada concepto, ponderando la nota promedio de cada línea por la proporción de empresas que calificaron a esa línea.

Como una aproximación general a la percepción de cada línea por parte de las empresas, obtuvo promedio simple de todos los aspectos para cada línea. Se aprecia que la línea de préstamos PyMEs de ANSES posee una calificación algo superior a las otras dos líneas, muy parejas éstas entre sí.

Cuadro 50: Líneas crediticias otorgadas por la Provincia de Buenos Aires

\begin{tabular}{|l|c|c|c|c|}
\hline & $\begin{array}{c}\text { Fuerza } \\
\text { Productiva }\end{array}$ & $\begin{array}{c}\text { Préstamos } \\
\text { PyMEs } \\
\text { ANSES }\end{array}$ & Fuerza PyME & $\begin{array}{c}\text { Nota } \\
\text { ponderada } \\
\text { del aspecto }\end{array}$ \\
\hline Tasa de interés & $5,6 \%$ & $7,6 \%$ & $7,2 \%$ & $7,21 \%$ \\
Plazo de amortización & $5,6 \%$ & $6,2 \%$ & $6,0 \%$ & $6,06 \%$ \\
Período de gracia & $2,5 \%$ & $2,5 \%$ & $3,4 \%$ & $2,71 \%$ \\
Requisitos & $6,4 \%$ & $7,0 \%$ & $4,2 \%$ & $6,18 \%$ \\
Tardanza & $6,3 \%$ & $7,1 \%$ & $4,2 \%$ & $6,23 \%$ \\
\hline Promedio simple & $5,3 \%$ & $6,1 \%$ & $5,0 \%$ & \\
\hline Empresas tomadoras que calificaron & 1 & 4 & 2 & 7 \\
\hline
\end{tabular}

Fuente: Elaboración propia en base a la información obtenida de las encuestas realizadas a las empresa. 


\subsection{Evaluación de los resultados sobre situación actual de las empresas y expectativas de corto plazo}

\section{Resultados Generales}

\subsection{1 . Demanda}

El 56\% de la muestra calificó a su situación como desfavorable. Para el 29,4\% de los encuestados la situación se presentó normal y en el $14,4 \%$ de los casos la situación resulta favorable (pregunta 23. a).

Entre quienes cuantificaron la variación negativa de su demanda para el primer cuatrimestre de 2010 respecto al mismo período del 2009 (72\% de la muestra) (pregunta 23.b), 33\% (de quienes indicaron una variación) manifestó que se redujo entre 20 y 40\%, 20,6\% que se redujo entre 45 y $65 \%$ y $19,0 \%$ que la caída fue hasta el $20 \%$. Sólo un 5,6\% manifestó que la caída supero el $65 \%$ interanual.

Quienes indicaron una suba de su demanda (10\% de la muestra), 6,8\% (de los casos con indicación de variación) indicó que resultó hasta un $20 \%$ superior a la del primer cuatrimestre de 2009 y un $4,7 \%$ de estos que fue superior al $20 \%$.

En cuanto a las expectativas sobre la demanda para el segundo semestre de 2010 en comparación con el mismo período de 2009 (pregunta 24.a), el 33,4\% de la muestra no espera cambios, el $26,4 \%$ espera una disminución de su demanda y el 2,6\% espera que disminuya fuertemente. Por otra parte, $21,2 \%$ espera que su demanda aumente.

Cuadro 51: Estimación del nivel de demanda de producto para el segundo trimestre de 2010 con relación al 2009

\begin{tabular}{|l|c|c|c|}
\hline \multicolumn{3}{|c|}{$\begin{array}{c}\text { Estimación del nivel de demanda de productos para el } \mathbf{2}^{\circ} \text { semestre de 2010, } \\
\text { con relación al mismo período de 2009 }\end{array}$} \\
\hline & Frecuencia & Porcentaje & $\begin{array}{c}\text { Porcentaje } \\
\text { acumulado }\end{array}$ \\
\hline Válidos: & 1 & & \\
Aumentará fuertemente & 35 & $21,2 \%$ & $21,5 \%$ \\
Aumentará & 55 & $33,4 \%$ & $54,9 \%$ \\
No tendrá cambios & 43 & $26,4 \%$ & $81,3 \%$ \\
Disminuirá & 4 & $2,6 \%$ & $83,9 \%$ \\
Disminuirá fuertemente & 26 & $16,0 \%$ & $100 \%$ \\
Ns/Nc & 164 & $100 \%$ & \\
Total & 1 & & $100 \%$ \\
Perdidos & 165 & $100 \%$ & $100 \%$ \\
\hline Total & & & \\
\hline
\end{tabular}

Fuente: Elaboración propia en base a la información obtenida de las encuestas realizadas a las empresa.

Entre quienes esperan una disminución (72,4\% de la muestra), el 26,2\% (de quienes expresaron variaciones) esperan que la caída sea entre el 0 y $20 \%$, en tanto que un $23,9 \%$ espera que la merma se ubique entre el 25 y $45 \%$, un 12,1\% espera que la disminución sea mayor al $50 \%$. 
Entre los que esperan un aumento, un $11,8 \%$ (de quienes manifestaron que habrá un cambio) prevé que este se ubique entre el 10 y el $30 \%$, otro $11,8 \%$ espera que la mejora sea inferior al $10 \%$. Solo el $5,5 \%$ de quienes esperan variaciones creen que la mejora será superior al $30 \%$.

Cabe señalar que al evaluar en forma conjunta la situación actual con las expectativas, el deterioro en la demanda alcanza un mayor nivel e involucra al 44,7\% de los encuestados. Ello puesto que al $15,8 \%$ que la considera actualmente desfavorable y seguirá igual, se añade quienes se encuentran en situación desfavorable y consideran que empeoraran $(17,7 \%)$ o empeorará fuertemente $(2,0 \%)$; quien estima que su demanda normal empeorará $(6,2 \%)$ o empeorará fuertemente $(0,4 \%)$ y quienes manifiestan estar con demanda favorable pero que esta disminuirá $(2,4 \%)$ o disminuirá fuertemente $(0,2 \%)$.

La condición estable alcanza al 12,7\%, conformados por quienes están en situación normal y no esperan cambios. Por su parte el optimismo acompaña al 26,4\% de los encuestados, conformado por el $17 \%$ que se encuentra en situación normal, favorable o muy favorable y esperan que su demanda mejore, y 9,4\% corresponden a quienes piensan que su demanda actual es desfavorable o muy desfavorable y mejorará.

Finalmente un 16,0\% de la muestra no puede indicar ninguna previsión para el segundo semestre y el 55,0\% no pudo cuantificar su previsión.

\subsection{2 . Estimaciones de las inversiones para el segundo semestre de 2010 con relación al mismo período de 2009}

El 50,2\% de los encuestados manifestó que no vislumbra cambios en los niveles de inversión, en perspectivas de las inversiones en el segundo semestre del año pasado (pregunta 25). No obstante ello, una porción significativa creen que éstas disminuirán o disminuirán fuertemente $(25,5 \%)$ mientas que el $16 \%$ estima que aumentará sus inversiones. Un 8,4\% no pudo estimar cómo evolucionarán sus inversiones.

Cuadro 52: Estimación de la inversión para el segundo trimestre de 2010 con relación al 2009

\begin{tabular}{|l|c|c|c|}
\hline \multicolumn{3}{|c|}{$\begin{array}{c}\text { Estimación de la evolución de las inversiones para el } \\
\text { relación al mismo período de 2009 }\end{array}$} \\
\hline & Frecuencia & Porcentaje & $\begin{array}{c}\text { Porcentaje } \\
\text { acumulado }\end{array}$ \\
\hline Válidos: & & & \\
Aumentará fuertemente & 1 & $0,6 \%$ & $0,6 \%$ \\
Aumentará & 25 & $15,4 \%$ & $16,0 \%$ \\
No tendrá cambios & 82 & $50,2 \%$ & $66,2 \%$ \\
Disminuirá & 33 & $20,0 \%$ & $86,2 \%$ \\
Disminuirá fuertemente & 9 & $5,5 \%$ & $91,7 \%$ \\
Ns/Nc & 14 & $8,4 \%$ & $100 \%$ \\
Total & 164 & $100 \%$ & \\
Perdidos & 1 & & $100 \%$ \\
\hline Total & 165 & $100 \%$ & 100 , con \\
\hline
\end{tabular}

Fuente: Elaboración propia en base a la información obtenida de las encuestas realizadas a las empresa 


\subsection{3 . Situación Financiera}

Con respecto a su situación financiera actual (pregunta 26.a) 51,3\% de la muestra la calificó como normal, $30,7 \%$ como desfavorable y $2,3 \%$ como muy desfavorable, en tanto que un $15 \%$ la consideró como favorable.

Un 45,8\% de la muestra expresa expectativas de mantener igual su situación financiera en el segundo trimestre del 2010 con relación al mismo periodo del 2009, el 22,4\% espera que empeore y $2,1 \%$ que empeore mucho. Solo el 16,6\% espera que su situación financiera mejore.

\section{Cuadro 53: Estimación de la situación financiera para el segundo trimestre de 2010 con relación al 2009}

\begin{tabular}{|c|c|c|c|}
\hline \multicolumn{4}{|c|}{$\begin{array}{l}\text { Estimación de la situación financiera para el } 2^{\circ} \text { semestre de } 2010 \text {, con relación } \\
\qquad \text { al mismo período de } 2009\end{array}$} \\
\hline & Frecuencia & Porcentaje & $\begin{array}{l}\text { Porcentaje } \\
\text { acumulado }\end{array}$ \\
\hline Válidos: & & & \\
\hline Mejorará significativamente & 0 & $0,3 \%$ & $0,3 \%$ \\
\hline Mejorará & 27 & $16,6 \%$ & $16,9 \%$ \\
\hline Se mantendrá igual & 75 & $45,8 \%$ & $62,7 \%$ \\
\hline Empeorará & 37 & $22,4 \%$ & $85,1 \%$ \\
\hline Empeorará significativamente & 3 & $2,1 \%$ & $87,2 \%$ \\
\hline $\mathrm{Ns} / \mathrm{Nc}$ & 21 & $12,8 \%$ & $100 \%$ \\
\hline Total & 163 & $100 \%$ & \\
\hline Perdidos & 2 & & \\
\hline Total & 165 & $100 \%$ & $100 \%$ \\
\hline
\end{tabular}

Por su parte, al evaluar en forma conjunta la situación actual con las expectativas, el 27,3\% de la muestra ve su situación financiera como normal y estiman que se mantendrá igual en el próximo semestre. Un 8,7\% de la muestra tiene idéntica opinión de su situación actual pero estiman que esta empeorará o empeorará significativamente $(0,8 \%)$.

En tanto, un 10,0\% de la muestra manifiesta que su situación financiera es desfavorable y que se mantendrá en idéntica condición en el segundo semestre de 2010.

Por su parte, un 11,6\% de la muestra opina que su situación financiera es desfavorable y prevé que empeorará o empeorará significativamente.

En resumen, el pesimismo alcanza al 33,1\% de la muestra que entiende que su situación financiera en el segundo semestre de 2010 se deteriorará o seguirá mal, comparándola con igual período de 2009, partiendo de diferentes condiciones en el primer semestre de 2010. En este mismo sentido, el optimismo alcanza al 20\% de la muestra, quienes opinan que su situación financiera mejorará o mejorará significativamente. Con expectativas neutras se encuentra el $27,3 \%$ de la muestra que consideró a su situación normal y no espera cambios en el segundo semestre de 2010, en perspectiva de igual período de 2009.

Cabe señalar que un 12,6\% de los encuestados no pudieron prever la evaluación de sus finanzas para el segundo semestre de 2009. 
El 92\% de quienes realizan exportaciones se avinieron a contestar respecto a la evolución de las mismas. Entre estos últimos, $47 \%$ indicó que disminuyeron, $41,1 \%$ que se mantienen estables y $11,8 \%$ que aumentaron. Estos guarismos sobre el total de las exportaciones serían: 43,3\%, 37,9\% y $10,9 \%$, respectivamente.

Cuadro 54: Estimación de las exportaciones para el segundo trimestre de 2010 con relación al 2009

\begin{tabular}{|l|c|c|c|}
\hline \multicolumn{4}{|c|}{ Evolución de las exportaciones } \\
\hline & Frecuencia & Porcentaje & $\begin{array}{c}\text { Porcentaje } \\
\text { acumulado }\end{array}$ \\
\hline Válidos: & 7 & $11,8 \%$ & $11,8 \%$ \\
Aumentaron & 25 & $41,1 \%$ & $52,9 \%$ \\
Se mantuvieron iguales & 29 & $47,0 \%$ & $100 \%$ \\
Disminuyeron & 61 & $100 \%$ & \\
Subtotal & 83 & $56,0 \%$ & \\
No exporta & 4 & $2,6 \%$ & \\
Exporta pero Nc & 148 & & \\
Total & 17 & $10,2 \%$ & \\
Perdidos & 165 & & $100 \%$ \\
\hline Total & & & \\
\hline
\end{tabular}

Fuente: Elaboración propia en base a la información obtenida de las encuestas realizadas a las empresa. 


\subsection{Análisis Econométrico}

En esta sección, se procede a trabajar con los datos provenientes de la encuesta contestada por las 165 empresas y series de datos obtenidas del BCRA, Reuters, Bloomberg y Ministerios de Economía de la Nación. El software utilizado es el STATA versión 11.0.

A continuación se presentan diferentes modelos econométricos utilizando la metodología de mínimos cuadrados ordinarios (MCO).

El primer paso del análisis es la observación de la correlación entre las variables a modelizar. A estos efectos, el resultado se expone a continuación:

\section{Cuadro 55:}

- Corr exporta empleado antigued b5 tomocre tcrealprom embi expomoi impobsk $(\mathrm{Obs}=35$ )

\begin{tabular}{lrrrrr} 
& $\begin{array}{l}\text { exporta } \\
\text { exporta }\end{array}$ & empleado & antigued & b5 & tomocre \\
empleado & 1,0000 & & & & \\
antigued & 0,0908 & 1,0000 & & & \\
b5 & 0,0203 & 0,1713 & 1,0000 & & \\
tomocre & 0,0985 & $-0,0129$ & 0,0999 & 1,0000 & \\
tcrealprom & 0,1599 & 0,3099 & 0,0410 & 0,2843 & 1,0000 \\
embi & $-0,0605$ & $-0,1270$ & 0,3865 & 0,0605 & $-0,3134$ \\
expomoi & 0,0972 & $-0,2347$ & 0,0808 & $-0,2920$ & $-0,1073$ \\
impobsk & 0,0442 & $-0,3383$ & 0,0585 & $-0,0793$ & $-0,0866$ \\
\multicolumn{7}{c}{ Dónde: } & 0,2865 & $-0,1272$ & $-0,0118$ & $-0,0339$ & 0,2732 \\
\multicolumn{7}{c}{ b5: es creencia de que el sistema financiero fomenta el desarrollo PyME. } \\
& Tomocre: la empresa tomo o no crédito & & \\
& Embi: riesgo país de argentina \\
& Expmoi: exportaciones de productos origen industrial & \\
& Impobs: importaciones de bienes de capital & & \\
& tcreal m: tipo de cambio real promedio &
\end{tabular}

El cuadro muestra que existe una correlación positiva muy importante entre el "embi" con las exportaciones de bienes de origen industrial y también entre el "embi" y la importaciones de bienes de capital. También se observa que las exportaciones de origen industrial y las importaciones de bienes de capital también existe una alta correlación, con lo cual se presenta un problema debido a que existe una alta colinealidad entre las variables que se consideraron para el estudio, la cual llevaría a sesgar el modelo que se planteara a continuación. Las demás variables no presentan gran nivel de correlación y los signos presentados por las mismas son los normales.

A continuación se presentan los modelos econométricos que más relevancia tienen para el estudio: 
Modelo 1:

El primer modelo planteado es:

$$
Y=\beta_{0}+\beta_{1} X_{0}+\beta_{2} X_{1}+\beta_{3} X_{2}+\beta_{4} X_{3}+\beta_{5} X_{4}+\beta_{6} X_{5}+\beta_{7} X_{6}+\mu
$$

Dónde: $Y=$ Empresa exportadora (variable Dummy)

$X_{0}=$ Antigüedad de las firmas

$X_{1}=$ Cantidad de empleados

$X_{2}=$ La empresa se ubica en La Plata (Variable Dummy)

$X_{3}=$ EMBI (Riesgo País)

$X_{4}=$ Tipo de Cambio Real Multilateral

$X_{5}=$ Total país de exportaciones MOI

$X_{6}=$ Importaciones bienes de Capital

$\mu=$ Error (ruido blanco)

$\beta_{0 \times \mathrm{m}}=$ parámetros

La salida de regresión para el modelo planteado es el siguiente:

\section{Cuadro 56:}

reg exporta empleado antigued zona embi tcrealprom b5 expomoi impobsk

\begin{tabular}{|c|c|c|c|c|c|}
\hline Source | & SS & $d f$ & MS & Number of obs & 35 \\
\hline & & & ---------- & $F(8, \quad 26)$ & 0.5 \\
\hline Model | & 1.08513287 & 8 & .135641609 & Prob $>\mathrm{F}$ & 0.810 \\
\hline Residual | & 6.45772427 & 26 & .24837401 & R-squared & 0.14 \\
\hline & & & ----------- & Adj R-squared & $=-0.11$ \\
\hline Total | & 7.54285714 & 34 & .221848739 & Root MSE & .49837 \\
\hline
\end{tabular}

\begin{tabular}{|c|c|c|c|c|c|c|}
\hline exporta & Coef. & Std. Err. & t & $P>|t|$ & {$[95 \%$ Conf } & Interval] \\
\hline empleado & .0007079 & .0027005 & 0.26 & 0.795 & -.004843 & .0062589 \\
\hline antigued & .000153 & .0058766 & 0.03 & 0.979 & -.0119266 & .0122326 \\
\hline zona & .0062658 & .2390961 & 0.03 & 0.979 & -.4852033 & .4977349 \\
\hline embi & -.0003084 & .0018119 & -0.17 & 0.866 & -.0040328 & .003416 \\
\hline tcrealprom & 1.385275 & 5.426263 & 0.26 & 0.801 & -9.768568 & 12.53912 \\
\hline b5 & .1499115 & .4190477 & 0.36 & 0.723 & -.7114534 & 1.011276 \\
\hline expomoi & -.0004153 & .0004807 & -0.86 & 0.395 & -.0014034 & .0005727 \\
\hline impobsk & .0011995 & .0007804 & 1.54 & 0.136 & -.0004047 & .0028037 \\
\hline _cons & -4.418988 & 17.76889 & -0.25 & 0.806 & -40.94347 & 32.10549 \\
\hline
\end{tabular}

En este primer modelo se observa que ninguna de las variables es significativa, el $\mathrm{R}$ cuadrado es muy bajo, con lo cual se puede concluir que este modelo no es bueno para explicar la decisión de las empresas a exportar. 
Modelo 2:

El segundo modelo planteado es:

$$
Y=\beta_{0}+\beta_{1} X_{0}+\beta_{2} X_{1}+\beta_{3} X_{2}+\beta_{4} X_{3}+\mu
$$

Dónde:

$Y=$ Empresa exportadora (variable Dummy)

$X_{0}=$ Antigüedad de las firmas

$X_{1}=$ Cantidad de empleados

$X_{2}=$ Tomo crédito (variable Dummy)

$X_{3}=$ Creencia que el sistema financiero ayuda al desarrollo de las PyMEs (b5)

$\mu=$ Error (ruido blanco)

$\beta_{0 \mathrm{~m}, 4}=$ parámetros

La salida de regresión para el modelo planteado es el siguiente:

Cuadro 57:

reg exporta empleado antigued b5 tomocre

\begin{tabular}{|c|c|c|c|c|c|c|}
\hline Source | & SS & $d f$ & MS & Number of obs & $=$ & 161 \\
\hline & & & & F( 4, 156) & $=$ & 2.55 \\
\hline Model | & 2.94412741 & 4 & .736031853 & Prob > F & $=$ & 0.0411 \\
\hline Residual | & 44.9564937 & 156 & .288182652 & R-squared & $=$ & 0.0615 \\
\hline & & & & Adj R-squared & $=$ & 0.0374 \\
\hline Total | & 47.9006211 & 160 & .299378882 & Root MSE & $=$ & .53683 \\
\hline
\end{tabular}

\begin{tabular}{|c|c|c|c|c|c|c|}
\hline exporta | & Coef. & Std. Err. & $t$ & $P>|t|$ & [95\% Conf. & Interval] \\
\hline empleado | & .0028133 & .001132 & 2.49 & 0.014 & .0005773 & .0050493 \\
\hline antigued & .0031096 & .0025877 & 1.20 & 0.231 & -.0020018 & .008221 \\
\hline b5 & -.1705138 & .1017249 & -1.68 & 0.096 & -.3714496 & .0304221 \\
\hline tomocre | & -.0080228 & .0888379 & -0.09 & 0.928 & -.1835031 & .1674576 \\
\hline _cons | & .3190592 & .0961744 & 3.32 & 0.001 & .1290871 & .5090312 \\
\hline
\end{tabular}

Este segundo modelo, a diferencia del primero, se omitió las variables: zona, embi, tipo de cambio real multilateral, exportaciones de moi e importaciones de bienes de capital y se agregó la variable toma crédito. Con lo cual surgió un cambio importante en el modelo ya que las variables empleado y la b5 se volvieron significativas en el modelo, al 5\% y al 10\% respectivamente. Lo cual estaría indicando que las empresas exportan más son las que contratan mayor cantidad de empleados y también aquellas que exportan más es porque tienen una creencia de que el sistema financiero fomenta el desarrollo PyME, es decir que exportan porque pueden tomar créditos para fomentar su capacidad productiva y de esa manera poder exportar más. 
Modelo 3:

El tercer modelo planteado es

$$
Y=\beta_{0}+\beta_{1} X_{0}+\beta_{2} X_{1}+\beta_{3} X_{2}+\beta_{4} X_{3}+\beta_{5} X_{4}+\beta_{6} X_{5}+\beta_{7} X_{6}+\mu
$$

Dónde: $Y=$ La empresa tomo crédito (variable Dummy)

$X_{0}=$ Antigüedad de las firmas

$X_{1}=$ Cantidad de empleados

$X_{2}=$ EMBI (Riesgo País)

$X_{3}=$ Creencia que el sistema financiero ayuda al desarrollo de las PyMEs (b5)

$X_{4}=$ Tipo de Cambio Real Multilateral

$X_{5}=$ Empresa exportadora (variable Dummy)

$X_{6}=$ La empresa se ubica en La Plata (Variable Dummy)

$\mu=$ Error (ruido blanco)

$\beta_{0 \mathrm{~m} .7}=$ parámetros

La salida de regresión para el modelo planteado es el siguiente:

\section{Cuadro 58:}

reg tomocre exporta empleado antigued zonaembi tcrealprom b5

\begin{tabular}{|c|c|c|c|c|c|c|}
\hline Source | & SS & $d f$ & \multicolumn{2}{|l|}{ IS } & \multirow{2}{*}{$\begin{array}{l}\text { Number of obs } \\
\text { F( 7, 153) }\end{array}$} & \multirow{2}{*}{$\begin{aligned}= & 161 \\
= & 2.40\end{aligned}$} \\
\hline & & & & & & \\
\hline Model & 3.95914255 & .56 & 91793 & & Prob $>F$ & $=0.0235$ \\
\hline Residual | & 36.1029693 & 153 & 67119 & & R-squared & 0.0988 \\
\hline---------+ & & & 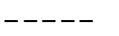 & & Adj $R$-squared & 0.0576 \\
\hline Total | & 40.0621118 & 160 & 88199 & & Root MSE & .48576 \\
\hline tomocre | & Coef. & Std. Err. & $t$ & $P>|t|$ & [95\% Conf. & Interval] \\
\hline exporta & - 0054108 & 0740725 & -007 & 0942 & -1517477 & 140 \\
\hline empleado & .002152 & .0010361 & 2.08 & 0.039 & .0001051 & .0041989 \\
\hline antigued | & -.0023131 & .0023978 & -0.96 & 0.336 & -.0070502 & .002424 \\
\hline zona | & .0991541 & .1104097 & 0.90 & 0.371 & -.1189704 & .317278 \\
\hline embi & -.0001004 & .0001548 & -0.65 & 0.518 & -.0004062 & .0002054 \\
\hline tcrealprom | & -.2543427 & .4402981 & -0.58 & 0.564 & -1.124191 & .61550 \\
\hline b5 । & .2627707 & .0933793 & 2.81 & 0.006 & .0782915 & .44724 \\
\hline cons & 1.462469 & 1.777066 & 0.82 & 0.412 & -2.048286 & 4.97322 \\
\hline
\end{tabular}

En este tercer modelo se cambia la variable explicada, en lugar de ver si las empresas exportan o no se pasa a observar si las empresas toman crédito o no en el sistema financiero, como se puede observar en este modelo las variables relevantes que sobresalen de la salida de regresión son la cantidad de empleados y si la creencia de que el sistema financiero ayuda al desarrollo de las PyMEs. Al observar que las variables presentan el signo positivo esperado, lo cual se tendería a pensar que aquellas empresas que tienen mayor cantidad de empleados presentan mayor disposición a tomar crédito; y aquellas empresas que confían en el sistema financiero son las que mayor nivel de crédito van a solicitar. A pesar de esto se puede observar que el $\mathrm{R}$ cuadrado es bajo, por lo cual se podría pensar que existe un problema de correlación de variable que no dejan que el modelo sea lo suficientemente bueno para obtener un análisis satisfactorio. 
El cuarto modelo que se desarrollo fue:

$$
Y=\beta_{0}+\beta_{1} X_{0}+\beta_{2} X_{1}+\beta_{3} X_{2}+\beta_{4} X_{3}+\mu
$$

Dónde:

$Y=$ La empresa tomo crédito (variable Dummy)

$X_{0}=$ Cantidad de empleados

$X_{1}=$ Creencia que el sistema financiero ayuda al desarrollo de las PyMEs (b5)

$X_{2}=$ Empresa exportadora (variable Dummy)

$X_{3}=$ La empresa se ubica en La Plata (Variable Dummy)

$\mu=$ Error (ruido blanco)

$\beta_{0 \mathrm{~m}, 4}=$ parámetros

\section{Cuadro 59:}

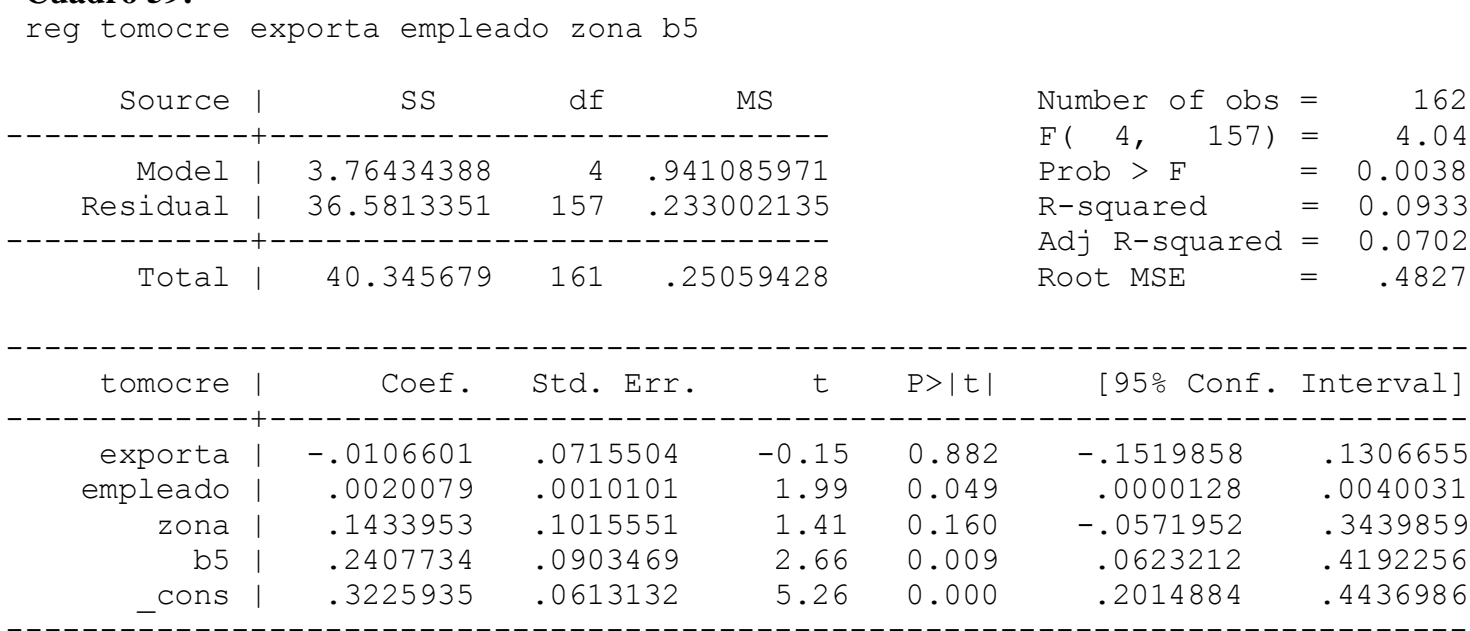

En este cuarto modelo se omitió variables para ver si de este modo se podía mejorar la $\mathrm{R}$ cuadrado, y el resultado no fue el esperado, debido a que las variables que fueron significativas en el modelo 3 se mantuvieron en este modelo y el R cuadrado se mantuvo sin alteraciones significativas. Por lo cual se podría pensar que el problema está en que existen variables que no se han tenido en cuenta y que deben ser consideradas para futuros estudios en la materia.

Como conclusión general se podría decir:

En cuanto a la especificación general de los modelos de regresión, el test $\mathrm{F}$ de significatividad conjunta no rechaza la hipótesis nula según la cual ninguna de las variables explicativas es estadísticamente distinta de cero, para todos los niveles de confianza.

También se puede observar que el estadístico R cuadrado de los cuatro modelos es muy bajo por lo que se podría decir que la variables dependientes no son explicadas por el modelo, por lo cual se puede llegar a pensar que existen problemas de endogeneidad del modelo provocado por un problema de variables omitidas que es un punto importante que quedara planteado para ser considerado en próximos análisis. 
En cuanto a los coeficientes de cada una de las variables se observa:

a) En el primer modelo planteado ninguna variable es significativa individualmente para cualquier nivel de confianza considerado.

b) En el segundo modelo existe una relación positiva entre las exportaciones y la creencia de que el sistema Financiero fomenta a las PyMEs y también con la cantidad de empleados, ambas variables son estadísticamente significativas al nivel de confianza del $10 \%$ y al 5\%, respectivamente. En términos estrictamente económicos, este resultado es compatible con la idea de aquellas empresas que exportan son las más grandes (medidas por el número de empleados) y son aqellas que creen en los bancos por lo cual toman crédito para aumentar su capacidad productiva.

c) En los modelos 3 y 4, en los cuales se observa una relación positiva entre la toma de créditos y la creencia de que el sistema Financiero fomenta a las PyMEs y también con la cantidad de empleados, ambas variables son estadísticamente significativas a cualquier nivel de confianza.

En términos estrictamente económicos, este resultado es bastante intuitivo ya que las empresas que creen en el sistema financiero son las que toman mayor cantidad de crédito y, por otro lado, las empresas más grandes en tamaño son las que poseen menores barreras a la hora de obtener un crédito.

Para finalizar, si bien los modelos establecidos no son buenos predictores de las variables bajo estudio, por problemas de endogeneidad, causada principalmente por la omisión de variables relevantes, sirven como punto de partida para futuros trabajos de investigación. 


\section{Conclusiones}

El presente estudio se encuadra en la línea de investigación que analiza las relaciones entre las empresas denominadas PyMEs y las entidades financieras en lo que respecta a las asimetrías informativas y su acceso al financiamiento, así como sus factores determinantes. Luego de diseñar una encuesta y suministrarla a una muestra de 165 pequeñas y medianas empresas pertenecientes a la ciudad de La Plata y localidades vecinas, se obtuvo un panel de datos y se analizó el grado de racionamiento financiero presentado por las firmas en este sector del conurbano bonaerense.

Del análisis realizado surge que la mayoría de la empresas que contestaron la encuesta son PyMEs medianas (30 empleados en promedio), con varios años de antigüedad en el mercado (30 años) y con un fuerte sesgo a exportar sus productos.

Por otro lado, se observa que las empresas que mantienen vínculo con un banco, o con muy pocos, son las que parecen mostrar un mayor grado de racionamiento financiero, siendo precisamente las de menor dimensión, más jóvenes y menos endeudadas. En otras palabras, se trata de las que se encuentran en las primeras etapas del ciclo de vida financiero, y por lo tanto, afrontan mayor problema de selección adversa. No obstante, otros factores como las características de los bancos o del sistema financiero del país donde se encuadra la PyME también pueden afectar el número de relaciones bancarias. Su análisis será objetivo de posteriores investigaciones en esta línea.

En cuanto a las fuentes de financiamiento que utilizan las empresas se observa un claro sesgo al autofinanciamiento, en segundo lugar se ubica el financiamiento por proveedores, seguido por el financiamiento mediante las entidades bancarias y por último la utilización de sistemas no formales. Se puede observar que, la baja utilización del sistema financiero como medio de financiación de las empresas (en comparación con la autofinanciación y financiamiento por proveedores) se debe principalmente a los excesivos requisitos, a las altas tasas y a la burocracia que presentan la mayoría de los bancos a la hora del otorgamiento de créditos.

Un dato de relevancia a destacar es la gran cantidad de empresarios que nunca averiguaron los requisitos para solicitar un crédito, esto sumados a aquellos que no consideran habitual la solicitud de un crédito y que un $60 \%$ de las respuestas obtenidas en cuanto al tiempo que tomó el último crédito fue "hace más de 5 años", nos llevé a pensar que la cultura del crédito no se encuentra incorporada en la sociedad empresarial estudiada. De los pocos créditos tomados, el más solicitado es el crédito empresarial con garantía empresaria, seguido por personal con destino a empresas (este último, en su mayoría, fue solicitado porque las empresas no cumplían con los requisitos para obtener el crédito empresarial con garantía empresaria o porque su obtención era más rápida y lo necesitaban con urgencia), es decir, la escasez de crédito no refleja únicamente una restricción, como es habitual pensar, por el lado de la oferta de crédito sino también una baja demanda de crédito. Los mayores exponentes de la oferta de crédito fueron: Banco Nación, Banco Provincia y el Banco Credicoop, siendo este último el que mayor valoración obtuvo como banco de confianza a la hora de solicitar un crédito u otras relaciones comerciales. Esto último puede llevarnos a concluir que no sólo son los bancos con sus grandes reglas burocráticas sino también la actitud pasiva que presentan los empresarios lo que lleva a que la brecha entre los intereses de ambas partes siga siendo cada vez más grande y las asimetrías informativas no tengan solución aparente. 
En cuanto a la distribución de los escasos créditos otorgados por los bancos, se observó, en la distribución total de los créditos, que el Banco Credicoop sobresale del resto, en particular por la gran cantidad de créditos empresariales con garantía personal y en menor medida los créditos empresariales con garantía empresarial y sin garantía que otorgó en comparación con los demás bancos, seguido por el Banco Provincia y el Banco Nación. Un punto importante a destacar es la alta participación que tuvo el Banco Santander en el otorgamiento de créditos personales con destino a empresa, que como se describió en el párrafo anterior fue el segundo en importancia en cuanto a su otorgamiento debido a que en su mayoría fue solicitado por empresas que no cumplían con los requisitos para obtener el crédito empresarial con garantía empresaria o porque su obtención era más rápida y lo necesitaban con urgencia.

En lo relacionado a cuál fue el destino del crédito obtenido, el $61 \%$ de los créditos se destinó a inversión (la categoría inversión incluyó: nuevos proyectos productivos, inversión en I+D, ampliación de planta, compras de maquinarias y mejoras de estructura de ventas y distribución), los bancos más destacados fueron el Banco Provincia y el Banco Credicoop seguidos por el Banco Nación y el Banco Santander. Haciendo un análisis más detallado de las finalidades dadas a los créditos obtenidos se observó que la compra de maquinaria ocupa más de un tercio de esos créditos y al banco más citado a declarar esta finalidad resulto ser el Banco Provincia seguido por el Banco Credicoop. El segundo destino más declarado fue la compra de materias primas, siendo el Banco Credicoop el que mayor cantidad de créditos otorgó para este fin seguido por el Banco Galicia. La tercera finalidad más citada resultó ser la ampliación de planta, siendo el Banco Provincia el que más crédito otorgó seguido por el Banco Nación.

En cuanto a los colaterales ofrecido como respaldo de los créditos obtenidos, se observa alta participación de los créditos a sola firma, debido a lo cual se puede inferir que la mayoría de los créditos no se trataron de montos importantes, o fueron ampliaciones, refinanciaciones o renovaciones y soslayaron la mención del colateral subyacente pues su compromiso previo seguía instrumentadamente válido o respondieron en perspectiva a incluir adelantos en cuenta corriente con esa condición. En segundo lugar se observa la prenda como instrumento ofrecido y en tercer lugar, los créditos hipotecarios.

En relación a las decisiones fallidas en cuanto a la toma de crédito, es decir aquellas empresas que fueron a los bancos a averiguar por los créditos y luego no lo tomaron, se puede observar que más del $50 \%$ de las empresas no lo tomaron. Entre los principales motivos se encuentran, en primer lugar, la tasa de interés inaccesible y requisitos inaccesibles; en segundo lugar, trámites y planillas complejos; y en tercer lugar, montos inapropiados. En cuanto a los bancos consultados, el que mayor consulta recibió fue el Banco Provincia, seguido por el Banco Credicoop y en tercer lugar, el Banco Nación.

En cuanto a la disposición empresaria a tomar crédito, bajo condiciones que los empresarios consideran adecuadas o accesibles sin afectar la marcha de la empresa, la conclusión que se obtiene está vinculada a los casos en que tomarían créditos según los niveles de "tasa de interés", "período de gracia" y "plazo de amortización", y las preferencias de destino de los créditos; teniendo los tres casos una tendencia preferencial similar. Se verifica que hay una mayor propensión hacia los créditos vinculados a capital de inversión. Los destinos más elegidos fueron, "compras de maquinarias", le sigue "ampliación de planta" y el "desarrollo de nuevos productos" en el tercer lugar. Por el contrario, los destinos menos elegidos son los relacionados con el capital de trabajo; los porcentajes más altos son la financiación de exportaciones, financiación de importaciones y financiación de ventas, las tres ubicadas entre el 20 y el $21 \%$ de los destinos elegidos. 
Con relación a las preferencias generales respecto a los bancos que operan en la región bajo estudio, cabe consignar que el grupo de bancos que concitaron mayor preferencia entre las firmas encuestadas estuvo conformada por de siete entidades: BBVA, Credicoop, Galicia, HSBC, Nación, Santander Rio y Banco Provincia. Este grupo concentró cerca del $90 \%$ de las preferencias, tanto cuando se menciona al banco de mayor preferencia como al de segunda o tercera preferencia.

Como banco de mayor preferencia, se ubica el Banco Credicoop, seguido por el Banco Nación y el Banco Provincia. Como segundo banco de preferencia, se encuentra el Banco Provincia, seguido por el Banco Credicoop y el Banco Santander Rio. Como tercer banco de preferencia, se ubica el Banco Provincia, el Banco Santander Rio y el Banco Nación en tercer lugar.

Por lo tanto, en preferencias generales, el banco mejor posicionado es el Credicoop, por ser elegido en el primer lugar y además por su alta representatividad como segundo y tercer banco preferido. El Banco Nación se ubica como segundo banco preferido y el Banco Provincia ocupa el tercer puesto de preferencia.

En cuanto a las líneas de crédito, se observa que una baja porción de los participantes conoce este tipo de instrumentos, y por lo general, las que mayor grado de conocimiento presentan son aquellas líneas fomentadas por el Estado Nacional, en particular se puede nombrar los prestamos PyMEs que otorga el ANSES. No existiendo una difusión tan marcada en otras alternativas como el mercado de capitales.

En lo referido a la evaluación de los resultados sobre la situación actual de las empresas y expectativas de corto plazo, se observa con respecto a la demanda, que el 57\% de la muestra calificó a su situación como desfavorable. Para el 29\% de los encuestados la situación se presentó normal y en el 14\% de los casos la situación resulta favorable.

Entre quienes cuantificaron la variación negativa de su demanda para el primer cuatrimestre de 2010 respecto al mismo lapso de 2009 (72\% de la muestra), 33\% (de quienes indicaron una variación) manifestó que se redujo entre 20 y 40\%, 20,6\% que se redujo entre 45 y $65 \%$ y 19,0\% que la caída fue hasta el 20\%. Sólo un 5,6\% manifestó que la caída superó el 65\% interanual.

En cuanto a las expectativas sobre la demanda para el segundo semestre de 2010 en comparación con el segundo semestre 2009, el 33,4\% de la muestra no espera cambios, el 26,4\% espera una disminución de su demanda y el 2,6\% espera que disminuya fuertemente. Por otra parte, $21,2 \%$ espera que su demanda aumente.

Con respecto a la inversión, la mitad de los encuestados manifestó que no vislumbra cambios en los niveles de inversión, en perspectivas de las inversiones durante el segundo semestre del año pasado. No obstante ello, una porción significativa creen que estas disminuirán o disminuirán fuertemente $(25,5 \%)$, mientas que el $16 \%$ estima que aumentará sus inversiones, como resultados más salientes.

En lo referido a la situación financiera, el pesimismo alcanza al 33,1\% de la muestra que entiende que su situación financiera en el segundo semestre de 2010 se deteriorará o seguirá mal, comparándola con igual período de 2009, partiendo de diferentes condiciones en el primer semestre de 2010. En este mismo sentido, el optimismo alcanza al 20\% de la muestra, quienes opinan que su situación financiera mejorará o mejorará significativamente. Con expectativas neutras se encuentra el $27,3 \%$ de la muestra que consideró a su situación normal y no espera cambios en el segundo semestre de 2010, en perspectiva de igual período de 2009.

En resumen, las Pequeñas y medianas empresas en Argentina dependen en gran medida del crédito bancario para financiar su crecimiento. Sin embargo, dicho financiamiento ha estado signado en la mayoría de los casos por condiciones prohibitivas, ya sean en términos de tasas de interés, plazos de los créditos, garantías exigidas, entre otras. Esto último redundó en serias limitaciones para las empresas, condicionando su desarrollo futuro. 


\section{Recomendaciones de política}

En función de las conclusiones arribadas y teniendo en cuenta el eficiente funcionamiento que presentan los mercados en los países desarrollados, se establece lo siguiente:

En coincidencia con la visión popular sobre el tema, el diagnostico básico es que el volumen de crédito disponible para estas empresas es muy escaso. Sin embargo, en contradicción a esta visión popular se sostiene que:

1. La asistencia financiera debería enfocarse en PyMEs que son excluidas del sistema bancario formal pero que al mismo tiempo tienen una aceptable capacidad y voluntad de pago. Por lo tanto, la asistencia no debería tener un alcance general a todos los sectores PyMEs, sino solo al subconjunto de buenas empresas con demanda de crédito insatisfecha por no contar sus potenciales acreedores con suficiente información cuantitativa sobre el desempeño pasado de la empresa y sobre sus flujos futuros esperados. En otras palabras, un programa de asistencia financiera eficiente y sostenible en el tiempo no debería asumir la forma de subsidio sin contraprestación o, similarmente, de préstamos incobrables.

2. La solución a esta falla de mercado deriva de problemas informativos involucra tanto al Estado como al sistema financiero y a los propios beneficiarios. Al estado le cabe la función de proveer como banca de segundo piso, los recursos financieros para viabilizar los programas de asistencia y de velar mediante un estricto control profesional de la banca comercial, por su uso adecuado al objetivo social planteado. La banca comercial por su parte, debería ser la encargada de seleccionar PyMEs con alta capacidad y voluntad de pago pero que no cumplen, al menos inicialmente, con los requisitos informativos que las entidades aplican normalmente. Dada que esta falla de mercado es la que justifica la presencia estatal en el sistema bancario, sería deseable que la banca pública lidere este proceso. Sin embargo ni la teoría y ni la evidencia acumulada para Argentina u otros países ofrecen argumentos en contra de la participación de entidades privadas como banca de primer piso. Por último, las propias PyMEs interesadas en este programa son las responsables de tomar acciones para mejorar la calidad y transparencia de su información contable histórica y proyectada, donde reside el principal obstáculo para insertarse en el mercado de crédito. La asistencia técnica y financiera del estado puede contribuir a eliminar barreras de costos y culturales que pueden frenar estas iniciativas a nivel interno de cada empresa;

3. La asistencia estatal no debería concretarse única ni necesariamente a través de la provisión de fondeo adicional para aumentar la cartera de crédito PyME de la banca comercial. El tipo de asistencia debería depender de ó de los objetivos que se fije el estado. Por ejemplo, además de la concesión de préstamos de bajo costo a las entidades, se podrían subsidiar los gastos administrativos de los bancos o mejorar o la inversión en mejoras del sistema informativo de las empresas, o se podría conceder garantías parciales de los préstamos realizados por la banca comercial. El objetivo de largo plazo de la asistencia debería ser en todos los casos la inserción de las PyMEs beneficiadas al mercado de crédito en condiciones competitivas de tasas, plazos y garantías, sin necesidad de apoyo estatal permanente. Por esta misma razón, el esquema debería orientarse principalmente hacia prestatarios no servidos con anterioridad por el sistema financiero; 
4. El inevitable surgimiento de conflictos de intereses entre las tres partes (estado, banca comercial y PyME) obliga a considerar seriamente los incentivos privados que pueden amenazar el cumplimiento de los objetivos sociales. Para desactivar esos incentivos oportunistas se requiere (i) un cuidadoso diseño de mecanismos de apoyo, (ii) un celoso control del uso de fondos, (iii) la contribución de penalidades a quienes infrinjan las reglas del programa, (iv) la realización de evaluaciones periódicas de costo y beneficio social, (v) un alto grado de transparencia informativa hacia todos los interesados directos e indirectos.

Además, de todas las recomendaciones que se pueden establecer en cuanto a la relación Estado, PyME, banca comercial, comienzan a emerger nuevas alternativas como ser el Mercado de Capitales. Dado que el desarrollo de este mercado resulta beneficioso para todos los actores por el lado de la empresa, obtiene fondeos en mejores condiciones en términos de plazo y tasa que la banca comercial estándar; por el lado del inversor, obtiene una buena rentabilidad por su inversión y seguridad jurídica; por el lado del gobierno, se beneficia de un mayor nivel de empleo y producción, al aumentar la actividad de las PyMEs, alentando el crecimiento económico nacional.

A pesar de su escaso desarrollo, cabe destacar que en medio de la fuerte crisis económica y financiera que atravesó el país tras la salida de la convertibilidad, en un contexto de default, devaluación de la moneda y ruptura de la cadena de pagos, y con la desaparición de las fuentes tradicionales de financiamiento, el mercado de capitales se mantuvo relativamente activo. No obstante mucho queda por delante.

Establecer políticas que impulsen el desarrollo del mercado de capitales como una alternativa de financiamiento de empresas es un deber de las autoridades públicas y privadas. Por el lado de la oferta de fondos (inversores) se requiere de instituciones fuertes que brinden estabilidad en las reglas del juego, que doten de seguridad jurídica a los inversores de modo que estos dirijan confiadamente su dinero a financiar todo tipo de proyecto productivo, sin tener que preocuparse por el humor del político de turno.

Por el lado de la demanda de fondos (empresas), si bien desde la creación del departamento PyME del BCRA existe una importante política de difusión del mercado, es preciso generar un mayor acercamiento con las unidades productivas de modo que dejen de ver a estos mercados como complejos o exclusivos de las grandes empresas.

Entre una variada gama de instrumentos elegibles según la necesidad particular de cada empresa, la emisión de deuda bajo la forma de obligaciones negociables emerge como un mecanismo eficaz para darle aire a la compañía desde el punto de vista financiero a la vez que mejora la imagen institucional por la oferta pública. Un perfil de inversores locales con clara preferencia por la renta fija complementa el favoritismo por este instrumento.

Permitir que la empresa se endeude en función a la estacionalidad de su negocio, y no adecuar el negocio en función del dinero que se puede tomar prestado, se vuelve vital para el mundo PyME. La disponibilidad de fondos para asignar a proyectos o empresas altamente rentables germina el desarrollo de la compañía, derramando sus beneficios a todo el sistema económico.

Se considera necesaria la realización de una mayor cantidad de estudios longitudinales, así como la extensión del estudio sobre las asimetrías informativas entre las empresas PyMEs y banco hacia otras localidades relevantes de la Provincia de Buenos Aires, como también hacia los países limítrofes. Por otro lado, las futuras investigaciones apuntan a temas relacionados con el 
uso de información y la trasmisión de conocimiento sobre nuevos mercados de créditos (el mercado de capitales entre otros) para ampliar el abanico de posibilidades con las que cuentan las empresas PyMEs para obtener financiamiento de una manera más fácil y segura.

Asimismo, se estima de utilidad la inclusión de modelos econométricos y simulaciones donde se pretenda mostrar algunos aspectos del racionamiento y exclusión del crédito que sufren las empresas, de tal forma de poder observar, qué características de las empresas permiten la mayor elegibilidad al crédito y constatar si todas las empresas con esas características han tenido préstamos bancarios. 


\section{Bibliografía:}

- AKERLOF, G.A. (1970) the market for lemons, quality uncertainly and the market mechanist, quarterly journal of economics, 97.

- BEBZUCK, RICARDO (2002) what determines the access to credit by SMEs in Argentina, preliminary version.

- BEBZUCK, RICARDO. “Asymmetric Information in Financial Markets”.1era. Edición. Reino Unido. Cambridge University Press. (2003).

- BECK, T., A. DEMIRGUC-KUNT y M. MARTINEZ PERIA (2008), "Bancarizando a las pymes alrededor del mundo: Determinantes, obstáculos, modelos de negocios y prácticas de financiamiento", presentación en el X Foro de la Microempresa, BID/FOMIN, Asunción.

- BLEGER, L. y ROZENWURCEL, G. (2000), "Financiamiento a las Pyme y cambio estructural en la Argentina", estudio de caso sobre fallas de mercado y problemas de información, Desarrollo Económico No 57 abril-junio. CNV (Comisión Nacional de Valores) (1998...), varios informes, Buenos Aires, Argentina.

- COASE, R. (1937), "The nature of the firm and their costs", Economic Insights. Federal Reserve Bank of Dallas Vol. 8. Number 3.

- CRISTINI, MARCELA Y BERMUDEZ, GUILLERMO (FIEL) Las PyMES en Argentina: ambiente de negocios y crecimiento exportador.

- DIAMOND, D W (1984) Financial intermediation and delegated monitoring, Review of economic studies, 51.

- FANELLI, J. M. (1997), "Movimiento de capitales y comportamiento de la inversión en Argentina" (en colaboración con C. Bonvecchi y R. Frenkel), en R. French-Davis y H. Reisen (comp.), Flujos de Capital e Inversión Productiva, Lecciones para América Latina, McGraw-Hill. CEPAL-OECD, Chile.

- GALINDO A. y MICCO, A. (2003), "Do state-owned banks promote growth? Crosscountry evidence for manufacturing industries", BID Working Paper No. 483, febrero.

- JAFEE, D and STIGLITZ, J (1990) Credit Rationing, en B. M. Friedman and F. Hahn, eds. Handbook of Monetary Economic. Vol. 2 Amsterdam: North Holland, capítulo 3.

- LOZANO, A., CARDONE RIPORTELLA, C. y CAZORLA PAPIS, L., "Una aproximación a los factores determinantes de la estructura de capital de las pequeñas y medianas empresas", (Anales del VIII Foro de Finanzas, Madrid, octubre de 2000).

- MASON, COLIN "El financiamiento y las pequeñas y medianas empresas". Publicado en "Desarrollo y Gestión de PyMEs: Aportes para un debate necesario", Universidad Nacional de General Sarmiento. Buenos Aires, Argentina, año 1998.

- MODIGLIANI y MILLER." The cost of capital, corporation finance and the theory of investment" (1958).

- MYERS, Stewart y MAJLUF. "Corporate Financing and Investment Decisions When Firms Have Information That Investors Do Not Have", N. Journal of Financial Economics, vol. 13. 1984.

- REVISTA ESPAÑOLA, vol. XXXVI, n 135, Relaciones bancarias y financieras de las PyMES. Análisis empírico del coste de capital, racionamiento de crédito y desempeño empresarial

- SAllouM, C. D. y VIGIER, H. P., Los problemas de financiamiento de las pequeña y mediana empresa: La relación bancos - PyMES.

- SElVA DOMINGUEZ, M. y GINER MANSO, Y., "Incidencia del racionamiento del crédito en la estructura financiera de las PYMEs", Revista Europea de Dirección y Economía de la Empresa, vol. 8, n 4, año 1999, pág. 125-134. 
- STIGLITZ, J. y WEISS, A. (1992), "Special Issue on financial markets institutions and policy", 694-724 Oxford Economic Papers, vol. 44, N 4, October. (1981), "Credit Rationing in Markets with Imperfect Information”, American Economic Review, 71, junio.

- TAYLOR, LANCE; O' CONNELL, STEPHEN. (1985) "A Minsky Crisis" The Quarterly Journal of Economics, vol. 100, the MIT Press.

- TENJO-GALARZA, FERNANDO (2002), "Credit Bubble and Stagnation in Colombia" mimeo. (1995), Corporate Finance Under Adjustment, Institute of Social Studies, La Haya, Países Bajos.

\section{Páginas Web:}

- Página Web de la Bolsa de Comercio de Buenos Aires: www.bcba.sba.com.ar

- Página Web de la Comisión Nacional de Valores: www.cnv.gov.ar

- Página Web de la Subsecretaria de la Pequeña y Mediana Empresa: www.sepyme.gov.ar

- Página Web del Instituto Argentino de Mercado de Capitales: www.iamc.sba.com.ar 


\section{Glosario:}

\section{Definiciones Conceptuales:}

- PyMEs: Son generalmente compañías que emplean a menos de 250 pero a más de diez individuos, de acuerdo a un criterio común. A las compañías que dan empleo a menos de diez personas se les conoce normalmente como micro-empresas.

- Bancos: Es una institución financiera que se encarga de administrar y prestar dinero.

- Crédito: La palabra crédito viene del latín credititus' (sustantivación del verbo credere: creer), que significa "cosa confiada". Así "crédito" en su origen significa entre otras cosas, confiar o tener confianza.

Se considerará crédito, el derecho que tiene una persona acreedora a recibir de otra deudora una cantidad en numerario entre otros; en general es el cambio de una riqueza presente por una futura, basado en la confianza y solvencia que se concede al deudor.

- Información asimétrica: Se da en la situación en la que un comprador y un vendedor tienen información diferente sobre una misma transacción, llevando a una situación de discriminación de precios, perjudicial para el consumidor ya que puede estar pagando más por el mismo producto que los demás. Esta información asimétrica conduce a la economía de mercado a un resultado macroeconómico socialmente ineficiente.

- Riesgo moral: es un concepto económico que describe una situación en la que un individuo aislado de la consecuencia de sus acciones- podría cambiar su comportamiento del que habría tenido si hubiera estado expuesto completamente a las consecuencias de sus acciones.

- Selección adversa: Se refiere al proceso de mercado en el cual ocurren "malos" resultados debido a las asimetrías de información entre vendedores y compradores: los "malos" productos o clientes serán probablemente los seleccionados.

- Mercados Financieros: Es un mecanismo que permite a los agentes económicos el intercambio de activos financieros. En general, cualquier mercado de materias primas podría ser considerado como un mercado financiero si el propósito del comprador no es el consumo inmediato del producto, sino el retraso del consumo en el tiempo.

\section{Definiciones Operacionales:}

Entre los indicadores que podemos desarrollar se encuentran:

* PyMES: Ventas totales: Cantidad total de ingresos percibidos por la venta de productos. Participación del mercado (market share): Determina la posición relativa de la empresa frente a sus competidores. Dotación de Personal: Cantidad de empleados de tiempo completo con respecto a la nómina total de empleados.

* Bancos: Banca privada comercia/banca total: indica la cantidad de bancos de capitales privados (nacional o extranjero) que se encuentra en una región determinada. Créditos/Depósitos: indica el porcentaje de préstamos que realiza el banco en relación a los ingresos que recibe de sus depositantes. Cantidad de clientes en comparación con otros bancos del mismo ramo, me indica la confianza que tienen los clientes sobre ese banco en relación a otro banco con iguales características.

* Créditos: Cantidad de créditos otorgados / total de créditos demandados, indica el porcentaje de créditos que da el banco en relación a la demanda que realizan los clientes.

* Riesgo Moral y Selección adversa: Utilización de fondos propios / cantidad total de la deuda demandada, este indicador me permite observar que tan bueno es el proyecto que realiza el deudor, cuanto mayor la cantidad de fondos propios más riesgo toma el deudor y menor será la probabilidad de que el proyecto fracase. Monto de garantías/ total de la deuda 
demandada: al igual que el anterior cuanto mayor cantidad de fondos tenga que poner el deudor para solventar la perdida si el proyecto fracasa menor será la probabilidad de que el proyecto fracase, ya que el deudor no tendrá incentivos a mentir debido a que perderá toda las garantías que otorgo para que le dieran el préstamo. Activos tangibles/activos totales: cuanto mayor cantidad de activos tangibles tenga el deudor mayor porcentaje de garantía le pedirán para cubrir problemas de incobrabilidad. Relación bancaria: cuanto menor sea la cantidad de bancos con los que opera una empresa menor es el problema de riesgo moral y selección adversa que sufre el sistema financiero, debido a que al relacionarse con un solo banco, este tiene toda la información en cuanto a la solvencia o insolvencia de la persona que le otorga el crédito.

* Mercado financiero: Desarrollo del mercado financiero de un país con relación a otros países. Créditos /PBI: indica que porcentaje del crecimiento de un país se debe a los créditos que otorga el mercado, es decir, ve al sistema financiero como el motor de crecimiento de la economía. Cantidad bancos / sistema financiero total: muestra que tan bancarizado está un país, por ejemplo Alemania e Inglaterra tienen un mercado de acciones muy desarrollado, en cambio los países subdesarrollados tienen un mercado bancario más desarrollado que el mercado accionario que es muy pequeño. Por lo cual las empresas en este tipo de país no utilizan mucho el recurso del mercado accionario. Es importante notar que el crecimiento del mercado accionario va de la mano con el mercado bancario, y con reglas claras, instituciones creíbles y con un sistema judicial que proteja a los inversores, entre otras cosas. 
15.1

Anexo I 


\section{Cuadro 1}

\begin{tabular}{|l|c|c|c|c|}
\hline \multicolumn{5}{|c|}{ Cantidad de empleados agrupados en rangos } \\
\hline & Frecuencia & Porcentaje & Porcentaje válido & $\begin{array}{c}\text { Porcentaje } \\
\text { acumulado }\end{array}$ \\
\hline Validos: & & & & \\
De 5 a 10 & 72 & $43,6 \%$ & $44,1 \%$ & $44,1 \%$ \\
De 11 a 25 & 43 & $26,0 \%$ & $26,3 \%$ & $70,4 \%$ \\
De 26 a 40 & 18 & $10,8 \%$ & $10,9 \%$ & $81,3 \%$ \\
De 41 a 50 & 7 & $4,1 \%$ & $4,2 \%$ & $85,5 \%$ \\
De 51 a 100 & 14 & $8,2 \%$ & $8,3 \%$ & $93,8 \%$ \\
De 101 a 150 & 6 & $3,7 \%$ & $3,7 \%$ & $97,5 \%$ \\
150 o más & 4 & $2,4 \%$ & $2,4 \%$ & $100 \%$ \\
Válidos Total & 163 & $98,8 \%$ & $100,0 \%$ & \\
& & & & \\
Perdidos & 2 & $1,2 \%$ & & $100 \%$ \\
\hline Total & & & & $100 \%$ \\
\hline
\end{tabular}

Fuente: Elaboración propia en base a la información obtenida de las encuestas realizadas a las empresas.

\section{Cuadro 2}

\begin{tabular}{|l|c|c|c|c|}
\hline \multicolumn{5}{|c|}{ Porcentual de la producciòn que exporta } \\
\hline & Frecuencia & Porcentaje & $\begin{array}{c}\text { Porcentaje } \\
\text { válido }\end{array}$ & $\begin{array}{c}\text { Porcentaje } \\
\text { acumulado }\end{array}$ \\
\hline Validos: & & & & \\
No exporta & 105 & $63,9 \%$ & $63,9 \%$ & $63,9 \%$ \\
1 a $10 \%$ & 34 & $20,6 \%$ & $20,6 \%$ & $84,5 \%$ \\
11 a $20 \%$ & 10 & $6,2 \%$ & $6,2 \%$ & $90,7 \%$ \\
21 a $30 \%$ & 7 & $4,1 \%$ & $4,1 \%$ & $94,8 \%$ \\
31 a $40 \%$ & 2 & $1,0 \%$ & $1,0 \%$ & $95,8 \%$ \\
71 a $80 \%$ & 3 & $2,1 \%$ & $2,1 \%$ & $97,9 \%$ \\
81 a $90 \%$ & 2 & $1,0 \%$ & $1,0 \%$ & $99 \%$ \\
Si exporta pero no especifico porcentual & 2 & $1,0 \%$ & $1,0 \%$ & $100 \%$ \\
& & & & \\
Perdidos & 0 & $0 \%$ & & \\
\hline Total & 165 & $100 \%$ & $100 \%$ & $100 \%$ \\
\hline
\end{tabular}

Fuente: Elaboración propia en base a la información obtenida de las encuestas realizadas a las empresas. 


\section{Cuadro 3}

\begin{tabular}{|l|c|c|c|c|}
\hline \multicolumn{5}{|c|}{ A través de proveedores } \\
\hline & Frecuencia & Porcentaje & Porcentaje válido & $\begin{array}{c}\text { Porcentaje } \\
\text { acumulado }\end{array}$ \\
\hline Validos: & 81 & $49,1 \%$ & $54,4 \%$ & $54,4 \%$ \\
$0 \%$ & 5 & $3,2 \%$ & $3,5 \%$ & $57,9 \%$ \\
1 a 10\% & 10 & $6,1 \%$ & $6,8 \%$ & $64,7 \%$ \\
11 a 20\% & 10 & $6,2 \%$ & $6,9 \%$ & $71,6 \%$ \\
21 a 30\% & 5 & $2,9 \%$ & $3,2 \%$ & $74,8 \%$ \\
31 a 40\% & 16 & $9,8 \%$ & $10,8 \%$ & $85,6 \%$ \\
41 a 50\% & 3 & $1,6 \%$ & $1,8 \%$ & $87,4 \%$ \\
51 a 60\% & 4 & $2,6 \%$ & $2,9 \%$ & $90,3 \%$ \\
61 a 70\% & 3 & $1,6 \%$ & $1,8 \%$ & $92,1 \%$ \\
71 a 80\% & 1 & $0,8 \%$ & $0,9 \%$ & $93,0 \%$ \\
81 a 90\% & 10 & $6,3 \%$ & $7,0 \%$ & $100,0 \%$ \\
91 a 100\% & 149 & $90,3 \%$ & $100,0 \%$ & \\
Válidos Total & & & & \\
Perdidos & 16 & $9,7 \%$ & & \\
\hline Total & 165 & $100 \%$ & $100 \%$ & $93 \%$ \\
\hline
\end{tabular}

Cuadro 4

\begin{tabular}{|c|c|c|c|c|}
\hline \multicolumn{5}{|c|}{ A través del sistema financiero } \\
\hline & Frecuencia & Porcentaje & Porcentaje válido & $\begin{array}{l}\text { Porcentaje } \\
\text { acumulado }\end{array}$ \\
\hline Validos: & & & & \\
\hline $0 \%$ & 101 & $61,1 \%$ & $68,6 \%$ & $68,6 \%$ \\
\hline 1 a $10 \%$ & 13 & $7,8 \%$ & $8,7 \%$ & $77,3 \%$ \\
\hline 11 a $20 \%$ & 13 & $8,0 \%$ & $9,0 \%$ & $86,3 \%$ \\
\hline 21 a $30 \%$ & 6 & $3,8 \%$ & $4,3 \%$ & $90,6 \%$ \\
\hline 31 a $40 \%$ & 3 & $1,9 \%$ & $2,1 \%$ & $92,7 \%$ \\
\hline 41 a $50 \%$ & 6 & $3,4 \%$ & $3,8 \%$ & $96,5 \%$ \\
\hline 51 a $60 \%$ & 0 & $0,3 \%$ & $0,3 \%$ & $96,8 \%$ \\
\hline 61 a $70 \%$ & 1 & $0,4 \%$ & $0,5 \%$ & $97,3 \%$ \\
\hline 71 a $80 \%$ & 1 & $0,6 \%$ & $0,7 \%$ & $98,0 \%$ \\
\hline 81 a $90 \%$ & 0 & $0,2 \%$ & $0,2 \%$ & $98,2 \%$ \\
\hline 91 a $100 \%$ & 3 & $1,6 \%$ & $1,8 \%$ & $100,0 \%$ \\
\hline Válidos Total & 147 & $89,1 \%$ & $100 \%$ & \\
\hline Perdidos & 18 & $10,9 \%$ & & \\
\hline Total & 165 & $100 \%$ & $100 \%$ & $100 \%$ \\
\hline
\end{tabular}

Fuente: Elaboración propia en base a la información obtenida de las encuestas realizadas a las empresas. 


\section{Cuadro 5}

\begin{tabular}{|l|c|c|c|c|}
\hline \multicolumn{5}{|c|}{ A través de sistema no formales de crédito } \\
\hline & Frecuencia & Porcentaje & Porcentaje válido & $\begin{array}{c}\text { Porcentaje } \\
\text { acumulado }\end{array}$ \\
\hline Validos: & 132 & $80,3 \%$ & $93,3 \%$ & $93,3 \%$ \\
$0 \%$ & 4 & $2,5 \%$ & $2,9 \%$ & $96,2 \%$ \\
1 a 10\% & 3 & $1,5 \%$ & $1,8 \%$ & $98,0 \%$ \\
11 a 20\% & 1 & $0,7 \%$ & $0,8 \%$ & $98,8 \%$ \\
21 a 30\% & 0 & $0,2 \%$ & $0,2 \%$ & $99,0 \%$ \\
31 a 40\% & 1 & $0,3 \%$ & $0,4 \%$ & $99,4 \%$ \\
41 a 50\% & 0 & $0,1 \%$ & $0,1 \%$ & $99,5 \%$ \\
61 a 70\% & 0 & $0,2 \%$ & $0,2 \%$ & $99,7 \%$ \\
71 a 80\% & 0 & $0,2 \%$ & $0,2 \%$ & $100 \%$ \\
91 a 100\% & 142 & $86,1 \%$ & $100 \%$ & \\
Válidos Total & & & & \\
& 23 & $13,9 \%$ & & $100 \%$ \\
\hline
\end{tabular}

Fuente: Elaboración propia en base a la información obtenida de las encuestas realizadas a las empresas.

\section{Cuadro 6}

\begin{tabular}{|c|c|c|c|c|}
\hline \multicolumn{5}{|c|}{ Mediante autofinanciamiento } \\
\hline & Frecuencia & Porcentaje & Porcentaje válido & $\begin{array}{l}\text { Porcentaje } \\
\text { acumulado }\end{array}$ \\
\hline Validos: & & & & \\
\hline $0 \%$ & 17 & $10,5 \%$ & $11,6 \%$ & $11,6 \%$ \\
\hline 1 a $10 \%$ & 3 & $1,5 \%$ & $1,7 \%$ & $13,3 \%$ \\
\hline 11 a $20 \%$ & 4 & $2,2 \%$ & $2,4 \%$ & $15,7 \%$ \\
\hline 21 a $30 \%$ & 5 & $3,0 \%$ & $3,3 \%$ & $19,0 \%$ \\
\hline 31 a $40 \%$ & 5 & $2,8 \%$ & $3,1 \%$ & $22,1 \%$ \\
\hline 41 a $50 \%$ & 20 & $12,1 \%$ & $13,4 \%$ & $35,5 \%$ \\
\hline 51 a $60 \%$ & 3 & $1,9 \%$ & $2,1 \%$ & $37,6 \%$ \\
\hline 61 a $70 \%$ & 8 & $5,1 \%$ & $5,6 \%$ & $43,2 \%$ \\
\hline 71 a $80 \%$ & 16 & $9,8 \%$ & $10,8 \%$ & $54,0 \%$ \\
\hline 81 a $90 \%$ & 7 & $4,2 \%$ & $4,6 \%$ & $58,6 \%$ \\
\hline 91 a $100 \%$ & 62 & $37,3 \%$ & $41,3 \%$ & $100 \%$ \\
\hline Válidos Total & 156 & $94,5 \%$ & $100 \%$ & \\
\hline Perdidos & 9 & $5,5 \%$ & & \\
\hline Total & 165 & $100 \%$ & $100 \%$ & $59 \%$ \\
\hline
\end{tabular}

Fuente: Elaboración propia en base a la información obtenida de las encuestas realizadas a las empresas. 


\section{Cuadro 7}

\begin{tabular}{|l|c|c|c|c|}
\hline \multicolumn{5}{|c|}{ Politica de tomar crédito } \\
\hline & Frecuencia & Porcentaje & Porcentaje válido & $\begin{array}{c}\text { Porcentaje } \\
\text { acumulado }\end{array}$ \\
\hline Válido & 28 & $17,0 \%$ & $17,3 \%$ & $17,3 \%$ \\
Habitual & 78 & $47,5 \%$ & $48,4 \%$ & $65,7 \%$ \\
No habitual & 56 & $33,7 \%$ & $34,3 \%$ & $100,0 \%$ \\
Nunca tomó crédito & 162 & $98,2 \%$ & & \\
Validos Total & 3 & $1,8 \%$ & & \\
& & & & $100 \%$ \\
\hline
\end{tabular}

Fuente: Elaboración propia en base a la información obtenida de las encuestas realizadas a las empresas.

Cuadro 8

\begin{tabular}{|l|c|c|c|c|}
\hline \multicolumn{5}{|c|}{ Tomo crédito } \\
\hline & Frecuencia & Porcentaje & Porcentaje válido & $\begin{array}{c}\text { Porcentaje } \\
\text { acumulado }\end{array}$ \\
\hline Válido & 63 & $38,4 \%$ & $39,6 \%$ & $39,6 \%$ \\
Si & 97 & $58,6 \%$ & $60,4 \%$ & $100,0 \%$ \\
Hace mas de 5 años o & 160 & $97,0 \%$ & & \\
Validos Total & 5 & $3,0 \%$ & & $100 \%$ \\
\hline
\end{tabular}

Fuente: Elaboración propia en base a la información obtenida de las encuestas realizadas a las empresas.

\section{Cuadro 9}

\begin{tabular}{|c|c|c|c|c|}
\hline \multicolumn{5}{|c|}{ Tiempo que hace que tomó el último crédito } \\
\hline & Frecuencia & Porcentaje & Porcentaje válido & $\begin{array}{l}\text { Porcentaje } \\
\text { acumulado }\end{array}$ \\
\hline Válido & & & & \\
\hline hace menos de 1 año & 29 & $17,4 \%$ & $17,9 \%$ & $17,9 \%$ \\
\hline entre 1 y 2 años & 20 & $12,3 \%$ & $12,7 \%$ & $30,6 \%$ \\
\hline entre 2 y 3 años & 8 & $5,1 \%$ & $5,3 \%$ & $35,9 \%$ \\
\hline entre 3 y 4 años & 3 & $2,0 \%$ & $2,1 \%$ & $38,0 \%$ \\
\hline entre 4 y 5 años & 3 & $1,6 \%$ & $1,6 \%$ & $39,6 \%$ \\
\hline $\begin{array}{l}\text { hace mas de } 5 \text { años o } \\
\text { nunca }\end{array}$ & 97 & $58,6 \%$ & $60,4 \%$ & $100,0 \%$ \\
\hline Validos Total & 160 & $97,0 \%$ & & \\
\hline Perdidos & 5 & $3,0 \%$ & & \\
\hline Total & 165 & $100 \%$ & $100 \%$ & $100 \%$ \\
\hline
\end{tabular}

Fuente: Elaboración propia en base a la información obtenida de las encuestas realizadas a las empresas. 


\section{Cuadro 10}

\begin{tabular}{|l|c|c|c|c|}
\hline \multicolumn{5}{|c|}{ Tipo de Crédito con relación al tipo de garantía } \\
\hline & Frecuencia & Porcentaje & Porcentaje válido & $\begin{array}{c}\text { Porcentaje } \\
\text { acumulado }\end{array}$ \\
\hline Validos: & & & & \\
Personal, pero con destinado a empresas & 8 & $5,1 \%$ & $13,7 \%$ & $13,7 \%$ \\
Empresarial con garantia empresarial & 40 & $24,5 \%$ & $65,2 \%$ & $78,9 \%$ \\
Empresarial con garantía personal & 6 & $3,9 \%$ & $10,4 \%$ & $89,3 \%$ \\
Empresarial sin garantía & 7 & $4,0 \%$ & $10,7 \%$ & $100,0 \%$ \\
Validos Total & 62 & $37,6 \%$ & & \\
& & & & \\
Perdidos & 103 & $62,4 \%$ & & $100 \%$ \\
\hline
\end{tabular}

Fuente: Elaboración propia en base a la información obtenida de las encuestas realizadas a las empresas.

\section{Cuadro 11}

\begin{tabular}{|l|c|c|c|c|}
\hline \multicolumn{5}{|c|}{ Finalidad del último crédito que obtuvo } \\
\hline & Frecuencia & Porcentaje & Porcentaje válido & $\begin{array}{c}\text { Porcentaje } \\
\text { acumulado }\end{array}$ \\
\hline Validos: & & & & \\
Financiación al cliente & 2 & $1,3 \%$ & $3,5 \%$ & $3,5 \%$ \\
Nuevos proyectos productivos & 5 & $2,8 \%$ & $7,4 \%$ & $10,9 \%$ \\
Inversión en I+D & 0 & $0,3 \%$ & $0,8 \%$ & $11,7 \%$ \\
Ampliación de planta & 6 & $3,7 \%$ & $9,8 \%$ & $21,5 \%$ \\
Compra de maquinaria & 23 & $13,9 \%$ & $37,1 \%$ & $58,6 \%$ \\
Compra de Materia Prima & 14 & $8,4 \%$ & $22,3 \%$ & $80,9 \%$ \\
Mejorar la estructura de vtas y distrib. & 4 & $2,4 \%$ & $6,3 \%$ & $87,2 \%$ \\
Financiación de exportaciones & 2 & $1,4 \%$ & $3,8 \%$ & $91,0 \%$ \\
Pago de salarios & 4 & $2,4 \%$ & $6,5 \%$ & $97,5 \%$ \\
Financiación de importaciones & 1 & $0,8 \%$ & $2,2 \%$ & $99,7 \%$ \\
Para pagar impuestos & 0 & $0,1 \%$ & $0,3 \%$ & $100 \%$ \\
& & & & \\
Válidos Total & 62 & $37,6 \%$ & $100 \%$ & \\
\hline Perdidos & 103 & $62,4 \%$ & & $100 \%$ \\
\hline Total & 165 & $100 \%$ & $100 \%$ & \\
\hline
\end{tabular}

Fuente: Elaboración propia en base a la información obtenida de las encuestas realizadas a las empresas. 


\section{Cuadro 12}

\begin{tabular}{|c|c|c|c|c|}
\hline \multicolumn{5}{|c|}{ Banco en el que accsedió al último crédito } \\
\hline & Frecuencia & Porcentaje & Porcentaje válido & $\begin{array}{l}\text { Porcentaje } \\
\text { acumulado }\end{array}$ \\
\hline Validos: & & & & \\
\hline Nación & 8 & $4,7 \%$ & $12,4 \%$ & $12,4 \%$ \\
\hline Provincia & 12 & $7,0 \%$ & $18,4 \%$ & $30,8 \%$ \\
\hline Macro & 0 & $0,1 \%$ & $0,3 \%$ & $31,1 \%$ \\
\hline Credicoop & 17 & $10,3 \%$ & $27,0 \%$ & $58,1 \%$ \\
\hline Galicia & 7 & $4,0 \%$ & $10,5 \%$ & $68,6 \%$ \\
\hline BBVA & 2 & $1,5 \%$ & $3,8 \%$ & $72,4 \%$ \\
\hline Santander & 6 & $3,4 \%$ & $8,9 \%$ & $81,3 \%$ \\
\hline Itau & 0 & $0,1 \%$ & $0,3 \%$ & $81,6 \%$ \\
\hline Ciudad & 2 & $1,2 \%$ & $3,2 \%$ & $84,8 \%$ \\
\hline HSBC & 2 & $1,2 \%$ & $3,2 \%$ & $88,0 \%$ \\
\hline Patagonia & 1 & $0,4 \%$ & $1,1 \%$ & $89,1 \%$ \\
\hline Superville & 1 & $0,5 \%$ & $1,4 \%$ & $90,5 \%$ \\
\hline Standard & 1 & $0,4 \%$ & $1,1 \%$ & $91,6 \%$ \\
\hline Citibank & 1 & $0,6 \%$ & $1,6 \%$ & $93,2 \%$ \\
\hline Comafi & 1 & $0,5 \%$ & $1,4 \%$ & $94,6 \%$ \\
\hline Otros & 3 & $2,1 \%$ & $5,4 \%$ & $100 \%$ \\
\hline Válidos Total & 63 & $38,2 \%$ & $100 \%$ & \\
\hline Perdidos & 102 & $61,8 \%$ & & \\
\hline Total & 165 & $100 \%$ & $100 \%$ & $100 \%$ \\
\hline
\end{tabular}

Fuente: Elaboración propia en base a la información obtenida de las encuestas realizadas a las empresas.

\section{Cuadro 13}

\begin{tabular}{|c|c|c|c|c|}
\hline \multicolumn{5}{|c|}{ Tipo de crédito que obtuvo } \\
\hline & Frecuencia & Porcentaje & Porcentaje válido & $\begin{array}{l}\text { Porcentaje } \\
\text { acumulado }\end{array}$ \\
\hline Válidos: & & & & \\
\hline Crédito a sola firma & 38 & $23,3 \%$ & $60,9 \%$ & $60,9 \%$ \\
\hline Credito hipotecario & 5 & $2,8 \%$ & $7,3 \%$ & $68,2 \%$ \\
\hline Credito prendario (incluye leasing) & 14 & $8,7 \%$ & $22,9 \%$ & $91,1 \%$ \\
\hline Fianza por SGR/FOGABA & 2 & $1,5 \%$ & $3,8 \%$ & $94,9 \%$ \\
\hline Otros & 3 & $1,9 \%$ & $5,1 \%$ & $100,0 \%$ \\
\hline Validos Total & 63 & $38,2 \%$ & & \\
\hline Perdidos & 102 & $61,8 \%$ & & \\
\hline Total & 165 & $100 \%$ & $100 \%$ & $95 \%$ \\
\hline
\end{tabular}

Fuente: Elaboración propia en base a la información obtenida de las encuestas realizadas a las empresas. 


\section{Cuadro 14}

\begin{tabular}{|l|c|c|c|c|}
\hline \multicolumn{5}{|c|}{ Evaluación del credito en cuanto a la tasa de interés } \\
\hline & Frecuencia & Porcentaje & Porcentaje válido & $\begin{array}{c}\text { Porcentaje } \\
\text { acumulado }\end{array}$ \\
\hline Válidos: & 3 & $1,8 \%$ & $4,9 \%$ & $4,9 \%$ \\
Muy accesible & 35 & $21,0 \%$ & $55,8 \%$ & $60,7 \%$ \\
Accesible & 18 & $11,2 \%$ & $29,8 \%$ & $90,5 \%$ \\
Alta & 6 & $3,6 \%$ & $9,5 \%$ & $100,0 \%$ \\
Muy alta & 62 & $37,6 \%$ & & \\
Validos Total & 103 & $62,4 \%$ & & \\
Perdidos & & & & \\
\hline Total & 165 & $100 \%$ & $100 \%$ & $100 \%$ \\
\hline
\end{tabular}

Fuente: Elaboración propia en base a la información obtenida de las encuestas realizadas a las empresas.

\section{Cuadro 16}

\begin{tabular}{|c|c|c|c|c|}
\hline \multicolumn{5}{|c|}{ Evaluación del credito en cuanto al período de gracia } \\
\hline & Frecuencia & Porcentaje & Porcentaje válido & $\begin{array}{l}\text { Porcentaje } \\
\text { acumulado }\end{array}$ \\
\hline Válidos: & & & & \\
\hline Muy conveniente & 1 & $0,4 \%$ & $1,1 \%$ & $1,1 \%$ \\
\hline Conveniente & 20 & $11,9 \%$ & $32,8 \%$ & $33,9 \%$ \\
\hline Corto & 6 & $3,9 \%$ & $10,6 \%$ & $44,5 \%$ \\
\hline Muy corto & 2 & $1,1 \%$ & $3,1 \%$ & $47,6 \%$ \\
\hline Nulo & 31 & $19,1 \%$ & $52,4 \%$ & $100,0 \%$ \\
\hline Validos Total & 60 & $36,4 \%$ & & \\
\hline Perdidos & 105 & $63,6 \%$ & & \\
\hline Total & 165 & $100 \%$ & $100 \%$ & $100 \%$ \\
\hline
\end{tabular}

Fuente: Elaboración propia en base a la información obtenida de las encuestas realizadas a las empresas.

\section{Cuadro 17}

\begin{tabular}{|l|c|c|c|c|}
\hline \multicolumn{3}{|c|}{ Evaluación del credito en cuanto al plazo de amortización } \\
\hline & Frecuencia & Porcentaje & Porcentaje válido & $\begin{array}{c}\text { Porcentaje } \\
\text { acumulado }\end{array}$ \\
\hline Válidos: & & & & \\
Muy conveniente & 1 & $0,7 \%$ & $1,9 \%$ & $1,9 \%$ \\
Conveniente & 42 & $25,5 \%$ & $69,1 \%$ & $71,0 \%$ \\
Corto & 15 & $8,9 \%$ & $24,0 \%$ & $95,0 \%$ \\
Muy corto & 3 & $1,8 \%$ & $5,0 \%$ & $100,0 \%$ \\
Validos Total & 61 & $37,0 \%$ & & \\
Perdidos & 104 & $63,0 \%$ & & \\
\hline Total & & & & \\
\hline
\end{tabular}

Fuente: Elaboración propia en base a la información obtenida de las encuestas realizadas a las empresas. 


\section{Cuadro 18}

\begin{tabular}{|l|c|c|c|c|}
\hline \multicolumn{5}{|c|}{ Evaluación del credito en cuanto al monto } \\
\hline & Frecuencia & Porcentaje & Porcentaje válido & $\begin{array}{c}\text { Porcentaje } \\
\text { acumulado }\end{array}$ \\
\hline Válidos: & 1 & $0,8 \%$ & $2,2 \%$ & $2,2 \%$ \\
Muy suficiente & 43 & $26,3 \%$ & $71,1 \%$ & $73,3 \%$ \\
Suficiente & 15 & $9,4 \%$ & $25,3 \%$ & $98,6 \%$ \\
Insuficiente & 1 & $0,5 \%$ & $1,4 \%$ & $100,0 \%$ \\
Muy insuficiente & 61 & $37,0 \%$ & & \\
Validos Total & 104 & $63,0 \%$ & & \\
Perdidos & & & & $100 \%$ \\
\hline Total & 165 & $100 \%$ & $100 \%$ & \\
\hline
\end{tabular}

Fuente: Elaboración propia en base a la información obtenida de las encuestas realizadas a las empresas.

\section{Cuadro 19}

\begin{tabular}{|l|c|c|c|c|}
\hline \multicolumn{5}{|c|}{ Evaluación del credito en cuanto a los requisitos solicitados } \\
\hline & Frecuencia & Porcentaje & Porcentaje válido & $\begin{array}{c}\text { Porcentaje } \\
\text { acumulado }\end{array}$ \\
\hline Válidos: & & & & \\
Muy accesible & 3 & $1,6 \%$ & $4,4 \%$ & $4,4 \%$ \\
Accesible & 44 & $26,9 \%$ & $72,7 \%$ & $77,1 \%$ \\
Alto & 10 & $5,9 \%$ & $16,0 \%$ & $93,1 \%$ \\
Muy alto & 4 & $2,6 \%$ & $6,9 \%$ & $100,0 \%$ \\
Validos Total & & & & \\
Perdidos & 104 & $63,0 \%$ & & \\
\hline Total & & & & \\
\hline
\end{tabular}

Fuente: Elaboración propia en base a la información obtenida de las encuestas realizadas a las empresas.

\section{Cuadro 20}

\begin{tabular}{|l|c|c|c|c|}
\hline \multicolumn{3}{|c|}{ Evaluación del credito en cuanto a la complejidad de los trámites y planillas } \\
\hline & Frecuencia & Porcentaje & Porcentaje válido & $\begin{array}{c}\text { Porcentaje } \\
\text { acumulado }\end{array}$ \\
\hline Válidos: & & & & \\
Muy sencillo & 4 & $2,4 \%$ & $6,4 \%$ & $6,4 \%$ \\
Sencillo & 40 & $24,1 \%$ & $65,2 \%$ & $71,6 \%$ \\
Complejo & 14 & $8,4 \%$ & $22,7 \%$ & $94,3 \%$ \\
Muy complejo & 4 & $2,1 \%$ & $5,8 \%$ & $100,1 \%$ \\
Validos Total & & & & \\
Perdidos & 104 & $63,0 \%$ & & \\
\hline Total & & & & \\
\hline
\end{tabular}

Fuente: Elaboración propia en base a la información obtenida de las encuestas realizadas a las empresas. 


\section{Cuadro 21}

\begin{tabular}{|l|c|c|c|c|}
\hline \multicolumn{5}{|c|}{ Evaluación del credito en cuanto a la atención para la gestión } \\
\hline & Frecuencia & Porcentaje & Porcentaje válido & $\begin{array}{c}\text { Porcentaje } \\
\text { acumulado }\end{array}$ \\
\hline Válidos: & 7 & $4,5 \%$ & $12,4 \%$ & $12,4 \%$ \\
Muy cordial & 52 & $31,3 \%$ & $86,2 \%$ & $98,6 \%$ \\
cordial & 1 & $0,4 \%$ & $1,1 \%$ & $99,7 \%$ \\
Mala & 0 & $0,1 \%$ & $0,3 \%$ & $100,0 \%$ \\
Muy mala & 60 & $36,4 \%$ & & \\
Validos Total & 105 & $63,6 \%$ & & \\
& & & & \\
Perdidos & 165 & $100 \%$ & $100 \%$ & $100 \%$ \\
\hline
\end{tabular}

Fuente: Elaboración propia en base a la información obtenida de las encuestas realizadas a las empresas.

\section{Cuadro 22}

\begin{tabular}{|c|c|c|c|c|}
\hline \multicolumn{5}{|c|}{ Evaluación del credito en cuanto al tiempo de adjudicación } \\
\hline & Frecuencia & Porcentaje & Porcentaje válido & $\begin{array}{l}\text { Porcentaje } \\
\text { acumulado }\end{array}$ \\
\hline Válidos: & & & & \\
\hline Muy rápido & 6 & $3,5 \%$ & $9,5 \%$ & $9,5 \%$ \\
\hline Rápido & 42 & $25,2 \%$ & $68,2 \%$ & $77,7 \%$ \\
\hline Lento & 11 & $6,7 \%$ & $18,1 \%$ & $95,8 \%$ \\
\hline Muy lento & 3 & $1,6 \%$ & $4,2 \%$ & $100,0 \%$ \\
\hline Validos Total & 61 & $37,0 \%$ & & \\
\hline Perdidos & 104 & $63,0 \%$ & & \\
\hline Total & 165 & $100 \%$ & $100 \%$ & $100 \%$ \\
\hline
\end{tabular}

Fuente: Elaboración propia en base a la información obtenida de las encuestas realizadas a las empresas.

\section{Cuadro 23}

\begin{tabular}{|c|c|c|c|c|}
\hline \multicolumn{5}{|c|}{ Empleo de documentos cheques y remesas } \\
\hline & Frecuencia & Porcentaje & Porcentaje válido & $\begin{array}{l}\text { Porcentaje } \\
\text { acumulado }\end{array}$ \\
\hline Válidos: & & & & \\
\hline $\mathrm{Si}$ & 51 & $31,1 \%$ & $32,3 \%$ & $32,3 \%$ \\
\hline No & 107 & $65,1 \%$ & $67,6 \%$ & $99,9 \%$ \\
\hline $\mathrm{Ns} / \mathrm{Nc}$ & 0 & $0,1 \%$ & $0,1 \%$ & $100,0 \%$ \\
\hline Validos Total & 159 & $96,4 \%$ & & \\
\hline Perdidos & 6 & $3,6 \%$ & & \\
\hline Total & 165 & $100 \%$ & $100 \%$ & $100 \%$ \\
\hline
\end{tabular}

Fuente: Elaboración propia en base a la información obtenida de las encuestas realizadas a las empresas. 


\section{Cuadro 24}

\begin{tabular}{|c|c|c|c|c|}
\hline \multicolumn{5}{|c|}{ Empleo de descubierto en cuenta corriente } \\
\hline & Frecuencia & Porcentaje & Porcentaje válido & $\begin{array}{l}\text { Porcentaje } \\
\text { acumulado }\end{array}$ \\
\hline Válidos: & & & & \\
\hline $\mathrm{Si}$ & 51 & $30,8 \%$ & $32,0 \%$ & $32,0 \%$ \\
\hline No & 108 & $65,4 \%$ & $67,9 \%$ & $99,9 \%$ \\
\hline $\mathrm{Ns} / \mathrm{Nc}$ & 0 & $0,1 \%$ & $0,1 \%$ & $100,0 \%$ \\
\hline Validos Total & 159 & $96,4 \%$ & & \\
\hline Perdidos & 6 & $3,6 \%$ & & \\
\hline Total & 165 & $100 \%$ & $100 \%$ & $100 \%$ \\
\hline
\end{tabular}

Fuente: Elaboración propia en base a la información obtenida de las encuestas realizadas a las empresas.

\section{Cuadro 25}

\begin{tabular}{|l|c|c|c|c|}
\hline \multicolumn{5}{|c|}{ Empleo de prestamos amortizables de interés vencidos (PAIV) } \\
\hline & Frecuencia & Porcentaje & Porcentaje válido & $\begin{array}{c}\text { Porcentaje } \\
\text { acumulado }\end{array}$ \\
\hline Válidos: & & & & \\
$\mathrm{Si}$ & 150 & $91,2 \%$ & $94,6 \%$ & $9,3 \%$ \\
No & 0 & $0,1 \%$ & $0,1 \%$ & $100,0 \%$ \\
Ns/Nc & 159 & $96,4 \%$ & & \\
Validos Total & 6 & $3,6 \%$ & & \\
Perdidos & & & & \\
\hline Total & 165 & $100 \%$ & $100 \%$ & $100 \%$ \\
\hline
\end{tabular}

Fuente: Elaboración propia en base a la información obtenida de las encuestas realizadas a las empresas.

\section{Cuadro 26}

\begin{tabular}{|c|c|c|c|c|}
\hline \multicolumn{5}{|c|}{ No emplea ninguna herramienta de financiamiento } \\
\hline & Frecuencia & Porcentaje & Porcentaje válido & $\begin{array}{l}\text { Porcentaje } \\
\text { acumulado }\end{array}$ \\
\hline Válidos: & & & & \\
\hline Si & 81 & $49,2 \%$ & $51,1 \%$ & $51,1 \%$ \\
\hline No & 78 & $47,0 \%$ & $48,8 \%$ & $99,9 \%$ \\
\hline $\mathrm{Ns} / \mathrm{Nc}$ & 0 & $0,1 \%$ & $0,1 \%$ & $100,0 \%$ \\
\hline Validos Total & 159 & $96,4 \%$ & & \\
\hline Perdidos & 6 & $3,6 \%$ & & \\
\hline Total & 165 & $100 \%$ & $100 \%$ & $100 \%$ \\
\hline
\end{tabular}

Fuente: Elaboración propia en base a la información obtenida de las encuestas realizadas a las empresas. 


\section{Cuadro 27}

\begin{tabular}{|c|c|c|c|c|}
\hline \multicolumn{5}{|c|}{ Casos que averiguaron por créditos y que luego no tomaron } \\
\hline & Frecuencia & Porcentaje & Porcentaje válido & $\begin{array}{l}\text { Porcentaje } \\
\text { acumulado }\end{array}$ \\
\hline Válidos: & & & & \\
\hline $\mathrm{Si}$ & 86 & $52,0 \%$ & $55,7 \%$ & $55,7 \%$ \\
\hline No & 56 & $33,9 \%$ & $36,3 \%$ & $92,0 \%$ \\
\hline $\mathrm{Ns} / \mathrm{Nc}$ & 12 & $7,5 \%$ & $8,0 \%$ & $100,0 \%$ \\
\hline Validos Total & 154 & $93,3 \%$ & & \\
\hline Perdidos & 11 & $6,7 \%$ & & \\
\hline Total & 165 & $100 \%$ & $100 \%$ & $100 \%$ \\
\hline
\end{tabular}

Fuente: Elaboración propia en base a la información obtenida de las encuestas realizadas a las empresas.

\section{Cuadro 28}

\begin{tabular}{|c|c|c|c|c|}
\hline \multicolumn{5}{|c|}{ Banco de mayor preferencia $\left(1^{\circ}\right)$} \\
\hline & Frecuencia & Porcentaje & Porcentaje válido & $\begin{array}{l}\text { Porcentaje } \\
\text { acumulado }\end{array}$ \\
\hline Válidos: & & & & \\
\hline Nación & 25 & $15,0 \%$ & $15,6 \%$ & $15,6 \%$ \\
\hline Provincia & 23 & $14,2 \%$ & $14,7 \%$ & $30,3 \%$ \\
\hline Macro & 1 & $0,6 \%$ & $0,6 \%$ & $30,9 \%$ \\
\hline Credicoop & 39 & $23,7 \%$ & $24,6 \%$ & $55,5 \%$ \\
\hline Galicia & 19 & $11,5 \%$ & $11,9 \%$ & $67,4 \%$ \\
\hline BBVA & 12 & $7,2 \%$ & $7,5 \%$ & $74,9 \%$ \\
\hline Santander & 19 & $11,3 \%$ & $11,7 \%$ & $86,6 \%$ \\
\hline Itau & 1 & $0,7 \%$ & $0,7 \%$ & $87,3 \%$ \\
\hline Ciudad & 1 & $0,9 \%$ & $0,9 \%$ & $88,2 \%$ \\
\hline HSBC & 6 & $3,5 \%$ & $3,6 \%$ & $91,8 \%$ \\
\hline Patagonia & 3 & $1,8 \%$ & $1,9 \%$ & $93,7 \%$ \\
\hline Superville & 1 & $0,9 \%$ & $0,9 \%$ & $94,6 \%$ \\
\hline Standard & 3 & $1,8 \%$ & $1,9 \%$ & $96,5 \%$ \\
\hline Citibank & 2 & $1,1 \%$ & $1,1 \%$ & $97,6 \%$ \\
\hline Comafi & 2 & $1,3 \%$ & $1,4 \%$ & $99,0 \%$ \\
\hline Otros & 2 & $1,0 \%$ & $1,0 \%$ & $100 \%$ \\
\hline Válidos Total & 159 & $96,4 \%$ & $100 \%$ & \\
\hline Perdidos & 6 & $3,6 \%$ & & \\
\hline Total & 165 & $100 \%$ & $100 \%$ & $100 \%$ \\
\hline
\end{tabular}

Fuente: Elaboración propia en base a la información obtenida de las encuestas realizadas a las empresas. 
Cuadro 29

\begin{tabular}{|c|c|c|c|c|}
\hline \multicolumn{5}{|c|}{ Banco de mayor preferencia $\left(2^{\circ}\right)$} \\
\hline & Frecuencia & Porcentaje & Porcentaje válido & $\begin{array}{l}\text { Porcentaje } \\
\text { acumulado }\end{array}$ \\
\hline Válidos: & & & & \\
\hline Nación & 16 & $9,8 \%$ & $13,1 \%$ & $13,1 \%$ \\
\hline Provincia & 27 & $16,3 \%$ & $21,9 \%$ & $35,0 \%$ \\
\hline Macro & 1 & $0,6 \%$ & $0,8 \%$ & $35,8 \%$ \\
\hline Credicoop & 18 & $10,7 \%$ & $14,3 \%$ & $50,1 \%$ \\
\hline Galicia & 14 & $8,3 \%$ & $11,2 \%$ & $61,3 \%$ \\
\hline BBVA & 11 & $6,7 \%$ & $9,0 \%$ & $70,3 \%$ \\
\hline Santander & 16 & $10,0 \%$ & $13,4 \%$ & $83,7 \%$ \\
\hline Itau & 1 & $0,4 \%$ & $0,6 \%$ & $84,3 \%$ \\
\hline Ciudad & 1 & $0,4 \%$ & $0,6 \%$ & $84,9 \%$ \\
\hline HSBC & 8 & $4,5 \%$ & $6,1 \%$ & $91,0 \%$ \\
\hline Patagonia & 2 & $1,4 \%$ & $1,9 \%$ & $92,9 \%$ \\
\hline Superville & 1 & $0,9 \%$ & $1,2 \%$ & $94,1 \%$ \\
\hline Standard & 3 & $1,7 \%$ & $2,3 \%$ & $96,4 \%$ \\
\hline Citibank & 2 & $1,0 \%$ & $1,4 \%$ & $97,8 \%$ \\
\hline Comafi & 2 & $1,0 \%$ & $1,4 \%$ & $99,2 \%$ \\
\hline Otros & 1 & $0,7 \%$ & $1,0 \%$ & $100 \%$ \\
\hline Válidos Total & 123 & $74,5 \%$ & $100 \%$ & \\
\hline Perdidos & 42 & $25,5 \%$ & & \\
\hline Total & 165 & $100 \%$ & $100 \%$ & $100 \%$ \\
\hline
\end{tabular}

Fuente: Elaboración propia en base a la información obtenida de las encuestas realizadas a las empresas. 


\section{Cuadro 30}

\begin{tabular}{|c|c|c|c|c|}
\hline \multicolumn{5}{|c|}{ Banco de mayor preferencia $\left(3^{\circ}\right)$} \\
\hline & Frecuencia & Porcentaje & Porcentaje válido & $\begin{array}{l}\text { Porcentaje } \\
\text { acumulado }\end{array}$ \\
\hline Válidos: & & & & \\
\hline Nación & 11 & $6,6 \%$ & $12,9 \%$ & $12,9 \%$ \\
\hline Provincia & 15 & $9,1 \%$ & $17,7 \%$ & $30,6 \%$ \\
\hline Macro & 2 & $1,3 \%$ & $2,6 \%$ & $33,2 \%$ \\
\hline Credicoop & 10 & $6,0 \%$ & $11,7 \%$ & $44,9 \%$ \\
\hline Galicia & 10 & $5,8 \%$ & $11,3 \%$ & $56,2 \%$ \\
\hline BBVA & 7 & $4,4 \%$ & $8,5 \%$ & $64,7 \%$ \\
\hline Santander & 12 & $7,4 \%$ & $14,3 \%$ & $79,0 \%$ \\
\hline Itau & 1 & $0,4 \%$ & $0,8 \%$ & $79,8 \%$ \\
\hline Ciudad & 2 & $0,9 \%$ & $1,8 \%$ & $81,6 \%$ \\
\hline HSBC & 5 & $3,2 \%$ & $6,3 \%$ & $87,9 \%$ \\
\hline Patagonia & 3 & $1,5 \%$ & $3,0 \%$ & $90,9 \%$ \\
\hline Superville & 0 & $0,1 \%$ & $0,2 \%$ & $91,1 \%$ \\
\hline Standard & 2 & $1,2 \%$ & $2,4 \%$ & $93,5 \%$ \\
\hline Citibank & 2 & $1,3 \%$ & $2,6 \%$ & $96,1 \%$ \\
\hline Comafi & 2 & $1,2 \%$ & $2,4 \%$ & $98,5 \%$ \\
\hline Otros & 1 & $0,8 \%$ & $1,6 \%$ & $100 \%$ \\
\hline Válidos Total & 85 & $51,5 \%$ & $100 \%$ & \\
\hline Perdidos & 80 & $48,5 \%$ & & \\
\hline Total & 165 & $100 \%$ & $100 \%$ & $100 \%$ \\
\hline
\end{tabular}

Fuente: Elaboración propia en base a la información obtenida de las encuestas realizadas a las empresas.

\section{Cuadro 31}

\begin{tabular}{|l|c|c|c|c|}
\hline \multicolumn{5}{|c|}{ Puntos de tasa de interés que reasignaría por un crédito agil y rápido para capital } \\
de trabajo \\
\hline & Frecuencia & Porcentaje & Porcentaje válido & $\begin{array}{c}\text { Porcentaje } \\
\text { acumulado }\end{array}$ \\
\hline Válidos: & & & & \\
0 & 84 & $51,2 \%$ & $52,8 \%$ & $52,8 \%$ \\
1 & 21 & $12,5 \%$ & $12,9 \%$ & $65,7 \%$ \\
2 & 31 & $18,8 \%$ & $19,4 \%$ & $85,1 \%$ \\
3 & 10 & $6,3 \%$ & $6,5 \%$ & $91,6 \%$ \\
4 & 5 & $3,0 \%$ & $3,1 \%$ & $94,7 \%$ \\
Más de 4 & 7 & $4,3 \%$ & $4,3 \%$ & $99,0 \%$ \\
Ns/Nc & 2 & $1,0 \%$ & $1,0 \%$ & $100,0 \%$ \\
Validos Total & 160 & $97,0 \%$ & & \\
& & & & \\
Perdidos & 5 & $3,0 \%$ & & $100 \%$ \\
\hline
\end{tabular}

Fuente: Elaboración propia en base a la información obtenida de las encuestas realizadas a las empresas. 


\section{Cuadro 32}

\begin{tabular}{|l|c|c|c|c|}
\hline \multicolumn{5}{|c|}{ Puntos de tasa de interés que reasignaría por un crédito agil y rápido para } \\
inversión \\
\hline & Frecuencia & Porcentaje & $\begin{array}{c}\text { Porcentaje } \\
\text { válido }\end{array}$ & $\begin{array}{c}\text { Porcentaje } \\
\text { acumulado }\end{array}$ \\
\hline Válidos: & 86 & $51,9 \%$ & $53,9 \%$ & $53,9 \%$ \\
0 & 20 & $11,9 \%$ & $12,3 \%$ & $66,2 \%$ \\
1 & 28 & $16,8 \%$ & $17,4 \%$ & $83,6 \%$ \\
2 & 13 & $7,7 \%$ & $8,0 \%$ & $91,6 \%$ \\
3 & 5 & $3,1 \%$ & $3,2 \%$ & $94,8 \%$ \\
4 & 6 & $3,8 \%$ & $3,9 \%$ & $98,7 \%$ \\
Más de 4 & 2 & $1,2 \%$ & $1,2 \%$ & $100 \%$ \\
Ns/Nc & 159 & $96,4 \%$ & & \\
Validos Total & & & & \\
Perdidos & 6 & $3,6 \%$ & & $100 \%$ \\
\hline
\end{tabular}

Fuente: Elaboración propia en base a la información obtenida de las encuestas realizadas a las empresas.

Cuadro 33

\begin{tabular}{|l|c|c|c|c|}
\hline \multicolumn{5}{|c|}{ Conoces la lineas crediticias de fomentos disponibles en la provincia } \\
\hline & Frecuencia & Porcentaje & $\begin{array}{c}\text { Porcentaje } \\
\text { válido }\end{array}$ & $\begin{array}{c}\text { Porcentaje } \\
\text { acumulado }\end{array}$ \\
\hline Válidos: & 57 & $34,3 \%$ & $34,3 \%$ & $34,3 \%$ \\
$\mathrm{Si}$ & 108 & $65,7 \%$ & $65,7 \%$ & $100,0 \%$ \\
No & 165 & $100,0 \%$ & & \\
Validos Total & 165 & $100 \%$ & $100 \%$ & $100 \%$ \\
\hline
\end{tabular}

Fuente: Elaboración propia en base a la información obtenida de las encuestas realizadas a las empresas.

\section{Cuadro 34}

\begin{tabular}{|l|c|c|c|c|}
\hline \multicolumn{5}{|c|}{ Conoces la línea Fuerza Productiva } \\
\hline & Frecuencia & Porcentaje & $\begin{array}{c}\text { Porcentaje } \\
\text { válido }\end{array}$ & $\begin{array}{c}\text { Porcentaje } \\
\text { acumulado }\end{array}$ \\
\hline Válidos: & 26 & $15,8 \%$ & $16,1 \%$ & $16,1 \%$ \\
Si & 136 & $82,4 \%$ & $83,9 \%$ & $100,0 \%$ \\
No & 162 & $98,2 \%$ & & \\
Validos Total & 3 & $1,8 \%$ & & \\
\hline Perdidos & 165 & $100 \%$ & $100 \%$ & $100 \%$ \\
\hline
\end{tabular}

Fuente: Elaboración propia en base a la información obtenida de las encuestas realizadas a las empresas. 


\section{Cuadro 35}

\begin{tabular}{|l|c|c|c|c|}
\hline \multicolumn{5}{|c|}{ Conoces la línea Préstamos PyMEs de ANSES } \\
\hline & Frecuencia & Porcentaje & $\begin{array}{c}\text { Porcentaje } \\
\text { válido }\end{array}$ & $\begin{array}{r}\text { Porcentaje } \\
\text { acumulado }\end{array}$ \\
\hline Válidos: & 32 & $19,2 \%$ & $19,6 \%$ & $19,6 \%$ \\
Si & 130 & $78,9 \%$ & $80,4 \%$ & $100,0 \%$ \\
No & 162 & $98,2 \%$ & & \\
Validos Total & 3 & $1,8 \%$ & & \\
\hline Perdidos & 165 & $100 \%$ & $100 \%$ & $100 \%$ \\
\hline
\end{tabular}

Fuente: Elaboración propia en base a la información obtenida de las encuestas realizadas a las empresas.

Cuadro 36

\begin{tabular}{|l|c|c|c|c|}
\hline \multicolumn{5}{|c|}{ Conoces la línea Fuerza PyME } \\
\hline & Frecuencia & Porcentaje & $\begin{array}{c}\text { Porcentaje } \\
\text { válido }\end{array}$ & $\begin{array}{c}\text { Porcentaje } \\
\text { acumulado }\end{array}$ \\
\hline Válidos: & 30 & $18,4 \%$ & $18,7 \%$ & $18,7 \%$ \\
Si & 132 & $79,8 \%$ & $81,3 \%$ & $100,0 \%$ \\
No & 162 & $98,2 \%$ & & \\
Validos Total & 3 & $1,8 \%$ & & $100 \%$ \\
\hline
\end{tabular}

Fuente: Elaboración propia en base a la información obtenida de las encuestas realizadas a las empresas.

Cuadro 37

\begin{tabular}{|l|c|c|c|c|}
\hline \multicolumn{5}{|c|}{ Conoces alguna otra línea de fomento } \\
\hline & Frecuencia & Porcentaje & $\begin{array}{c}\text { Porcentaje } \\
\text { válido }\end{array}$ & $\begin{array}{c}\text { Porcentaje } \\
\text { acumulado }\end{array}$ \\
\hline Válidos: & 11 & $6,9 \%$ & $7,0 \%$ & $7,0 \%$ \\
Si & 151 & $91,3 \%$ & $93,0 \%$ & $100,0 \%$ \\
No & 162 & $98,2 \%$ & & \\
Validos Total & 3 & $1,8 \%$ & & \\
\hline Perdidos & 165 & $100 \%$ & $100 \%$ & $100 \%$ \\
\hline
\end{tabular}

Fuente: Elaboración propia en base a la información obtenida de las encuestas realizadas a las empresas. 
Cuadro 38

\begin{tabular}{|l|c|c|c|c|}
\hline \multicolumn{5}{|c|}{ Utilizó alguna línea crediticia de fomento disponible en la provincia } \\
\hline & Frecuencia & Porcentaje & $\begin{array}{c}\text { Porcentaje } \\
\text { válido }\end{array}$ & $\begin{array}{c}\text { Porcentaje } \\
\text { acumulado }\end{array}$ \\
\hline Válidos: & 8 & $5,0 \%$ & $5,0 \%$ & $5,0 \%$ \\
Si & 157 & $95,0 \%$ & $95,0 \%$ & $100,0 \%$ \\
No & 165 & $100,0 \%$ & & \\
Validos Total & 165 & $100 \%$ & $100 \%$ & $100 \%$ \\
\hline
\end{tabular}

Fuente: Elaboración propia en base a la información obtenida de las encuestas realizadas a las empresas.

\section{Cuadro 39}

\begin{tabular}{|l|c|c|c|c|}
\hline \multicolumn{4}{|c|}{ Utilizó alguna línea Fuerza Productiva } \\
\hline & Frecuencia & Porcentaje & $\begin{array}{c}\text { Porcentaje } \\
\text { válido }\end{array}$ & $\begin{array}{c}\text { Porcentaje } \\
\text { acumulado }\end{array}$ \\
\hline Válidos: & 1 & $0,9 \%$ & $0,9 \%$ & $0,9 \%$ \\
Si & 164 & $99,1 \%$ & $99,1 \%$ & $100,0 \%$ \\
No & 165 & $100,0 \%$ & & \\
Validos Total & 165 & $100 \%$ & $100 \%$ & $100 \%$ \\
\hline Total & & & & \\
\hline
\end{tabular}

Fuente: Elaboración propia en base a la información obtenida de las encuestas realizadas a las empresas. Cuadro 40

\begin{tabular}{|l|c|c|c|c|}
\hline \multicolumn{5}{|c|}{ Utilizó alguna línea de Prestamos PyMEs de ANSES } \\
\hline & Frecuencia & Porcentaje & $\begin{array}{c}\text { Porcentaje } \\
\text { válido }\end{array}$ & $\begin{array}{c}\text { Porcentaje } \\
\text { acumulado }\end{array}$ \\
\hline Válidos: & 5 & $2,9 \%$ & $2,9 \%$ & $2,9 \%$ \\
Si & 160 & $97,1 \%$ & $97,1 \%$ & $100,0 \%$ \\
No & 165 & $100,0 \%$ & & \\
Validos Total & 165 & $100 \%$ & $100 \%$ & $100 \%$ \\
\hline
\end{tabular}

Fuente: Elaboración propia en base a la información obtenida de las encuestas realizadas a las empresas.

\section{Cuadro 41}

\begin{tabular}{|l|c|c|c|c|}
\hline \multicolumn{5}{|c|}{ Utilizó la línea fuerza PyME } \\
\hline & Frecuencia & Porcentaje & $\begin{array}{c}\text { Porcentaje } \\
\text { válido }\end{array}$ & $\begin{array}{r}\text { Porcentaje } \\
\text { acumulado }\end{array}$ \\
\hline Válidos: & 2 & $1,2 \%$ & $1,2 \%$ & $1,2 \%$ \\
Si & 163 & $98,8 \%$ & $98,8 \%$ & $100,0 \%$ \\
No & 165 & $100,0 \%$ & & \\
Validos Total & 165 & $100 \%$ & $100 \%$ & $100 \%$ \\
\hline Total & & & & \\
\hline
\end{tabular}

Fuente: Elaboración propia en base a la información obtenida de las encuestas realizadas a las empresas. 


\section{Cuadro 42}

\begin{tabular}{|l|c|c|c|c|}
\hline \multicolumn{5}{|c|}{ Utilizó alguna otra línea de fomento disponible en la provincia } \\
\hline & Frecuencia & Porcentaje & $\begin{array}{c}\text { Porcentaje } \\
\text { válido }\end{array}$ & $\begin{array}{c}\text { Porcentaje } \\
\text { acumulado }\end{array}$ \\
\hline Válidos: & 1 & $0,9 \%$ & $0,9 \%$ & $0,9 \%$ \\
Si & 164 & $99,1 \%$ & $99,1 \%$ & $100,0 \%$ \\
No & 165 & $100,0 \%$ & & \\
Validos Total & 165 & $100 \%$ & $100 \%$ & $100 \%$ \\
\hline
\end{tabular}

Fuente: Elaboración propia en base a la información obtenida de las encuestas realizadas a las empresas.

Cuadro 43

\begin{tabular}{|l|c|c|c|c|}
\hline \multicolumn{5}{|c|}{ Municipios en donde está emplazadas la empresa } \\
\hline & Frecuencia & Porcentaje & $\begin{array}{c}\text { Porcentaje } \\
\text { válido }\end{array}$ & $\begin{array}{c}\text { Porcentaje } \\
\text { acumulado }\end{array}$ \\
\hline Válidos: & 37 & $22,4 \%$ & $22,4 \%$ & $22,4 \%$ \\
Avellaneda & 15 & $9,1 \%$ & $9,1 \%$ & $31,5 \%$ \\
Berazategui & 13 & $7,9 \%$ & $7,9 \%$ & $39,4 \%$ \\
Ensenada & 4 & $2,4 \%$ & $2,4 \%$ & $41,8 \%$ \\
Florencio Varela & 36 & $21,8 \%$ & $21,8 \%$ & $63,6 \%$ \\
La Plata & 6 & $3,6 \%$ & $3,6 \%$ & $67,3 \%$ \\
Magdalena & 14 & $8,5 \%$ & $8,5 \%$ & $75,8 \%$ \\
Berisso & 40 & $24,2 \%$ & $24,2 \%$ & $100 \%$ \\
Quilmes & 165 & $100,0 \%$ & $100 \%$ & \\
Válidos Total & & & & \\
& 0 & $0,0 \%$ & & $100 \%$ \\
\hline
\end{tabular}

Fuente: Elaboración propia en base a la información obtenida de las encuestas realizadas a las empresas. 


\section{Cuadro 44}

\begin{tabular}{|c|c|c|c|c|}
\hline \multicolumn{5}{|c|}{ Bloque industrial x 12} \\
\hline & Frecuencia & Porcentaje & $\begin{array}{c}\text { Porcentaje } \\
\text { válido }\end{array}$ & $\begin{array}{l}\text { Porcentaje } \\
\text { acumulado }\end{array}$ \\
\hline Válidos: & & & & \\
\hline Alimentos & 7 & $4,3 \%$ & $4,3 \%$ & $4,3 \%$ \\
\hline Productos textiles y cueros & 15 & $8,8 \%$ & $8,8 \%$ & $13,1 \%$ \\
\hline Madera & 4 & $2,2 \%$ & $2,2 \%$ & $15,3 \%$ \\
\hline Papel y productos de papel & 8 & $4,9 \%$ & $4,9 \%$ & $20,2 \%$ \\
\hline Petroleo & 0 & $0,3 \%$ & $0,3 \%$ & $20,5 \%$ \\
\hline Químicos, caucho y plástico & 34 & $20,6 \%$ & $20,6 \%$ & $41,1 \%$ \\
\hline Minerales no metalicos & 4 & $2,2 \%$ & $2,2 \%$ & $43,3 \%$ \\
\hline Metales comunes y productos elaborados de metal & 47 & $28,6 \%$ & $28,6 \%$ & $71,9 \%$ \\
\hline Maquinaria y equipos & 13 & $8,0 \%$ & $8,0 \%$ & $79,9 \%$ \\
\hline Aparatos electricos en general (TV, radio, etc) & 17 & $10,2 \%$ & $10,2 \%$ & $90,1 \%$ \\
\hline Vehiculos y otros transportes & 11 & $6,7 \%$ & $6,7 \%$ & $96,8 \%$ \\
\hline Fabricación de muebles y otras industrias & 5 & $3,3 \%$ & $3,3 \%$ & $100 \%$ \\
\hline Válidos Total & 165 & $100 \%$ & $100 \%$ & \\
\hline Perdidos & 0 & $0,0 \%$ & & \\
\hline Total & 165 & $100 \%$ & $100 \%$ & $100 \%$ \\
\hline
\end{tabular}

Fuente: Elaboración propia en base a la información obtenida de las encuestas realizadas a las empresas.

Cuadro 45

\begin{tabular}{|l|c|c|c|c|}
\hline \multicolumn{5}{|c|}{ Antigüedad agrupada en rangos } \\
\hline & Frecuencia & Porcentaje & $\begin{array}{c}\text { Porcentaje } \\
\text { válido }\end{array}$ & $\begin{array}{c}\text { Porcentaje } \\
\text { acumulado }\end{array}$ \\
\hline Válidos: & 14 & $8,2 \%$ & $8,3 \%$ & $8,3 \%$ \\
De 1 a 5 años & 20 & $12,0 \%$ & $12,1 \%$ & $20,4 \%$ \\
De 6 a 10 años & 35 & $21,3 \%$ & $21,4 \%$ & $41,8 \%$ \\
De 11 a 20 años & 30 & $17,9 \%$ & $18,0 \%$ & $59,8 \%$ \\
De 21 a 30 años & 30 & $18,1 \%$ & $18,2 \%$ & $78,0 \%$ \\
De 31 a 40 ñaos & 21 & $12,6 \%$ & $12,7 \%$ & $90,7 \%$ \\
De 41 a 50 años & 15 & $9,1 \%$ & $9,2 \%$ & $100 \%$ \\
51años o más & 164 & $99,4 \%$ & $100 \%$ & \\
Válidos Total & 1 & $0,6 \%$ & & $100 \%$ \\
\hline
\end{tabular}

Fuente: Elaboración propia en base a la información obtenida de las encuestas realizadas a las empresas. 


\section{Cuadro 46}

\begin{tabular}{|c|c|c|c|c|}
\hline \multicolumn{5}{|c|}{ Codigo CIIU (2 digitos) } \\
\hline & Frecuencia & Porcentaje & $\begin{array}{c}\text { Porcentaje } \\
\text { válido }\end{array}$ & $\begin{array}{l}\text { Porcentaje } \\
\text { acumulado }\end{array}$ \\
\hline Válidos: & & & & \\
\hline Elaboración de alimentos y bebidas & 7 & $4,3 \%$ & $4,3 \%$ & $4,3 \%$ \\
\hline Fabricación de productos textiles & 4 & $2,6 \%$ & $2,6 \%$ & $6,9 \%$ \\
\hline Fabricación de prendas de vestir, terminación y tenido de pieles & 3 & $1,8 \%$ & $1,8 \%$ & $8,7 \%$ \\
\hline Curtido y terminación de cueros & 7 & $4,4 \%$ & $4,4 \%$ & $13,1 \%$ \\
\hline Producción de madera y fabricación de productos & 4 & $2,2 \%$ & $2,2 \%$ & $15,3 \%$ \\
\hline Fabricación de papel & 5 & $3,2 \%$ & $3,2 \%$ & $18,5 \%$ \\
\hline Actividades de edición e impresión & 3 & $1,7 \%$ & $1,7 \%$ & $20,2 \%$ \\
\hline Fabricación de coque y productos de refinados de petroleo & 0 & $0,3 \%$ & $0,3 \%$ & $20,5 \%$ \\
\hline Fabricación de sustancia y productos químicos & 12 & $7,5 \%$ & $7,5 \%$ & $28,0 \%$ \\
\hline Fabricación de caucho y plástico & 22 & $13,1 \%$ & $13,1 \%$ & $41,1 \%$ \\
\hline Fabricación de otros productos minerales no metalicos & 4 & $2,2 \%$ & $2,2 \%$ & $43,3 \%$ \\
\hline Fabricación de metales comunes & 1 & $0,9 \%$ & $0,9 \%$ & $44,2 \%$ \\
\hline Fabricacion de productos elaborados de metal & 46 & $27,7 \%$ & $27,7 \%$ & $71,9 \%$ \\
\hline Fabricación de maquinarias y equipos & 13 & $8,0 \%$ & $8,0 \%$ & $79,9 \%$ \\
\hline Fabricación de maquinarias de oficina & 0 & $0,1 \%$ & $0,1 \%$ & $80,0 \%$ \\
\hline Fabricación de maquinarias y aparatos electricos & 12 & $7,5 \%$ & $7,5 \%$ & $87,5 \%$ \\
\hline Fabricación de aparatos de TV, radio y comunicación & 1 & $0,8 \%$ & $0,8 \%$ & $88,3 \%$ \\
\hline Fabricación de instrumentos médicos & 3 & $1,7 \%$ & $1,7 \%$ & $90,0 \%$ \\
\hline Frabricación de vehiculos automotores & 9 & $5,3 \%$ & $5,3 \%$ & $95,3 \%$ \\
\hline Fabricación de otro tipo de transporte & 2 & $1,3 \%$ & $1,3 \%$ & $96,6 \%$ \\
\hline Fabricación de muebles; industria manufacturera & 5 & $3,3 \%$ & $3,3 \%$ & $99,9 \%$ \\
\hline Válidos Total & 165 & $100 \%$ & $100 \%$ & \\
\hline Perdidos & 0 & $0,0 \%$ & & \\
\hline Total & 165 & $100 \%$ & $100 \%$ & $100 \%$ \\
\hline
\end{tabular}

Fuente: Elaboración propia en base a la información obtenida de las encuestas realizadas a las empresas. 
Cuadro 47

\begin{tabular}{|c|c|c|c|c|c|c|c|c|c|c|c|c|}
\hline & & \multicolumn{11}{|c|}{ Finalidad del último crédito obtenido } \\
\hline & & $\begin{array}{l}\text { Finan. a } \\
\text { cliente }\end{array}$ & $\begin{array}{c}\text { Nuevos } \\
\text { proyectos } \\
\text { productivos }\end{array}$ & $\mid \begin{array}{c}\text { Inversion en } \\
I+D\end{array}$ & $\begin{array}{c}\text { Ampliación } \\
\text { de planta }\end{array}$ & $\begin{array}{l}\text { Compra de } \\
\text { maquinaria }\end{array}$ & $\begin{array}{c}\text { compra de } \\
\text { materia } \\
\text { prima }\end{array}$ & $\begin{array}{l}\text { Mej. De estruc. } \\
\text { Vtas y distrib. }\end{array}$ & $\begin{array}{l}\text { Finan. De } \\
\text { Expo }\end{array}$ & $\begin{array}{l}\text { Pago de } \\
\text { salarios }\end{array}$ & $\begin{array}{l}\text { Finan. De } \\
\text { Impo }\end{array}$ & $\begin{array}{c}\text { Pagar } \\
\text { impuestos }\end{array}$ \\
\hline Nación & $\begin{array}{l}\text { Recuento } \\
\% \text { de banco } \\
\% \text { del total }\end{array}$ & $\begin{array}{c}1 \\
2,22 \\
0,28\end{array}$ & $\begin{array}{c}1 \\
2,22 \\
0,28 \\
\end{array}$ & $\begin{array}{l}0 \\
- \\
-\end{array}$ & $\begin{array}{c}9 \\
20 \\
2,5\end{array}$ & $\begin{array}{c}21 \\
46,67 \\
5,83\end{array}$ & $\begin{array}{c}9 \\
20 \\
2,5\end{array}$ & $\begin{array}{l}0 \\
- \\
-\end{array}$ & $\begin{array}{c}2 \\
4,44 \\
0,56\end{array}$ & $\begin{array}{c}1 \\
2,22 \\
0,28\end{array}$ & $\begin{array}{c}1 \\
2,22 \\
0,28\end{array}$ & $\begin{array}{l}0 \\
- \\
-\end{array}$ \\
\hline Provincia & $\begin{array}{l}\text { Recuento } \\
\% \text { de banco } \\
\% \text { del total }\end{array}$ & $\begin{array}{c}1 \\
1,49 \\
0,28\end{array}$ & $\begin{array}{c}4 \\
5,97 \\
1,11 \\
\end{array}$ & $\begin{array}{l}0 \\
- \\
-\end{array}$ & $\begin{array}{c}11 \\
16,42 \\
3,06\end{array}$ & $\begin{array}{c}31 \\
46,27 \\
8,61\end{array}$ & $\begin{array}{c}11 \\
16,42 \\
3,06\end{array}$ & $\begin{array}{c}3 \\
4,48 \\
0,83\end{array}$ & $\begin{array}{c}1 \\
1,49 \\
0,28\end{array}$ & $\begin{array}{c}3 \\
4,48 \\
0,83\end{array}$ & $\begin{array}{c}2 \\
2,99 \\
0,56\end{array}$ & $\begin{array}{l}0 \\
- \\
-\end{array}$ \\
\hline Credicoop & $\begin{array}{l}\text { Recuento } \\
\% \text { de banco } \\
\% \text { del total }\end{array}$ & $\begin{array}{c}6 \\
6,06 \\
1,67\end{array}$ & $\begin{array}{c}7 \\
7,07 \\
1,94\end{array}$ & $\begin{array}{c}1 \\
1,01 \\
0,28\end{array}$ & $\begin{array}{c}4 \\
4,04 \\
1,11\end{array}$ & $\begin{array}{c}27 \\
27,27 \\
7,5\end{array}$ & $\begin{array}{c}24 \\
24,24 \\
6,67\end{array}$ & $\begin{array}{c}10 \\
10,1 \\
2,78\end{array}$ & $\begin{array}{c}5 \\
5,05 \\
1,39\end{array}$ & $\begin{array}{c}11 \\
11,11 \\
3,06\end{array}$ & $\begin{array}{c}3 \\
3,03 \\
0,83\end{array}$ & $\begin{array}{c}1 \\
1,01 \\
0,28\end{array}$ \\
\hline Galicia & $\begin{array}{l}\text { Recuento } \\
\% \text { de banco } \\
\% \text { del total }\end{array}$ & $\begin{array}{c}1 \\
2,56 \\
0,28\end{array}$ & $\begin{array}{c}3 \\
7,69 \\
0,83\end{array}$ & $\begin{array}{c}1 \\
2,56 \\
0,28\end{array}$ & $\begin{array}{l}0 \\
- \\
-\end{array}$ & $\begin{array}{c}10 \\
25,64 \\
2,78\end{array}$ & $\begin{array}{c}14 \\
35,9 \\
3,89\end{array}$ & $\begin{array}{c}3 \\
7,69 \\
0,83\end{array}$ & $\begin{array}{c}2 \\
5,13 \\
0,56\end{array}$ & $\begin{array}{c}5 \\
12,82 \\
1,39\end{array}$ & $\begin{array}{l}0 \\
- \\
-\end{array}$ & $\begin{array}{l}0 \\
- \\
-\end{array}$ \\
\hline BBVA & $\begin{array}{l}\text { Recuento } \\
\% \text { de banco } \\
\% \text { del total }\end{array}$ & $\begin{array}{l}0 \\
- \\
-\end{array}$ & $\begin{array}{c}1 \\
7,14 \\
0,28\end{array}$ & $\begin{array}{l}0 \\
- \\
-\end{array}$ & $\begin{array}{l}0 \\
- \\
-\end{array}$ & $\begin{array}{c}5 \\
35,71 \\
1,39 \\
\end{array}$ & $\begin{array}{c}5 \\
35,71 \\
1,39\end{array}$ & $\begin{array}{c}2 \\
14,29 \\
0,56\end{array}$ & $\begin{array}{c}1 \\
7,14 \\
0,28\end{array}$ & $\begin{array}{l}0 \\
- \\
- \\
\end{array}$ & $\begin{array}{l}0 \\
- \\
-\end{array}$ & $\begin{array}{l}0 \\
- \\
-\end{array}$ \\
\hline Santander & $\begin{array}{l}\text { Recuento } \\
\% \text { de banco } \\
\% \text { del total }\end{array}$ & $\begin{array}{c}1 \\
3,33 \\
0,28 \\
\end{array}$ & $\begin{array}{c}3 \\
10 \\
0,83 \\
\end{array}$ & $\begin{array}{l}0 \\
- \\
- \\
\end{array}$ & $\begin{array}{c}2 \\
6,67 \\
0,56 \\
\end{array}$ & $\begin{array}{c}17 \\
56,67 \\
4,72 \\
\end{array}$ & $\begin{array}{c}6 \\
20 \\
1,67\end{array}$ & $\begin{array}{l}0 \\
- \\
- \\
\end{array}$ & $\begin{array}{c}1 \\
3,33 \\
0,28\end{array}$ & $\begin{array}{l}0 \\
- \\
-\end{array}$ & $\begin{array}{l}0 \\
- \\
-\end{array}$ & $\begin{array}{l}0 \\
- \\
-\end{array}$ \\
\hline HSBC & $\begin{array}{l}\text { Recuento } \\
\% \text { de banco } \\
\% \text { del total }\end{array}$ & $\begin{array}{l}0 \\
- \\
-\end{array}$ & $\begin{array}{c}1 \\
10 \\
0,28\end{array}$ & $\begin{array}{l}0 \\
- \\
-\end{array}$ & $\begin{array}{l}0 \\
- \\
-\end{array}$ & $\begin{array}{c}5 \\
50 \\
1,39\end{array}$ & $\begin{array}{c}1 \\
10 \\
0,28\end{array}$ & $\begin{array}{c}1 \\
10 \\
0,28\end{array}$ & $\begin{array}{c}1 \\
10 \\
0,28\end{array}$ & $\begin{array}{c}1 \\
10 \\
0,28\end{array}$ & $\begin{array}{l}0 \\
- \\
-\end{array}$ & $\begin{array}{l}0 \\
- \\
-\end{array}$ \\
\hline Total & $\begin{array}{l}\text { Recuento } \\
\% \text { de banco } \\
\% \text { del total }\end{array}$ & $\begin{array}{c}13 \\
3,81 \\
3,81 \\
\end{array}$ & $\begin{array}{c}12 \\
7,22 \\
7,22\end{array}$ & $\begin{array}{c}3 \\
0,83 \\
0,83\end{array}$ & $\begin{array}{c}35 \\
9,72 \\
9,72\end{array}$ & $\begin{array}{c}134 \\
37,22 \\
37,22\end{array}$ & $\begin{array}{c}79 \\
21,94 \\
21,94\end{array}$ & $\begin{array}{c}23 \\
6,39 \\
6,39\end{array}$ & $\begin{array}{c}14 \\
3,89 \\
3,89\end{array}$ & $\begin{array}{c}24 \\
6,67 \\
6,67\end{array}$ & $\begin{array}{c}8 \\
2,22 \\
2,22\end{array}$ & $\begin{array}{c}1 \\
0,28 \\
0,28\end{array}$ \\
\hline
\end{tabular}


Calificaciones de diferentes aspectos de la prestación de servicios financieros y de la oferta crediticia por los encuestados

Cuadro 48

\begin{tabular}{|c|c|c|c|c|c|c|c|c|c|c|c|c|c|c|c|c|c|c|c|c|c|c|c|c|}
\hline & \multicolumn{8}{|c|}{ Calificación para el banco $1^{\circ}$} & \multicolumn{8}{|c|}{ Calificación para el banco $2^{\circ}$} & \multicolumn{8}{|c|}{ Calificación para el banco $3^{\circ}$} \\
\hline & & & 1 & 2 & 3 & 4 & 5 & Total & & & 1 & 2 & 3 & 4 & 5 & Total & & & 1 & 2 & 3 & 4 & 5 & Total \\
\hline \multirow{8}{*}{ 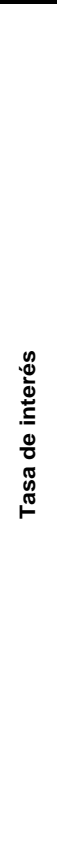 } & Nación & $\begin{array}{l}\text { Recuento } \\
\text { \% de banco } \\
\% \text { del total }\end{array}$ & $\begin{array}{c}9 \\
10,1 \\
1,6\end{array}$ & $\begin{array}{c}11 \\
12,4 \\
1,9\end{array}$ & $\begin{array}{c}34 \\
38,2 \\
5,9\end{array}$ & $\begin{array}{c}18 \\
20,2 \\
3,1\end{array}$ & $\begin{array}{c}17 \\
19,1 \\
2,9\end{array}$ & \begin{tabular}{|c|}
89 \\
100 \\
15,4 \\
\end{tabular} & Nación & \begin{tabular}{|l} 
Recuento \\
\% de banco \\
$\%$ del total
\end{tabular} & $\begin{array}{c}8 \\
10,7 \\
1,9\end{array}$ & $\begin{array}{l}18 \\
24 \\
4,3 \\
\end{array}$ & $\begin{array}{c}34 \\
45,3 \\
8,2 \\
\end{array}$ & $\begin{array}{c}11 \\
14,7 \\
2,6\end{array}$ & $\begin{array}{c}4 \\
5,3 \\
1\end{array}$ & $\begin{array}{c}75 \\
100 \\
18\end{array}$ & Nación & \begin{tabular}{|l} 
Recuento \\
\% de banco \\
$\%$ del total
\end{tabular} & $\begin{array}{c}11 \\
21,6 \\
3,9\end{array}$ & $\begin{array}{c}21 \\
41,2 \\
7,4\end{array}$ & $\begin{array}{c}14 \\
27,5 \\
4,9\end{array}$ & $\begin{array}{c}4 \\
7,8 \\
1,4\end{array}$ & $\begin{array}{c}1 \\
2 \\
0,4\end{array}$ & $\begin{array}{c}51 \\
100 \\
18\end{array}$ \\
\hline & Provincia & \begin{tabular}{|l|} 
Recuento \\
$\%$ de banco \\
$\%$ del total \\
\end{tabular} & \begin{tabular}{c|}
14 \\
17,1 \\
2,4 \\
\end{tabular} & $\begin{array}{c}10 \\
12,2 \\
1,7 \\
\end{array}$ & $\begin{array}{c}29 \\
35,4 \\
5 \\
\end{array}$ & $\begin{array}{c}14 \\
17,1 \\
2,4 \\
\end{array}$ & $\begin{array}{c}15 \\
18,3 \\
2,6 \\
\end{array}$ & $\begin{array}{c}82 \\
100 \\
14,1 \\
\end{array}$ & Provincia & \begin{tabular}{|l|} 
Recuento \\
$\%$ de banco \\
$\%$ del total
\end{tabular} & $\begin{array}{l}11 \\
19 \\
2,6 \\
\end{array}$ & $\begin{array}{l}11 \\
19 \\
2,6 \\
\end{array}$ & $\begin{array}{c}22 \\
37,9 \\
5,3 \\
\end{array}$ & $\begin{array}{c}12 \\
20,7 \\
2,9 \\
\end{array}$ & $\begin{array}{c}2 \\
3,4 \\
0,5 \\
\end{array}$ & $\begin{array}{c}58 \\
100 \\
13,9 \\
\end{array}$ & Provincia & \begin{tabular}{|l|} 
Recuento \\
$\%$ de banco \\
$\%$ del total
\end{tabular} & $\begin{array}{c}7 \\
18,9 \\
2,5 \\
\end{array}$ & $\begin{array}{c}11 \\
29,7 \\
3,9 \\
\end{array}$ & $\begin{array}{c}12 \\
32,4 \\
4,2 \\
\end{array}$ & $\begin{array}{c}6 \\
16,2 \\
2,1 \\
\end{array}$ & $\begin{array}{c}1 \\
2,7 \\
0,4 \\
\end{array}$ & $\begin{array}{c}37 \\
100 \\
13,1 \\
\end{array}$ \\
\hline & Credicoop & \begin{tabular}{|l|} 
Recuento \\
$\%$ de banco \\
$\%$ del total
\end{tabular} & \begin{tabular}{c|}
20 \\
12,8 \\
3,5 \\
\end{tabular} & $\begin{array}{c}20 \\
12,8 \\
3,5 \\
\end{array}$ & $\begin{array}{c}52 \\
33,3 \\
9 \\
\end{array}$ & $\begin{array}{c}41 \\
26,3 \\
7,1\end{array}$ & $\begin{array}{c}23 \\
14,7 \\
4 \\
\end{array}$ & $\begin{array}{l}156 \\
100 \\
27,1 \\
\end{array}$ & Credicoop & \begin{tabular}{|l|} 
Recuento \\
$\%$ de banco \\
$\%$ del total
\end{tabular} & $\begin{array}{c}19 \\
18,6 \\
4,5 \\
\end{array}$ & $\begin{array}{c}16 \\
15,7 \\
3,8 \\
\end{array}$ & $\begin{array}{c}36 \\
35,3 \\
8,6 \\
\end{array}$ & $\begin{array}{c}19 \\
18,6 \\
4,6 \\
\end{array}$ & $\begin{array}{c}12 \\
11,8 \\
2,9 \\
\end{array}$ & $\begin{array}{l}102 \\
100 \\
24,4 \\
\end{array}$ & Credicoop & \begin{tabular}{|l|} 
Recuento \\
$\%$ de banco \\
$\%$ del total
\end{tabular} & $\begin{array}{c}18 \\
28,6 \\
6,3 \\
\end{array}$ & $\begin{array}{c}9 \\
14,3 \\
3,2\end{array}$ & $\begin{array}{c}23 \\
36,5 \\
8,1 \\
\end{array}$ & $\begin{array}{c}7 \\
11,1 \\
2,5 \\
\end{array}$ & $\begin{array}{c}6 \\
9,5 \\
2,1\end{array}$ & $\begin{array}{c}63 \\
100 \\
22,2 \\
\end{array}$ \\
\hline & Galicia & \begin{tabular}{|l|} 
Recuento \\
$\%$ de banco \\
$\%$ del total
\end{tabular} & $\begin{array}{c}13 \\
16,7 \\
2,2 \\
\end{array}$ & $\begin{array}{c}11 \\
14,1 \\
1,9 \\
\end{array}$ & $\begin{array}{c}29 \\
37,2 \\
5 \\
\end{array}$ & $\begin{array}{c}16 \\
20,5 \\
2,8 \\
\end{array}$ & $\begin{array}{c}9 \\
11,5 \\
1,6 \\
\end{array}$ & $\begin{array}{c}78 \\
100 \\
13,5 \\
\end{array}$ & Galicia & \begin{tabular}{|l|} 
Recuento \\
$\%$ de banco \\
$\%$ del total
\end{tabular} & $\begin{array}{c}8 \\
14,3 \\
1,9 \\
\end{array}$ & $\begin{array}{c}10 \\
17,9 \\
2,4 \\
\end{array}$ & $\begin{array}{r}18 \\
32,1 \\
4,3 \\
\end{array}$ & $\begin{array}{c}18 \\
28,6 \\
3,8 \\
\end{array}$ & $\begin{array}{c}4 \\
7,1 \\
1 \\
\end{array}$ & $\begin{array}{c}58 \\
100 \\
13,4 \\
\end{array}$ & Galicia & \begin{tabular}{|l|} 
Recuento \\
$\%$ de banco \\
$\%$ del total
\end{tabular} & $\begin{array}{c}7 \\
16,7 \\
2,5 \\
\end{array}$ & $\begin{array}{c}7 \\
16,7 \\
2,5 \\
\end{array}$ & $\begin{array}{c}11 \\
26,2 \\
3,9 \\
\end{array}$ & $\begin{array}{c}15 \\
35,7 \\
5,3 \\
\end{array}$ & $\begin{array}{c}2 \\
4,8 \\
0,7 \\
\end{array}$ & $\begin{array}{c}42 \\
100 \\
14,9 \\
\end{array}$ \\
\hline & BBVA & \begin{tabular}{|l|} 
Recuento \\
$\%$ de banco \\
$\%$ del total
\end{tabular} & $\begin{array}{c}4 \\
10,8 \\
0,7\end{array}$ & $\begin{array}{c}8 \\
21,6 \\
1,4\end{array}$ & $\begin{array}{l}10 \\
27 \\
1,7\end{array}$ & $\begin{array}{c}13 \\
35,1 \\
2,2\end{array}$ & $\begin{array}{c}2 \\
5,4 \\
0,3\end{array}$ & $\begin{array}{c}37 \\
100 \\
6,3\end{array}$ & BBVA & \begin{tabular}{|l} 
Recuento \\
$\%$ de banco \\
$\%$ del total
\end{tabular} & $\begin{array}{c}1 \\
3,6 \\
0,2\end{array}$ & $\begin{array}{c}4 \\
14,3 \\
1 \\
\end{array}$ & $\begin{array}{c}10 \\
35,7 \\
2,4 \\
\end{array}$ & $\begin{array}{c}7 \\
25 \\
1,7\end{array}$ & $\begin{array}{c}6 \\
21,4 \\
1,4\end{array}$ & $\begin{array}{c}28 \\
100 \\
6,7\end{array}$ & BBVA & \begin{tabular}{|l|} 
Recuento \\
$\%$ de banco \\
$\%$ del total
\end{tabular} & $\begin{array}{c}1 \\
4,3 \\
0,4\end{array}$ & $\begin{array}{c}5 \\
21,7 \\
1,8\end{array}$ & $\begin{array}{c}6 \\
26,1 \\
2,1\end{array}$ & $\begin{array}{c}7 \\
30,4 \\
2,5\end{array}$ & $\begin{array}{c}4 \\
17,4 \\
1,4\end{array}$ & $\begin{array}{c}23 \\
100 \\
8,2\end{array}$ \\
\hline & Santander & \begin{tabular}{|l} 
Recuento \\
$\%$ de banco \\
$\%$ del total \\
\end{tabular} & $\begin{array}{c}15 \\
21,7 \\
2,6 \\
\end{array}$ & $\begin{array}{c}13 \\
18,8 \\
2,2 \\
\end{array}$ & $\begin{array}{c}19 \\
27,5 \\
3,3 \\
\end{array}$ & $\begin{array}{c}17 \\
24,6 \\
2,9 \\
\end{array}$ & $\begin{array}{c}5 \\
7,2 \\
0,9 \\
\end{array}$ & $\begin{array}{c}69 \\
100 \\
11,9 \\
\end{array}$ & Santander & \begin{tabular}{|l|} 
Recuento \\
$\%$ de banco \\
$\%$ del total
\end{tabular} & $\begin{array}{c}6 \\
12,5 \\
1,4 \\
\end{array}$ & $\begin{array}{c}6 \\
12,5 \\
1,4 \\
\end{array}$ & $\begin{array}{c}18 \\
37,5 \\
4,3 \\
\end{array}$ & $\begin{array}{r}12 \\
25 \\
2,9 \\
\end{array}$ & $\begin{array}{c}6 \\
12,5 \\
1,5 \\
\end{array}$ & $\begin{array}{c}48 \\
100 \\
11,5 \\
\end{array}$ & Santander & \begin{tabular}{|l|} 
Recuento \\
$\%$ de banco \\
$\%$ del total
\end{tabular} & $\begin{array}{c}5 \\
14,7 \\
1,8 \\
\end{array}$ & $\begin{array}{c}2 \\
5,9 \\
0,7 \\
\end{array}$ & $\begin{array}{c}16 \\
47,1 \\
5,6 \\
\end{array}$ & $\begin{array}{c}7 \\
20,8 \\
2,5 \\
\end{array}$ & $\begin{array}{c}4 \\
11,8 \\
1,4 \\
\end{array}$ & $\begin{array}{c}34 \\
100 \\
12 \\
\end{array}$ \\
\hline & HSBC & \begin{tabular}{|l|} 
Recuento \\
$\%$ de banco \\
$\%$ del total
\end{tabular} & $\begin{array}{c}8 \\
40 \\
1,4\end{array}$ & $\begin{array}{c}3 \\
15 \\
0,5\end{array}$ & $\begin{array}{c}5 \\
25 \\
0,9\end{array}$ & $\begin{array}{c}3 \\
15 \\
0,5\end{array}$ & $\begin{array}{c}1 \\
5 \\
0,2\end{array}$ & $\begin{array}{c}20 \\
100 \\
3,5\end{array}$ & HSBC & \begin{tabular}{|l|} 
Recuento \\
$\%$ de banco \\
$\%$ del total
\end{tabular} & $\begin{array}{c}3 \\
27,3 \\
0,7\end{array}$ & $\begin{array}{c}1 \\
9,1 \\
0,2\end{array}$ & $\begin{array}{c}3 \\
27,3 \\
0,7\end{array}$ & $\begin{array}{c}3 \\
27,3 \\
0,7\end{array}$ & $\begin{array}{c}1 \\
9,1 \\
0,2\end{array}$ & $\begin{array}{c}11 \\
100 \\
2,5\end{array}$ & HSBC & \begin{tabular}{|l|} 
Recuento \\
$\%$ de banco \\
$\%$ del total
\end{tabular} & $\begin{array}{c}1 \\
16,7 \\
0,4\end{array}$ & $\begin{array}{l}0 \\
0 \\
0\end{array}$ & $\begin{array}{c}3 \\
50 \\
1,1\end{array}$ & $\begin{array}{c}2 \\
33,3 \\
0,7\end{array}$ & $\begin{array}{l}0 \\
0 \\
0\end{array}$ & $\begin{array}{c}6 \\
100 \\
2,2\end{array}$ \\
\hline & Total & \begin{tabular}{|l} 
Recuento \\
$\%$ de banco \\
$\%$ del total
\end{tabular} & $\begin{array}{c}94 \\
16,2 \\
16,2\end{array}$ & $\begin{array}{c}83 \\
14,3 \\
14,3\end{array}$ & $\begin{array}{l}196 \\
33,9 \\
33,9\end{array}$ & $\begin{array}{l}130 \\
22,5 \\
22,5\end{array}$ & $\begin{array}{c}76 \\
13,1 \\
13,1\end{array}$ & $\begin{array}{l}579 \\
100 \\
100\end{array}$ & Total & \begin{tabular}{|l} 
Recuento \\
$\%$ de banco \\
$\%$ del total
\end{tabular} & $\begin{array}{c}63 \\
15,1 \\
15,1\end{array}$ & $\begin{array}{l}75 \\
18 \\
18\end{array}$ & $\begin{array}{l}153 \\
36,7 \\
36,7\end{array}$ & $\begin{array}{c}89 \\
21,3 \\
21,3\end{array}$ & $\begin{array}{l}37 \\
8,9 \\
8,9\end{array}$ & $\begin{array}{l}417 \\
100 \\
100\end{array}$ & Total & \begin{tabular}{|l} 
Recuento \\
$\%$ de banco \\
$\%$ del total
\end{tabular} & $\begin{array}{c}60 \\
21,1 \\
21,1\end{array}$ & $\begin{array}{c}60 \\
21,1 \\
21,1\end{array}$ & $\begin{array}{l}94 \\
33 \\
33\end{array}$ & $\begin{array}{c}50 \\
17,5 \\
17,5\end{array}$ & $\begin{array}{l}21 \\
7,4 \\
7,4\end{array}$ & $\begin{array}{l}285 \\
100 \\
100\end{array}$ \\
\hline
\end{tabular}


Cuadro 49

\begin{tabular}{|c|c|c|c|c|c|c|c|c|c|c|c|c|c|c|c|c|c|c|c|c|c|c|c|c|}
\hline & \multicolumn{8}{|c|}{ Calificación para el banco $1^{\circ}$} & \multicolumn{8}{|c|}{ Calificación para el banco $2^{\circ}$} & \multicolumn{8}{|c|}{ Calificación para el banco $3^{\circ}$} \\
\hline & & & 1 & 2 & 3 & 4 & 5 & Total & & & 1 & 2 & 3 & 4 & 5 & Total & & & 1 & 2 & 3 & 4 & 5 & Total \\
\hline \multirow{8}{*}{ 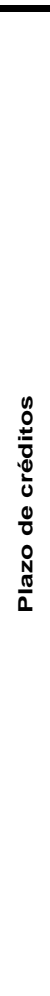 } & Nación & $\begin{array}{l}\text { Recuento } \\
\% \text { de banco } \\
\% \text { del total }\end{array}$ & $\begin{array}{c}11 \\
15,28 \\
2,236\end{array}$ & $\begin{array}{c}11 \\
15,3 \\
2,24\end{array}$ & $\begin{array}{c}23 \\
31,9 \\
4,7\end{array}$ & $\begin{array}{c}14 \\
19,4 \\
2,8\end{array}$ & $\begin{array}{c}13 \\
18,1 \\
2,6\end{array}$ & $\begin{array}{c}72 \\
100 \\
14,6\end{array}$ & Nación & \begin{tabular}{|l} 
Recuento \\
$\%$ de banco \\
$\%$ del total
\end{tabular} & $\begin{array}{c}9 \\
15,8 \\
2,6\end{array}$ & $\begin{array}{c}13 \\
22,8 \\
3,8\end{array}$ & $\begin{array}{c}18 \\
31,6 \\
5,3\end{array}$ & $\begin{array}{c}12 \\
21,1 \\
3,5\end{array}$ & $\begin{array}{c}5 \\
8,8 \\
1,5\end{array}$ & $\begin{array}{c}57 \\
100 \\
16,7\end{array}$ & Nación & $\begin{array}{l}\text { Recuento } \\
\% \text { de banco } \\
\% \text { del total }\end{array}$ & $\begin{array}{c}10 \\
24,4 \\
4,2\end{array}$ & $\begin{array}{c}12 \\
29,3 \\
5\end{array}$ & $\begin{array}{c}13 \\
31,7 \\
5,5\end{array}$ & $\begin{array}{c}4 \\
9,8 \\
1,7\end{array}$ & $\begin{array}{c}2 \\
4,9 \\
0,8\end{array}$ & $\begin{array}{c}41 \\
100 \\
17\end{array}$ \\
\hline & Provincia & $\begin{array}{l}\text { Recuento } \\
\% \text { de banco } \\
\% \text { del total }\end{array}$ & $\begin{array}{c}11 \\
16,67 \\
2,236 \\
\end{array}$ & $\begin{array}{c}13 \\
19,7 \\
2,64\end{array}$ & $\begin{array}{c}18 \\
27,3 \\
3,7 \\
\end{array}$ & $\begin{array}{c}13 \\
19,7 \\
2,6 \\
\end{array}$ & $\begin{array}{c}11 \\
16,7 \\
2,2 \\
\end{array}$ & $\begin{array}{c}66 \\
100 \\
13,376 \\
\end{array}$ & Provincia & $\begin{array}{l}\text { Recuento } \\
\% \text { de banco } \\
\% \text { del total }\end{array}$ & $\begin{array}{c}7 \\
15,6 \\
2,1 \\
\end{array}$ & $\begin{array}{c}7 \\
15,6 \\
2,1 \\
\end{array}$ & $\begin{array}{c}16 \\
35,6 \\
4,7 \\
\end{array}$ & $\begin{array}{c}14 \\
31,1 \\
4,1 \\
\end{array}$ & $\begin{array}{c}1 \\
2,2 \\
0,3\end{array}$ & $\begin{array}{c}45 \\
100,1 \\
13,3 \\
\end{array}$ & Provincia & $\begin{array}{l}\text { Recuento } \\
\% \text { de banco } \\
\% \text { del total }\end{array}$ & $\begin{array}{c}3 \\
10,7 \\
1,3\end{array}$ & $\begin{array}{c}7 \\
25 \\
2,9\end{array}$ & $\begin{array}{c}11 \\
39,3 \\
4,6 \\
\end{array}$ & $\begin{array}{c}6 \\
21,4 \\
2,5 \\
\end{array}$ & $\begin{array}{c}1 \\
3,6 \\
0,4\end{array}$ & $\begin{array}{c}28 \\
100 \\
11,7\end{array}$ \\
\hline & Credicoop & \begin{tabular}{|l|} 
Recuento \\
$\%$ de banco \\
$\%$ del total
\end{tabular} & $\begin{array}{c}15 \\
10,56 \\
3,049\end{array}$ & $\begin{array}{c}20 \\
14,1 \\
4,07\end{array}$ & $\begin{array}{c}46 \\
32,4 \\
9,3\end{array}$ & $\begin{array}{c}41 \\
28,9 \\
8,3\end{array}$ & $\begin{array}{c}20 \\
14,1 \\
4,1\end{array}$ & $\begin{array}{c}142 \\
100 \\
28,819\end{array}$ & Credicoop & \begin{tabular}{|l} 
Recuento \\
$\%$ de banco \\
$\%$ del total
\end{tabular} & $\begin{array}{c}13 \\
15,7 \\
3,8\end{array}$ & $\begin{array}{c}21 \\
25,3 \\
6,2\end{array}$ & $\begin{array}{c}30 \\
36,1 \\
8,8\end{array}$ & $\begin{array}{c}12 \\
14,5 \\
3,5\end{array}$ & $\begin{array}{c}7 \\
8,4 \\
2,1\end{array}$ & $\begin{array}{c}83 \\
100 \\
24,4\end{array}$ & Credicoop & \begin{tabular}{|l} 
Recuento \\
$\%$ de banco \\
$\%$ del total
\end{tabular} & $\begin{array}{c}12 \\
23,5 \\
5\end{array}$ & $\begin{array}{c}11 \\
21,6 \\
4,6\end{array}$ & $\begin{array}{c}14 \\
27,5 \\
5,9\end{array}$ & $\begin{array}{c}10 \\
19,6 \\
4,2\end{array}$ & $\begin{array}{c}4 \\
7,8 \\
1,7\end{array}$ & $\begin{array}{c}51 \\
100 \\
21,4\end{array}$ \\
\hline & Galicia & $\begin{array}{l}\text { Recuento } \\
\% \text { de banco } \\
\% \text { del total }\end{array}$ & $\begin{array}{c}13 \\
16,7 \\
2,2 \\
\end{array}$ & $\begin{array}{c}11 \\
14,1 \\
1,9\end{array}$ & $\begin{array}{c}29 \\
37,2 \\
5 \\
\end{array}$ & $\begin{array}{c}16 \\
20,5 \\
2,8 \\
\end{array}$ & $\begin{array}{c}9 \\
11,5 \\
1,6 \\
\end{array}$ & $\begin{array}{c}78 \\
100 \\
13,5\end{array}$ & Galicia & $\begin{array}{l}\text { Recuento } \\
\% \text { de banco } \\
\% \text { del total }\end{array}$ & $\begin{array}{c}9 \\
18,4 \\
2,6 \\
\end{array}$ & $\begin{array}{c}3 \\
6,1 \\
0,9\end{array}$ & $\begin{array}{c}11 \\
22,4 \\
3,2 \\
\end{array}$ & $\begin{array}{c}16 \\
32,7 \\
4,7 \\
\end{array}$ & $\begin{array}{c}10 \\
20,4 \\
2,9 \\
\end{array}$ & $\begin{array}{c}49 \\
100 \\
14,3\end{array}$ & Galicia & $\begin{array}{l}\text { Recuento } \\
\% \text { de banco } \\
\% \text { del total }\end{array}$ & $\begin{array}{c}6 \\
15,8 \\
2,5 \\
\end{array}$ & \begin{tabular}{c|}
4 \\
10,5 \\
1,7 \\
\end{tabular} & $\begin{array}{c}15 \\
39,5 \\
6,3 \\
\end{array}$ & $\begin{array}{c}10 \\
26,3 \\
4,2 \\
\end{array}$ & $\begin{array}{c}3 \\
7,9 \\
1,3\end{array}$ & $\begin{array}{c}38 \\
100 \\
16\end{array}$ \\
\hline & BBVA & \begin{tabular}{|l|} 
Recuento \\
$\%$ de banco \\
$\%$ del total
\end{tabular} & $\begin{array}{c}4 \\
10,8 \\
0,7\end{array}$ & $\begin{array}{c}8 \\
21,6 \\
1,4\end{array}$ & $\begin{array}{l}10 \\
27 \\
1,7\end{array}$ & $\begin{array}{c}13 \\
35,1 \\
2,2\end{array}$ & $\begin{array}{c}2 \\
5,4 \\
0,3\end{array}$ & $\begin{array}{l}37 \\
100 \\
6,3\end{array}$ & BBVA & \begin{tabular}{|l} 
Recuento \\
$\%$ de banco \\
$\%$ del total
\end{tabular} & $\begin{array}{c}3 \\
11,5 \\
0,9\end{array}$ & $\begin{array}{c}2 \\
7,7 \\
0,6\end{array}$ & $\begin{array}{c}9 \\
34,6 \\
2,6\end{array}$ & $\begin{array}{c}8 \\
30,8 \\
2,3\end{array}$ & $\begin{array}{c}4 \\
15,4 \\
1,2\end{array}$ & $\begin{array}{c}26 \\
100 \\
7,6\end{array}$ & BBVA & \begin{tabular}{|l} 
Recuento \\
$\%$ de banco \\
$\%$ del total
\end{tabular} & $\begin{array}{c}4 \\
17,4 \\
1,7\end{array}$ & $\begin{array}{c}1 \\
4,3 \\
0,4\end{array}$ & $\begin{array}{c}8 \\
34,8 \\
3,4\end{array}$ & $\begin{array}{c}7 \\
30 \\
2,9\end{array}$ & $\begin{array}{c}3 \\
13 \\
1,3\end{array}$ & $\begin{array}{c}23 \\
100 \\
9,7\end{array}$ \\
\hline & Santander & \begin{tabular}{|l|} 
Recuento \\
$\%$ de banco \\
$\%$ del total
\end{tabular} & $\begin{array}{c}15 \\
21,7 \\
2,6\end{array}$ & $\begin{array}{c}13 \\
18,8 \\
2,2\end{array}$ & $\begin{array}{c}19 \\
27,5 \\
3,3\end{array}$ & $\begin{array}{c}17 \\
24,6 \\
2,9\end{array}$ & $\begin{array}{c}5 \\
7,2 \\
0,9\end{array}$ & $\begin{array}{c}69 \\
100 \\
11,9\end{array}$ & Santander & \begin{tabular}{|l} 
Recuento \\
$\%$ de banco \\
$\%$ del total
\end{tabular} & $\begin{array}{c}6 \\
15,4 \\
1,8\end{array}$ & $\begin{array}{c}3 \\
7,7 \\
0,9\end{array}$ & $\begin{array}{c}13 \\
33,3 \\
3,8\end{array}$ & $\begin{array}{c}14 \\
35,9 \\
4,1\end{array}$ & $\begin{array}{c}3 \\
7,7 \\
0,9\end{array}$ & $\begin{array}{c}39 \\
100 \\
11,5\end{array}$ & Santander & \begin{tabular}{|l} 
Recuento \\
$\%$ de banco \\
$\%$ del total
\end{tabular} & $\begin{array}{c}2 \\
7,7 \\
0,8\end{array}$ & $\begin{array}{c}3 \\
11,5 \\
1,3\end{array}$ & $\begin{array}{c}12 \\
46,2 \\
5\end{array}$ & $\begin{array}{c}7 \\
26,9 \\
2,9\end{array}$ & $\begin{array}{c}2 \\
7,7 \\
0,8\end{array}$ & $\begin{array}{c}26 \\
100 \\
10,8\end{array}$ \\
\hline & HSBC & $\begin{array}{l}\text { Recuento } \\
\% \text { de banco } \\
\% \text { del total }\end{array}$ & $\begin{array}{c}8 \\
40 \\
1,4 \\
\end{array}$ & $\begin{array}{c}3 \\
15 \\
0,5\end{array}$ & $\begin{array}{c}5 \\
25 \\
0,9\end{array}$ & $\begin{array}{c}3 \\
15 \\
0,5\end{array}$ & $\begin{array}{c}1 \\
5 \\
0,2\end{array}$ & $\begin{array}{c}20 \\
100 \\
3,5\end{array}$ & HSBC & $\begin{array}{l}\text { Recuento } \\
\% \text { de banco } \\
\% \text { del total }\end{array}$ & $\begin{array}{c}3 \\
30 \\
0,9\end{array}$ & $\begin{array}{l}0 \\
0 \\
0\end{array}$ & $\begin{array}{c}5 \\
50 \\
1,5\end{array}$ & $\begin{array}{c}1 \\
10 \\
0,3\end{array}$ & $\begin{array}{c}1 \\
10 \\
0,3\end{array}$ & $\begin{array}{c}10 \\
100 \\
3,0 \\
\end{array}$ & HSBC & $\begin{array}{l}\text { Recuento } \\
\% \text { de banco } \\
\% \text { del total }\end{array}$ & $\begin{array}{c}1 \\
14,3 \\
0,4 \\
\end{array}$ & $\begin{array}{l}0 \\
0 \\
0\end{array}$ & $\begin{array}{c}2 \\
28,6 \\
0,8 \\
\end{array}$ & $\begin{array}{c}3 \\
42,9 \\
1,3\end{array}$ & $\begin{array}{c}1 \\
14,3 \\
0,4 \\
\end{array}$ & $\begin{array}{c}7 \\
100 \\
2,9\end{array}$ \\
\hline & Total & $\begin{array}{l}\text { Recuento } \\
\% \text { de banco } \\
\% \text { del total }\end{array}$ & $\begin{array}{c}94 \\
16,2 \\
16,2\end{array}$ & $\begin{array}{c}83 \\
14,3 \\
14,3\end{array}$ & $\begin{array}{l}196 \\
33,9 \\
33,9\end{array}$ & $\begin{array}{l}130 \\
22,5 \\
22,5\end{array}$ & $\begin{array}{c}76 \\
13,1 \\
13,1\end{array}$ & $\begin{array}{l}579 \\
100 \\
100\end{array}$ & Total & $\begin{array}{l}\text { Recuento } \\
\% \text { de banco } \\
\% \text { del total }\end{array}$ & $\begin{array}{c}56 \\
16,4 \\
16,4\end{array}$ & \begin{tabular}{c|}
56 \\
16,4 \\
16,4
\end{tabular} & $\begin{array}{l}112 \\
32,8 \\
32,8\end{array}$ & \begin{tabular}{c|}
84 \\
24,6 \\
24,6
\end{tabular} & $\begin{array}{l}33 \\
9,7 \\
9,7\end{array}$ & $\begin{array}{l}341 \\
100 \\
100\end{array}$ & Total & $\begin{array}{l}\text { Recuento } \\
\% \text { de banco } \\
\% \text { del total }\end{array}$ & \begin{tabular}{c|}
47 \\
19,7 \\
19,7
\end{tabular} & \begin{tabular}{c|}
44 \\
18,5 \\
18,5
\end{tabular} & $\begin{array}{c}80 \\
33,6 \\
33,6\end{array}$ & $\begin{array}{c}48 \\
20,2 \\
20,2\end{array}$ & $\begin{array}{l}19 \\
8 \\
8\end{array}$ & $\begin{array}{l}238 \\
100 \\
100\end{array}$ \\
\hline
\end{tabular}

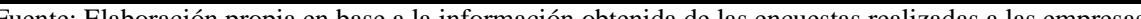


Cuadro 50

\begin{tabular}{|c|c|c|c|c|c|c|c|c|c|c|c|c|c|c|c|c|c|c|c|c|c|c|c|c|}
\hline & \multicolumn{8}{|c|}{ Calificación para el banco $1^{\circ}$} & \multicolumn{8}{|c|}{ Calificación para el banco $2^{\circ}$} & \multicolumn{8}{|c|}{ Calificación para el banco $3^{\circ}$} \\
\hline & & & 1 & 2 & 3 & 4 & 5 & Total & & & 1 & 2 & 3 & 4 & 5 & Total & & & 1 & 2 & 3 & 4 & 5 & Total \\
\hline \multirow{8}{*}{$\begin{array}{l}\frac{\pi}{0} \\
\frac{\pi}{0} \\
0 \\
0 \\
\circ \\
\frac{0}{0} \\
\frac{0}{0} \\
0\end{array}$} & Nación & \begin{tabular}{|l} 
Recuento \\
$\%$ de banco \\
$\%$ del total
\end{tabular} & $\begin{array}{c}20 \\
32,3 \% \\
4,515 \\
\end{array}$ & $\begin{array}{c}9 \\
14,5 \% \\
2,03\end{array}$ & \begin{tabular}{|c|}
19 \\
$30,6 \%$ \\
4,289 \\
\end{tabular} & $\begin{array}{c}3 \\
4,8 \% \\
0,677\end{array}$ & \begin{tabular}{c|c|}
11 \\
$17,7 \%$ \\
2,48 \\
\end{tabular} & $\begin{array}{c}62 \\
100 \% \\
13,991\end{array}$ & Nación & \begin{tabular}{|l} 
Recuento \\
$\%$ de banco \\
$\%$ del total
\end{tabular} & $\begin{array}{c}18 \\
38,3 \% \\
6,08\end{array}$ & $\begin{array}{c}6 \\
12,8 \% \\
2,03 \\
\end{array}$ & $\begin{array}{c}15 \\
31,9 \% \\
5,068 \\
\end{array}$ & $\begin{array}{c}4 \\
8,5 \% \\
1,35 \\
\end{array}$ & $\begin{array}{c}4 \\
8,5 \% \\
1,35 \\
\end{array}$ & $\begin{array}{c}47 \\
100,0 \% \\
15,878\end{array}$ & Nación & $\begin{array}{l}\text { Recuento } \\
\% \text { de banco } \\
\% \text { del total }\end{array}$ & \begin{tabular}{c|}
13 \\
$41,9 \%$ \\
6,37 \\
\end{tabular} & \begin{tabular}{|c|}
7 \\
$22,6 \%$ \\
3,43 \\
\end{tabular} & $\begin{array}{c}10 \\
32,3 \% \\
4,9 \\
\end{array}$ & $\begin{array}{c}0 \\
0,0 \% \\
0\end{array}$ & $\begin{array}{c}1 \\
3,2 \% \\
0,49 \\
\end{array}$ & $\begin{array}{c}31 \\
100 \% \\
15\end{array}$ \\
\hline & Provincia & \begin{tabular}{|l|} 
Recuento \\
$\%$ de banco \\
$\%$ del total
\end{tabular} & $\begin{array}{c}19 \\
30,6 \% \\
4,289 \\
\end{array}$ & $\begin{array}{c}14 \\
22,6 \% \\
3,16\end{array}$ & $\begin{array}{c}16 \\
25,8 \% \\
3,812 \\
\end{array}$ & $\begin{array}{c}6 \\
9,7 \% \\
1,354 \\
\end{array}$ & $\begin{array}{c}9 \\
14,5 \% \\
2,03\end{array}$ & $\begin{array}{c}64 \\
103 \% \\
14,645 \\
\end{array}$ & Provincia & \begin{tabular}{|l|} 
Recuento \\
$\%$ de banco \\
$\%$ del total
\end{tabular} & $\begin{array}{c}11 \\
27,5 \% \\
3,72\end{array}$ & $\begin{array}{c}10 \\
25,0 \% \\
3,38 \\
\end{array}$ & \begin{tabular}{|c|}
11 \\
$27,5 \%$ \\
3,716 \\
\end{tabular} & \begin{tabular}{|c|}
7 \\
$17,5 \%$ \\
2,36 \\
\end{tabular} & $\begin{array}{c}1 \\
2,5 \% \\
0,34\end{array}$ & \begin{tabular}{c|}
40 \\
$100,0 \%$ \\
13,516
\end{tabular} & Provincia & \begin{tabular}{|l|} 
Recuento \\
$\%$ de banco \\
$\%$ del total
\end{tabular} & \begin{tabular}{|c|}
6 \\
$25,0 \%$ \\
2,94
\end{tabular} & $\begin{array}{c}9 \\
37,5 \% \\
4,41 \\
\end{array}$ & \begin{tabular}{|c|}
5 \\
$20,8 \%$ \\
2,45
\end{tabular} & $\begin{array}{c}4 \\
16,7 \% \\
1,96\end{array}$ & $\begin{array}{c}0 \\
0,0 \% \\
0\end{array}$ & $\begin{array}{c}24 \\
100 \% \\
11,76\end{array}$ \\
\hline & Credicoop & \begin{tabular}{|l|} 
Recuento \\
$\%$ de banco \\
$\%$ del total
\end{tabular} & \begin{tabular}{|c|}
29 \\
$46,8 \%$ \\
6,546 \\
\end{tabular} & $\begin{array}{c}21 \\
33,9 \% \\
4,74 \\
\end{array}$ & \begin{tabular}{c|}
40 \\
$64,5 \%$ \\
9,029 \\
\end{tabular} & $\begin{array}{c}29 \\
46,8 \% \\
6,546\end{array}$ & $\begin{array}{c}13 \\
21,0 \% \\
2,93\end{array}$ & $\begin{array}{c}132 \\
213 \% \\
29,791 \\
\end{array}$ & Credicoop & \begin{tabular}{|l} 
Recuento \\
$\%$ de banco \\
$\%$ del total
\end{tabular} & $\begin{array}{c}20 \\
25,6 \% \\
6,76\end{array}$ & $\begin{array}{c}18 \\
23,1 \% \\
6,08 \\
\end{array}$ & $\begin{array}{c}25 \\
32,1 \% \\
8,44 \\
\end{array}$ & \begin{tabular}{|c|}
10 \\
$12,8 \%$ \\
3,38 \\
\end{tabular} & $\begin{array}{c}5 \\
6,4 \% \\
1,69 \\
\end{array}$ & \begin{tabular}{c|}
78 \\
$100,0 \%$ \\
26,35 \\
\end{tabular} & Credicoop & \begin{tabular}{|l|} 
Recuento \\
$\%$ de banco \\
$\%$ del total
\end{tabular} & \begin{tabular}{c|}
15 \\
$31,9 \%$ \\
7,35 \\
\end{tabular} & $\begin{array}{c}10 \\
21,3 \% \\
4,9 \\
\end{array}$ & \begin{tabular}{|c|}
15 \\
$31,9 \%$ \\
7,35 \\
\end{tabular} & $\begin{array}{c}4 \\
8,5 \% \\
1,96 \\
\end{array}$ & $\begin{array}{c}3 \\
6,4 \% \\
1,47 \\
\end{array}$ & $\begin{array}{c}47 \\
100 \% \\
23,03 \\
\end{array}$ \\
\hline & Galicia & $\begin{array}{l}\text { Recuento } \\
\% \text { de banco } \\
\% \text { del total }\end{array}$ & \begin{tabular}{|c|}
12 \\
$19,4 \%$ \\
2,709 \\
\end{tabular} & \begin{tabular}{|c|}
7 \\
$11,3 \%$ \\
1,58 \\
\end{tabular} & \begin{tabular}{|c|}
16 \\
$25,8 \%$ \\
3,612 \\
\end{tabular} & \begin{tabular}{|c|}
9 \\
$14,5 \%$ \\
2,032 \\
\end{tabular} & \begin{tabular}{|c|}
8 \\
$12,9 \%$ \\
1,81 \\
\end{tabular} & $\begin{array}{c}52 \\
84 \% \\
11,74 \\
\end{array}$ & Galicia & $\begin{array}{l}\text { Recuento } \\
\% \text { de banco } \\
\% \text { del total }\end{array}$ & \begin{tabular}{|c|}
10 \\
$25,6 \%$ \\
3,38 \\
\end{tabular} & \begin{tabular}{|c|}
8 \\
$20,5 \%$ \\
2,03 \\
\end{tabular} & $\begin{array}{c}7 \\
17,9 \% \\
2,365 \\
\end{array}$ & \begin{tabular}{|c|}
8 \\
$20,5 \%$ \\
2,7 \\
\end{tabular} & \begin{tabular}{|c|}
6 \\
$15,4 \%$ \\
2,03 \\
\end{tabular} & \begin{tabular}{|c|}
39 \\
$100,0 \%$ \\
12,505 \\
\end{tabular} & Galicia & 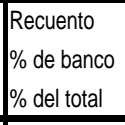 & $\begin{array}{c}10 \\
33,3 \% \\
4,9 \\
\end{array}$ & $\begin{array}{c}2 \\
6,7 \% \\
0,98 \\
\end{array}$ & \begin{tabular}{|c|}
5 \\
$16,7 \%$ \\
2,45 \\
\end{tabular} & \begin{tabular}{|c|}
11 \\
$36,7 \%$ \\
5,39 \\
\end{tabular} & $\begin{array}{c}2 \\
6,7 \% \\
0,98 \\
\end{array}$ & $\begin{array}{r}30 \\
100 \% \\
14,7 \\
\end{array}$ \\
\hline & BBVA & \begin{tabular}{|l|} 
Recuento \\
$\%$ de banco \\
$\%$ del total
\end{tabular} & \begin{tabular}{|c|}
8 \\
$12,9 \%$ \\
1,806 \\
\end{tabular} & $\begin{array}{c}4 \\
6,5 \% \\
0,9\end{array}$ & $\begin{array}{c}9 \\
14,5 \% \\
2,032 \\
\end{array}$ & $\begin{array}{c}9 \\
14,5 \% \\
2,032\end{array}$ & $\begin{array}{c}2 \\
3,2 \% \\
0,45\end{array}$ & $\begin{array}{c}32 \\
52 \% \\
7,22 \\
\end{array}$ & BBVA & \begin{tabular}{|l} 
Recuento \\
$\%$ de banco \\
$\%$ del total
\end{tabular} & $\begin{array}{c}4 \\
17,4 \% \\
1,35 \\
\end{array}$ & $\begin{array}{c}2 \\
8,7 \% \\
0,89 \\
\end{array}$ & $\begin{array}{c}9 \\
39,1 \% \\
3,041\end{array}$ & \begin{tabular}{|c|}
6 \\
$26,1 \%$ \\
2,03 \\
\end{tabular} & $\begin{array}{c}2 \\
8,7 \% \\
0,68 \\
\end{array}$ & $\begin{array}{c}23 \\
100,0 \% \\
7,991\end{array}$ & BBVA & \begin{tabular}{|l} 
Recuento \\
$\%$ de banco \\
$\%$ del total
\end{tabular} & $\begin{array}{c}5 \\
23,8 \% \\
2,45\end{array}$ & $\begin{array}{c}2 \\
9,5 \% \\
0,98 \\
\end{array}$ & \begin{tabular}{|c|}
8 \\
$38,1 \%$ \\
3,92
\end{tabular} & $\begin{array}{c}4 \\
19,0 \% \\
1,96\end{array}$ & $\begin{array}{c}2 \\
9,5 \% \\
0,98 \\
\end{array}$ & $\begin{array}{c}21 \\
100 \% \\
10,29\end{array}$ \\
\hline & Santander & $\begin{array}{l}\text { Recuento } \\
\% \text { de banco } \\
\% \text { del total }\end{array}$ & \begin{tabular}{|c|}
20 \\
$32,3 \%$ \\
4,515 \\
\end{tabular} & $\begin{array}{c}3 \\
4,8 \% \\
0,68 \\
\end{array}$ & \begin{tabular}{|c|}
13 \\
$21,0 \%$ \\
2,935 \\
\end{tabular} & \begin{tabular}{|c|}
9 \\
$14,5 \%$ \\
2,032 \\
\end{tabular} & \begin{tabular}{|c|}
7 \\
$11,3 \%$ \\
1,58 \\
\end{tabular} & $\begin{array}{c}52 \\
84 \% \\
11,742 \\
\end{array}$ & Santander & $\begin{array}{l}\text { Recuento } \\
\% \text { de banco } \\
\% \text { del total }\end{array}$ & $\begin{array}{c}12 \\
32,4 \% \\
4,05 \\
\end{array}$ & $\begin{array}{c}2 \\
5,4 \% \\
0,68 \\
\end{array}$ & $\begin{array}{c}11 \\
29,7 \% \\
3,716 \\
\end{array}$ & \begin{tabular}{|c|}
8 \\
$21,6 \%$ \\
2,7 \\
\end{tabular} & \begin{tabular}{|c|}
4 \\
$10,8 \%$ \\
1,35 \\
\end{tabular} & \begin{tabular}{|c|}
37 \\
$100,0 \%$ \\
12,496 \\
\end{tabular} & Santander & $\begin{array}{l}\text { Recuento } \\
\% \text { de banco } \\
\% \text { del total }\end{array}$ & \begin{tabular}{|c|}
7 \\
$28,0 \%$ \\
3,43 \\
\end{tabular} & \begin{tabular}{c|}
3 \\
$12,0 \%$ \\
1,47 \\
\end{tabular} & \begin{tabular}{|c|}
8 \\
$32,0 \%$ \\
3,92 \\
\end{tabular} & \begin{tabular}{|c|}
5 \\
$20,0 \%$ \\
2,45 \\
\end{tabular} & \begin{tabular}{c|}
2 \\
$8,0 \%$ \\
0,98 \\
\end{tabular} & $\begin{array}{c}25 \\
100 \% \\
12,25 \\
\end{array}$ \\
\hline & HSBC & \begin{tabular}{|l|} 
Recuento \\
$\%$ de banco \\
$\%$ del total
\end{tabular} & \begin{tabular}{|c|}
10 \\
$16,1 \%$ \\
2,257 \\
\end{tabular} & \begin{tabular}{|c}
0 \\
$0,0 \%$ \\
0 \\
\end{tabular} & \begin{tabular}{|c|}
3 \\
$4,8 \%$ \\
0,677 \\
\end{tabular} & $\begin{array}{c}1 \\
1,6 \% \\
0,226 \\
\end{array}$ & $\begin{array}{c}1 \\
1,6 \% \\
0,23\end{array}$ & $\begin{array}{c}15 \\
24 \% \\
3,39 \\
\end{array}$ & HSBC & $\begin{array}{l}\text { Recuento } \\
\% \text { de banco } \\
\% \text { del total }\end{array}$ & $\begin{array}{c}4 \\
57,1 \% \\
1,35\end{array}$ & $\begin{array}{c}0 \\
0,0 \% \\
0 \\
\end{array}$ & $\begin{array}{c}2 \\
28,6 \% \\
0,676 \\
\end{array}$ & \begin{tabular}{c|}
1 \\
$14,3 \%$ \\
0,34 \\
\end{tabular} & $\begin{array}{c}0 \\
0,0 \% \\
0\end{array}$ & \begin{tabular}{|c|}
7 \\
$100,0 \%$ \\
2,4 \\
\end{tabular} & HSBC & \begin{tabular}{|l} 
Recuento \\
$\%$ de banco \\
$\%$ del total
\end{tabular} & \begin{tabular}{|c|}
1 \\
$16,7 \%$ \\
0,49 \\
\end{tabular} & \begin{tabular}{|c|} 
\\
$16,7 \%$ \\
0,49 \\
\end{tabular} & \begin{tabular}{|c|}
2 \\
$33,3 \%$ \\
0,98 \\
\end{tabular} & $\begin{array}{c}2 \\
33,3 \% \\
0,98\end{array}$ & $\begin{array}{c}0 \\
0,0 \% \\
0\end{array}$ & $\begin{array}{c}6 \\
100 \% \\
2,94 \\
\end{array}$ \\
\hline & Total & \begin{tabular}{|l} 
Recuento \\
$\%$ de banco \\
$\%$ del total
\end{tabular} & \begin{tabular}{|c|}
129 \\
$29,1 \%$ \\
0,2912
\end{tabular} & \begin{tabular}{|c|}
64 \\
$14,4 \%$ \\
0,144
\end{tabular} & \begin{tabular}{|c|}
124 \\
$28,0 \%$ \\
0,2799
\end{tabular} & $\begin{array}{c}71 \\
16,0 \% \\
0,1603\end{array}$ & \begin{tabular}{|c|}
55 \\
$12,4 \%$ \\
0,124
\end{tabular} & $\begin{array}{c}443 \\
100 \% \\
100 \%\end{array}$ & Total & \begin{tabular}{|l} 
Recuento \\
$\%$ de banco \\
$\%$ del total
\end{tabular} & $\begin{array}{c}88 \\
29,7 \% \\
0,2973\end{array}$ & $\begin{array}{c}50 \\
16,9 \% \\
0,1689\end{array}$ & \begin{tabular}{|c|}
88 \\
$29,7 \%$ \\
0,2973
\end{tabular} & \begin{tabular}{|c|}
48 \\
$16,2 \%$ \\
0,1622 \\
\end{tabular} & $\begin{array}{c}22 \\
7,4 \% \\
0,0743\end{array}$ & \begin{tabular}{c|}
296 \\
$100,0 \%$ \\
$100 \%$
\end{tabular} & Total & \begin{tabular}{|l} 
Recuento \\
$\%$ de banco \\
$\%$ del total
\end{tabular} & \begin{tabular}{|c|}
68 \\
$33,3 \%$ \\
0,3333 \\
\end{tabular} & $\begin{array}{c}38 \\
18,6 \% \\
0,1863\end{array}$ & \begin{tabular}{|c|}
56 \\
$27,5 \%$ \\
0,2745 \\
\end{tabular} & $\begin{array}{c}31 \\
15,2 \% \\
0,152\end{array}$ & \begin{tabular}{|c|}
11 \\
$5,4 \%$ \\
0,0539 \\
\end{tabular} & $\begin{array}{c}204 \\
100 \% \\
100 \%\end{array}$ \\
\hline
\end{tabular}

Fuente: Elaboración propia en base a la información obtenida de las encuestas realizadas a las empresas. 
Cuadro 51

\begin{tabular}{|c|c|c|c|c|c|c|c|c|c|c|c|c|c|c|c|c|c|c|c|c|c|c|c|c|}
\hline & \multicolumn{8}{|c|}{ Calificación para el banco $1^{\circ}$} & \multicolumn{8}{|c|}{ Calificación para el banco $2^{\circ}$} & \multicolumn{8}{|c|}{ Calificación para el banco $3^{\circ}$} \\
\hline & & & 1 & 2 & 3 & 4 & 5 & Total & & & 1 & 2 & 3 & 4 & 5 & Total & & & 1 & 2 & 3 & 4 & 5 & Total \\
\hline \multirow{8}{*}{ 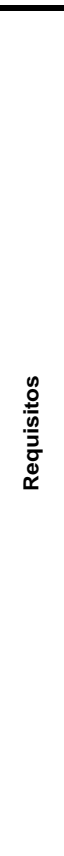 } & Nación & $\begin{array}{l}\text { Recuento } \\
\% \text { de banco } \\
\% \text { del total }\end{array}$ & \begin{tabular}{|c|}
28 \\
$31,8 \%$ \\
4,754 \\
\end{tabular} & $\begin{array}{c}11 \\
12,5 \% \\
1,87\end{array}$ & \begin{tabular}{|c|}
28 \\
$31,8 \%$ \\
4,754 \\
\end{tabular} & $\begin{array}{c}10 \\
11,4 \% \\
1,698\end{array}$ & $\begin{array}{c}11 \\
12,5 \% \\
1,87\end{array}$ & \begin{tabular}{|c|}
88 \\
$100 \%$ \\
14,946 \\
\end{tabular} & Nación & \begin{tabular}{|l} 
Recuento \\
$\%$ de banco \\
$\%$ del total
\end{tabular} & $\begin{array}{c}23 \\
30,7 \% \\
5,36\end{array}$ & $\begin{array}{c}6 \\
8,0 \% \\
1,4\end{array}$ & $\begin{array}{c}24 \\
32,0 \% \\
5,594\end{array}$ & \begin{tabular}{|c|}
15 \\
$20,0 \%$ \\
3,5 \\
\end{tabular} & $\begin{array}{c}7 \\
9,3 \% \\
1,63 \\
\end{array}$ & \begin{tabular}{|c|}
75 \\
$100 \%$ \\
17,484 \\
\end{tabular} & Nación & \begin{tabular}{|l} 
Recuento \\
$\%$ de banco \\
$\%$ del total
\end{tabular} & $\begin{array}{c}20 \\
37 \% \\
6,64\end{array}$ & $\begin{array}{c}4 \\
7 \% \\
1,33\end{array}$ & $\begin{array}{c}22 \\
41 \% \\
7,31\end{array}$ & $\begin{array}{c}6 \\
11 \% \\
1,99\end{array}$ & $\begin{array}{c}2 \\
4 \% \\
0,66\end{array}$ & $\begin{array}{c}54 \\
100 \% \\
18\end{array}$ \\
\hline & Provincia & \begin{tabular}{|l} 
Recuento \\
$\%$ de banco \\
$\%$ del total
\end{tabular} & \begin{tabular}{|c|}
23 \\
$27,4 \%$ \\
3,905
\end{tabular} & $\begin{array}{c}12 \\
14,3 \% \\
2,04\end{array}$ & $\begin{array}{c}24 \\
28,6 \% \\
4,075\end{array}$ & $\begin{array}{c}13 \\
15,5 \% \\
2,207\end{array}$ & $\begin{array}{c}12 \\
14,3 \% \\
2,04\end{array}$ & \begin{tabular}{|c|}
84 \\
$100 \%$ \\
14,267
\end{tabular} & Provincia & \begin{tabular}{|l} 
Recuento \\
$\%$ de banco \\
$\%$ del total
\end{tabular} & $\begin{array}{c}16 \\
26,2 \% \\
3,73\end{array}$ & $\begin{array}{c}10 \\
16,4 \% \\
2,33\end{array}$ & $\begin{array}{c}16 \\
26,2 \% \\
3,73\end{array}$ & \begin{tabular}{|c|}
15 \\
$24,6 \%$ \\
3,5
\end{tabular} & $\begin{array}{c}4 \\
6,6 \% \\
0,93\end{array}$ & $\begin{array}{c}61 \\
100 \% \\
14,22\end{array}$ & Provincia & \begin{tabular}{|l} 
Recuento \\
$\%$ de banco \\
$\%$ del total
\end{tabular} & $\begin{array}{c}11 \\
0,275 \\
3,65\end{array}$ & $\begin{array}{c}11 \\
0,275 \\
3,65\end{array}$ & $\begin{array}{c}7 \\
0,175 \\
2,33\end{array}$ & $\begin{array}{c}8 \\
0,2 \\
2,66\end{array}$ & $\begin{array}{c}3 \\
0,075 \\
1\end{array}$ & $\begin{array}{c}40 \\
1 \\
13,29\end{array}$ \\
\hline & Credicoop & \begin{tabular}{|l} 
Recuento \\
$\%$ de banco \\
$\%$ del total
\end{tabular} & \begin{tabular}{|c|}
25 \\
$16,2 \%$ \\
4,244
\end{tabular} & $\begin{array}{c}18 \\
11,7 \% \\
3,06\end{array}$ & $\begin{array}{c}37 \\
24,0 \% \\
6,282\end{array}$ & $\begin{array}{c}44 \\
28,6 \% \\
7,47\end{array}$ & $\begin{array}{c}30 \\
19,5 \% \\
5,09\end{array}$ & \begin{tabular}{|c|}
154 \\
$100 \%$ \\
26,146
\end{tabular} & Credicoop & \begin{tabular}{|l} 
Recuento \\
$\%$ de banco \\
$\%$ del total
\end{tabular} & $\begin{array}{c}20 \\
20,8 \% \\
4,68\end{array}$ & $\begin{array}{c}19 \\
19,8 \% \\
4,43\end{array}$ & $\begin{array}{c}27 \\
28,1 \% \\
6,294\end{array}$ & \begin{tabular}{|c|}
14 \\
$14,6 \%$ \\
3,26
\end{tabular} & $\begin{array}{c}16 \\
16,7 \% \\
3,26\end{array}$ & \begin{tabular}{|c|}
96 \\
$100 \%$ \\
21,924 \\
\end{tabular} & Credicoop & \begin{tabular}{|l} 
Recuento \\
$\%$ de banco \\
$\%$ del total
\end{tabular} & $\begin{array}{c}14 \\
0,2222 \\
4,65\end{array}$ & \begin{tabular}{|c|}
12 \\
0,1905 \\
3,99
\end{tabular} & \begin{tabular}{|c|}
19 \\
0,3016 \\
6,31
\end{tabular} & \begin{tabular}{|c|}
9 \\
0,1429 \\
2,99
\end{tabular} & \begin{tabular}{|c|}
9 \\
0,1429 \\
2,99
\end{tabular} & $\begin{array}{c}63 \\
100 \% \\
20,93\end{array}$ \\
\hline & Galicia & \begin{tabular}{|l} 
Recuento \\
$\%$ de banco \\
$\%$ del total
\end{tabular} & \begin{tabular}{c|}
11 \\
$14,3 \%$ \\
1,868 \\
\end{tabular} & $\begin{array}{c}8 \\
10,4 \% \\
1,36\end{array}$ & \begin{tabular}{c|}
20 \\
$26,0 \%$ \\
3,396 \\
\end{tabular} & \begin{tabular}{|c|}
21 \\
$27,3 \%$ \\
3,585
\end{tabular} & \begin{tabular}{|c|}
17 \\
$22,1 \%$ \\
2,89
\end{tabular} & \begin{tabular}{|c|}
77 \\
$100 \%$ \\
13,099 \\
\end{tabular} & Galicia & \begin{tabular}{|l} 
Recuento \\
$\%$ de banco \\
$\%$ del total
\end{tabular} & $\begin{array}{c}8 \\
13,6 \% \\
4,66\end{array}$ & $\begin{array}{c}12 \\
20,3 \% \\
4,43\end{array}$ & $\begin{array}{c}13 \\
22,0 \% \\
6,2294\end{array}$ & \begin{tabular}{|c|}
16 \\
$27,1 \%$ \\
3,26
\end{tabular} & \begin{tabular}{|c|}
10 \\
$16,9 \%$ \\
3,73 \\
\end{tabular} & \begin{tabular}{|c|}
59 \\
1 \\
22,3094 \\
\end{tabular} & Galicia & \begin{tabular}{|l} 
Recuento \\
$\%$ de banco \\
$\%$ del total
\end{tabular} & $\begin{array}{c}10 \\
0,2326 \\
3,32\end{array}$ & \begin{tabular}{|c|}
6 \\
0,1395 \\
1,99
\end{tabular} & \begin{tabular}{|c|}
11 \\
0,2558 \\
3,65 \\
\end{tabular} & \begin{tabular}{|c|}
10 \\
0,2326 \\
3,32 \\
\end{tabular} & $\begin{array}{c}6 \\
0,1395 \\
1,99\end{array}$ & $\begin{array}{c}43 \\
100 \% \\
14,27\end{array}$ \\
\hline & BBVA & \begin{tabular}{|l} 
Recuento \\
$\%$ de banco \\
$\%$ del total
\end{tabular} & \begin{tabular}{|c|}
8 \\
$19,5 \%$ \\
1,358
\end{tabular} & $\begin{array}{c}7 \\
17,1 \% \\
1,19\end{array}$ & \begin{tabular}{|c|}
9 \\
$22,0 \%$ \\
1,528
\end{tabular} & $\begin{array}{c}8 \\
19,5 \% \\
1,358\end{array}$ & \begin{tabular}{|c|}
9 \\
$22,0 \%$ \\
1,53
\end{tabular} & \begin{tabular}{c|}
41 \\
$100 \%$ \\
6,964
\end{tabular} & BBVA & $\begin{array}{l}\text { Recuento } \\
\% \text { de banco } \\
\% \text { del total }\end{array}$ & $\begin{array}{c}6 \\
19,4 \% \\
1,4\end{array}$ & $\begin{array}{c}9 \\
29,0 \% \\
2,1\end{array}$ & $\begin{array}{c}6 \\
19,4 \% \\
1,399\end{array}$ & \begin{tabular}{|c|}
4 \\
$12,9 \%$ \\
0,93
\end{tabular} & $\begin{array}{c}6 \\
19,4 \% \\
1,4\end{array}$ & $\begin{array}{c}31 \\
100 \% \\
7,229\end{array}$ & BBVA & \begin{tabular}{|l} 
Recuento \\
$\%$ de banco \\
$\%$ del total
\end{tabular} & $\begin{array}{c}4 \\
0,1538 \\
1,33\end{array}$ & \begin{tabular}{|c|}
6 \\
0,2308 \\
1,99
\end{tabular} & \begin{tabular}{|c|}
6 \\
0,2308 \\
1,99 \\
\end{tabular} & \begin{tabular}{|c|}
5 \\
0,1923 \\
1,86
\end{tabular} & \begin{tabular}{|c|}
5 \\
0,1923 \\
1,66
\end{tabular} & $\begin{array}{c}26 \\
1 \\
8,83\end{array}$ \\
\hline & Santander & \begin{tabular}{|l} 
Recuento \\
$\%$ de banco \\
$\%$ del total
\end{tabular} & \begin{tabular}{|c|}
14 \\
$19,4 \%$ \\
2,377 \\
\end{tabular} & $\begin{array}{c}2 \\
2,8 \% \\
0,34 \\
\end{array}$ & $\begin{array}{c}24 \\
33,3 \% \\
4,075 \\
\end{array}$ & $\begin{array}{c}14 \\
19,4 \% \\
2,377\end{array}$ & \begin{tabular}{|c|}
18 \\
$25,0 \%$ \\
3,08
\end{tabular} & \begin{tabular}{c|}
72 \\
$100 \%$ \\
12,22 \\
\end{tabular} & Santander & \begin{tabular}{|l} 
Recuento \\
$\%$ de banco \\
$\%$ del total
\end{tabular} & $\begin{array}{c}10 \\
18,5 \% \\
2,33 \\
\end{array}$ & $\begin{array}{c}3 \\
5,6 \% \\
0,7\end{array}$ & $\begin{array}{c}15 \\
27,8 \% \\
3,497\end{array}$ & \begin{tabular}{|c|}
15 \\
$27,8 \%$ \\
3,5 \\
\end{tabular} & \begin{tabular}{c|}
11 \\
$20,4 \%$ \\
2,56
\end{tabular} & $\begin{array}{c}54 \\
1 \\
12,587\end{array}$ & Santander & \begin{tabular}{|l} 
Recuento \\
$\%$ de banco \\
$\%$ del total
\end{tabular} & $\begin{array}{c}7 \\
0,1892 \\
2,33\end{array}$ & $\begin{array}{c}5 \\
0,1351 \\
1,66\end{array}$ & \begin{tabular}{|c|}
8 \\
0,2162 \\
2,66 \\
\end{tabular} & \begin{tabular}{|c|}
8 \\
0,2162 \\
2,66 \\
\end{tabular} & $\begin{array}{c}9 \\
0,2432 \\
2,99\end{array}$ & $\begin{array}{c}37 \\
1 \\
12,3\end{array}$ \\
\hline & HSBC & \begin{tabular}{|l} 
Recuento \\
$\%$ de banco \\
$\%$ del total
\end{tabular} & \begin{tabular}{|c|}
5 \\
$26 \%$ \\
0,849
\end{tabular} & $\begin{array}{c}0 \\
0 \% \\
0\end{array}$ & \begin{tabular}{|c|}
6 \\
$32 \%$ \\
1,019
\end{tabular} & $\begin{array}{c}4 \\
21 \% \\
0,679\end{array}$ & \begin{tabular}{c|}
4 \\
$21 \%$ \\
0,68
\end{tabular} & \begin{tabular}{c|}
19 \\
$100 \%$ \\
3,227
\end{tabular} & HSBC & \begin{tabular}{|l} 
Recuento \\
$\%$ de banco \\
$\%$ del total
\end{tabular} & $\begin{array}{c}2 \\
16,7 \% \\
0,47\end{array}$ & $\begin{array}{c}1 \\
8,3 \% \\
0,23\end{array}$ & $\begin{array}{c}4 \\
33,3 \% \\
0,932\end{array}$ & \begin{tabular}{|c|}
3 \\
$25,0 \%$ \\
0,7
\end{tabular} & $\begin{array}{c}2 \\
16,7 \% \\
0,47\end{array}$ & $\begin{array}{c}12 \\
1 \\
2,8\end{array}$ & HSBC & \begin{tabular}{|l} 
Recuento \\
$\%$ de banco \\
$\%$ del total
\end{tabular} & $\begin{array}{l}0 \\
0 \\
0\end{array}$ & $\begin{array}{c}1 \\
0,1111 \\
0,33\end{array}$ & \begin{tabular}{|c|}
2 \\
0,2222 \\
0,66
\end{tabular} & \begin{tabular}{|c|}
3 \\
0,3333 \\
1
\end{tabular} & \begin{tabular}{|c|}
3 \\
0,3333 \\
1
\end{tabular} & $\begin{array}{c}9 \\
1 \\
2,99\end{array}$ \\
\hline & Total & \begin{tabular}{|l} 
Recuento \\
$\%$ de banco \\
$\%$ del total
\end{tabular} & \begin{tabular}{|c|}
124 \\
$20,4 \%$ \\
0,2036 \\
\end{tabular} & $\begin{array}{c}81 \\
13,3 \% \\
0,133\end{array}$ & $\begin{array}{c}170 \\
27,9 \% \\
0,2791\end{array}$ & \begin{tabular}{|c|}
124 \\
$20,4 \%$ \\
0,2036
\end{tabular} & \begin{tabular}{|c|}
110 \\
$18,1 \%$ \\
0,1806
\end{tabular} & $\begin{array}{c}609 \\
100 \% \\
1\end{array}$ & Total & \begin{tabular}{|l} 
Recuento \\
$\%$ de banco \\
$\%$ del total
\end{tabular} & $\begin{array}{c}93 \\
21,7 \% \\
0,2168\end{array}$ & $\begin{array}{c}66 \\
15,4 \% \\
0,1538\end{array}$ & $\begin{array}{c}121 \\
28,2 \% \\
0,2821\end{array}$ & $\begin{array}{c}90 \\
21,0 \% \\
0,2098 \\
\end{array}$ & \begin{tabular}{|c|}
59 \\
$13,8 \%$ \\
0,1375 \\
\end{tabular} & $\begin{array}{c}429 \\
1 \\
1\end{array}$ & Total & \begin{tabular}{|l} 
Recuento \\
$\%$ de banco \\
$\%$ del total
\end{tabular} & $\begin{array}{c}76 \\
25,2 \% \\
25,2 \%\end{array}$ & $\begin{array}{c}48 \\
15,9 \% \\
15,9 \%\end{array}$ & \begin{tabular}{|c|}
83 \\
$27,6 \%$ \\
$27,6 \%$ \\
\end{tabular} & \begin{tabular}{|c|}
53 \\
$17,6 \%$ \\
$17,6 \%$
\end{tabular} & \begin{tabular}{|c|}
41 \\
$13,6 \%$ \\
$13,6 \%$
\end{tabular} & $\begin{array}{c}301 \\
100 \% \\
100 \%\end{array}$ \\
\hline
\end{tabular}

Fuente: Elaboración propia en base a la información obtenida de las encuestas realizadas a las empresas. 
Cuadro 52

\begin{tabular}{|c|c|c|c|c|c|c|c|c|c|c|c|c|c|c|c|c|c|c|c|c|c|c|c|c|}
\hline & \multicolumn{8}{|c|}{ Calificación para el banco $1^{\circ}$} & \multicolumn{8}{|c|}{${\text { Calificación para el banco } 2^{\circ}}^{\circ}$} & \multicolumn{8}{|c|}{ Calificación para el banco $3^{\circ}$} \\
\hline & & & 1 & 2 & 3 & 4 & 5 & Total & & & 1 & 2 & 3 & 4 & 5 & Total & & & 1 & 2 & 3 & 4 & 5 & Total \\
\hline \multirow{8}{*}{ 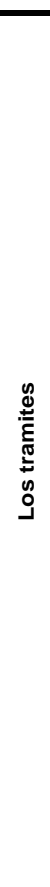 } & Nación & \begin{tabular}{|l|} 
Recuento \\
$\%$ de banco \\
$\%$ del total
\end{tabular} & $\begin{array}{c}15 \\
0,1744 \\
2,591\end{array}$ & \begin{tabular}{|c|}
15 \\
0,1744 \\
2,59
\end{tabular} & $\begin{array}{c}36 \\
0,4186 \\
6,218\end{array}$ & $\begin{array}{c}8 \\
0,093 \\
1,382\end{array}$ & \begin{tabular}{|c|}
12 \\
0,1395 \\
2,07
\end{tabular} & $\begin{array}{c}86 \\
1 \\
14,851\end{array}$ & Nación & \begin{tabular}{|l|} 
Recuento \\
$\%$ de banco \\
$\%$ del total
\end{tabular} & $\begin{array}{c}10 \\
0,137 \\
2,4\end{array}$ & $\begin{array}{c}13 \\
0,1781 \\
3,12\end{array}$ & \begin{tabular}{|c|}
30 \\
0,411 \\
7,194
\end{tabular} & \begin{tabular}{|c|}
12 \\
0,1644 \\
2,88
\end{tabular} & \begin{tabular}{|c|}
8 \\
0,1096 \\
1,92
\end{tabular} & \begin{tabular}{|c|}
73 \\
1 \\
17,514 \\
\end{tabular} & Nación & \begin{tabular}{|l|} 
Recuento \\
$\%$ de banco \\
$\%$ del total
\end{tabular} & \begin{tabular}{|c|}
8 \\
0,1509 \\
2,72
\end{tabular} & \begin{tabular}{|c|}
11 \\
0,2075 \\
3,74
\end{tabular} & \begin{tabular}{|c|}
26 \\
0,4906 \\
8,84
\end{tabular} & \begin{tabular}{|c|}
5 \\
0,0943 \\
1,7 \\
\end{tabular} & \begin{tabular}{|c|}
3 \\
0,0566 \\
1,02
\end{tabular} & $\begin{array}{c}53 \\
1 \\
18\end{array}$ \\
\hline & Provincia & \begin{tabular}{|l|} 
Recuento \\
$\%$ de banco \\
$\%$ del total
\end{tabular} & $\begin{array}{c}19 \\
0,2289 \\
3,282\end{array}$ & \begin{tabular}{|c|}
18 \\
0,2169 \\
3,11
\end{tabular} & $\begin{array}{c}22 \\
0,2651 \\
3,8\end{array}$ & \begin{tabular}{|c|}
11 \\
0,1325 \\
1,9 \\
\end{tabular} & \begin{tabular}{|c|}
13 \\
0,1566 \\
2,25 \\
\end{tabular} & \begin{tabular}{|c|}
83 \\
1 \\
14,342
\end{tabular} & Provincia & \begin{tabular}{|l|} 
Recuento \\
$\%$ de banco \\
$\%$ del total
\end{tabular} & \begin{tabular}{|c|}
15 \\
0,2459 \\
3,6
\end{tabular} & $\begin{array}{c}6 \\
0,0984 \\
1,44\end{array}$ & \begin{tabular}{|c|}
16 \\
0,2623 \\
3,837 \\
\end{tabular} & \begin{tabular}{|c|}
16 \\
0,2623 \\
3,84 \\
\end{tabular} & \begin{tabular}{|c|} 
\\
0,1311 \\
1,92 \\
\end{tabular} & \begin{tabular}{|c|}
61 \\
1 \\
14,637 \\
\end{tabular} & Provincia & \begin{tabular}{|l} 
Recuento \\
$\%$ de banco \\
$\%$ del total
\end{tabular} & \begin{tabular}{|c|}
12 \\
0,2927 \\
4,08 \\
\end{tabular} & \begin{tabular}{|c|}
7 \\
0,1707 \\
2,38 \\
\end{tabular} & \begin{tabular}{|c|} 
\\
0,2195 \\
3,06 \\
\end{tabular} & \begin{tabular}{|c|}
7 \\
0,1707 \\
2,38 \\
\end{tabular} & \begin{tabular}{|c|}
6 \\
0,1463 \\
2,04 \\
\end{tabular} & $\begin{array}{c}41 \\
1 \\
13,94\end{array}$ \\
\hline & Credicoop & \begin{tabular}{|l|} 
Recuento \\
$\%$ de banco \\
$\%$ del total \\
\end{tabular} & $\begin{array}{c}21 \\
0,1382 \\
3,627 \\
\end{array}$ & \begin{tabular}{|c|}
17 \\
0,1118 \\
2,94 \\
\end{tabular} & $\begin{array}{c}40 \\
0,2632 \\
6,908 \\
\end{array}$ & \begin{tabular}{|c|}
43 \\
0,2829 \\
7,427 \\
\end{tabular} & \begin{tabular}{|c|}
31 \\
0,2039 \\
5,35 \\
\end{tabular} & \begin{tabular}{|c}
152 \\
1 \\
26,252 \\
\end{tabular} & Credicoop & \begin{tabular}{|l|} 
Recuento \\
$\%$ de banco \\
$\%$ del total
\end{tabular} & \begin{tabular}{|c|}
16 \\
0,1798 \\
3,84 \\
\end{tabular} & \begin{tabular}{|c|}
15 \\
0,1685 \\
3,6 \\
\end{tabular} & \begin{tabular}{|c|}
32 \\
0,3596 \\
7,674 \\
\end{tabular} & \begin{tabular}{|c|}
10 \\
0,1124 \\
2,4 \\
\end{tabular} & \begin{tabular}{|c|}
16 \\
0,1798 \\
3,84 \\
\end{tabular} & \begin{tabular}{|c|}
89 \\
1 \\
21,354 \\
\end{tabular} & Credicoop & \begin{tabular}{|l} 
Recuento \\
$\%$ de banco \\
$\%$ del total
\end{tabular} & \begin{tabular}{|c|}
14 \\
0,2333 \\
4,76 \\
\end{tabular} & \begin{tabular}{|c|}
13 \\
0,2167 \\
4,42 \\
\end{tabular} & $\begin{array}{c}16 \\
0,2667 \\
5,44\end{array}$ & $\begin{array}{c}9 \\
0,15 \\
3,06 \\
\end{array}$ & \begin{tabular}{|c|}
8 \\
0,1333 \\
2,72 \\
\end{tabular} & $\begin{array}{c}60 \\
1 \\
20,4 \\
\end{array}$ \\
\hline & Galicia & \begin{tabular}{|l} 
Recuento \\
$\%$ de banco \\
$\%$ del total \\
\end{tabular} & $\begin{array}{c}6 \\
0,08 \\
1,036 \\
\end{array}$ & $\begin{array}{c}7 \\
0,0933 \\
1,21 \\
\end{array}$ & $\begin{array}{c}20 \\
0,2667 \\
3,454 \\
\end{array}$ & \begin{tabular}{|c|}
23 \\
0,3067 \\
3,972 \\
\end{tabular} & \begin{tabular}{|c|}
19 \\
0,2533 \\
3,28 \\
\end{tabular} & \begin{tabular}{|c|}
75 \\
1 \\
12,952 \\
\end{tabular} & Galicia & \begin{tabular}{|l} 
Recuento \\
$\%$ de banco \\
$\%$ del total
\end{tabular} & \begin{tabular}{|c|}
5 \\
0,0877 \\
1,2 \\
\end{tabular} & $\begin{array}{c}8 \\
0,1404 \\
1,92 \\
\end{array}$ & \begin{tabular}{|c|}
21 \\
0,3684 \\
5,038 \\
\end{tabular} & \begin{tabular}{|c|}
14 \\
0,2456 \\
3,36 \\
\end{tabular} & \begin{tabular}{|c|}
9 \\
0,1579 \\
2,16 \\
\end{tabular} & \begin{tabular}{|c|}
57 \\
1 \\
13,678 \\
\end{tabular} & Galicia & \begin{tabular}{|l} 
Recuento \\
$\%$ de banco \\
$\%$ del total \\
\end{tabular} & \begin{tabular}{|c|}
7 \\
0,1707 \\
2,38
\end{tabular} & \begin{tabular}{|c|}
6 \\
0,1463 \\
2,04 \\
\end{tabular} & \begin{tabular}{|c|}
11 \\
0,2683 \\
3,74 \\
\end{tabular} & \begin{tabular}{|c|}
12 \\
0,2927 \\
4,08 \\
\end{tabular} & $\begin{array}{c}5 \\
0,122 \\
1,7 \\
\end{array}$ & $\begin{array}{c}41 \\
1 \\
13,94 \\
\end{array}$ \\
\hline & BBVA & \begin{tabular}{|l|} 
Recuento \\
$\%$ de banco \\
$\%$ del total
\end{tabular} & $\begin{array}{c}4 \\
0,0952 \\
0,691\end{array}$ & \begin{tabular}{|c|}
6 \\
0,1429 \\
1,04 \\
\end{tabular} & $\begin{array}{c}10 \\
0,2381 \\
1,727\end{array}$ & \begin{tabular}{|c|}
12 \\
0,2857 \\
2,073 \\
\end{tabular} & \begin{tabular}{|c|}
10 \\
0,2381 \\
1,73 \\
\end{tabular} & \begin{tabular}{|c|}
42 \\
1 \\
7,261
\end{tabular} & BBVA & \begin{tabular}{|l} 
Recuento \\
$\%$ de banco \\
$\%$ del total
\end{tabular} & \begin{tabular}{|c|}
5 \\
0,1613 \\
1,2
\end{tabular} & $\begin{array}{c}4 \\
0,129 \\
0,96\end{array}$ & \begin{tabular}{|c|}
14 \\
0,4516 \\
3,357 \\
\end{tabular} & \begin{tabular}{|c|} 
\\
0,0323 \\
0,24
\end{tabular} & \begin{tabular}{|c|}
7 \\
0,2258 \\
1,68 \\
\end{tabular} & $\begin{array}{c}31 \\
1 \\
7,437\end{array}$ & BBVA & \begin{tabular}{|l} 
Recuento \\
$\%$ de banco \\
$\%$ del total
\end{tabular} & $\begin{array}{c}3 \\
0,125 \\
1,02\end{array}$ & $\begin{array}{c}3 \\
0,125 \\
1,02\end{array}$ & $\begin{array}{c}7 \\
0,2917 \\
2,38\end{array}$ & $\begin{array}{c}6 \\
0,25 \\
2,04\end{array}$ & \begin{tabular}{|c|}
5 \\
0,2083 \\
1,7
\end{tabular} & $\begin{array}{c}24 \\
1 \\
8,16\end{array}$ \\
\hline & Santander & \begin{tabular}{|l|} 
Recuento \\
$\%$ de banco \\
$\%$ del total
\end{tabular} & $\begin{array}{c}9 \\
0,1324 \\
1,554 \\
\end{array}$ & $\begin{array}{c}2 \\
0,0294 \\
0,35\end{array}$ & \begin{tabular}{|c|}
17 \\
0,25 \\
2,936 \\
\end{tabular} & \begin{tabular}{|c|}
18 \\
0,2647 \\
3,109 \\
\end{tabular} & \begin{tabular}{|c|}
22 \\
0,3235 \\
3,8 \\
\end{tabular} & \begin{tabular}{|c|}
68 \\
1 \\
11,749 \\
\end{tabular} & Santander & \begin{tabular}{|l} 
Recuento \\
$\%$ de banco \\
$\%$ del total
\end{tabular} & \begin{tabular}{|c|}
7 \\
0,1321 \\
1,68 \\
\end{tabular} & $\begin{array}{c}4 \\
0,0755 \\
0,96\end{array}$ & \begin{tabular}{|c|}
14 \\
0,2642 \\
3,357 \\
\end{tabular} & \begin{tabular}{|c|}
14 \\
0,2642 \\
3,36 \\
\end{tabular} & \begin{tabular}{|c|}
14 \\
0,2642 \\
3,36 \\
\end{tabular} & \begin{tabular}{|c|}
53 \\
1 \\
12,717 \\
\end{tabular} & Santander & \begin{tabular}{|l} 
Recuento \\
$\%$ de banco \\
$\%$ del total
\end{tabular} & \begin{tabular}{|c|}
4 \\
0,1111 \\
1,36 \\
\end{tabular} & \begin{tabular}{|c|}
6 \\
0,1667 \\
2,04 \\
\end{tabular} & $\begin{array}{c}9 \\
0,25 \\
3,06 \\
\end{array}$ & \begin{tabular}{|c|}
7 \\
0,1944 \\
2,38 \\
\end{tabular} & \begin{tabular}{|c|}
10 \\
0,2778 \\
3,4 \\
\end{tabular} & $\begin{array}{c}36 \\
1 \\
12,24 \\
\end{array}$ \\
\hline & HSBC & \begin{tabular}{|l|} 
Recuento \\
$\%$ de banco \\
$\%$ del total \\
\end{tabular} & $\begin{array}{c}5 \\
0,25 \\
0,864 \\
\end{array}$ & $\begin{array}{c}1 \\
0,05 \\
0,17 \\
\end{array}$ & $\begin{array}{c}5 \\
0,25 \\
0,864 \\
\end{array}$ & $\begin{array}{c}3 \\
0,15 \\
0,518 \\
\end{array}$ & $\begin{array}{c}6 \\
0,3 \\
1,04 \\
\end{array}$ & $\begin{array}{c}20 \\
1 \\
3,454 \\
\end{array}$ & HSBC & \begin{tabular}{|l|} 
Recuento \\
$\%$ de banco \\
$\%$ del total
\end{tabular} & \begin{tabular}{|c|}
2 \\
0,1538 \\
0,48 \\
\end{tabular} & $\begin{array}{c}1 \\
0,0769 \\
0,24 \\
\end{array}$ & \begin{tabular}{|c|}
3 \\
0,2308 \\
0,719 \\
\end{tabular} & \begin{tabular}{|c|}
3 \\
0,2308 \\
0,72 \\
\end{tabular} & \begin{tabular}{|c|}
4 \\
0,3077 \\
0,96 \\
\end{tabular} & $\begin{array}{c}13 \\
1 \\
3,1\end{array}$ & HSBC & \begin{tabular}{|l|} 
Recuento \\
$\%$ de banco \\
$\%$ del total \\
\end{tabular} & $\begin{array}{c}1 \\
0,1111 \\
0,34 \\
\end{array}$ & $\begin{array}{l}0 \\
0 \\
0 \\
\end{array}$ & \begin{tabular}{|c|}
2 \\
0,2222 \\
0,68 \\
\end{tabular} & \begin{tabular}{|c|}
3 \\
0,3333 \\
1,02 \\
\end{tabular} & \begin{tabular}{|c|}
3 \\
0,3333 \\
1,02 \\
\end{tabular} & $\begin{array}{r}9 \\
1 \\
3,06 \\
\end{array}$ \\
\hline & Total & \begin{tabular}{|l} 
Recuento \\
$\%$ de banco \\
$\%$ del total
\end{tabular} & \begin{tabular}{|c|}
84 \\
0,1451 \\
0,1451
\end{tabular} & \begin{tabular}{|c|}
69 \\
0,1192 \\
0,1192 \\
\end{tabular} & $\begin{array}{c}170 \\
0,2936 \\
0,2936\end{array}$ & \begin{tabular}{|c|}
131 \\
0,2263 \\
0,2263
\end{tabular} & \begin{tabular}{|c|}
125 \\
0,2159 \\
0,2159 \\
\end{tabular} & $\begin{array}{c}579 \\
1 \\
1\end{array}$ & Total & \begin{tabular}{|l} 
Recuento \\
$\%$ de banco \\
$\%$ del total
\end{tabular} & \begin{tabular}{|c|}
63 \\
0,1511 \\
0,1511
\end{tabular} & $\begin{array}{c}57 \\
0,1367 \\
0,1367\end{array}$ & \begin{tabular}{|c|}
147 \\
0,3525 \\
0,3525 \\
\end{tabular} & \begin{tabular}{|c|}
79 \\
0,1894 \\
0,1894
\end{tabular} & \begin{tabular}{|c|}
71 \\
0,1703 \\
0,1703 \\
\end{tabular} & $\begin{array}{c}417 \\
1 \\
1\end{array}$ & Total & \begin{tabular}{|l} 
Recuento \\
$\%$ de banco \\
$\%$ del total
\end{tabular} & \begin{tabular}{|c|}
55 \\
0,1871 \\
0,1871
\end{tabular} & \begin{tabular}{|c|}
51 \\
0,1735 \\
0,1735
\end{tabular} & \begin{tabular}{|c|}
91 \\
0,3095 \\
0,3095 \\
\end{tabular} & \begin{tabular}{|c|}
52 \\
0,1769 \\
0,1769 \\
\end{tabular} & \begin{tabular}{|c|}
45 \\
0,1531 \\
0,1531
\end{tabular} & $\begin{array}{c}294 \\
1 \\
1\end{array}$ \\
\hline
\end{tabular}

Fuente: Elaboración propia en base a la información obtenida de las encuestas realizadas a las empresas. 
Cuadro 53

\begin{tabular}{|c|c|c|c|c|c|c|c|c|c|c|c|c|c|c|c|c|c|c|c|c|c|c|c|c|}
\hline & \multicolumn{8}{|c|}{ Calificación para el banco $1^{\circ}$} & \multicolumn{8}{|c|}{ Calificación para el banco $2^{\circ}$} & \multicolumn{8}{|c|}{ Calificación para el banco $3^{\circ}$} \\
\hline & & & 1 & 2 & \begin{tabular}{|l|l}
3 \\
\end{tabular} & 4 & 5 & Total & & & \begin{tabular}{|l|l}
1 \\
\end{tabular} & 2 & 3 & 4 & 5 & Total & & & 1 & 2 & 3 & 4 & 5 & Total \\
\hline \multirow{8}{*}{ 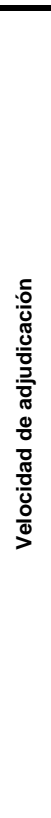 } & Nación & $\begin{array}{l}\text { Recuento } \\
\% \text { de banco } \\
\% \text { del total }\end{array}$ & \begin{tabular}{|c|}
10 \\
0,1639 \\
1,984
\end{tabular} & $\begin{array}{c}11 \\
0,1803 \\
2,18\end{array}$ & \begin{tabular}{|c|}
17 \\
0,2787 \\
3,373 \\
\end{tabular} & \begin{tabular}{|c|}
12 \\
0,1967 \\
2,381 \\
\end{tabular} & \begin{tabular}{|c|}
11 \\
0,1803 \\
2,18
\end{tabular} & $\begin{array}{c}61 \\
1 \\
12,098 \\
\end{array}$ & Nación & $\begin{array}{l}\text { Recuento } \\
\% \text { de banco } \\
\% \text { del total }\end{array}$ & \begin{tabular}{|c|}
6 \\
0,1277 \\
1,71 \\
\end{tabular} & \begin{tabular}{|c|}
9 \\
0,1915 \\
2,57
\end{tabular} & \begin{tabular}{|c|}
17 \\
0,3617 \\
4,857
\end{tabular} & \begin{tabular}{|c|}
8 \\
0,1702 \\
2,29 \\
\end{tabular} & \begin{tabular}{|c|}
7 \\
0,1489 \\
2
\end{tabular} & \begin{tabular}{|c|}
47 \\
1 \\
13,427 \\
\end{tabular} & Nación & $\begin{array}{l}\text { Recuento } \\
\% \text { de banco } \\
\% \text { del total }\end{array}$ & \begin{tabular}{|c|}
8 \\
0,2353 \\
3,27
\end{tabular} & \begin{tabular}{|c|}
5 \\
0,1471 \\
2,04 \\
\end{tabular} & $\begin{array}{c}11 \\
0,3235 \\
4,49\end{array}$ & \begin{tabular}{|c|}
4 \\
0,1176 \\
1,63
\end{tabular} & \begin{tabular}{|c|}
6 \\
0,1765 \\
2,45
\end{tabular} & $\begin{array}{c}34 \\
1 \\
14\end{array}$ \\
\hline & Provincia & \begin{tabular}{|l} 
Recuento \\
$\%$ de banco \\
$\%$ del total
\end{tabular} & \begin{tabular}{|c|}
15 \\
0,2113 \\
2,976 \\
\end{tabular} & $\begin{array}{c}15 \\
0,2113 \\
2,98\end{array}$ & \begin{tabular}{|c|}
15 \\
0,2113 \\
2,976 \\
\end{tabular} & \begin{tabular}{|c|}
16 \\
0,2254 \\
3,175 \\
\end{tabular} & \begin{tabular}{|c|}
10 \\
0,1408 \\
1,98
\end{tabular} & \begin{tabular}{|c|}
71 \\
1 \\
14,087 \\
\end{tabular} & Provincia & $\begin{array}{l}\text { Recuento } \\
\% \text { de banco } \\
\% \text { del total }\end{array}$ & \begin{tabular}{|c|}
9 \\
0,1765 \\
2,57 \\
\end{tabular} & \begin{tabular}{|c|}
10 \\
0,1961 \\
2,86 \\
\end{tabular} & \begin{tabular}{|c|}
12 \\
0,2353 \\
3,429 \\
\end{tabular} & \begin{tabular}{|c|}
15 \\
0,2941 \\
4,29 \\
\end{tabular} & $\begin{array}{c}5 \\
0,098 \\
1,43\end{array}$ & $\begin{array}{c}51 \\
1 \\
14,579 \\
\end{array}$ & Provincia & \begin{tabular}{|l} 
Recuento \\
$\%$ de banco \\
$\%$ del total
\end{tabular} & \begin{tabular}{|c|} 
\\
0,2813 \\
3,67 \\
\end{tabular} & \begin{tabular}{|c|}
7 \\
0,2188 \\
2,86 \\
\end{tabular} & $\begin{array}{c}6 \\
0,1875 \\
2,45\end{array}$ & $\begin{array}{c}4 \\
0,125 \\
1,63 \\
\end{array}$ & \begin{tabular}{|c|}
6 \\
0,1875 \\
2,45
\end{tabular} & $\begin{array}{c}32 \\
1 \\
13,06\end{array}$ \\
\hline & Credicoop & \begin{tabular}{|l} 
Recuento \\
$\%$ de banco \\
$\%$ del total
\end{tabular} & $\begin{array}{c}18 \\
0,1324 \\
3,571\end{array}$ & $\begin{array}{c}12 \\
0,0882 \\
2,38\end{array}$ & \begin{tabular}{|c|}
35 \\
0,2574 \\
6,944 \\
\end{tabular} & \begin{tabular}{|c|}
41 \\
0,3015 \\
8,135 \\
\end{tabular} & \begin{tabular}{|c|}
30 \\
0,2206 \\
5,95
\end{tabular} & \begin{tabular}{|c|}
136 \\
1 \\
26,98 \\
\end{tabular} & Credicoop & \begin{tabular}{|l} 
Recuento \\
$\%$ de banco \\
$\%$ del total
\end{tabular} & \begin{tabular}{|c|}
19 \\
0,2375 \\
5,43 \\
\end{tabular} & \begin{tabular}{|c|}
12 \\
0,15 \\
3,43
\end{tabular} & \begin{tabular}{|c|}
25 \\
0,3125 \\
7,143 \\
\end{tabular} & $\begin{array}{c}8 \\
0,1 \\
2,29\end{array}$ & $\begin{array}{c}16 \\
0,2 \\
4,57\end{array}$ & \begin{tabular}{|c|}
80 \\
1 \\
22,863
\end{tabular} & Credicoop & \begin{tabular}{|l} 
Recuento \\
$\%$ de banco \\
$\%$ del total
\end{tabular} & \begin{tabular}{|c|}
14 \\
0,2857 \\
5,71 \\
\end{tabular} & \begin{tabular}{|c|}
6 \\
0,1224 \\
2,45 \\
\end{tabular} & $\begin{array}{c}11 \\
0,2245 \\
4,49\end{array}$ & \begin{tabular}{|c|}
8 \\
0,1633 \\
3,27
\end{tabular} & \begin{tabular}{|c|}
10 \\
0,2041 \\
4,08 \\
\end{tabular} & $\begin{array}{c}49 \\
1 \\
20\end{array}$ \\
\hline & Galicia & \begin{tabular}{|l} 
Recuento \\
$\%$ de banco \\
$\%$ del total
\end{tabular} & \begin{tabular}{|c|}
2 \\
0,0286 \\
0,397
\end{tabular} & $\begin{array}{c}3 \\
0,0429 \\
0,6\end{array}$ & \begin{tabular}{|c|}
24 \\
0,3429 \\
4,762 \\
\end{tabular} & \begin{tabular}{|c|}
20 \\
0,2857 \\
3,968
\end{tabular} & $\begin{array}{c}21 \\
0,3 \\
4,17\end{array}$ & \begin{tabular}{|c|}
70 \\
1 \\
13,897
\end{tabular} & Galicia & \begin{tabular}{|l} 
Recuento \\
$\%$ de banco \\
$\%$ del total
\end{tabular} & \begin{tabular}{c|}
6 \\
0,1154 \\
1,71
\end{tabular} & \begin{tabular}{|c|}
6 \\
0,1154 \\
1,71
\end{tabular} & \begin{tabular}{|c|}
16 \\
0,3077 \\
4,571
\end{tabular} & \begin{tabular}{|c|}
16 \\
0,3077 \\
4,57
\end{tabular} & \begin{tabular}{|c|}
8 \\
0,1538 \\
2,29
\end{tabular} & \begin{tabular}{|c|}
52 \\
1 \\
14,851
\end{tabular} & Galicia & \begin{tabular}{|l} 
Recuento \\
$\%$ de banco \\
$\%$ del total
\end{tabular} & $\begin{array}{c}9 \\
0,225 \\
3,67\end{array}$ & $\begin{array}{c}2 \\
0,05 \\
0,82\end{array}$ & $\begin{array}{l}16 \\
0,4 \\
6,53\end{array}$ & \begin{tabular}{|c|}
9 \\
0,225 \\
3,67
\end{tabular} & $\begin{array}{c}4 \\
0,1 \\
1,63\end{array}$ & $\begin{array}{c}40 \\
1 \\
16,32\end{array}$ \\
\hline & BBVA & \begin{tabular}{|l} 
Recuento \\
$\%$ de banco \\
$\%$ del total
\end{tabular} & \begin{tabular}{|c|}
5 \\
0,1351 \\
0,992 \\
\end{tabular} & $\begin{array}{c}4 \\
0,1081 \\
0,79\end{array}$ & \begin{tabular}{|c|}
5 \\
0,1351 \\
0,992 \\
\end{tabular} & \begin{tabular}{|c|}
11 \\
0,2973 \\
2,183 \\
\end{tabular} & \begin{tabular}{|c|}
12 \\
0,3243 \\
2,38 \\
\end{tabular} & \begin{tabular}{|c|}
37 \\
1 \\
7,337 \\
\end{tabular} & BBVA & \begin{tabular}{|l} 
Recuento \\
$\%$ de banco \\
$\%$ del total
\end{tabular} & \begin{tabular}{c|c|}
2 \\
0,0769 \\
0,57
\end{tabular} & \begin{tabular}{|c|} 
\\
0,2692 \\
2 \\
\end{tabular} & \begin{tabular}{|c|}
7 \\
0,2692 \\
2 \\
\end{tabular} & \begin{tabular}{|c|}
5 \\
0,1923 \\
1,43 \\
\end{tabular} & \begin{tabular}{|c|}
5 \\
0,1923 \\
1,43 \\
\end{tabular} & $\begin{array}{c}26 \\
1 \\
7,43\end{array}$ & BBVA & $\begin{array}{l}\text { Recuento } \\
\% \text { de banco } \\
\% \text { del total }\end{array}$ & \begin{tabular}{|c|} 
\\
0,0476 \\
0,41 \\
\end{tabular} & \begin{tabular}{|c|}
4 \\
0,1905 \\
1,63 \\
\end{tabular} & $\begin{array}{c}4 \\
0,1905 \\
1,63 \\
\end{array}$ & \begin{tabular}{|c|}
6 \\
0,2857 \\
2,45
\end{tabular} & \begin{tabular}{|c|}
6 \\
0,2857 \\
2,45 \\
\end{tabular} & $\begin{array}{c}21 \\
1 \\
8,57\end{array}$ \\
\hline & Santander & \begin{tabular}{|l} 
Recuento \\
$\%$ de banco \\
$\%$ del total
\end{tabular} & \begin{tabular}{|c|}
8 \\
0,129 \\
1,587 \\
\end{tabular} & $\begin{array}{c}1 \\
0,0161 \\
0,2\end{array}$ & \begin{tabular}{|c|}
18 \\
0,2903 \\
3,571 \\
\end{tabular} & \begin{tabular}{|c|}
10 \\
0,1613 \\
1,984 \\
\end{tabular} & \begin{tabular}{|c|}
25 \\
0,4032 \\
4,96
\end{tabular} & \begin{tabular}{|c|}
62 \\
1 \\
12,302 \\
\end{tabular} & Santander & $\begin{array}{l}\text { Recuento } \\
\% \text { de banco } \\
\% \text { del total }\end{array}$ & \begin{tabular}{|c|}
5 \\
0,1087 \\
1,43 \\
\end{tabular} & \begin{tabular}{|c|}
3 \\
0,0652 \\
0,86
\end{tabular} & \begin{tabular}{|c|}
14 \\
0,3043 \\
4
\end{tabular} & \begin{tabular}{|c|}
13 \\
0,2826 \\
3,71 \\
\end{tabular} & \begin{tabular}{|c|}
11 \\
0,2391 \\
3,14
\end{tabular} & $\begin{array}{c}46 \\
1 \\
13,14\end{array}$ & Santander & \begin{tabular}{|l} 
Recuento \\
$\%$ de banco \\
$\%$ del total
\end{tabular} & \begin{tabular}{|c|}
7 \\
0,2188 \\
2,86
\end{tabular} & \begin{tabular}{|c|}
4 \\
0,125 \\
1,63
\end{tabular} & $\begin{array}{c}6 \\
0,1875 \\
2,45\end{array}$ & \begin{tabular}{c|}
3 \\
0,0938 \\
1,22
\end{tabular} & $\begin{array}{c}12 \\
0,375 \\
4,99 \\
\end{array}$ & $\begin{array}{c}32 \\
1 \\
13,15\end{array}$ \\
\hline & HSBC & \begin{tabular}{|l} 
Recuento \\
$\%$ de banco \\
$\%$ del total
\end{tabular} & $\begin{array}{c}5 \\
0,2632 \\
0,992 \\
\end{array}$ & $\begin{array}{c}1 \\
0,0526 \\
0,2\end{array}$ & \begin{tabular}{|c|}
4 \\
0,2105 \\
0,794 \\
\end{tabular} & \begin{tabular}{|c|}
4 \\
0,2105 \\
0,794 \\
\end{tabular} & \begin{tabular}{|c|}
5 \\
0,2632 \\
0,99
\end{tabular} & $\begin{array}{c}19 \\
1 \\
3,77\end{array}$ & HSBC & \begin{tabular}{|l} 
Recuento \\
$\%$ de banco \\
$\%$ del total
\end{tabular} & \begin{tabular}{|c|}
2 \\
0,1818 \\
0,57 \\
\end{tabular} & \begin{tabular}{|c|} 
\\
0,0909 \\
0,29 \\
\end{tabular} & \begin{tabular}{|c|}
3 \\
0,2727 \\
0,657
\end{tabular} & \begin{tabular}{|c|}
2 \\
0,1818 \\
0,57 \\
\end{tabular} & \begin{tabular}{|c|}
3 \\
0,2727 \\
0,86 \\
\end{tabular} & $\begin{array}{c}11 \\
1 \\
3,1\end{array}$ & HSBC & $\begin{array}{l}\text { Recuento } \\
\% \text { de banco } \\
\% \text { del total }\end{array}$ & $\begin{array}{c}1 \\
0,125 \\
0,41\end{array}$ & $\begin{array}{c}1 \\
0,125 \\
0,41\end{array}$ & $\begin{array}{c}3 \\
0,375 \\
1,22 \\
\end{array}$ & $\begin{array}{c}1 \\
0,125 \\
0,41\end{array}$ & $\begin{array}{c}2 \\
0,25 \\
0,82\end{array}$ & $\begin{array}{c}8 \\
1 \\
3,27\end{array}$ \\
\hline & Total & \begin{tabular}{|l} 
Recuento \\
$\%$ de banco \\
$\%$ del total
\end{tabular} & \begin{tabular}{|c|}
68 \\
$13,5 \%$ \\
$13,5 \%$ \\
\end{tabular} & $\begin{array}{c}51 \\
10,1 \% \\
10,1 \%\end{array}$ & \begin{tabular}{|c|}
133 \\
$26,4 \%$ \\
$26,4 \%$ \\
\end{tabular} & \begin{tabular}{|c|}
123 \\
$24,4 \%$ \\
$24,4 \%$ \\
\end{tabular} & \begin{tabular}{|c|}
129 \\
$25,6 \%$ \\
$25,6 \%$ \\
\end{tabular} & $\begin{array}{c}504 \\
100 \% \\
100 \%\end{array}$ & Total & \begin{tabular}{|l} 
Recuento \\
$\%$ de banco \\
$\%$ del total
\end{tabular} & \begin{tabular}{c|}
53 \\
$15,1 \%$ \\
$15,1 \%$
\end{tabular} & \begin{tabular}{|c|}
56 \\
$16,0 \%$ \\
$16,0 \%$ \\
\end{tabular} & \begin{tabular}{|c|}
105 \\
$30,0 \%$ \\
$30,0 \%$ \\
\end{tabular} & \begin{tabular}{|c|}
76 \\
$21,7 \%$ \\
$21,7 \%$ \\
\end{tabular} & \begin{tabular}{|c|}
60 \\
$17,1 \%$ \\
$17,1 \%$ \\
\end{tabular} & $\begin{array}{c}350 \\
100 \% \\
100 \%\end{array}$ & Total & \begin{tabular}{|l} 
Recuento \\
$\%$ de banco \\
$\%$ del total
\end{tabular} & \begin{tabular}{|c|}
58 \\
$23,7 \%$ \\
$23,7 \%$ \\
\end{tabular} & \begin{tabular}{|c|}
36 \\
$14,7 \%$ \\
$14,7 \%$ \\
\end{tabular} & \begin{tabular}{|c|}
64 \\
$26,1 \%$ \\
$26,1 \%$ \\
\end{tabular} & \begin{tabular}{|c|}
38 \\
$15,5 \%$ \\
$15,5 \%$
\end{tabular} & \begin{tabular}{|c|}
49 \\
$20,0 \%$ \\
$20,0 \%$ \\
\end{tabular} & $\begin{array}{c}245 \\
100 \% \\
100 \%\end{array}$ \\
\hline
\end{tabular}


Cuadro 54

\begin{tabular}{|c|c|c|c|c|c|c|c|c|c|c|c|c|c|c|c|c|c|c|c|c|c|c|c|c|}
\hline & \multicolumn{8}{|c|}{ Calificación para el banco $1^{\circ}$} & \multicolumn{8}{|c|}{ Calificación para el banco $2^{\circ}$} & \multicolumn{8}{|c|}{ Calificación para el banco $3^{\circ}$} \\
\hline & & & 1 & 2 & 3 & 4 & 5 & Total & & & 1 & 2 & 3 & 4 & 5 & Total & & & 1 & 2 & 3 & 4 & 5 & Total \\
\hline \multirow{8}{*}{ 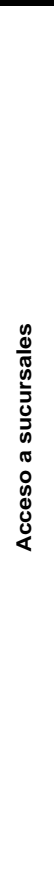 } & Nación & $\mid \begin{array}{l}\text { Recuento } \\
\% \text { de banco } \\
\% \text { del total }\end{array}$ & $\begin{array}{c}8 \\
0,058 \\
0,9 \\
\end{array}$ & $\begin{array}{c}6 \\
0,0435 \\
0,7\end{array}$ & \begin{tabular}{|c|}
34 \\
0,2464 \\
3,8 \\
\end{tabular} & \begin{tabular}{|c|}
43 \\
0,3116 \\
4,8 \\
\end{tabular} & \begin{tabular}{|c|}
47 \\
0,3406 \\
5,3 \\
\end{tabular} & $\begin{array}{c}138 \\
1 \\
15,5\end{array}$ & Nación & $\mid \begin{array}{l}\text { Recuento } \\
\% \text { de banco } \\
\% \text { del total }\end{array}$ & \begin{tabular}{|c|}
4 \\
0,0348 \\
0,6
\end{tabular} & \begin{tabular}{|c|}
7 \\
0,0609 \\
1,1 \\
\end{tabular} & \begin{tabular}{|c|}
32 \\
0,2783 \\
5 \\
\end{tabular} & \begin{tabular}{|c|}
32 \\
0,2783 \\
5 \\
\end{tabular} & \begin{tabular}{|c|}
40 \\
0,3478 \\
6,2 \\
\end{tabular} & $\begin{array}{c}115 \\
1 \\
17,9\end{array}$ & Nación & $\begin{array}{l}\text { Recuento } \\
\% \text { de banco } \\
\% \text { del total }\end{array}$ & \begin{tabular}{c|}
3 \\
0,039 \\
0,7
\end{tabular} & \begin{tabular}{|c|}
7 \\
0,0909 \\
1,6 \\
\end{tabular} & \begin{tabular}{|c|}
23 \\
0,2987 \\
5,4 \\
\end{tabular} & \begin{tabular}{|c|}
21 \\
0,2727 \\
4,9 \\
\end{tabular} & \begin{tabular}{|c|}
23 \\
0,2987 \\
5,4 \\
\end{tabular} & $\begin{array}{c}77 \\
1 \\
18\end{array}$ \\
\hline & Provincia & \begin{tabular}{|l} 
Recuento \\
$\%$ de banco \\
$\%$ del total
\end{tabular} & $\begin{array}{c}4 \\
0,0323 \\
0,4 \\
\end{array}$ & $\begin{array}{c}6 \\
0,0484 \\
0,7\end{array}$ & \begin{tabular}{|c|}
20 \\
0,1613 \\
2,2 \\
\end{tabular} & \begin{tabular}{|c|}
39 \\
0,3145 \\
4,4 \\
\end{tabular} & \begin{tabular}{|c|}
55 \\
0,4435 \\
6,2 \\
\end{tabular} & $\begin{array}{c}124 \\
1 \\
13,9\end{array}$ & Provincia & \begin{tabular}{|l} 
Recuento \\
$\%$ de banco \\
$\%$ del total
\end{tabular} & $\begin{array}{c}2 \\
0,0215 \\
0,3\end{array}$ & \begin{tabular}{|c|}
8 \\
0,086 \\
1,2 \\
\end{tabular} & \begin{tabular}{|c|}
20 \\
0,2151 \\
3,1 \\
\end{tabular} & \begin{tabular}{|c|}
22 \\
0,2366 \\
3,4 \\
\end{tabular} & \begin{tabular}{|c|}
41 \\
0,4409 \\
6,4 \\
\end{tabular} & $\begin{array}{c}93 \\
1 \\
14,4 \\
\end{array}$ & Provincia & \begin{tabular}{|l} 
Recuento \\
$\%$ de banco \\
$\%$ del total
\end{tabular} & \begin{tabular}{c|}
1 \\
0,0169 \\
0,2
\end{tabular} & \begin{tabular}{|c|}
2 \\
0,0339 \\
0,5 \\
\end{tabular} & \begin{tabular}{|c|}
13 \\
0,2203 \\
3 \\
\end{tabular} & \begin{tabular}{|c|}
13 \\
0,2203 \\
3 \\
\end{tabular} & \begin{tabular}{|c|}
30 \\
0,5085 \\
7
\end{tabular} & $\begin{array}{c}59 \\
1 \\
13,8\end{array}$ \\
\hline & Credicoop & \begin{tabular}{|l} 
Recuento \\
$\%$ de banco \\
$\%$ del total
\end{tabular} & \begin{tabular}{c|}
4 \\
0,0179 \\
0,4 \\
\end{tabular} & $\begin{array}{c}5 \\
0,0223 \\
0,6\end{array}$ & \begin{tabular}{|c|}
43 \\
0,192 \\
4,8 \\
\end{tabular} & \begin{tabular}{|c|}
72 \\
0,3214 \\
8,1 \\
\end{tabular} & \begin{tabular}{|c|}
100 \\
0,4464 \\
11,2 \\
\end{tabular} & $\begin{array}{c}224 \\
1 \\
25,1\end{array}$ & Credicoop & \begin{tabular}{|l} 
Recuento \\
$\%$ de banco \\
$\%$ del total
\end{tabular} & $\begin{array}{c}8 \\
0,0563 \\
1,2 \\
\end{array}$ & \begin{tabular}{|c|}
7 \\
0,0493 \\
1,1 \\
\end{tabular} & \begin{tabular}{|c|}
41 \\
0,2887 \\
6,4 \\
\end{tabular} & \begin{tabular}{|c|}
44 \\
0,3099 \\
6,8 \\
\end{tabular} & \begin{tabular}{|c|}
42 \\
0,2958 \\
6,5 \\
\end{tabular} & $\begin{array}{c}142 \\
1 \\
22\end{array}$ & Credicoop & \begin{tabular}{|l} 
Recuento \\
$\%$ de banco \\
$\%$ del total
\end{tabular} & \begin{tabular}{c|}
3 \\
0,0357 \\
0,7 \\
\end{tabular} & \begin{tabular}{|c|}
9 \\
0,1071 \\
2,1 \\
\end{tabular} & \begin{tabular}{|c|}
22 \\
0,2619 \\
5,2
\end{tabular} & \begin{tabular}{|c|}
29 \\
0,3452 \\
6,8 \\
\end{tabular} & $\begin{array}{c}21 \\
0,25 \\
4,9\end{array}$ & $\begin{array}{c}84 \\
1 \\
19,7\end{array}$ \\
\hline & Galicia & \begin{tabular}{|l|} 
Recuento \\
$\%$ de banco \\
$\%$ del total
\end{tabular} & $\begin{array}{c}2 \\
0,0187 \\
0,2 \\
\end{array}$ & \begin{tabular}{|c|}
4 \\
0,0374 \\
0,4 \\
\end{tabular} & \begin{tabular}{|c|}
17 \\
0,1589 \\
1,9 \\
\end{tabular} & \begin{tabular}{|c|}
25 \\
0,2336 \\
2,8 \\
\end{tabular} & \begin{tabular}{|c|}
59 \\
0,5514 \\
6,6 \\
\end{tabular} & $\begin{array}{c}107 \\
1 \\
11,9 \\
\end{array}$ & Galicia & \begin{tabular}{|l|} 
Recuento \\
$\%$ de banco \\
$\%$ del total \\
\end{tabular} & \begin{tabular}{|c|}
6 \\
0,0741 \\
0,9 \\
\end{tabular} & \begin{tabular}{|c|}
5 \\
0,0617 \\
0,8 \\
\end{tabular} & \begin{tabular}{|c|}
15 \\
0,1852 \\
2,3 \\
\end{tabular} & \begin{tabular}{|c|}
28 \\
0,3457 \\
4,4 \\
\end{tabular} & \begin{tabular}{|c|}
27 \\
0,3333 \\
4,2 \\
\end{tabular} & $\begin{array}{c}81 \\
1 \\
12,6 \\
\end{array}$ & Galicia & $\mid \begin{array}{l}\text { Recuento } \\
\% \text { de banco } \\
\% \text { del total }\end{array}$ & \begin{tabular}{c|}
5 \\
0,0893 \\
1,2 \\
\end{tabular} & \begin{tabular}{|c|}
3 \\
0,0536 \\
0,7 \\
\end{tabular} & \begin{tabular}{|c|}
10 \\
0,1786 \\
2,3 \\
\end{tabular} & \begin{tabular}{|c|}
18 \\
0,3214 \\
4,2 \\
\end{tabular} & \begin{tabular}{|c|}
20 \\
0,3571 \\
4,7 \\
\end{tabular} & $\begin{array}{c}56 \\
1 \\
13,1 \\
\end{array}$ \\
\hline & BBVA & \begin{tabular}{|l|} 
Recuento \\
$\%$ de banco \\
$\%$ del total \\
\end{tabular} & $\begin{array}{c}1 \\
0,0149 \\
0,1 \\
\end{array}$ & \begin{tabular}{|c|}
4 \\
0,0597 \\
0,4 \\
\end{tabular} & \begin{tabular}{|c|}
9 \\
0,1343 \\
1 \\
\end{tabular} & \begin{tabular}{|c|}
20 \\
0,2985 \\
2,2 \\
\end{tabular} & \begin{tabular}{|c|}
33 \\
0,4925 \\
3,7 \\
\end{tabular} & $\begin{array}{c}67 \\
1 \\
7,4 \\
\end{array}$ & BBVA & \begin{tabular}{|l|} 
Recuento \\
$\%$ de banco \\
$\%$ del total \\
\end{tabular} & $\begin{array}{c}2 \\
0,04 \\
0,3 \\
\end{array}$ & $\begin{array}{c}1 \\
0,02 \\
0,2 \\
\end{array}$ & $\begin{array}{c}14 \\
0,28 \\
2,2 \\
\end{array}$ & $\begin{array}{c}12 \\
0,24 \\
1,9 \\
\end{array}$ & $\begin{array}{c}21 \\
0,42 \\
3,3 \\
\end{array}$ & $\begin{array}{c}50 \\
1 \\
7,9 \\
\end{array}$ & BBVA & \begin{tabular}{|l|} 
Recuento \\
$\%$ de banco \\
$\%$ del total
\end{tabular} & \begin{tabular}{c|}
4 \\
0,1143 \\
0,9 \\
\end{tabular} & \begin{tabular}{|c|}
1 \\
0,0286 \\
0,2 \\
\end{tabular} & $\begin{array}{c}7 \\
0,2 \\
1,6 \\
\end{array}$ & $\begin{array}{c}9 \\
0,2571 \\
2,1 \\
\end{array}$ & $\begin{array}{l}14 \\
0,4 \\
3,3 \\
\end{array}$ & $\begin{array}{c}35 \\
1 \\
8,1 \\
\end{array}$ \\
\hline & Santander & \begin{tabular}{|l|} 
Recuento \\
$\%$ de banco \\
$\%$ del total
\end{tabular} & $\begin{array}{c}4 \\
0,0377 \\
0,4 \\
\end{array}$ & \begin{tabular}{|c|}
3 \\
0,0283 \\
0,3 \\
\end{tabular} & \begin{tabular}{|c|}
18 \\
0,1698 \\
2 \\
\end{tabular} & \begin{tabular}{|c|}
29 \\
0,2736 \\
3,3 \\
\end{tabular} & \begin{tabular}{|c|}
52 \\
0,4906 \\
5,8 \\
\end{tabular} & $\begin{array}{c}106 \\
1 \\
11,8 \\
\end{array}$ & Santander & \begin{tabular}{|l} 
Recuento \\
$\%$ de banco \\
$\%$ del total
\end{tabular} & \begin{tabular}{|c|}
4 \\
0,0506 \\
0,6 \\
\end{tabular} & \begin{tabular}{|c|}
8 \\
0,1013 \\
1,2 \\
\end{tabular} & \begin{tabular}{|c|}
15 \\
0,1899 \\
2,3 \\
\end{tabular} & \begin{tabular}{|c|}
19 \\
0,2405 \\
3 \\
\end{tabular} & \begin{tabular}{|c|}
33 \\
0,4177 \\
5,1 \\
\end{tabular} & $\begin{array}{c}79 \\
1 \\
12,2 \\
\end{array}$ & Santander & \begin{tabular}{|l|} 
Recuento \\
$\%$ de banco \\
$\%$ del total
\end{tabular} & \begin{tabular}{c|}
2 \\
0,0357 \\
0,5 \\
\end{tabular} & \begin{tabular}{|c|}
7 \\
0,125 \\
1,6 \\
\end{tabular} & \begin{tabular}{|c|}
10 \\
0,1786 \\
2,3 \\
\end{tabular} & \begin{tabular}{|c|}
11 \\
0,1964 \\
2,6 \\
\end{tabular} & \begin{tabular}{|c|}
26 \\
0,4643 \\
6,1 \\
\end{tabular} & $\begin{array}{c}56 \\
1 \\
13,1 \\
\end{array}$ \\
\hline & HSBC & \begin{tabular}{|l} 
Recuento \\
$\%$ de banco \\
$\%$ del total
\end{tabular} & $\begin{array}{c}3 \\
0,0909 \\
0,3\end{array}$ & \begin{tabular}{|c|}
4 \\
0,1212 \\
0,4
\end{tabular} & \begin{tabular}{|c|}
6 \\
0,1818 \\
0,7
\end{tabular} & $\begin{array}{c}9 \\
0,2727 \\
1\end{array}$ & \begin{tabular}{|c|}
11 \\
0,3333 \\
1,2
\end{tabular} & $\begin{array}{c}33 \\
1 \\
3,6\end{array}$ & HSBC & \begin{tabular}{|l} 
Recuento \\
$\%$ de banco \\
$\%$ del total
\end{tabular} & $\begin{array}{c}3 \\
0,1304 \\
0,5\end{array}$ & $\begin{array}{l}0 \\
0 \\
0\end{array}$ & \begin{tabular}{|c|}
7 \\
0,3043 \\
1,1
\end{tabular} & \begin{tabular}{|c|}
7 \\
0,3043 \\
1,1 \\
\end{tabular} & \begin{tabular}{|c|}
6 \\
0,2609 \\
0,9 \\
\end{tabular} & $\begin{array}{c}23 \\
1 \\
3,6\end{array}$ & HSBC & \begin{tabular}{|l} 
Recuento \\
$\%$ de banco \\
$\%$ del total
\end{tabular} & \begin{tabular}{|c|}
2 \\
0,1333 \\
0,5 \\
\end{tabular} & \begin{tabular}{|c|} 
\\
0,0667 \\
0,2
\end{tabular} & $\begin{array}{c}3 \\
0,2 \\
0,7\end{array}$ & \begin{tabular}{|c|}
4 \\
0,2667 \\
0,9
\end{tabular} & \begin{tabular}{|c|}
5 \\
0,3333 \\
1,2
\end{tabular} & $\begin{array}{c}15 \\
1 \\
3,5\end{array}$ \\
\hline & Total & \begin{tabular}{|l} 
Recuento \\
$\%$ de banco \\
$\%$ del total
\end{tabular} & $\begin{array}{c}31 \\
3,5 \% \\
3,5 \% \\
\end{array}$ & \begin{tabular}{|c|}
34 \\
$3,8 \%$ \\
$3,8 \%$ \\
\end{tabular} & \begin{tabular}{|c|}
164 \\
$18,4 \%$ \\
$18,4 \%$ \\
\end{tabular} & \begin{tabular}{|c|}
264 \\
$29,6 \%$ \\
$29,6 \%$ \\
\end{tabular} & \begin{tabular}{|c|}
399 \\
$44,7 \%$ \\
$44,7 \%$ \\
\end{tabular} & $\begin{array}{c}892 \\
100 \% \\
100 \%\end{array}$ & Total & \begin{tabular}{|l|} 
Recuento \\
$\%$ de banco \\
$\%$ del total
\end{tabular} & $\begin{array}{c}33 \\
5,1 \% \\
5,1 \%\end{array}$ & \begin{tabular}{c|}
39 \\
$6,1 \%$ \\
$6,1 \%$
\end{tabular} & \begin{tabular}{|c|}
160 \\
$24,9 \%$ \\
$24,9 \%$ \\
\end{tabular} & \begin{tabular}{|c|}
178 \\
$27,7 \%$ \\
$27,7 \%$ \\
\end{tabular} & \begin{tabular}{|c|}
233 \\
$36,2 \%$ \\
$36,2 \%$ \\
\end{tabular} & $\begin{array}{c}643 \\
100 \% \\
100 \%\end{array}$ & Total & \begin{tabular}{|l|} 
Recuento \\
$\%$ de banco \\
$\%$ del total
\end{tabular} & $\begin{array}{c}22 \\
5,2 \% \\
5,2 \%\end{array}$ & \begin{tabular}{|c|}
33 \\
$7,7 \%$ \\
$7,7 \%$
\end{tabular} & $\begin{array}{c}98 \\
23,0 \% \\
23,0 \% \\
\end{array}$ & \begin{tabular}{|c|}
116 \\
$27,2 \%$ \\
$27,2 \%$
\end{tabular} & \begin{tabular}{|c|}
158 \\
$37,0 \%$ \\
$37,0 \%$ \\
\end{tabular} & $\begin{array}{c}427 \\
100 \% \\
100 \% \\
\end{array}$ \\
\hline
\end{tabular}


Cuadro 55

\begin{tabular}{|c|c|c|c|c|c|c|c|c|c|c|c|c|c|c|c|c|c|c|c|c|c|c|c|c|}
\hline & \multicolumn{8}{|c|}{ Calificación para el banco $1^{\circ}$} & \multicolumn{8}{|c|}{ Calificación para el banco $2^{\circ}$} & \multicolumn{8}{|c|}{ Calificación para el banco $3^{\circ}$} \\
\hline & & & 1 & 2 & 3 & 4 & 5 & Total & & & 1 & 2 & 3 & 4 & 5 & Total & & & 1 & 2 & 3 & 4 & 5 & Total \\
\hline \multirow{8}{*}{ 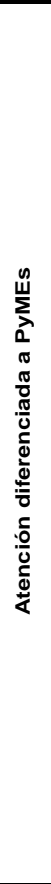 } & Nación & \begin{tabular}{|l} 
Recuento \\
$\%$ de banco \\
$\%$ del total
\end{tabular} & $\begin{array}{c}20 \\
0,1653 \\
2,45\end{array}$ & $\begin{array}{c}14 \\
0,1157 \\
1,72\end{array}$ & $\begin{array}{c}31 \\
0,2562 \\
3,804\end{array}$ & $\begin{array}{c}31 \\
0,2562 \\
3,804\end{array}$ & \begin{tabular}{|c|}
25 \\
0,2066 \\
3,067
\end{tabular} & $\begin{array}{c}121 \\
1 \\
14,845\end{array}$ & Nación & $\begin{array}{l}\text { Recuento } \\
\% \text { de banco } \\
\% \text { del total }\end{array}$ & \begin{tabular}{|c|}
15 \\
0,1563 \\
2,75 \\
\end{tabular} & $\begin{array}{c}11 \\
0,1146 \\
2,02\end{array}$ & \begin{tabular}{|c|}
29 \\
0,3021 \\
5,321 \\
\end{tabular} & $\begin{array}{c}24 \\
0,25 \\
4,404\end{array}$ & \begin{tabular}{c|}
17 \\
0,1771 \\
3,119
\end{tabular} & \begin{tabular}{|c|}
96 \\
1 \\
17,614 \\
\end{tabular} & Nación & $\mid \begin{array}{l}\text { Recuento } \\
\% \text { de banco } \\
\% \text { del total }\end{array}$ & $\begin{array}{c}9 \\
0,15 \\
2,7\end{array}$ & $\begin{array}{c}9 \\
0,15 \\
2,65\end{array}$ & $\begin{array}{c}18 \\
0,3 \\
5,31\end{array}$ & $\begin{array}{c}19 \\
0,3167 \\
5,605\end{array}$ & \begin{tabular}{|c|}
5 \\
0,0833 \\
1,475
\end{tabular} & $\begin{array}{c}60 \\
1 \\
18\end{array}$ \\
\hline & Provincia & \begin{tabular}{|l} 
Recuento \\
$\%$ de banco \\
$\%$ del total
\end{tabular} & $\begin{array}{c}11 \\
0,1038 \\
1,35 \\
\end{array}$ & $\begin{array}{c}13 \\
0,1226 \\
1,6 \\
\end{array}$ & \begin{tabular}{|c}
29 \\
0,2736 \\
3,558 \\
\end{tabular} & $\begin{array}{c}30 \\
0,283 \\
3,681 \\
\end{array}$ & $\begin{array}{c}23 \\
0,217 \\
2,822\end{array}$ & $\begin{array}{c}106 \\
1 \\
13,011 \\
\end{array}$ & Provincia & \begin{tabular}{|l} 
Recuento \\
$\%$ de banco \\
$\%$ del total \\
\end{tabular} & $\begin{array}{c}9 \\
0,1125 \\
1,65 \\
\end{array}$ & $\begin{array}{c}9 \\
0,1125 \\
1,65 \\
\end{array}$ & \begin{tabular}{c|}
22 \\
0,275 \\
4,037
\end{tabular} & \begin{tabular}{|c|}
27 \\
0,3375 \\
4,954 \\
\end{tabular} & \begin{tabular}{c|}
13 \\
0,1625 \\
2,385 \\
\end{tabular} & $\begin{array}{c}80 \\
1 \\
14,676 \\
\end{array}$ & Provincia & \begin{tabular}{|l} 
Recuento \\
$\%$ de banco \\
$\%$ del total \\
\end{tabular} & \begin{tabular}{|c|}
7 \\
0,1628 \\
2,1 \\
\end{tabular} & \begin{tabular}{|c|}
2 \\
0,0465 \\
0,59 \\
\end{tabular} & \begin{tabular}{|c|}
15 \\
0,3488 \\
4,42 \\
\end{tabular} & $\begin{array}{c}10 \\
0,2326 \\
2,95 \\
\end{array}$ & $\begin{array}{c}9 \\
0,2093 \\
2,655 \\
\end{array}$ & $\begin{array}{c}43 \\
1 \\
12,715 \\
\end{array}$ \\
\hline & Credicoop & \begin{tabular}{|l|} 
Recuento \\
$\%$ de banco \\
$\%$ del total
\end{tabular} & \begin{tabular}{|c|}
8 \\
0,0364 \\
0,98 \\
\end{tabular} & $\begin{array}{c}13 \\
0,0591 \\
1,6 \\
\end{array}$ & \begin{tabular}{|c}
45 \\
0,2045 \\
5,521 \\
\end{tabular} & $\begin{array}{c}77 \\
0,35 \\
9,448 \\
\end{array}$ & $\begin{array}{c}77 \\
0,35 \\
9,448 \\
\end{array}$ & $\begin{array}{c}220 \\
1 \\
26,997 \\
\end{array}$ & Credicoop & \begin{tabular}{|l} 
Recuento \\
$\%$ de banco \\
$\%$ del total \\
\end{tabular} & \begin{tabular}{|c|}
17 \\
0,1318 \\
3,12 \\
\end{tabular} & \begin{tabular}{|c|}
19 \\
0,1473 \\
3,49 \\
\end{tabular} & \begin{tabular}{|c|}
42 \\
0,3256 \\
7,706 \\
\end{tabular} & \begin{tabular}{|c|}
26 \\
0,2016 \\
4,771 \\
\end{tabular} & \begin{tabular}{|c|}
25 \\
0,1938 \\
4,587 \\
\end{tabular} & \begin{tabular}{|c|}
129 \\
1 \\
23,674 \\
\end{tabular} & Credicoop & \begin{tabular}{|l|} 
Recuento \\
$\%$ de banco \\
$\%$ del total \\
\end{tabular} & $\begin{array}{c}9 \\
0,125 \\
2,7 \\
\end{array}$ & $\begin{array}{c}12 \\
0,1667 \\
3,54 \\
\end{array}$ & \begin{tabular}{|c|}
26 \\
0,3611 \\
7,67 \\
\end{tabular} & \begin{tabular}{|c|}
16 \\
0,2222 \\
4,72 \\
\end{tabular} & $\begin{array}{c}9 \\
0,125 \\
2,655 \\
\end{array}$ & \begin{tabular}{|c}
72 \\
1 \\
21,285 \\
\end{tabular} \\
\hline & Galicia & \begin{tabular}{|l} 
Recuento \\
$\%$ de banco \\
$\%$ del total
\end{tabular} & \begin{tabular}{|c|}
6 \\
0,0583 \\
0,74 \\
\end{tabular} & $\begin{array}{c}7 \\
0,068 \\
0,86 \\
\end{array}$ & $\begin{array}{c}22 \\
0,2136 \\
2,699 \\
\end{array}$ & \begin{tabular}{|c|}
27 \\
0,2621 \\
3,313 \\
\end{tabular} & \begin{tabular}{|c|}
41 \\
0,3981 \\
5,031 \\
\end{tabular} & $\begin{array}{c}103 \\
1 \\
12,643 \\
\end{array}$ & Galicia & \begin{tabular}{|l|} 
Recuento \\
$\%$ de banco \\
$\%$ del total
\end{tabular} & \begin{tabular}{|c|}
9 \\
0,1268 \\
1,65 \\
\end{tabular} & $\begin{array}{c}11 \\
0,1549 \\
2,02 \\
\end{array}$ & \begin{tabular}{|c|}
16 \\
0,2254 \\
2,936 \\
\end{tabular} & \begin{tabular}{|c|}
19 \\
0,2676 \\
3,486 \\
\end{tabular} & \begin{tabular}{|c|}
16 \\
0,2254 \\
2,936 \\
\end{tabular} & \begin{tabular}{|c|}
71 \\
1 \\
13,028 \\
\end{tabular} & Galicia & \begin{tabular}{|l} 
Recuento \\
$\%$ de banco \\
$\%$ del total
\end{tabular} & \begin{tabular}{|c|}
7 \\
0,1522 \\
2,1 \\
\end{tabular} & $\begin{array}{c}7 \\
0,1522 \\
2,06 \\
\end{array}$ & \begin{tabular}{|c|}
11 \\
0,2391 \\
3,24 \\
\end{tabular} & $\begin{array}{c}8 \\
0,1739 \\
2,36 \\
\end{array}$ & \begin{tabular}{|c|}
13 \\
0,2826 \\
3,835 \\
\end{tabular} & $\begin{array}{c}46 \\
1 \\
13,595 \\
\end{array}$ \\
\hline & BBVA & \begin{tabular}{|l} 
Recuento \\
$\%$ de banco \\
$\%$ del total
\end{tabular} & \begin{tabular}{c|}
8 \\
0,1333 \\
0,98 \\
\end{tabular} & $\begin{array}{c}3 \\
0,05 \\
0,37\end{array}$ & $\begin{array}{c}14 \\
0,2333 \\
1,718 \\
\end{array}$ & $\begin{array}{c}10 \\
0,1667 \\
1,227\end{array}$ & \begin{tabular}{|c|}
25 \\
0,4167 \\
3,067 \\
\end{tabular} & $\begin{array}{c}60 \\
1 \\
7,362 \\
\end{array}$ & BBVA & $\begin{array}{l}\text { Recuento } \\
\% \text { de banco } \\
\% \text { del total }\end{array}$ & \begin{tabular}{|c|}
7 \\
0,1795 \\
1,28 \\
\end{tabular} & $\begin{array}{c}2 \\
0,0513 \\
0,37\end{array}$ & \begin{tabular}{|c|}
12 \\
0,3077 \\
2,202 \\
\end{tabular} & \begin{tabular}{|c|}
10 \\
0,2564 \\
1,835 \\
\end{tabular} & \begin{tabular}{|c|}
8 \\
0,2051 \\
1,468 \\
\end{tabular} & $\begin{array}{c}39 \\
1 \\
7,155\end{array}$ & BBVA & \begin{tabular}{|l} 
Recuento \\
$\%$ de banco \\
$\%$ del total
\end{tabular} & $\begin{array}{c}7 \\
0,25 \\
2,1\end{array}$ & $\begin{array}{c}3 \\
0,1071 \\
0,88\end{array}$ & $\begin{array}{c}7 \\
0,25 \\
2,06\end{array}$ & $\begin{array}{c}7 \\
0,25 \\
2,065\end{array}$ & $\begin{array}{c}4 \\
0,1429 \\
1,18\end{array}$ & $\begin{array}{c}28 \\
1 \\
8,285 \\
\end{array}$ \\
\hline & Santander & \begin{tabular}{|l} 
Recuento \\
$\%$ de banco \\
$\%$ del total
\end{tabular} & \begin{tabular}{|c|}
7 \\
0,0753 \\
0,86 \\
\end{tabular} & \begin{tabular}{|c|}
7 \\
0,0753 \\
0,86 \\
\end{tabular} & \begin{tabular}{|c|}
18 \\
0,1935 \\
2,209 \\
\end{tabular} & \begin{tabular}{|c|}
27 \\
0,2903 \\
3,313 \\
\end{tabular} & \begin{tabular}{|c|}
34 \\
0,3656 \\
4,172 \\
\end{tabular} & $\begin{array}{c}93 \\
1 \\
11,414 \\
\end{array}$ & Santander & \begin{tabular}{|l} 
Recuento \\
$\%$ de banco \\
$\%$ del total \\
\end{tabular} & \begin{tabular}{|c|}
5 \\
0,0769 \\
0,92 \\
\end{tabular} & \begin{tabular}{|c}
5 \\
0,0769 \\
0,92 \\
\end{tabular} & \begin{tabular}{|c|}
10 \\
0,1538 \\
1,835 \\
\end{tabular} & \begin{tabular}{|c|}
26 \\
0,4 \\
4,771 \\
\end{tabular} & \begin{tabular}{|c|}
19 \\
0,2923 \\
3,486 \\
\end{tabular} & \begin{tabular}{|c|}
65 \\
1 \\
11,932 \\
\end{tabular} & Santander & \begin{tabular}{|l|} 
Recuento \\
$\%$ de banco \\
$\%$ del total \\
\end{tabular} & \begin{tabular}{|c|}
3 \\
0,075 \\
0,9 \\
\end{tabular} & $\begin{array}{c}4 \\
0,1 \\
1,18 \\
\end{array}$ & $\begin{array}{c}11 \\
0,275 \\
3,24 \\
\end{array}$ & $\begin{array}{c}13 \\
0,325 \\
3,825 \\
\end{array}$ & $\begin{array}{c}9 \\
0,225 \\
2,655 \\
\end{array}$ & $\begin{array}{c}40 \\
1 \\
11,8 \\
\end{array}$ \\
\hline & HSBC & \begin{tabular}{|l} 
Recuento \\
$\%$ de banco \\
$\%$ del total \\
\end{tabular} & \begin{tabular}{|c|}
7 \\
0,2333 \\
0,86 \\
\end{tabular} & \begin{tabular}{|c|}
2 \\
0,0667 \\
0,25 \\
\end{tabular} & \begin{tabular}{|c|}
4 \\
0,1333 \\
0,491 \\
\end{tabular} & $\begin{array}{c}9 \\
0,3 \\
1,104 \\
\end{array}$ & \begin{tabular}{|c|}
8 \\
0,2667 \\
0,982 \\
\end{tabular} & $\begin{array}{c}30 \\
1 \\
3,687 \\
\end{array}$ & HSBC & \begin{tabular}{|l} 
Recuento \\
$\%$ de banco \\
$\%$ del total \\
\end{tabular} & \begin{tabular}{|c|}
5 \\
0,2778 \\
0,92 \\
\end{tabular} & \begin{tabular}{|c}
1 \\
0,0556 \\
0,18 \\
\end{tabular} & \begin{tabular}{|c|}
3 \\
0,1667 \\
0,55 \\
\end{tabular} & \begin{tabular}{|c|}
6 \\
0,3333 \\
1,101 \\
\end{tabular} & \begin{tabular}{|c|}
3 \\
0,1667 \\
0,55 \\
\end{tabular} & $\begin{array}{c}18 \\
1 \\
3,3 \\
\end{array}$ & HSBC & $\begin{array}{l}\text { Recuento } \\
\% \text { de banco } \\
\% \text { del total }\end{array}$ & \begin{tabular}{|c|}
2 \\
0,1818 \\
0,6 \\
\end{tabular} & $\begin{array}{l}0 \\
0 \\
0 \\
\end{array}$ & \begin{tabular}{|c|} 
\\
0,0909 \\
0,29 \\
\end{tabular} & \begin{tabular}{|c|}
6 \\
0,5455 \\
1,77 \\
\end{tabular} & \begin{tabular}{|c|}
2 \\
0,1818 \\
0,59 \\
\end{tabular} & $\begin{array}{r}11 \\
1 \\
3,25 \\
\end{array}$ \\
\hline & Total & \begin{tabular}{|l} 
Recuento \\
$\%$ de banco \\
$\%$ del total
\end{tabular} & \begin{tabular}{|c|}
72 \\
$8,8 \%$ \\
$8,8 \%$ \\
\end{tabular} & \begin{tabular}{c|c|}
66 \\
$8,1 \%$ \\
$8,1 \%$
\end{tabular} & $\begin{array}{c}179 \\
22,0 \% \\
22,0 \%\end{array}$ & \begin{tabular}{|c|}
234 \\
$28,7 \%$ \\
$28,7 \%$
\end{tabular} & \begin{tabular}{|c|}
264 \\
$32,4 \%$ \\
$32,4 \%$ \\
\end{tabular} & \begin{tabular}{|c|}
815 \\
$100 \%$ \\
$100 \%$ \\
\end{tabular} & Total & $\begin{array}{l}\text { Recuento } \\
\% \text { de banco } \\
\% \text { del total }\end{array}$ & \begin{tabular}{c|}
69 \\
$12,7 \%$ \\
$12,7 \%$
\end{tabular} & \begin{tabular}{|c|}
64 \\
$11,7 \%$ \\
$11,7 \%$
\end{tabular} & \begin{tabular}{|c|}
156 \\
$28,6 \%$ \\
$28,6 \%$ \\
\end{tabular} & \begin{tabular}{|c|}
145 \\
$26,6 \%$ \\
$26,6 \%$ \\
\end{tabular} & \begin{tabular}{|c|}
111 \\
$20,4 \%$ \\
$20,4 \%$ \\
\end{tabular} & $\begin{array}{c}545 \\
100 \% \\
100 \%\end{array}$ & Total & \begin{tabular}{|l} 
Recuento \\
$\%$ de banco \\
$\%$ del total
\end{tabular} & \begin{tabular}{|c|}
45 \\
$13,7 \%$ \\
$13,7 \%$ \\
\end{tabular} & \begin{tabular}{|c|}
33 \\
$10,0 \%$ \\
$10,0 \%$ \\
\end{tabular} & \begin{tabular}{|c|}
107 \\
$32,5 \%$ \\
$32,5 \%$ \\
\end{tabular} & $\begin{array}{c}87 \\
26,4 \% \\
26,4 \% \\
\end{array}$ & $\begin{array}{c}57 \\
17,3 \% \\
17,3 \% \\
\end{array}$ & $\begin{array}{c}329 \\
100 \% \\
100 \% \\
\end{array}$ \\
\hline
\end{tabular}

Fuente: Elaboración propia en base a la información obtenida de las encuestas realizadas a las empresas. 
Cuadro 56

\begin{tabular}{|c|c|c|c|c|c|c|c|c|c|c|c|c|c|c|c|c|c|c|c|c|c|c|c|c|}
\hline & \multicolumn{8}{|c|}{ Calificación para el banco $1^{\circ}$} & \multicolumn{8}{|c|}{ Calificación para el banco $2^{\circ}$} & \multicolumn{8}{|c|}{ Calificación para el banco $3^{\circ}$} \\
\hline & & & 1 & 2 & 3 & 4 & 5 & Total & & & 1 & 2 & 3 & 4 & 5 & Total & & & 1 & 2 & 3 & 4 & 5 & Total \\
\hline \multirow{8}{*}{ 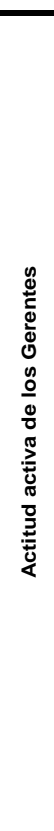 } & Nación & \begin{tabular}{|l} 
Recuento \\
$\%$ de banco \\
$\%$ del total
\end{tabular} & \begin{tabular}{c|}
13 \\
0,1287 \\
1,71 \\
\end{tabular} & $\begin{array}{c}12 \\
0,1188 \\
1,58\end{array}$ & \begin{tabular}{|c|}
25 \\
0,2475 \\
3,289 \\
\end{tabular} & \begin{tabular}{|c|}
26 \\
0,2574 \\
3,421 \\
\end{tabular} & \begin{tabular}{|c|}
25 \\
0,2475 \\
3,289 \\
\end{tabular} & $\begin{array}{c}101 \\
1 \\
13,289\end{array}$ & Nación & \begin{tabular}{|l} 
Recuento \\
$\%$ de banco \\
$\%$ del total
\end{tabular} & \begin{tabular}{c|}
8 \\
0,1013 \\
1,62 \\
\end{tabular} & \begin{tabular}{|c|}
11 \\
0,1392 \\
2,22 \\
\end{tabular} & \begin{tabular}{|c|}
19 \\
0,2405 \\
3,383 \\
\end{tabular} & \begin{tabular}{|c|}
19 \\
0,2405 \\
3,383 \\
\end{tabular} & \begin{tabular}{|c|}
22 \\
0,2785 \\
4,444 \\
\end{tabular} & $\begin{array}{c}79 \\
1 \\
15,05\end{array}$ & Nación & $\begin{array}{l}\text { Recuento } \\
\% \text { de banco } \\
\% \text { del total }\end{array}$ & \begin{tabular}{|c|}
5 \\
0,1087 \\
1,7 \\
\end{tabular} & $\begin{array}{c}4 \\
0,087 \\
1,37 \\
\end{array}$ & \begin{tabular}{c|}
19 \\
0,413 \\
6,48
\end{tabular} & \begin{tabular}{|c|}
11 \\
0,2391 \\
3,754 \\
\end{tabular} & \begin{tabular}{|c|}
7 \\
0,1522 \\
2,389 \\
\end{tabular} & $\begin{array}{c}46 \\
1 \\
16\end{array}$ \\
\hline & Provincia & \begin{tabular}{|l} 
Recuento \\
$\%$ de banco \\
$\%$ del total
\end{tabular} & \begin{tabular}{|c|}
8 \\
0,0842 \\
1,05 \\
\end{tabular} & $\begin{array}{c}10 \\
0,1053 \\
1,32\end{array}$ & \begin{tabular}{|c|}
21 \\
0,2211 \\
2,763 \\
\end{tabular} & \begin{tabular}{|c|}
33 \\
0,3474 \\
4,342 \\
\end{tabular} & \begin{tabular}{|c|}
23 \\
0,2421 \\
3,026 \\
\end{tabular} & \begin{tabular}{|c|}
95 \\
1 \\
12,501 \\
\end{tabular} & Provincia & \begin{tabular}{|l|} 
Recuento \\
$\%$ de banco \\
$\%$ del total
\end{tabular} & \begin{tabular}{|c|}
5 \\
0,0704 \\
1,01 \\
\end{tabular} & \begin{tabular}{|c|}
8 \\
0,1127 \\
1,62 \\
\end{tabular} & \begin{tabular}{|c|}
20 \\
0,2817 \\
4,04 \\
\end{tabular} & \begin{tabular}{|c|}
26 \\
0,3662 \\
5,253 \\
\end{tabular} & \begin{tabular}{|c|}
12 \\
0,169 \\
2,424 \\
\end{tabular} & $\begin{array}{c}71 \\
1 \\
14,347\end{array}$ & Provincia & \begin{tabular}{|l} 
Recuento \\
$\%$ de banco \\
$\%$ del total
\end{tabular} & \begin{tabular}{c|}
4 \\
0,129 \\
1,4 \\
\end{tabular} & \begin{tabular}{|c|}
1 \\
0,0323 \\
0,34 \\
\end{tabular} & \begin{tabular}{|c|}
11 \\
0,3548 \\
3,75 \\
\end{tabular} & \begin{tabular}{|c|}
9 \\
0,2903 \\
3,072 \\
\end{tabular} & \begin{tabular}{|c|}
6 \\
0,1935 \\
2,048 \\
\end{tabular} & $\begin{array}{c}31 \\
1 \\
10,61 \\
\end{array}$ \\
\hline & Credicoop & \begin{tabular}{|l} 
Recuento \\
$\%$ de banco \\
$\%$ del total
\end{tabular} & \begin{tabular}{|c|}
8 \\
0,0383 \\
1,05
\end{tabular} & $\begin{array}{c}9 \\
0,0431 \\
1,18\end{array}$ & $\begin{array}{c}46 \\
0,2201 \\
6,053\end{array}$ & \begin{tabular}{|c|}
75 \\
0,3589 \\
9,868
\end{tabular} & \begin{tabular}{|c|}
71 \\
0,3397 \\
9,342 \\
\end{tabular} & $\begin{array}{c}209 \\
1 \\
27,493\end{array}$ & Credicoop & \begin{tabular}{|l} 
Recuento \\
$\%$ de banco \\
$\%$ del total
\end{tabular} & \begin{tabular}{c|}
13 \\
0,113 \\
2,83
\end{tabular} & \begin{tabular}{|c|}
14 \\
0,1217 \\
2,83
\end{tabular} & \begin{tabular}{|c|}
39 \\
0,3391 \\
7,879
\end{tabular} & \begin{tabular}{|c|}
29 \\
0,2522 \\
5,859 \\
\end{tabular} & \begin{tabular}{|c|}
20 \\
0,1739 \\
4,04
\end{tabular} & $\begin{array}{c}115 \\
1 \\
23,438\end{array}$ & Credicoop & \begin{tabular}{|l} 
Recuento \\
$\%$ de banco \\
$\%$ del total
\end{tabular} & \begin{tabular}{|c|}
6 \\
0,0909 \\
2
\end{tabular} & \begin{tabular}{|c|}
17 \\
0,2576 \\
5,8
\end{tabular} & \begin{tabular}{|c|}
16 \\
0,2424 \\
5,46
\end{tabular} & \begin{tabular}{|c|}
17 \\
0,2576 \\
5,802 \\
\end{tabular} & $\begin{array}{c}10 \\
0,1515 \\
3,413\end{array}$ & \begin{tabular}{|c|}
66 \\
1 \\
22,475
\end{tabular} \\
\hline & Galicia & \begin{tabular}{|l} 
Recuento \\
$\%$ de banco \\
$\%$ del total
\end{tabular} & \begin{tabular}{|c|}
7 \\
0,0707 \\
0,92 \\
\end{tabular} & $\begin{array}{c}8 \\
0,0808 \\
1,05\end{array}$ & \begin{tabular}{|c|}
14 \\
0,1414 \\
1,842 \\
\end{tabular} & \begin{tabular}{|c|}
28 \\
0,2828 \\
3,684
\end{tabular} & \begin{tabular}{|c|c|}
42 & \\
0,4242 \\
5,526 \\
\end{tabular} & $\begin{array}{c}99 \\
1 \\
13,022\end{array}$ & Galicia & \begin{tabular}{|l} 
Recuento \\
$\%$ de banco \\
$\%$ del total
\end{tabular} & \begin{tabular}{|c|}
7 \\
0,1045 \\
1,41 \\
\end{tabular} & \begin{tabular}{|c|}
9 \\
0,1343 \\
1,82 \\
\end{tabular} & \begin{tabular}{|c|}
18 \\
0,2687 \\
3,636 \\
\end{tabular} & \begin{tabular}{|c|}
19 \\
0,2836 \\
3,838 \\
\end{tabular} & \begin{tabular}{|c|}
14 \\
0,209 \\
2,828 \\
\end{tabular} & $\begin{array}{c}67 \\
1 \\
13,532 \\
\end{array}$ & Galicia & \begin{tabular}{|l} 
Recuento \\
$\%$ de banco \\
$\%$ del total
\end{tabular} & \begin{tabular}{|c|}
5 \\
0,119 \\
1,7 \\
\end{tabular} & \begin{tabular}{|c|}
9 \\
0,2143 \\
3,07 \\
\end{tabular} & \begin{tabular}{|c|}
10 \\
0,2381 \\
3,41
\end{tabular} & \begin{tabular}{|c|}
8 \\
0,1905 \\
2,73 \\
\end{tabular} & \begin{tabular}{|c|}
10 \\
0,2381 \\
3,413
\end{tabular} & \begin{tabular}{|c|}
42 \\
1 \\
14,33 \\
\end{tabular} \\
\hline & BBVA & \begin{tabular}{|l} 
Recuento \\
$\%$ de banco \\
$\%$ del total
\end{tabular} & \begin{tabular}{|c|}
4 \\
0,0656 \\
0,53
\end{tabular} & $\begin{array}{c}7 \\
0,1148 \\
0,92\end{array}$ & \begin{tabular}{|c|}
11 \\
0,1803 \\
1,447
\end{tabular} & \begin{tabular}{|c|}
15 \\
0,2459 \\
1,974 \\
\end{tabular} & \begin{tabular}{|c|}
24 \\
0,3934 \\
3,158 \\
\end{tabular} & $\begin{array}{c}61 \\
1 \\
8,029 \\
\end{array}$ & BBVA & \begin{tabular}{|l} 
Recuento \\
$\%$ de banco \\
$\%$ del total
\end{tabular} & \begin{tabular}{|c|}
6 \\
0,1667 \\
1,21 \\
\end{tabular} & \begin{tabular}{|c|}
4 \\
0,1111 \\
0,81 \\
\end{tabular} & \begin{tabular}{|c|}
11 \\
0,3056 \\
2,222 \\
\end{tabular} & \begin{tabular}{|c|}
11 \\
0,3056 \\
2,222 \\
\end{tabular} & \begin{tabular}{|c|}
4 \\
0,1111 \\
0,808 \\
\end{tabular} & $\begin{array}{c}36 \\
1 \\
7,272 \\
\end{array}$ & BBVA & \begin{tabular}{|l} 
Recuento \\
$\%$ de banco \\
$\%$ del total
\end{tabular} & \begin{tabular}{|c|}
4 \\
0,1667 \\
1,4 \\
\end{tabular} & \begin{tabular}{|c|}
5 \\
0,2083 \\
1,71 \\
\end{tabular} & \begin{tabular}{|c|}
7 \\
0,2917 \\
2,39 \\
\end{tabular} & \begin{tabular}{|c|}
7 \\
0,2917 \\
2,389 \\
\end{tabular} & \begin{tabular}{|c|}
1 \\
0,0417 \\
0,341
\end{tabular} & $\begin{array}{c}24 \\
1 \\
8,23\end{array}$ \\
\hline & Santander & \begin{tabular}{|l|} 
Recuento \\
$\%$ de banco \\
$\%$ del total
\end{tabular} & \begin{tabular}{|c|}
7 \\
0,0805 \\
0,92
\end{tabular} & $\begin{array}{c}1 \\
0,0115 \\
0,13\end{array}$ & $\begin{array}{c}20 \\
0,2299 \\
2,632 \\
\end{array}$ & \begin{tabular}{|c|}
30 \\
0,3448 \\
3,947
\end{tabular} & \begin{tabular}{|c|}
29 \\
0,3333 \\
3,816 \\
\end{tabular} & $\begin{array}{c}87 \\
1 \\
11,445\end{array}$ & Santander & \begin{tabular}{|l} 
Recuento \\
$\%$ de banco \\
$\%$ del total
\end{tabular} & \begin{tabular}{|c|}
6 \\
0,0923 \\
1,21 \\
\end{tabular} & \begin{tabular}{|c|}
4 \\
0,0615 \\
0,81 \\
\end{tabular} & \begin{tabular}{|c|}
13 \\
0,2 \\
2,626
\end{tabular} & \begin{tabular}{|c|}
23 \\
0,3538 \\
4,646 \\
\end{tabular} & \begin{tabular}{c|}
19 \\
0,2923 \\
3,838 \\
\end{tabular} & $\begin{array}{c}65 \\
1 \\
13,13 \\
\end{array}$ & Santander & \begin{tabular}{|l} 
Recuento \\
$\%$ de banco \\
$\%$ del total
\end{tabular} & \begin{tabular}{|c|}
5 \\
0,1282 \\
1,7 \\
\end{tabular} & \begin{tabular}{|c|}
4 \\
0,1026 \\
1,37 \\
\end{tabular} & \begin{tabular}{|c|}
9 \\
0,2308 \\
3,07
\end{tabular} & \begin{tabular}{|c|}
15 \\
0,3846 \\
5,119 \\
\end{tabular} & \begin{tabular}{|c|}
6 \\
0,1538 \\
2,048
\end{tabular} & $\begin{array}{c}39 \\
1 \\
13,307\end{array}$ \\
\hline & HSBC & \begin{tabular}{|l} 
Recuento \\
$\%$ de banco \\
$\%$ del total
\end{tabular} & \begin{tabular}{|c|}
5 \\
0,1667 \\
0,66
\end{tabular} & $\begin{array}{c}2 \\
0,0667 \\
0,26\end{array}$ & \begin{tabular}{|c|}
5 \\
0,1667 \\
0,658 \\
\end{tabular} & \begin{tabular}{|c|}
11 \\
0,3667 \\
1,447
\end{tabular} & \begin{tabular}{|c|}
7 \\
0,2333 \\
0,921 \\
\end{tabular} & $\begin{array}{c}30 \\
1 \\
3,946 \\
\end{array}$ & HSBC & \begin{tabular}{|l} 
Recuento \\
$\%$ de banco \\
$\%$ del total
\end{tabular} & \begin{tabular}{c|}
6 \\
0,3158 \\
1,21 \\
\end{tabular} & \begin{tabular}{|c|}
2 \\
0,1053 \\
0,4 \\
\end{tabular} & \begin{tabular}{|c|}
4 \\
0,2105 \\
0,808 \\
\end{tabular} & \begin{tabular}{|c|}
5 \\
0,2632 \\
1,01 \\
\end{tabular} & \begin{tabular}{|c|}
2 \\
0,1053 \\
0,404 \\
\end{tabular} & $\begin{array}{c}19 \\
1 \\
3,8\end{array}$ & HSBC & \begin{tabular}{|l} 
Recuento \\
$\%$ de banco \\
$\%$ del total
\end{tabular} & \begin{tabular}{|c|}
1 \\
0,0909 \\
0,3 \\
\end{tabular} & \begin{tabular}{|c|}
1 \\
0,0909 \\
0,34 \\
\end{tabular} & \begin{tabular}{|c|}
2 \\
0,1818 \\
0,68 \\
\end{tabular} & \begin{tabular}{|c|}
5 \\
0,4545 \\
1,706 \\
\end{tabular} & \begin{tabular}{|c|}
2 \\
0,1818 \\
0,683 \\
\end{tabular} & $\begin{array}{c}11 \\
1 \\
3,709 \\
\end{array}$ \\
\hline & Total & \begin{tabular}{|l} 
Recuento \\
$\%$ de banco \\
$\%$ del total
\end{tabular} & $\begin{array}{c}56 \\
7,4 \% \\
7,4 \%\end{array}$ & $\begin{array}{c}57 \\
7,5 \% \\
7,5 \%\end{array}$ & \begin{tabular}{|c|}
153 \\
$20,1 \%$ \\
$20,1 \%$
\end{tabular} & \begin{tabular}{|c|}
239 \\
$31,4 \%$ \\
$31,4 \%$
\end{tabular} & \begin{tabular}{|c|}
255 \\
$33,6 \%$ \\
$33,6 \%$ \\
\end{tabular} & $\begin{array}{c}760 \\
100 \% \\
100 \%\end{array}$ & Total & \begin{tabular}{|l} 
Recuento \\
$\%$ de banco \\
$\%$ del total
\end{tabular} & \begin{tabular}{c|}
53 \\
$10,7 \%$ \\
$10,7 \%$
\end{tabular} & \begin{tabular}{|c|}
62 \\
$12,5 \%$ \\
$12,5 \%$ \\
\end{tabular} & \begin{tabular}{|c|}
137 \\
$27,7 \%$ \\
$27,7 \%$
\end{tabular} & \begin{tabular}{c|c}
142 \\
$28,7 \%$ \\
$28,7 \%$
\end{tabular} & \begin{tabular}{|c|}
101 \\
$20,4 \%$ \\
$20,4 \%$
\end{tabular} & $\begin{array}{c}495 \\
100 \% \\
100 \%\end{array}$ & Total & \begin{tabular}{|l} 
Recuento \\
$\%$ de banco \\
$\%$ del total
\end{tabular} & \begin{tabular}{|c|}
31 \\
$10,6 \%$ \\
$10,6 \%$ \\
\end{tabular} & \begin{tabular}{|c|}
52 \\
$17,7 \%$ \\
$17,7 \%$ \\
\end{tabular} & \begin{tabular}{|c|}
83 \\
$28,3 \%$ \\
$28,3 \%$ \\
\end{tabular} & \begin{tabular}{|c|}
78 \\
$26,6 \%$ \\
$26,6 \%$ \\
\end{tabular} & \begin{tabular}{|c|}
49 \\
$16,7 \%$ \\
$16,7 \%$
\end{tabular} & \begin{tabular}{|c|}
293 \\
$100 \%$ \\
$100 \%$ \\
\end{tabular} \\
\hline
\end{tabular}


Cuadro 57

\begin{tabular}{|c|c|c|c|c|c|c|c|c|c|c|c|c|c|c|c|c|c|c|c|c|c|c|c|c|}
\hline & \multicolumn{8}{|c|}{ Calificación para el banco $1^{\circ}$} & \multicolumn{8}{|c|}{ Calificación para el banco $2^{\circ}$} & \multicolumn{8}{|c|}{ Calificación para el banco $3^{\circ}$} \\
\hline & & & 1 & 2 & 3 & 4 & 5 & Total & & & 1 & 2 & 3 & 4 & 5 & Total & & & 1 & 2 & 3 & 4 & 5 & Total \\
\hline \multirow{7}{*}{ 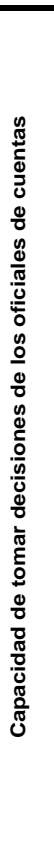 } & Nación & \begin{tabular}{|l} 
Recuento \\
$\%$ de banco \\
$\%$ del total
\end{tabular} & \begin{tabular}{c|}
17 \\
0,1735 \\
2,22
\end{tabular} & $\begin{array}{c}17 \\
0,1735 \\
2,22\end{array}$ & \begin{tabular}{|c|}
26 \\
0,2653 \\
3,394 \\
\end{tabular} & \begin{tabular}{|c|}
20 \\
0,2041 \\
2,611
\end{tabular} & $\begin{array}{c}18 \\
0,1837 \\
2,35\end{array}$ & $\begin{array}{c}98 \\
1 \\
12,795 \\
\end{array}$ & Nación & $\begin{array}{l}\text { Recuento } \\
\% \text { de banco } \\
\% \text { del total }\end{array}$ & $\begin{array}{c}14 \\
0,2059 \\
2,83 \\
\end{array}$ & $\begin{array}{c}3 \\
0,0441 \\
2,63\end{array}$ & \begin{tabular}{|c|}
23 \\
0,3382 \\
4,646 \\
\end{tabular} & \begin{tabular}{|c|}
15 \\
0,2206 \\
3,03 \\
\end{tabular} & \begin{tabular}{|c|}
13 \\
0,1912 \\
2,626 \\
\end{tabular} & \begin{tabular}{|c|}
68 \\
1 \\
15,762 \\
\end{tabular} & Nación & $\begin{array}{l}\text { Recuento } \\
\% \text { de banco } \\
\% \text { del total }\end{array}$ & $\begin{array}{c}10 \\
0,2273 \\
3,5 \\
\end{array}$ & \begin{tabular}{|c|}
6 \\
0,1364 \\
2,1 \\
\end{tabular} & \begin{tabular}{|c|}
12 \\
0,2727 \\
4,2 \\
\end{tabular} & \begin{tabular}{|c|}
10 \\
0,2273 \\
3,497 \\
\end{tabular} & \begin{tabular}{c|}
6 \\
0,1364 \\
2,098
\end{tabular} & $\begin{array}{c}44 \\
1 \\
15\end{array}$ \\
\hline & Credicoop & \begin{tabular}{|l} 
Recuento \\
$\%$ de banco \\
$\%$ del total
\end{tabular} & \begin{tabular}{c|}
9 \\
0,0427 \\
1,17 \\
\end{tabular} & $\begin{array}{c}14 \\
0,0664 \\
1,83 \\
\end{array}$ & \begin{tabular}{|c|}
63 \\
0,2986 \\
8,225 \\
\end{tabular} & \begin{tabular}{|c|}
68 \\
0,3223 \\
8,877
\end{tabular} & $\begin{array}{c}57 \\
0,2701 \\
7,441\end{array}$ & \begin{tabular}{|c|}
211 \\
1 \\
27,543 \\
\end{tabular} & Credicoop & \begin{tabular}{|l|} 
Recuento \\
$\%$ de banco \\
$\%$ del total
\end{tabular} & $\begin{array}{c}15 \\
0,1293 \\
3,03 \\
\end{array}$ & \begin{tabular}{|c|}
18 \\
0,1552 \\
3,64 \\
\end{tabular} & \begin{tabular}{|c|}
39 \\
0,3362 \\
7,879 \\
\end{tabular} & \begin{tabular}{|c|}
28 \\
0,2414 \\
5,657 \\
\end{tabular} & \begin{tabular}{|c|}
16 \\
0,1379 \\
3,232 \\
\end{tabular} & \begin{tabular}{|c|}
116 \\
1 \\
23,438 \\
\end{tabular} & Credicoop & \begin{tabular}{|l|} 
Recuento \\
$\%$ de banco \\
$\%$ del total
\end{tabular} & $\begin{array}{c}8 \\
0,2051 \\
2,8 \\
\end{array}$ & \begin{tabular}{|c|}
6 \\
0,1538 \\
2,1 \\
\end{tabular} & \begin{tabular}{|c|} 
\\
0,2051 \\
2,8 \\
\end{tabular} & \begin{tabular}{c|}
10 \\
0,2564 \\
3,497
\end{tabular} & \begin{tabular}{|c|}
7 \\
0,1795 \\
2,448 \\
\end{tabular} & $\begin{array}{c}39 \\
1 \\
13,645 \\
\end{array}$ \\
\hline & Galicia & \begin{tabular}{|l} 
Recuento \\
$\%$ de banco \\
$\%$ del total
\end{tabular} & \begin{tabular}{c|c|}
7 & \\
0,0986 \\
0,92
\end{tabular} & $\begin{array}{c}8 \\
0,1127 \\
1,05\end{array}$ & \begin{tabular}{|c|}
14 \\
0,1972 \\
1,842
\end{tabular} & \begin{tabular}{|c|}
28 \\
0,3944 \\
3,684
\end{tabular} & $\begin{array}{c}14 \\
0,1972 \\
5,526\end{array}$ & $\begin{array}{c}71 \\
1 \\
13,022 \\
\end{array}$ & Galicia & $\begin{array}{l}\text { Recuento } \\
\% \text { de banco } \\
\% \text { del total }\end{array}$ & $\begin{array}{c}11 \\
0,1667 \\
2,22\end{array}$ & $\begin{array}{c}8 \\
0,1212 \\
1,82 \\
\end{array}$ & \begin{tabular}{|c|}
17 \\
0,2576 \\
3,434
\end{tabular} & $\begin{array}{c}21 \\
0,3182 \\
4,242 \\
\end{array}$ & $\begin{array}{c}9 \\
0,1364 \\
1,818\end{array}$ & $\begin{array}{c}66 \\
1 \\
13,534 \\
\end{array}$ & Galicia & $\begin{array}{l}\text { Recuento } \\
\% \text { de banco } \\
\% \text { del total }\end{array}$ & $\begin{array}{c}6 \\
0,2222 \\
2,1\end{array}$ & \begin{tabular}{c|}
3 \\
0,1111 \\
1,05 \\
\end{tabular} & \begin{tabular}{|c|}
8 \\
0,2963 \\
2,8
\end{tabular} & \begin{tabular}{|c|}
8 \\
0,2963 \\
2,797
\end{tabular} & $\begin{array}{c}2 \\
0,0741 \\
0,699 \\
\end{array}$ & $\begin{array}{c}27 \\
1 \\
9,446 \\
\end{array}$ \\
\hline & BBVA & \begin{tabular}{|l} 
Recuento \\
$\%$ de banco \\
$\%$ del total
\end{tabular} & \begin{tabular}{|c|c|}
4 \\
0,0656 \\
0,53
\end{tabular} & \begin{tabular}{|c|}
7 \\
0,1148 \\
0,92
\end{tabular} & \begin{tabular}{|c|}
11 \\
0,1803 \\
1,447
\end{tabular} & \begin{tabular}{|c|}
15 \\
0,2459 \\
1,974
\end{tabular} & $\begin{array}{c}24 \\
0,3934 \\
3,158\end{array}$ & $\begin{array}{c}61 \\
1 \\
8,029\end{array}$ & BBVA & $\begin{array}{l}\text { Recuento } \\
\% \text { de banco } \\
\% \text { del total }\end{array}$ & $\begin{array}{c}5 \\
0,1316 \\
1,01\end{array}$ & \begin{tabular}{|c|}
8 \\
0,2105 \\
1,62
\end{tabular} & \begin{tabular}{|c|}
11 \\
0,2895 \\
2,222
\end{tabular} & $\begin{array}{c}10 \\
0,2632 \\
2,02\end{array}$ & \begin{tabular}{|c|}
4 \\
0,1053 \\
0,808
\end{tabular} & $\begin{array}{c}38 \\
1 \\
7,68\end{array}$ & BBVA & $\begin{array}{l}\text { Recuento } \\
\% \text { de banco } \\
\% \text { del total }\end{array}$ & $\begin{array}{c}2 \\
0,0526 \\
0,7\end{array}$ & \begin{tabular}{|c|}
6 \\
0,1579 \\
2,1
\end{tabular} & \begin{tabular}{|c|}
13 \\
0,3421 \\
4,55 \\
\end{tabular} & \begin{tabular}{|c|}
11 \\
0,2895 \\
3,846
\end{tabular} & \begin{tabular}{|c|}
6 \\
0,1579 \\
2,098
\end{tabular} & \begin{tabular}{|c|}
38 \\
1 \\
13,294
\end{tabular} \\
\hline & Santander & $\begin{array}{l}\text { Recuento } \\
\% \text { de banco } \\
\% \text { del total }\end{array}$ & \begin{tabular}{c|}
7 \\
0,0805 \\
0,92 \\
\end{tabular} & $\begin{array}{c}1 \\
0,0115 \\
0,13\end{array}$ & \begin{tabular}{|c|}
20 \\
0,2299 \\
2,632 \\
\end{tabular} & \begin{tabular}{|c|}
30 \\
0,3448 \\
3,947 \\
\end{tabular} & $\begin{array}{c}29 \\
0,3333 \\
3,816 \\
\end{array}$ & \begin{tabular}{|c|}
87 \\
1 \\
11,445 \\
\end{tabular} & Santander & \begin{tabular}{|l} 
Recuento \\
$\%$ de banco \\
$\%$ del total
\end{tabular} & $\begin{array}{c}7 \\
0,1094 \\
1,41 \\
\end{array}$ & \begin{tabular}{|c|}
5 \\
0,0781 \\
1,01 \\
\end{tabular} & \begin{tabular}{|c|}
18 \\
0,2813 \\
3,636 \\
\end{tabular} & \begin{tabular}{|c|}
20 \\
0,3125 \\
4,04 \\
\end{tabular} & \begin{tabular}{|c|}
14 \\
0,2188 \\
2,828 \\
\end{tabular} & $\begin{array}{c}64 \\
1 \\
12,924 \\
\end{array}$ & Santander & \begin{tabular}{|l} 
Recuento \\
$\%$ de banco \\
$\%$ del total
\end{tabular} & $\begin{array}{l}0 \\
0 \\
0\end{array}$ & \begin{tabular}{|c|}
2 \\
0,6667 \\
0,7 \\
\end{tabular} & \begin{tabular}{|c|}
1 \\
0,3333 \\
0,35 \\
\end{tabular} & \begin{tabular}{|l|}
0 \\
0 \\
0 \\
\end{tabular} & \begin{tabular}{|l|}
0 \\
0 \\
0 \\
\end{tabular} & $\begin{array}{c}3 \\
1 \\
1,05 \\
\end{array}$ \\
\hline & HSBC & \begin{tabular}{|l|} 
Recuento \\
$\%$ de banco \\
$\%$ del total
\end{tabular} & \begin{tabular}{c|}
5 \\
0,1667 \\
0,66
\end{tabular} & $\begin{array}{c}2 \\
0,0667 \\
0,28\end{array}$ & \begin{tabular}{|c|}
5 \\
0,1667 \\
0,658 \\
\end{tabular} & \begin{tabular}{|c|}
11 \\
0,3667 \\
1,447
\end{tabular} & $\begin{array}{c}7 \\
0,2333 \\
0,921\end{array}$ & $\begin{array}{c}30 \\
1 \\
3,966\end{array}$ & HSBC & $\begin{array}{l}\text { Recuento } \\
\% \text { de banco } \\
\% \text { del total }\end{array}$ & $\begin{array}{c}5 \\
0,2632 \\
1,01\end{array}$ & $\begin{array}{l}0 \\
0 \\
0\end{array}$ & \begin{tabular}{|c|}
7 \\
0,3684 \\
1,414
\end{tabular} & \begin{tabular}{c|c}
4 \\
0,2105 \\
0,808
\end{tabular} & $\begin{array}{c}3 \\
0,1579 \\
0,606\end{array}$ & $\begin{array}{c}19 \\
1 \\
3,8\end{array}$ & HSBC & $\begin{array}{l}\text { Recuento } \\
\% \text { de banco } \\
\% \text { del total }\end{array}$ & $\begin{array}{c}3 \\
0,375 \\
1\end{array}$ & $\begin{array}{c}1 \\
0,125 \\
0,35\end{array}$ & $\begin{array}{c}4 \\
0,5 \\
1,4\end{array}$ & $\begin{array}{l}0 \\
0 \\
0\end{array}$ & $\begin{array}{l}0 \\
0 \\
0\end{array}$ & $\begin{array}{c}8 \\
1 \\
2,75\end{array}$ \\
\hline & Total & $\begin{array}{l}\text { Recuento } \\
\% \text { de banco } \\
\text { \% del total }\end{array}$ & $\begin{array}{c}56 \\
7,4 \% \\
7,4 \%\end{array}$ & \begin{tabular}{c|}
57 \\
$7,5 \%$ \\
$7,5 \%$ \\
\end{tabular} & \begin{tabular}{|c|}
153 \\
$20,1 \%$ \\
$20,1 \%$
\end{tabular} & \begin{tabular}{|c|}
239 \\
$31,4 \%$ \\
$31,4 \%$ \\
\end{tabular} & $\begin{array}{c}255 \\
33,6 \% \\
33,6 \%\end{array}$ & \begin{tabular}{|c|}
760 \\
$100 \%$ \\
$100 \%$ \\
\end{tabular} & Total & \begin{tabular}{|l} 
Recuento \\
$\%$ de banco \\
$\%$ del total
\end{tabular} & \begin{tabular}{|c|}
66 \\
$13,3 \%$ \\
$13,3 \%$ \\
\end{tabular} & \begin{tabular}{|c|}
70 \\
$14,1 \%$ \\
$14,1 \%$ \\
\end{tabular} & \begin{tabular}{|c|}
155 \\
$31,3 \%$ \\
$31,3 \%$ \\
\end{tabular} & \begin{tabular}{|c|}
129 \\
$26,1 \%$ \\
$26,1 \%$ \\
\end{tabular} & \begin{tabular}{|c|}
75 \\
$15,2 \%$ \\
$15,2 \%$ \\
\end{tabular} & $\begin{array}{c}495 \\
100 \% \\
100 \% \\
\end{array}$ & Total & $\begin{array}{l}\text { Recuento } \\
\% \text { de banco } \\
\% \text { del total }\end{array}$ & \begin{tabular}{|c|}
45 \\
$15,7 \%$ \\
$15,7 \%$ \\
\end{tabular} & \begin{tabular}{|c|}
43 \\
$15,0 \%$ \\
$15,0 \%$ \\
\end{tabular} & \begin{tabular}{|c|}
86 \\
$30,1 \%$ \\
$30,1 \%$ \\
\end{tabular} & \begin{tabular}{|c|}
76 \\
$26,6 \%$ \\
$26,6 \%$ \\
\end{tabular} & \begin{tabular}{|c|}
36 \\
$12,6 \%$ \\
$12,6 \%$ \\
\end{tabular} & \begin{tabular}{|c|}
286 \\
$100 \%$ \\
$100 \%$ \\
\end{tabular} \\
\hline
\end{tabular}

Fuente: Elaboración propia en base a la información obtenida de las encuestas realizadas a las empresas. 


\section{Cuadro 58}

\begin{tabular}{|c|c|c|c|c|c|c|c|c|c|c|c|c|c|c|c|c|c|c|c|c|c|c|c|c|}
\hline & \multicolumn{8}{|c|}{ Calificación para el banco $1^{\circ}$} & \multicolumn{8}{|c|}{ Calificación para el banco $2^{\circ}$} & \multicolumn{8}{|c|}{ Calificación para el banco $3^{\circ}$} \\
\hline & & & 1 & 2 & 3 & 4 & 5 & Total & & & 1 & 2 & 3 & 4 & 5 & Total & & & 1 & 2 & 3 & 4 & 5 & Total \\
\hline \multirow{8}{*}{ 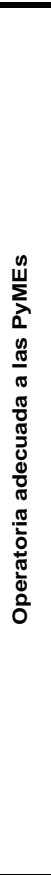 } & Nación & $\begin{array}{l}\text { Recuento } \\
\text { \% de banco } \\
\text { \% del total }\end{array}$ & \begin{tabular}{c|}
21 \\
0,181 \\
2,61
\end{tabular} & $\begin{array}{c}15 \\
0,1293 \\
1,87\end{array}$ & \begin{tabular}{|c|}
31 \\
0,2672 \\
3,856
\end{tabular} & \begin{tabular}{|c|}
34 \\
0,2931 \\
4,229
\end{tabular} & $\begin{array}{c}15 \\
0,1293 \\
1,866\end{array}$ & $\begin{array}{c}116 \\
1 \\
14,431\end{array}$ & Nación & \begin{tabular}{|l} 
Recuento \\
$\%$ de banco \\
$\%$ del total
\end{tabular} & $\begin{array}{c}20 \\
0,2105 \\
3,74\end{array}$ & \begin{tabular}{|c|}
15 \\
0,1579 \\
2,8
\end{tabular} & $\begin{array}{c}30 \\
0,3158 \\
5,607\end{array}$ & \begin{tabular}{|c|c|}
17 \\
0,1789 \\
3,178
\end{tabular} & \begin{tabular}{|c|}
13 \\
0,1368 \\
2,43
\end{tabular} & $\begin{array}{c}95 \\
1\end{array}$ & Nación & $\begin{array}{l}\text { Recuento } \\
\% \text { de banco } \\
\% \text { del total }\end{array}$ & $\begin{array}{c}16 \\
0,2759 \\
4,9\end{array}$ & \begin{tabular}{|c|}
10 \\
0,1724 \\
3,05
\end{tabular} & \begin{tabular}{|c|}
18 \\
0,3103 \\
5,49
\end{tabular} & \begin{tabular}{|c|}
12 \\
0,2069 \\
3,659 \\
\end{tabular} & \begin{tabular}{|c|}
2 \\
0,0345 \\
0,61
\end{tabular} & $\begin{array}{c}58 \\
1 \\
18\end{array}$ \\
\hline & Provincia & $\begin{array}{l}\text { Recuento } \\
\% \text { de banco } \\
\% \text { del total }\end{array}$ & \begin{tabular}{c|}
16 \\
0,1495 \\
1,99 \\
\end{tabular} & $\begin{array}{c}13 \\
0,1215 \\
1,62 \\
\end{array}$ & $\begin{array}{c}32 \\
0,2991 \\
3,98 \\
\end{array}$ & $\begin{array}{c}23 \\
0,215 \\
2,861\end{array}$ & $\begin{array}{c}23 \\
0,215 \\
2,61\end{array}$ & \begin{tabular}{|c|}
107 \\
1 \\
13,061
\end{tabular} & Provincia & \begin{tabular}{|l} 
Recuento \\
$\%$ de banco \\
$\%$ del total
\end{tabular} & $\begin{array}{c}17 \\
0,2125 \\
3,18 \\
\end{array}$ & \begin{tabular}{|c|} 
\\
0,0875 \\
1,31 \\
\end{tabular} & $\begin{array}{c}30 \\
0,375 \\
5,607\end{array}$ & $\begin{array}{c}15 \\
0,1875 \\
2,804 \\
\end{array}$ & \begin{tabular}{|c|}
11 \\
0,1375 \\
2,056 \\
\end{tabular} & $\begin{array}{c}80 \\
1 \\
14,957\end{array}$ & Provincia & $\begin{array}{l}\text { Recuento } \\
\text { \% de banco } \\
\% \text { del total }\end{array}$ & $\begin{array}{c}12 \\
0,2727 \\
3,7\end{array}$ & $\begin{array}{c}7 \\
0,1591 \\
2,13\end{array}$ & $\begin{array}{c}11 \\
0,25 \\
3,35\end{array}$ & \begin{tabular}{|c|}
7 \\
0,1591 \\
2,134 \\
\end{tabular} & $\begin{array}{c}7 \\
0,1591 \\
2,134 \\
\end{array}$ & \begin{tabular}{|c|}
44 \\
1 \\
13,448 \\
\end{tabular} \\
\hline & Credicoop & \begin{tabular}{|l} 
Recuento \\
$\%$ de banco \\
$\%$ del total
\end{tabular} & \begin{tabular}{c|}
17 \\
0,0794 \\
2,11
\end{tabular} & $\begin{array}{c}8 \\
0,0374 \\
1\end{array}$ & \begin{tabular}{|c|}
54 \\
0,2523 \\
6,716 \\
\end{tabular} & \begin{tabular}{|c|}
66 \\
0,3084 \\
8,209 \\
\end{tabular} & $\begin{array}{c}69 \\
0,3224 \\
8,582\end{array}$ & \begin{tabular}{|c|}
214 \\
1 \\
26,617
\end{tabular} & Credicoop & \begin{tabular}{|l} 
Recuento \\
$\%$ de banco \\
$\%$ del total
\end{tabular} & $\begin{array}{c}19 \\
0,1557 \\
3,55\end{array}$ & \begin{tabular}{c|}
15 \\
0,123 \\
2,8
\end{tabular} & $\begin{array}{c}52 \\
0,4262 \\
9,72\end{array}$ & \begin{tabular}{c|}
17 \\
0,1393 \\
3,178
\end{tabular} & \begin{tabular}{|c|}
19 \\
0,1557 \\
3,551
\end{tabular} & $\begin{array}{c}122 \\
1 \\
22,799\end{array}$ & Credicoop & \begin{tabular}{|l} 
Recuento \\
$\%$ de banco \\
$\%$ del total
\end{tabular} & $\begin{array}{c}8 \\
0,1212 \\
2,4\end{array}$ & $\begin{array}{c}12 \\
0,1818 \\
3,66\end{array}$ & \begin{tabular}{|c|}
29 \\
0,4394 \\
8,84 \\
\end{tabular} & \begin{tabular}{|c|}
11 \\
0,1667 \\
3,354 \\
\end{tabular} & $\begin{array}{c}6 \\
0,0909 \\
1,829\end{array}$ & $\begin{array}{c}66 \\
1 \\
20,083\end{array}$ \\
\hline & Galicia & \begin{tabular}{|l} 
Recuento \\
$\%$ de banco \\
$\%$ del total
\end{tabular} & \begin{tabular}{|c|}
7 \\
0,0335 \\
0,87 \\
\end{tabular} & $\begin{array}{c}10 \\
0,0478 \\
1,24\end{array}$ & \begin{tabular}{|c|}
126 \\
0,6029 \\
1,99
\end{tabular} & $\begin{array}{c}23 \\
0,11 \\
2,861\end{array}$ & $\begin{array}{c}43 \\
0,2057 \\
5,348 \\
\end{array}$ & \begin{tabular}{|c|}
209 \\
1 \\
12,309 \\
\end{tabular} & Galicia & \begin{tabular}{|l} 
Recuento \\
$\%$ de banco \\
$\%$ del total
\end{tabular} & $\begin{array}{c}7 \\
0,1045 \\
1,31\end{array}$ & \begin{tabular}{|c|}
11 \\
0,1642 \\
2,06 \\
\end{tabular} & $\begin{array}{c}17 \\
0,2537 \\
3,178\end{array}$ & $\begin{array}{c}15 \\
0,2239 \\
2,804 \\
\end{array}$ & \begin{tabular}{|c|}
17 \\
0,2537 \\
3,178
\end{tabular} & $\begin{array}{c}67 \\
1 \\
12,53 \\
\end{array}$ & Galicia & $\begin{array}{l}\text { Recuento } \\
\% \text { de banco } \\
\% \text { del total }\end{array}$ & $\begin{array}{c}6 \\
0,1333 \\
1,8\end{array}$ & $\begin{array}{c}5 \\
0,1111 \\
1,52\end{array}$ & \begin{tabular}{|c|}
15 \\
0,3333 \\
4,57 \\
\end{tabular} & \begin{tabular}{|c|}
10 \\
0,2222 \\
3,049 \\
\end{tabular} & \begin{tabular}{c|}
9 \\
0,2 \\
2,744 \\
\end{tabular} & $\begin{array}{c}45 \\
1 \\
13,683 \\
\end{array}$ \\
\hline & BBVA & \begin{tabular}{|l|} 
Recuento \\
$\%$ de banco \\
$\%$ del total
\end{tabular} & \begin{tabular}{c|}
5 \\
0,0806 \\
0,62 \\
\end{tabular} & $\begin{array}{c}9 \\
0,1452 \\
1,12\end{array}$ & \begin{tabular}{|c|}
13 \\
0,2097 \\
1,617
\end{tabular} & \begin{tabular}{|c|}
13 \\
0,2097 \\
1,617 \\
\end{tabular} & $\begin{array}{c}22 \\
0,3548 \\
2,736\end{array}$ & $\begin{array}{c}62 \\
1 \\
7,71\end{array}$ & BBVA & \begin{tabular}{|l} 
Recuento \\
$\%$ de banco \\
$\%$ del total
\end{tabular} & $\begin{array}{c}5 \\
0,125 \\
0,93\end{array}$ & $\begin{array}{c}5 \\
0,125 \\
0,93 \\
\end{array}$ & $\begin{array}{c}13 \\
0,325 \\
2,43 \\
\end{array}$ & $\begin{array}{c}11 \\
0,275 \\
2,056 \\
\end{array}$ & $\begin{array}{c}6 \\
0,15 \\
1,121\end{array}$ & $\begin{array}{c}40 \\
1 \\
7,467\end{array}$ & BBVA & $\begin{array}{l}\text { Recuento } \\
\% \text { de banco } \\
\% \text { del total }\end{array}$ & $\begin{array}{c}7 \\
0,2593 \\
2,1\end{array}$ & $\begin{array}{c}3 \\
0,1111 \\
0,91\end{array}$ & \begin{tabular}{|c|}
10 \\
0,3704 \\
3,05 \\
\end{tabular} & \begin{tabular}{|c|}
5 \\
0,1852 \\
1,524 \\
\end{tabular} & $\begin{array}{c}2 \\
0,0741 \\
0,61\end{array}$ & \begin{tabular}{|c|}
27 \\
1 \\
8,194 \\
\end{tabular} \\
\hline & intander & \begin{tabular}{|l} 
Recuento \\
$\%$ de banco \\
$\%$ del total
\end{tabular} & \begin{tabular}{|c|}
5 \\
0,0521 \\
0,62 \\
\end{tabular} & $\begin{array}{c}14 \\
0,1458 \\
1,74 \\
\end{array}$ & \begin{tabular}{|c|}
22 \\
0,2292 \\
2,736
\end{tabular} & \begin{tabular}{|c|}
34 \\
0,3542 \\
4,229 \\
\end{tabular} & $\begin{array}{c}21 \\
0,2188 \\
2,612\end{array}$ & \begin{tabular}{|c|}
96 \\
1 \\
11,937 \\
\end{tabular} & Santander & \begin{tabular}{|l|} 
Recuento \\
$\%$ de banco \\
$\%$ del total
\end{tabular} & $\begin{array}{c}3 \\
0,0462 \\
0,56\end{array}$ & \begin{tabular}{|c|}
6 \\
0,0923 \\
1,12 \\
\end{tabular} & \begin{tabular}{|c|}
20 \\
0,3077 \\
3,738
\end{tabular} & \begin{tabular}{|c|}
24 \\
0,3692 \\
4,486 \\
\end{tabular} & \begin{tabular}{|c|}
12 \\
0,1846 \\
2,243 \\
\end{tabular} & $\begin{array}{c}65 \\
1 \\
12,147\end{array}$ & Santander & \begin{tabular}{|l} 
Recuento \\
$\%$ de banco \\
$\%$ del total
\end{tabular} & $\begin{array}{c}3 \\
0,0732 \\
0,9\end{array}$ & $\begin{array}{c}5 \\
0,122 \\
1,52 \\
\end{array}$ & \begin{tabular}{|c|}
13 \\
0,3171 \\
3,96 \\
\end{tabular} & \begin{tabular}{|c|}
11 \\
0,2683 \\
3,354 \\
\end{tabular} & $\begin{array}{c}9 \\
0,2195 \\
2,744 \\
\end{array}$ & $\begin{array}{c}41 \\
1 \\
12,478 \\
\end{array}$ \\
\hline & HSBC & \begin{tabular}{|l|} 
Recuento \\
$\%$ de banco \\
$\%$ del total
\end{tabular} & \begin{tabular}{c|}
5 \\
0,1667 \\
0,62 \\
\end{tabular} & \begin{tabular}{|c|}
5 \\
0,1667 \\
1,74
\end{tabular} & \begin{tabular}{|c|}
7 \\
0,2333 \\
2,736 \\
\end{tabular} & \begin{tabular}{|c|}
8 \\
0,2667 \\
4,229 \\
\end{tabular} & $\begin{array}{c}5 \\
0,1667 \\
2,612\end{array}$ & \begin{tabular}{|c|}
30 \\
1 \\
11,937
\end{tabular} & HSBC & \begin{tabular}{|l} 
Recuento \\
$\%$ de banco \\
$\%$ del total
\end{tabular} & $\begin{array}{c}4 \\
0,2105 \\
0,75\end{array}$ & \begin{tabular}{|c|}
3 \\
0,1579 \\
0,56
\end{tabular} & \begin{tabular}{|c|}
5 \\
0,2632 \\
0,935
\end{tabular} & \begin{tabular}{|c|}
5 \\
0,2632 \\
0,935
\end{tabular} & \begin{tabular}{|c|}
2 \\
0,1053 \\
0,374 \\
\end{tabular} & $\begin{array}{c}19 \\
1 \\
3,6\end{array}$ & HSBC & $\begin{array}{l}\text { Recuento } \\
\text { \% de banco } \\
\% \text { del total }\end{array}$ & $\begin{array}{c}1 \\
0,0909 \\
0,3\end{array}$ & $\begin{array}{c}1 \\
0,0909 \\
0,3\end{array}$ & \begin{tabular}{|c|}
4 \\
0,3636 \\
1,22 \\
\end{tabular} & \begin{tabular}{|c|}
5 \\
0,4545 \\
1,524 \\
\end{tabular} & $\begin{array}{l}0 \\
0 \\
0\end{array}$ & \begin{tabular}{|c|}
11 \\
1 \\
3,344
\end{tabular} \\
\hline & Total & \begin{tabular}{|l} 
Recuento \\
$\%$ de banco \\
$\%$ del total
\end{tabular} & \begin{tabular}{c|}
79 \\
$9,8 \%$ \\
$9,8 \%$
\end{tabular} & \begin{tabular}{|c|}
84 \\
$10,4 \%$ \\
$10,4 \%$
\end{tabular} & \begin{tabular}{|c|}
188 \\
$23,4 \%$ \\
$23,4 \%$
\end{tabular} & \begin{tabular}{|c|}
225 \\
$28,0 \%$ \\
$28,0 \%$
\end{tabular} & \begin{tabular}{|c|}
228 \\
$28,4 \%$ \\
$28,4 \%$
\end{tabular} & \begin{tabular}{|c|}
804 \\
$100 \%$ \\
$100 \%$
\end{tabular} & Total & \begin{tabular}{|l} 
Recuento \\
$\%$ de banco \\
$\%$ del total
\end{tabular} & $\begin{array}{c}76 \\
14,2 \% \\
14,2 \%\end{array}$ & \begin{tabular}{|c|}
68 \\
$12,7 \%$ \\
$12,7 \%$
\end{tabular} & \begin{tabular}{|c|}
187 \\
$35,0 \%$ \\
$35,0 \%$
\end{tabular} & \begin{tabular}{|c|}
114 \\
$21,3 \%$ \\
$21,3 \%$
\end{tabular} & \begin{tabular}{|c|}
90 \\
$16,8 \%$ \\
$16,8 \%$
\end{tabular} & $\begin{array}{c}535 \\
100 \% \\
100 \%\end{array}$ & Total & \begin{tabular}{|l} 
Recuento \\
$\%$ de banco \\
$\%$ del total
\end{tabular} & $\begin{array}{c}55 \\
16,8 \% \\
16,8 \%\end{array}$ & $\begin{array}{c}54 \\
16,5 \% \\
16,5 \%\end{array}$ & \begin{tabular}{|c|}
112 \\
$34,1 \%$ \\
$34,1 \%$
\end{tabular} & \begin{tabular}{|c|}
66 \\
$20,1 \%$ \\
$20,1 \%$
\end{tabular} & $\begin{array}{c}41 \\
12,5 \% \\
12,5 \%\end{array}$ & $\begin{array}{c}328 \\
100 \% \\
100 \%\end{array}$ \\
\hline
\end{tabular}

Fuente: Elaboración propia en base a la información obtenida de las encuestas realizadas a las empresas. 
15.2

Anexo II 


\section{Cuestionario}

\section{A. Datos de la Empresa}

\begin{tabular}{|l|l|l|l|l|}
\hline 1.Rubro o Actividad Principal & \multicolumn{2}{|l|}{} & \\
\hline 2. Antigüedad (Años) & & 3. Cantidad de empleados & 4.Exporta & $\%$ \\
\hline
\end{tabular}

\section{B. El sistema financiero en general}

5. A partir de su experiencia, ¿Ud. Cree que el sistema financiero argentino ayuda al desarrollo de las PyMEs?

\begin{tabular}{|l|l|l|l|l|l|l|l|l|l|}
\hline Mucho (1) & & Algo (2) & & Poco (3) & & Nada (4) & Ns/Nc (5) & \\
\hline
\end{tabular}

6. A partir de su experiencia. Usted cree que el ritmo de crecimiento de su empresa se habría acelerado si hubiera contado con un acceso al crédito más fluido y más barato?

\begin{tabular}{|l|l|l|l|l|l|l|l|l|l|}
\hline Mucho (1) & & Algo (2) & & Poco (3) & & Nada (4) & Ns/Nc (5) & \\
\hline
\end{tabular}

7. En que porcentual diría usted que ha financiado su empresa en el pasado..... (Expresar en porcentaje)

\begin{tabular}{|l|r|}
\hline a través de las empresas proveedoras & $\%$ \\
\hline a través del sistema financiero & $\%$ \\
\hline sistemas no formales de crédito & $\%$ \\
\hline mediante auto financiamiento & $\%$ \\
\hline
\end{tabular}

\section{Necesidades crediticias}

8. En su política empresarial la conducta de tomar crédito es:

\begin{tabular}{|l|l|}
\hline Habitual & \\
\hline No habitual & \\
\hline Nunca tomar crédito & \\
\hline
\end{tabular}

9. La empresa que usted dirige o gerencia ha tomado crédito en el sistema financiero....

\begin{tabular}{|l|l|}
\hline Hace menos de 1 año? & \\
\hline Entre 1 y 2 años? & \\
\hline Entre 2 y 3 años? & \\
\hline Entre 4 y 5 años? & \\
\hline Más de 5 años o nunca & \\
\hline
\end{tabular}

10. a. El tipo de crédito era...

\begin{tabular}{|l|l|}
\hline Personal, pero destinado a la empresa & \\
\hline Empresarial con garantía empresarial & \\
\hline Empresarial con garantía personal & \\
\hline Empresarial sin garantía & \\
\hline
\end{tabular}


10. b. Si el crédito tomado fue personal con destino empresario. ¿Tomo un crédito personal con destino a la empresa porque los créditos empresarios:

\begin{tabular}{|l|l|}
\hline No podía cumplir con los requisitos? & \\
\hline No le alcanzaron los montos de los créditos empresarios? & \\
\hline Era más rápido y lo necesitaba con urgencia? & \\
\hline No había créditos para empresas disponibles? & \\
\hline Otros & \\
\hline
\end{tabular}

11. a. Con relación al último crédito que obtuvo, ¿podría indicar cuales fueron sus fines?

\begin{tabular}{|l|l|}
\hline Financiación a clientes & \\
\hline Nuevos proyectos productivos? & \\
\hline Inversiones en Investigación y Desarrollo? & \\
\hline Ampliación de planta? & \\
\hline Compra de maquinarias? & \\
\hline Compra de materias primas? & \\
\hline Mejorar la estructura de venta y distribución? & \\
\hline Financiación de exportaciones? & \\
\hline Pagos de salarios? & \\
\hline Financiación de importaciones? & \\
\hline Para pagar impuestos? & \\
\hline
\end{tabular}

11. b. ¿Recuerda en que banco la obtuvo?

\begin{tabular}{|l|l|}
\hline Nación & \\
\hline Provincia & \\
\hline Macro & \\
\hline Credicoop & \\
\hline Galicia & \\
\hline BBVA & \\
\hline Santander & \\
\hline Itau & \\
\hline Ciudad & \\
\hline Otro. ¿Cuál? & \\
\hline
\end{tabular}

12. ¿Qué tipo de crédito obtuvo?

\begin{tabular}{|l|l|}
\hline Crédito a sola firma & \\
\hline Crédito hipotecario & \\
\hline Crédito prendario (incluye leasing) & \\
\hline Fianza por SGR & \\
\hline Otro & \\
\hline
\end{tabular}

13. ¿Cuál de las siguientes fuentes de financiamiento utiliza habitualmente?

\begin{tabular}{|l|l|}
\hline Descuento de documentos, cheque y remesas & \\
\hline Descubierto en cuenta corriente & \\
\hline Prestamos amortizables de interés vencido (PAIV) & \\
\hline Ninguna & \\
\hline
\end{tabular}


14. En su opinión, el acceso al crédito obtenido presentó:

\begin{tabular}{|l|l|}
\hline \multicolumn{2}{|c|}{ a. Tasa de interés } \\
\hline Muy accesible & \\
\hline Accesible & \\
\hline Alta & \\
\hline Muy Alta & \\
\hline
\end{tabular}

\begin{tabular}{|l|l|}
\hline \multicolumn{2}{|l|}{ b. Período de gracia } \\
\hline Muy conveniente & \\
\hline Conveniente & \\
\hline Corto & \\
\hline Muy corto & \\
\hline Nulo & \\
\hline
\end{tabular}

\begin{tabular}{|l|l|}
\hline \multicolumn{2}{|c|}{ c. Plazo } \\
\hline Muy conveniente & \\
\hline Conveniente & \\
\hline Corto & \\
\hline Muy corto & \\
\hline
\end{tabular}

\begin{tabular}{|l|l|}
\hline \multicolumn{2}{|c|}{ d. Monto } \\
\hline Muy suficiente & \\
\hline Suficiente & \\
\hline Insuficiente & \\
\hline Muy insuficiente & \\
\hline
\end{tabular}

\begin{tabular}{|l|l|}
\hline \multicolumn{2}{|l|}{ e. Requisitos solicitados } \\
\hline Muy accesible & \\
\hline Accesible & \\
\hline Alto & \\
\hline Muy Alto & \\
\hline
\end{tabular}

\begin{tabular}{|l|l|}
\hline \multicolumn{1}{|c|}{$\begin{array}{c}\text { f. Tramites y } \\
\text { Planillas }\end{array}$} \\
\hline Muy sencillo & \\
\hline Sencillo & \\
\hline Complejos & \\
\hline Muy Complejos & \\
\hline
\end{tabular}

\begin{tabular}{|l|l|}
\hline $\begin{array}{c}\text { g. Atención para la } \\
\text { gestión }\end{array}$ \\
\hline Muy cordial & \\
\hline Cordial & \\
\hline Mala & \\
\hline Muy Mala & \\
\hline
\end{tabular}

\begin{tabular}{|l|l|}
\hline \multicolumn{2}{|c|}{$\begin{array}{c}\text { h. Tiempo de } \\
\text { adjudicación }\end{array}$} \\
\hline Muy Rápido & \\
\hline Rápido & \\
\hline Lento & \\
\hline Muy Lento & \\
\hline
\end{tabular}

15. Si usted averiguo y no tomó crédito. ¿Podría indicar cuales fueron los motivos de su negativa y a que banco se presentó?

\begin{tabular}{|l|l|l|l|l|}
\hline Banco & & & & Ns/Nc \\
\hline Tasa de interés inaccesible & & & & \\
\hline Período de gracias exiguos & & & & \\
\hline Plazos inconvenientes & & & & \\
\hline Montos inapropiados & & & & \\
\hline Requisitos inaccesibles & & & & \\
\hline Tramites y planillas complejos & & & & \\
\hline Atención para la gestión hostil & & & & \\
\hline Demasiado tiempo de adjudicación & & & & \\
\hline Otros & & & & \\
\hline
\end{tabular}

16. a. Para acceder a un crédito en las actuales circunstancias, cuales condiciones considera accesibles en cuanto ha:

\begin{tabular}{|l|l|c|c|c|c|c|c|c|c|c|c|c|c|c|}
\hline \multirow{2}{*}{ Destino del crédito } & \multicolumn{4}{|c|}{ Tasa máxima } & \multicolumn{3}{c|}{ Plazo mínimo de gracia } & \multicolumn{3}{|c|}{ Plazo mínimo de amortización } \\
\cline { 2 - 12 } & $\begin{array}{c}\text { hasta } \\
9 \%\end{array}$ & $\begin{array}{c}10 \mathrm{a} \\
15 \%\end{array}$ & $\begin{array}{c}16 \mathrm{a} \\
20 \%\end{array}$ & $\begin{array}{c}21 \% \text { o } \\
\text { más }\end{array}$ & $\begin{array}{c}\text { Hasta } \\
6 \mathrm{~m}\end{array}$ & $\begin{array}{c}\text { hasta } \\
12 \mathrm{~m}\end{array}$ & $\begin{array}{c}\text { hasta } \\
24 \mathrm{~m}\end{array}$ & $\begin{array}{l}1 \mathrm{a} \\
2 \mathrm{a}\end{array}$ & $3 \mathrm{a}$ & $4 \mathrm{a}$ & $5 \mathrm{a}$ & más de $5 \mathrm{a}$ \\
\hline $\begin{array}{l}\text { Nuevos proyectos } \\
\text { productivos }\end{array}$ & & & & & & & & & & & & & \\
\hline Inversión en I+D & & & & & & & & & & & & & & \\
\hline $\begin{array}{l}\text { Ampliación de } \\
\text { planta }\end{array}$ & & & & & & & & & & & & & \\
\hline $\begin{array}{l}\text { Compra de } \\
\text { maquinarias }\end{array}$ & & & & & & & & & & & & \\
\hline
\end{tabular}

\begin{tabular}{|l|l|l|l|l|l|l|l|l|l|l|l|l|l|}
\hline $\begin{array}{l}\text { Compras de } \\
\text { materias primas }\end{array}$ & & & & & & & & & & & & \\
\hline $\begin{array}{l}\text { Mejora de estructura } \\
\text { de ventas y distrib. }\end{array}$ & & & & & & & & & & & & & \\
\hline $\begin{array}{l}\text { Financiación de } \\
\text { exportaciones }\end{array}$ & & & & & & & & & & & & & \\
\hline $\begin{array}{l}\text { Financiación de } \\
\text { ventas intermedias }\end{array}$ & & & & & & & & & & & & & \\
\hline $\begin{array}{l}\text { Financiación de } \\
\text { importaciones }\end{array}$ & & & & & & & & & & & & & \\
\hline
\end{tabular}

\begin{tabular}{|l|l|l|l|l|l|l|l|l|l|l|l|l|l|}
\hline Pagos de salarios & & & & & & & & & & & & & \\
\hline Pagos de impuestos & & & & & & & & & & & & & \\
\hline Otros & & & & & & & & & & & & & \\
\hline Ns/Nc & & & & & & & & & & & & & \\
\hline
\end{tabular}


16. b. Dadas estas condiciones, su empresa estaría dispuesta a tomar nuevos créditos?

\section{A. Usos de servicios bancarios}

\begin{tabular}{|l|l|}
\hline $\mathrm{SI}$ & \\
\hline $\mathrm{NO}$ & \\
\hline $\mathrm{Ns} / \mathrm{Nc}$ & \\
\hline
\end{tabular}

17. Para las siguientes operaciones, ¿cuáles bancos prefiere? (marque uno o más)

\begin{tabular}{|l|l|l|l|l|l|}
\hline \multirow{2}{*}{} & \multicolumn{2}{|c|}{ Públicos } & \multicolumn{3}{c|}{ Privados } \\
\cline { 2 - 6 } & Nación & Provincia & & & \\
\hline Cuenta corriente & & & & & \\
\hline Caja de ahorro & & & & & \\
\hline Plazo fijo & & & & & \\
\hline Pago de salario & & & & & \\
\hline Pago de impuestos & & & & & \\
\hline Inversiones financieras & & & & & \\
\hline Cobro de facturas & & & & & \\
\hline Otros & & & & & \\
\hline
\end{tabular}

\section{B. Imagen del sistema bancario}

18. Con cuál de los siguientes bancos preferiría trabajar, por orden (no más de 3)

\begin{tabular}{|l|l|}
\hline Nación & \\
\hline Provincia & \\
\hline Macro & \\
\hline Credicoop & \\
\hline Galicia & \\
\hline
\end{tabular}

\begin{tabular}{|l|l|}
\hline BBVA & \\
\hline Santander & \\
\hline Itau & \\
\hline Ciudad & \\
\hline Otro & \\
\hline
\end{tabular}

19. ¿Cómo calificaría de 1 a 5 (siendo 5 el valor más positivo) a los bancos mencionados previamente?

\begin{tabular}{|l|l|l|l|l|}
\hline Bancos & 1 & 2 & 3 & Ns/Nc \\
\hline Tasa de interés & & & & \\
\hline Plazos del crédito & & & & \\
\hline Período de gracias & & & & \\
\hline Los requisitos & & & & \\
\hline Los tramites & & & & \\
\hline Velocidad de adjudicación & & & & \\
\hline
\end{tabular}

20. De los bancos por usted mencionados anteriormente, califique de 1 a 5 (siendo 5 el valor más positivo) los siguientes aspectos:

\begin{tabular}{|l|l|l|l|l|}
\hline Banco & 1 & 2 & 3 & Ns/Nc \\
\hline Accesos a las sucursales & & & & \\
\hline Banca PyMEs & & & & \\
\hline $\begin{array}{l}\text { Cuentan con gerentes con } \\
\text { actitud activa }\end{array}$ & & & & \\
\hline $\begin{array}{l}\text { Capacidad de decisión de los } \\
\text { oficiales de cuenta }\end{array}$ & & & & \\
\hline $\begin{array}{l}\text { Atención específica a } \\
\text { empresarios }\end{array}$ & & & & \\
\hline $\begin{array}{l}\text { acceso a saldos rápidamente } \\
\text { por teléfono o Internet }\end{array}$ & & & & \\
\hline $\begin{array}{l}\text { Detalles de operaciones por } \\
\text { Internet }\end{array}$ & & & & \\
\hline $\begin{array}{l}\text { La operatoria se adecua a las } \\
\text { necesidades de las PyMEs }\end{array}$ & & & & \\
\hline
\end{tabular}


21. ¿Cuántos puntos adicionales en la tasa de interés valdría para usted la obtención de un crédito que le asegure sencillez de tramitación y rapidez en el otorgamiento?

a. Para un crédito destinado a capital de trabajo

\begin{tabular}{|l|l|}
\hline 0 & \\
\hline 1 & \\
\hline 2 & \\
\hline
\end{tabular}

b. Para un crédito destinado a inversión (maquinarias)

\begin{tabular}{|l|l|}
\hline 0 & \\
\hline 1 & \\
\hline 2 & \\
\hline
\end{tabular}

\begin{tabular}{|c|c|}
\hline 3 & \\
\hline 4 & \\
\hline $\begin{array}{c}\text { más de } \\
4\end{array}$ & \\
\hline
\end{tabular}

22. ¿Conoce las líneas crediticias de fomentos disponibles en la Provincia?

SI

NO

a. ¿Cuáles?

\begin{tabular}{|l|l|}
\hline Fuerza productiva & \\
\hline Prestamos PyMEs de ANSES & \\
\hline Fuerza PyME & \\
\hline Otros & \\
\hline
\end{tabular}

c. ¿Utilizó alguna?

SI

b. ¿Cómo las conoció?

\begin{tabular}{|l|l|}
\hline Fue al banco & \\
\hline Por otra empresa & \\
\hline $\begin{array}{l}\text { Por asociaciones } \\
\text { empresaria }\end{array}$ & \\
\hline Por publicidad & \\
\hline Otros & \\
\hline
\end{tabular}

d. ¿Cuáles?

\begin{tabular}{|l|l|}
\hline Fuerza productiva & \\
\hline Prestamos PyMEs de ANSES & \\
\hline Fuerza PyME & \\
\hline Otros & \\
\hline
\end{tabular}

\section{Situación y expectativas}

23. a ¿Cuál es el nivel de demanda actual de sus productos?

\begin{tabular}{|l|l|}
\hline Favorable & \\
\hline Normal & \\
\hline Desfavorable & \\
\hline Ns/Nc & \\
\hline
\end{tabular}

23. b. En qué porcentaje aumento o disminuyo su demanda en el primer cuatrimestre del 2010 (enero- abril), en relación al mismo período del 2009 ?

24. a. Como cree que evolucionará su demanda en el segundo semestre del 2010 (julio-diciembre) con relación al mismo período del 2009 ?

\begin{tabular}{|l|l|}
\hline Aumentará fuertemente & \\
\hline Aumentará & \\
\hline No tendrá cambios & \\
\hline Disminuirá & \\
\hline Disminuirá fuertemente & \\
\hline Ns/Nc & \\
\hline
\end{tabular}

24. b Podría estimar el porcentaje de variación para el segundo semestre del 2010 (julio diciembre) con relación al mismo período 2009 ? 
25. ¿Cómo cree que evolucionarán sus inversiones en el segundo semestre del 2010 (julio diciembre)?

\begin{tabular}{|l|l|}
\hline Aumentará fuertemente & \\
\hline Aumentará & \\
\hline No tendrá cambios & \\
\hline Disminuirá & \\
\hline Disminuirá fuertemente & \\
\hline Ns/Nc & \\
\hline
\end{tabular}

26. a. En términos generales, ¿Cómo evalúa su situación financiera?

\begin{tabular}{|l|l|}
\hline Muy Favorable & \\
\hline Favorable & \\
\hline Normal & \\
\hline Desfavorable & \\
\hline Muy desfavorable & \\
\hline Ns/Nc & \\
\hline
\end{tabular}

26. b. Cómo evalúa que variará su situación financiera en el segundo semestre de 2010 (julio-diciembre)

\begin{tabular}{|l|l|}
\hline Mejora significativamente & \\
\hline Mejorará & \\
\hline Se mantendrá igual & \\
\hline Empeorará & \\
\hline Empeorará significativamente & \\
\hline Ns/Nc & \\
\hline
\end{tabular}

27. Para quienes exportan, ¿cómo evolucionaron sus exportaciones en lo que va del año?

\begin{tabular}{|l|l|}
\hline Aumentaron & \\
\hline Se mantuvieron igual & \\
\hline Disminuyeron & \\
\hline
\end{tabular}

